VerbNet.Br: construção semiautomática de um léxico verbal online e independente de domínio para o português do Brasil 
Data de Depósito:

Assinatura:

\title{
VerbNet.Br: construção semiautomática de um léxico verbal online e independente de domínio para o português do Brasil
}

\author{
Carolina Evaristo Scarton
}

Orientadora: Profa. Dra. Sandra Maria Aluísio

\begin{abstract}
Dissertação apresentada ao Instituto de Ciências Matemáticas e de Computação - ICMC-USP, como parte dos requisitos para obtenção do título de Mestre em Ciências - Ciências de Computação e Matemática Computacional. VERSÃO REVISADA
\end{abstract}

USP - São Carlos

Março 2013 
Ficha catalográfica elaborada pela Biblioteca Prof. Achille Bassi e Seção Técnica de Informática, ICMC/USP, com os dados fornecidos pelo(a) autor(a)

S285v Scarton, Carolina Evaristo

S285v VerbNet.Br: construção semiautomática de um léxico verbal online e independente de domínio para o português do Brasil / Carolina Evaristo Scarton; orientadora Sandra Maria Aluísio. -- São Carlos, 2013. $242 \mathrm{p}$.

Dissertação (Mestrado - Programa de Pós-Graduação en Ciências de Computação e Matemática Computacional) -Instituto de Ciências Matemáticas e de Computação, Universidade de São Paulo, 2013.

1. Recursos Léxicos Computacionais. 2. Verb Clustering. 3. Classes de Levin. 4. Processamento de Línguas Naturais. 5. Linguística Computacional. I. Aluísio, Sandra Maria, orient. II. Título. 
Aos meus avós Antonio Scarton, Durvalina Scarton e Maria Martha de Lima Aos meus pais Luis Antonio Scarton e Lourdes Scarton Ao meu noivo Tiago de Freitas Pereira 


\section{Agradecimentos}

A FAPESP (Fundação de Amparo a Pesquisa do Estado de São Paulo) por financiar este mestrado (processo: 2010/03785-0) e por financiar o estágio no exterior (processo: 2011/22882-0).

Ao Instituto de Ciências Matemáticas e de Computação (ICMC), em especial ao Serviço de Pós-Graduação e à Seção Técnica de Informática (principalmente ao técnico Erick Previato, responsável pelo NILC), por fornecer todos os recursos necessários para execução deste mestrado.

Aos professores do NILC pela dedicação e pelo conhecimento transmitido.

Aos professores Thiago Pardo e Maria José Finatto, que tanto contribuíram com este projeto no exame de qualificação.

À Profa. Dra. Anna Korhonen por me receber e me orientar, durante estágio na Universidade de Cambridge/UK, com muita prestatividade, atenção e carinho. Também agradeço ao aluno de doutorado Lin Sun pela ajuda com os algoritmos de agrupamento de dados.

À Link House, em especial aos "wardens” Mel Robinson, Lil Robinson, Steve Baker, Sam Baker, Leeann Moe e Hastings Banks, por permitirem que eu fizesse parte dessa família e me receberem com muito, mas muito amor. Também agradeço a Sra. Patrícia Lebus pela ajuda com o inglês.

Aos SPGs de Letras e de Informática da UFRGS, por me receberem em visita técnica, em especial, às professoras Dra. Aline Villavicencio e Dra. Maria José Finatto e aos alunos Leonardo Zilio e Adriano Zanette que muito contribuíram para este mestrado.

Ao grupo de pesquisa CELiC da FCLAR-UNESP-Araraquara, em especial ao Prof. Dr. Bento Carlos Dias da Silva por permitir que os resultados da WordNet.Br fossem utilizados nesta pesquisa e por me receber para uma visita técnica que foi fundamental para desenvolver este mestrado.

Aos amigos do NILC pelo apoio, ajuda, risadas, cafés, discussões, enfim, por tornarem meu dia-a-dia muito especial. 
Aos amigos da LifeLong Workout, pelos adoráveis momentos de descontração e por muitas pizzas.

À Dra. Magali Duran, pelo apoio nesta empreitada, pela amizade e por, simplesmente, me ouvir quando precisei.

À Profa. Dra. Sandra Maria Aluísio, pela orientação, paciência e, por muitas vezes, fazer o papel de mãe.

Às minhas amigas do Sul Aline Evers e Bianca Pasqualini, por sempre estarem bem humoradas e me fazerem rir muito.

Aos amigos de Cambridge, em especial a Carol Gasperin, Ana Martinez, Nina Sartorio, Mariana Fonseca e Judith Simon por fazerem minha estadia em Cambridge ser maravilhosa.

Aos meus amigos de longa data, principalmente aos amigos de São Carlos: Diego Silva, Rosane Maffei, Debora Medeiros e, principalmente, ao meu grande amigo e "irmãozão" Geovane Shimizu, por simplesmente serem meus amigos e estarem lá quando precisei.

Às pessoas da minha família que acreditaram em mim, principalmente a minha prima Natalia Scarton Rodrigues e aos meus tios Rita de Lima Barreira e Sidnei Zago Barreira que sempre se preocuparam comigo e me apoiaram.

Aos meus avós Antonio Scarton, Durvalina Scarton e Maria Martha de Lima, por todo amor que sempre me deram.

Ao meu irmão Daniel Evaristo Scarton, por todo o apoio e carinho na etapa final deste mestrado.

Ao meu melhor amigo, meu companheiro Tiago de Freitas Pereira, pelo carinho, paciência, compreensão e amor durante todos esses anos.

E finalmente, aos meus pais, por, simplesmente, TUDO.

Muito Obrigada! 


\section{Acknowledgements}

My acknowledgements go:

To FAPESP (The Funding Council for The State of São Paulo), for financing this research (process: 2010/03785-0) and an internship abroad (process: 2011/22882-0).

To Institute of Mathematics and Computer Science (ICMC), especially to Graduate Office and Informatics Technical Office (mainly to Erick Previato, responsible for NILC lab), for making all the resources for this research available.

To all Professors of NILC, for their dedication and knowledge transmitted.

To Professors Thiago Pardo and Maria José Finatto, who gave an invaluable contribution to this research on the qualification exam.

To Professor Anna Korhonen, for her warm welcome and thoughtful supervision during my internship at Cambridge University/UK. I would also like to thank the Phd student Lin Sun for helping me with clustering algorithms.

To Link House, especially the wardens Mel Robinson, Lil Robinson, Steve Baker, Sam Baker, Leeann Moe and Hastings Banks, for making me part of this family and welcoming me with love. I would also like to thank Miss Patrícia Lebus for helping me with English language.

To Language and Informatics Graduate Programmes of UFRGS, for welcoming me in a technical visit, especially to professors Aline Villavicencio and Maria José Finatto. I would also like to thank Leonardo Zilio and Adriano Zanette for their important contribution to this research.

To CELiC research group of FCLAR-UNESP-Araraquara, especially to professor Bento Carlos Dias da Silva, for allowing me to use the results of WordNet.Br and for welcoming me in a technical visit.

To my friends at NILC for their help, support, jokes, coffees, discussions and, finally, for making my everyday life very special.

To my friends of LifeLong Workout, for the lovely moments of relaxation and for a lot of pizzas. 
To Magali Duran, for all her help in this research and for her friendship.

To Professor Sandra Maria Aluísio, for her thoughtful supervision, wide patience and, for being sometimes like a mother for me.

To my southern friends Aline Evers and Bianca Pasqualini, for always being in a good humor and for the great time we had.

To my friends at Cambridge, especially to Carol Gasperin, Ana Martinez, Nina Sartorio, Mariana Fonseca and Judith Simon, for making my time in Cambridge amazing.

To my old friends, especially to my friends from São Carlos: Diego Silva, Rosane Maffei, Debora Medeiros and, mainly, to my "big brother" Geovane Shimizu, for their friendship and for being there when I needed.

To my family, mainly to my cousin Natalia Scarton Rodrigues, my aunt Rita de Lima Barreira and my uncle Sidnei Zago Barreira, for their kind concerns and support.

To my grandparents Antonio Scarton, Durvalina Scarton and Maria Martha de Lima, for all their love.

To my brother Daniel Evaristo Scarton, for all his help, support and care in the final stages of this research.

To my best friend, my fiancée Tiago de Freitas Pereira, for his care, patience and love throughout all these years.

And, finally, to my parents, for EVERYTHING.

Thank you so much! 


\section{Resumo}

A criação de recursos linguístico-computacionais de base, como é o caso dos léxicos computacionais, é um dos focos da área de Processamento de Línguas Naturais (PLN). Porém, a maioria dos recursos léxicos computacionais existentes é específica da língua inglesa. Dentre os recursos já desenvolvidos para a língua inglesa, tem-se a VerbNet, que é um léxico com informações semânticas e sintáticas dos verbos do inglês, independente de domínio, construído com base nas classes verbais de Levin, além de possuir mapeamentos para a WordNet de Princeton (WordNet). Considerando que há poucos estudos computacionais sobre as classes de Levin, que é a base da VerbNet, para línguas diferentes do inglês, e dada a carência de um léxico para o português nos moldes da VerbNet do inglês, este trabalho teve como objetivo a criação de um recurso léxico para o português do Brasil (chamado VerbNet.Br), semelhante à VerbNet. A construção manual destes recursos geralmente é inviável devido ao tempo gasto e aos erros inseridos pelo autor humano. Portanto, há um grande esforço na área para a criação destes recursos apoiada por técnicas computacionais. Uma técnica reconhecida e bastante usada é o uso de aprendizado de máquina em córpus para extrair informação linguística. A outra é o uso de recursos já existentes para outras línguas, em geral o inglês, visando à construção de um novo recurso alinhado, aproveitando-se de atributos multilingues/cross-linguísticos (cross-linguistic) (como é o caso da classificação verbal de Levin). O método proposto neste mestrado para a construção da VerbNet.Br é genérico, porque pode ser utilizado para a construção de recursos semelhantes para outras linguas, além do português do Brasil. Além disso, futuramente, será possivel estender este recurso via criação de subclasses de conceitos. $O$ método para criação da VerbNet.Br é fundamentado em quatro etapas: três automáticas e uma manual. Porém, também foram realizados experimentos sem o uso da etapa manual, constatando-se, com isso, que ela pode ser descartada sem afetar a precisão e abrangência dos resultados. A avaliação do recurso criado foi realizada de forma intrínseca qualitativa e quantitativa. A avaliação qualitativa consistiu: (a) da análise manual de algumas classes da VerbNet, criando um gold standard para o português do Brasil; (b) da comparação do gold standard criado com os resultados da VerbNet.Br, obtendo resultados promissores, por volta de 60\% de f-measure; e (c) da comparação dos resultados da VerbNet.Br com resultados de agrupamento de verbos, concluindo que ambos os métodos apresentam resultados similares. A avaliação quantitativa considerou a taxa de aceitação dos membros das classes da VerbNet.Br, apresentando resultados na faixa de $90 \%$ de aceitação dos membros em cada classe. Uma das contribuições deste mestrado é a primeira versão da VerbNet.Br, que precisa de validação linguística, mas que já contém informação para ser utilizada em tarefas de PLN, com precisão e abrangência de 44\% e 92,89\%, respectivamente.

Palavras chave: alternâncias sintáticas, papéis temáticos, recursos léxicos computacionais, VerbNet, WordNet, WordNet.Br, classes de Levin, VerbNet.Br 


\section{Abstract}

Building computational-linguistic base resources, like computational lexical resources (CLR), is one of the goals of Natural Language Processing (NLP). However, most computational lexicons are specific to English. One of the resources already developed for English is the VerbNet, a lexicon with domain-independent semantic and syntactic information of English verbs. It is based on Levin's verb classification, with mappings to Princeton's WordNet (WordNet). Since only a few computational studies for languages other than English have been made about Levin's classification, and given the lack of a Portuguese CLR similar to VerbNet, the goal of this research was to create a CLR for Brazilian Portuguese (called VerbNet.Br). The manual building of these resources is usually unfeasible because it is time consuming and it can include many human-made errors. Therefore, great efforts have been made to build such resources with the aid of computational techniques. One of these techniques is machine learning, a widely known and used method for extracting linguistic information from corpora. Another one is the use of pre-existing resources for other languages, most commonly English, to support the building of new aligned resources, taking advantage of some multilingual/cross-linguistic features (like the ones in Levin's verb classification). The method proposed here for the creation of VerbNet.Br is generic, therefore it may be used to build similar resources for languages other than Brazilian Portuguese. Moreover, the proposed method also allows for a future extension of the resource via subclasses of concepts. The VerbNet.Br has a four-step method: three automatic and one manual. However, experiments were also carried out without the manual step, which can be discarded without affecting precision and recall. The evaluation of the resource was intrinsic, both qualitative and quantitative. The qualitative evaluation consisted in: (a) manual analysis of some VerbNet classes, resulting in a Brazilian Portuguese gold standard; (b) comparison of this gold standard with the VerbNet.Br results, presenting promising results (almost $60 \%$ of $f$-measure); and (c), comparison of the VerbNet.Br results to verb clustering results, showing that both methods achieved similar results. The quantitative evaluation considered the acceptance rate of candidate members of VerbNet.Br, showing results around $90 \%$ of acceptance. One of the contributions of this research is to present the first version of VerbNet.Br. Although it still requires linguistic validation, it already provides information to be used in NLP tasks, with precision and recall of $44 \%$ and $92.89 \%$, respectively.

Keywords: diathesis alternations, thematic roles, computational lexical resources, VerbNet, WordNet, WordNet.Br, Levin verb classes, VerbNet.Br 


\section{Lista de Figuras}

Figura 1: Esquematização do método de criação da VerbNet.Br a partir de outros recursos .. 11

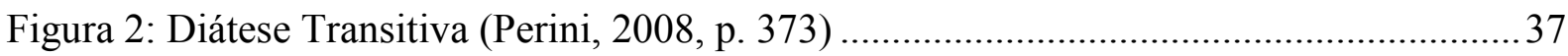

Figura 3: Tela de Entrada da WordNet (versão WEB) ......................................................... 51

Figura 4: Exemplo de um alinhamento entre a WordNet.Br e a WordNet (Di Felipo e Dias-da

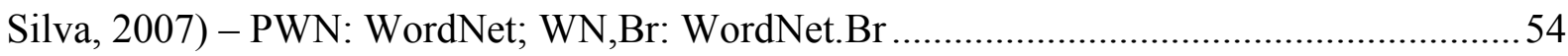

Figura 5: Exemplo do resultado da FrameNet na busca pela palavra buy..............................55

Figura 6: Descrição do frame Commerce_buy ....................................................................56

Figura 7: Exemplo da unidade lexical "abandonar" na FrameNet Brasil ...............................5 57

Figura 8: Exemplo de um frameset do PropBank (retirado de Palmer et al. (2005)) ...............58

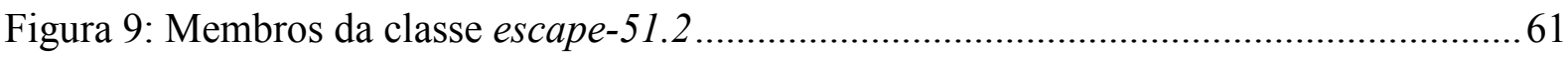

Figura 10: Hierarquia das restrições seletivas da VerbNet (Kipper, 2005)..............................64

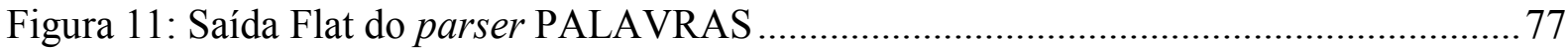

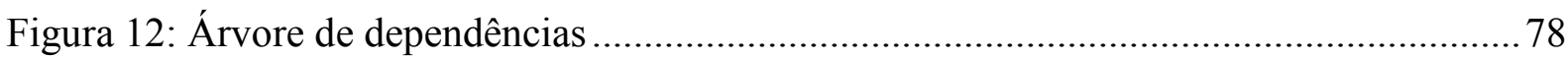

Figura 13: Exemplo de entrada para o verbo "armar" no Léxico do NILC (retirada de Zanette

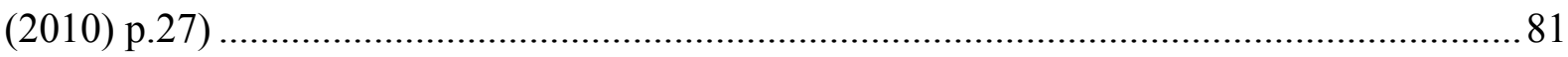

Figura 14: Lista de possíveis argumentos (objetos) do verbo "armar".................................. 81

Figura 15: Matriz de entrada para o algoritmo de agrupamento de dados (retirado de Kipper

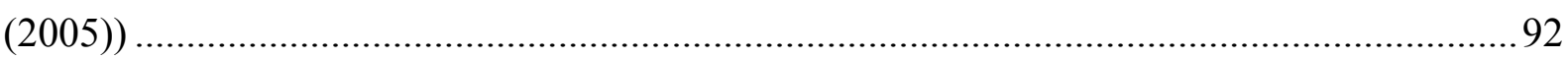

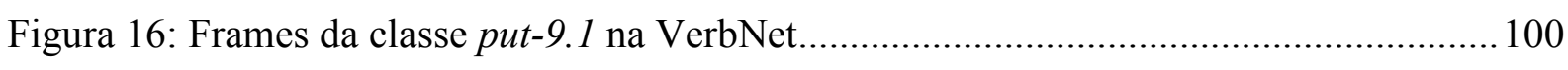

Figura 17: Esquema da tarefa de definição dos candidatos a membros da VerbNet.Br......... 103

Figura 18: Descrição da tarefa de definição dos membros das classes da VerbNet.Br.......... 106

Figura 19: Gold Standard criado para a língua inglesa (retirado de Sun (2007)).................. 113

Figura 20: Precisão, Abrangência e $f$-measure global para todos os experimentos ................ 122

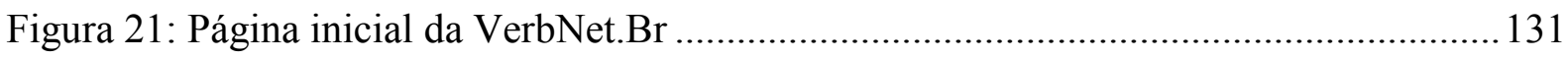




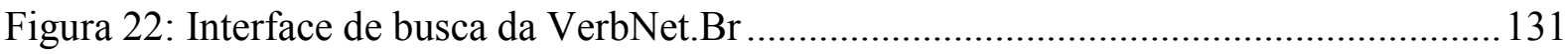

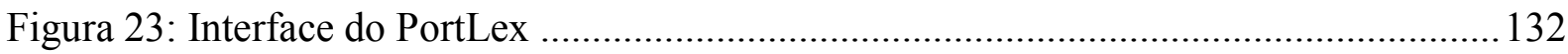

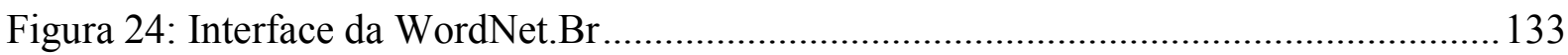

Figura 25: Saída com erros gerada pelo PALAVRAS …...................................................... 141 


\section{Lista de Tabelas}

Tabela 1: Parte da classe leave-52.1 da VerbNet 6

Tabela 2: Classe put-9.1 na VerbNet.Br 12

Tabela 3: Comportamento dos verbos touch, hit, cut e break 22

Tabela 4: Lista das possíveis relações entre a WordNet.Br com a WordNet 53

Tabela 5: Classe confess-37.10 inserida na VerbNet de acordo com o trabalho de Korhonen e Briscoe (2004) 68

Tabela 6: Evolução da VerbNet (retirada do trabalho de Kipper(2005)) 68

Tabela 7: classe Carry - compatibilidade entre verbos do inglês e português (retirada do trabalho de Kipper (2005))

Tabela 8: Comparação entre os recursos WordNet, PropBank, FrameNet e VerbNet. 72

Tabela 9: Exemplos de frames para o verbo "comprar" 79

Tabela 10: Resumo dos trabalhos apresentados no Capítulo 4 .95

Tabela 11: Frames traduzidos para o português para a classe put-9.1 100

Tabela 12: Informações sobre os córpus utilizados 102

Tabela 13: Frames para o verbos instalar 102

Tabela 14: Membros da classe put-9.1 da VerbNet. 104

Tabela 15: Membros da classe put-9.1 e os synsets da WordNet.Br..... 105

Tabela 16: Verbos selecionados para a classe put-9.1 (considerando a Etapa 1)

Tabela 17: Resultados Gerais para cada experimento

Tabela 18: Gold standard para o português do Brasil

Tabela 19: Resultados de precisão para os experimentos considerando as classes do gold standard..... 119

Tabela 20: Resultados de abrangência para os experimentos considerando as classes do gold standard..... 
Tabela 21: Resultados de f-measure para os experimentos considerando as classes do gold standard.

Tabela 22: Resultados de $f$-measure para 16 classes .......................................................... 126

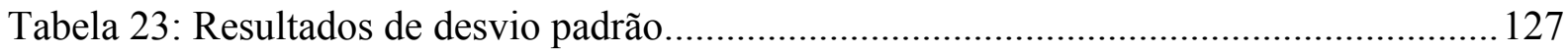

Tabela 24: Verbos ambíguos no gold standard do português .............................................. 128

Tabela 25: Comparação dos resultados da VerbNet.Br com os resultados da tarefa de

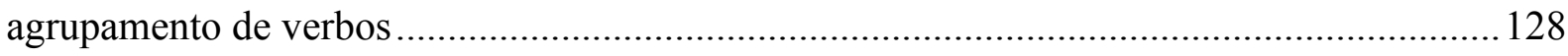

Tabela 26: Taxa de membros aceitos para cada classe do gold standard .............................. 130

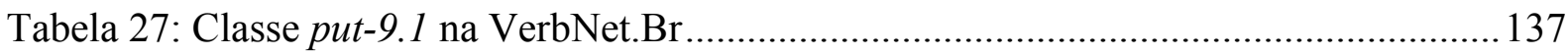

Tabela 28: Comparação da VerbNet com a VerbNet.Br ........................................................ 139

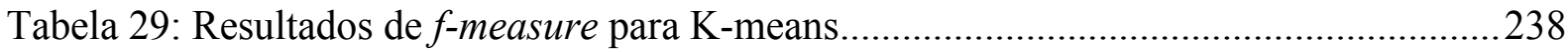

Tabela 30: Resultados de f-measure para MNCut Spectral Cluster .....................................239

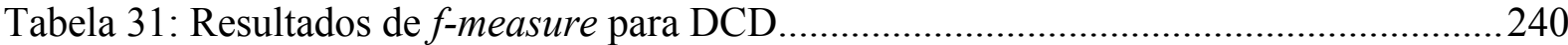

Tabela 32: Resultados de $f$-measure por grupos de frequência ..........................................241

Tabela 33: Resultados de $f$-measure para inglês, francês e português ..................................242 


\section{Lista de Fórmulas}

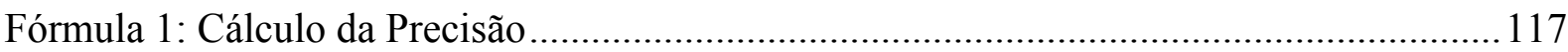

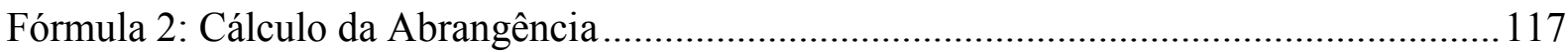

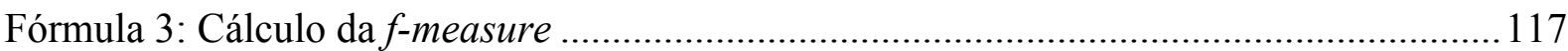

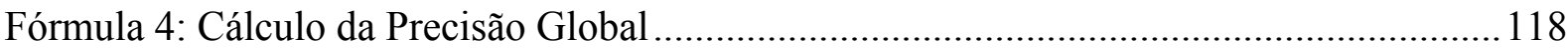

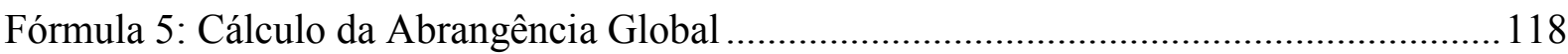

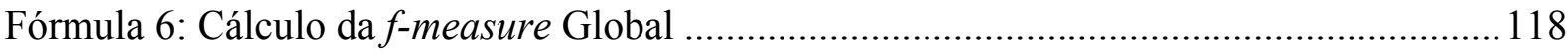

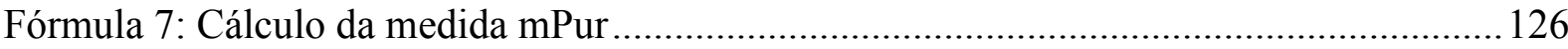

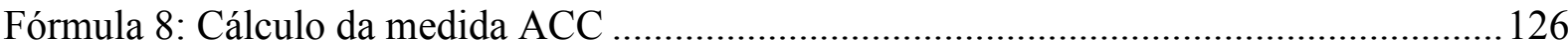

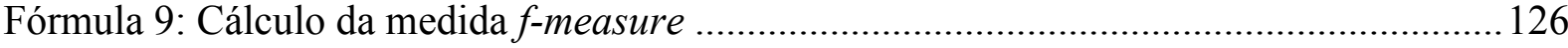

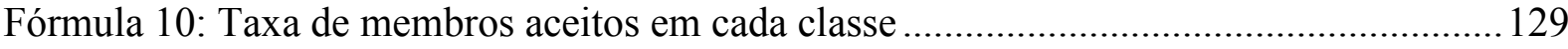

Fórmula 11: Taxa de membros aceitos em toda a VerbNet.Br ..........................................129 


\section{Lista de Definições}

Alternância sintática - alternâncias nas expressões dos argumentos de um verbo (ou predicador), algumas vezes acompanhadas de mudança de sentido (também conhecidas como alternâncias de diátese) (Levin, 1993).

Estruturas de Subcategorização (subcategorization frames) - descrevem, no nível da sintaxe, as diferentes combinações de argumentos que cada verbo pode apresentar (Messiant et al., 2008). Portanto, se assemelham, sintaticamente, ao conceito de alternância sintática. Por exemplo, o verbo “comprar" (to buy) é subcategorizado, por exemplo, no simples frame transitivo ("Eu comprei uma bola" - SN V SN) como também no frame com um sintagma nominal seguido de um sintagma preposicional regido pela preposição "para” (“Eu comprei uma bola para João" - SN V SN SP[para]).

Frames sintáticos - descrevem construções como transitivas, intransitivas, frases preposicionais, e um grande conjunto das alternâncias propostas por Levin (Kipper, 2005). Neste trabalho, assumiu-se que frames sintáticos e as estruturas de subcategorização são sinônimos.

Papéis temáticos - descrevem a relação semântica subjacente entre um verbo (ou predicador) e seus argumentos e são usados para descrever padrões léxicos e semânticos no comportamento dos verbos (Kipper, 2005).

Predicados semânticos - fornecem as relações entre participantes e eventos e são responsáveis por definir os componentes de significado de cada classe da VerbNet (Kipper, 2005).

Restrições seletivas - são restrições impostas aos papéis semânticos que definem a semântica permitida para a palavra que ocupará determinado papel (como exemplo, o traço animado em substantivos) (Kipper, 2005).

Verbos inergativos - verbos que admitem objeto direto, mas podem ser usados intransitivamente (sem objeto) com transferência do objeto para posição do sujeito.

Verbos inacusativos - verbos que admitem objeto direto, mas podem ser usados intransitivamente (sem objeto). 
Agrupamento de dados (clustering) - técnica de aprendizado de máquina não supervisionado que agrupa dados de acordo com os padrões que eles apresentam (Witten e Frank, 2005).

Grupo de dados (cluster) - grupo de dados inferido pela tarefa de agrupamento. 


\section{Lista de Abreviaturas}

ACC - Objeto direto (etiqueta do parser PALAVRAS (Bick, 2000))

CELiC - Estudos Linguístico-Computacionais da Linguagem

FCLAR - Faculdade de Ciências e Letras de Araraquara

ICMC - Instituto de Ciências Matemáticas e de Computação

LC - Linguística Computacional

NILC - Núcleo Interinstitucional de Linguística Computacional

SN - Sintagma Nominal (noun phrase)

PLN - Processamento de Língua Natural

SP - Sintagma Preposicional (prepositional phrase)

SPG - Programa de Pós-Graduação

PIV - Objeto indireto (etiqueta do parser PALAVRAS (Bick, 2000))

PWN - WordNet de Princeton

SCF - Frame de subcategorização (subcategorization frames)

UFMG - Universidade Federal de Minas Gerais

UFRGS - Universidade Federal do Rio Grande do Sul

UNESP - Universidade Estadual Paulista "Júlio de Mesquita Filho"

USP - Universidade de São Paulo

V - Verbo 


\section{Sumário}

\section{PARTE I: APRESENTAÇÃO E FUNDAMENTAÇÃO TÉORICA DE BASE.

CAPÍTULO 1: INTRODUÇÃO.............................................................. 1

1.1. ConteXtulalização e MotivaÇão ............................................................................1

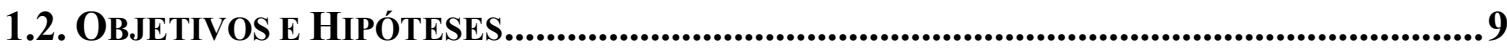

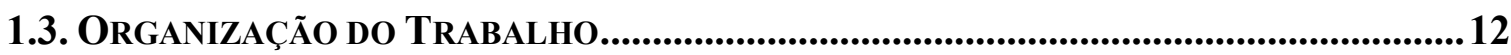

CAPÍTULO 2: PAPÉIS TEMÁTICOS, AS ALTERNÂNCIAS SINTÁTICAS E AS CLASSES DE LEVIN..................................................... 15

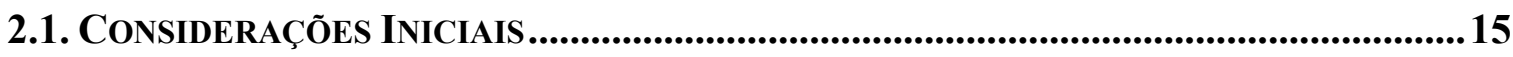

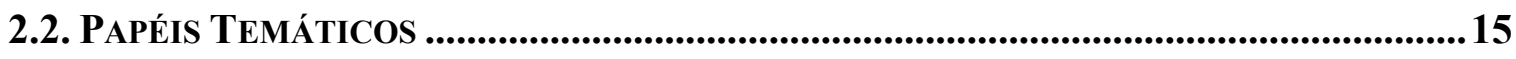

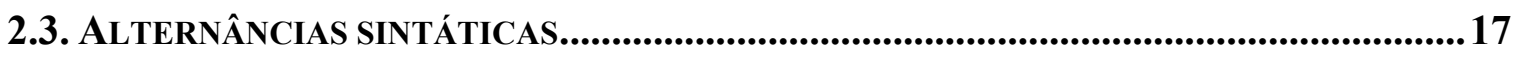

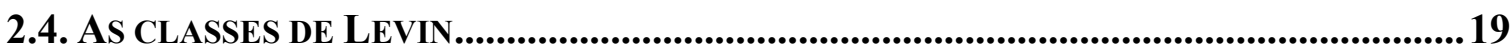

2.5. TRABALHOS COM VERBOS NO BRASIL ............................................................23

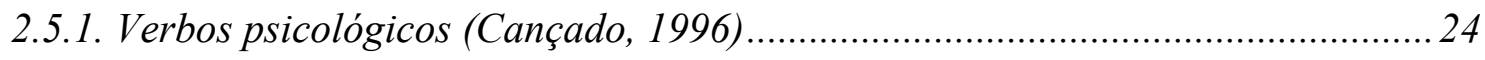

2.5.2. A alternância causativa no português do Brasil (Chagas de Souza, 2000) ......... 27

2.5.3. A construção adversativa (Chagas de Souza, 2001) ............................................. 29

2.5.4. Estudo dos verbos relacionados com o verbo roubar (Ávila, 2006)..................... 30

2.5.5. A alternância causativo-ergativa no português do Brasil (Ciríaco, 2007)........... 32

2.5.6. O estudo dos verbos de movimento (Moraes, 2008) ............................................. 33

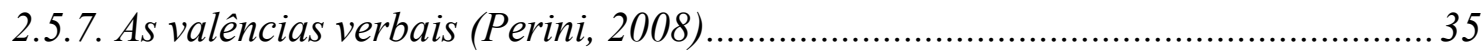

2.5.8. O estudo dos verbos de modo de movimento (Amaral, 2010) .............................. 38

2.5.9. Catálogo de verbos do português do Brasil (Cançado et al., 2012) .................... 39

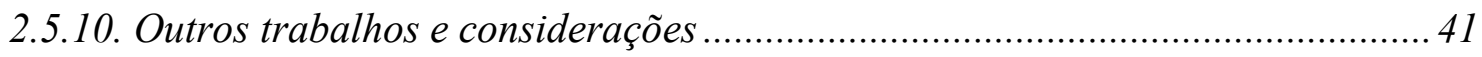




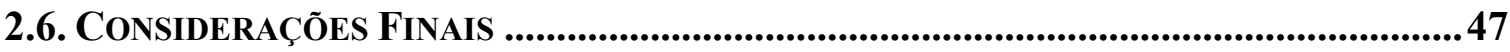

PARTE II: FUNDAMENTAÇÃO TÉORICA COMPUTACIONAL ......... 49

CAPÍTULO 3: RECURSOS LÉXICOS E A VERBNET...............................49

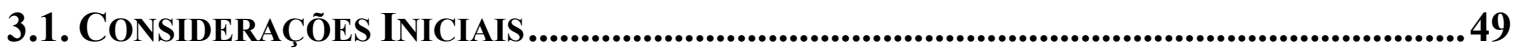

3.2. Trabalhos relacionados: wordnets, Framenet e PropBank ...................... 49

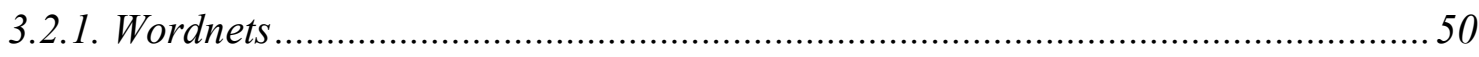

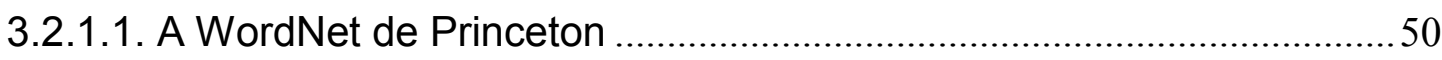

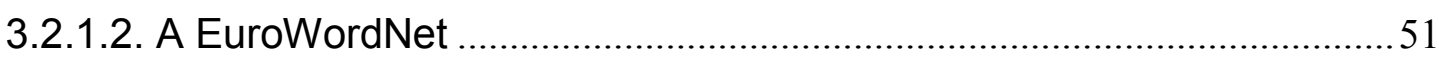

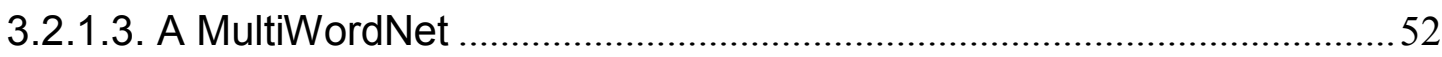

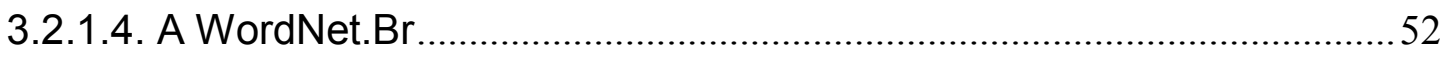

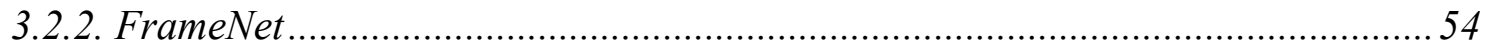

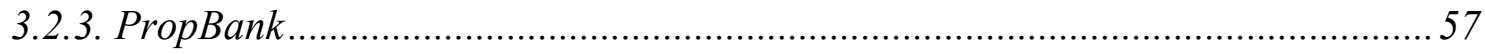

3.3. VERBNET ..........................................................................................................................5 59

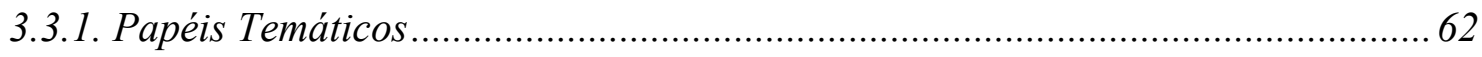

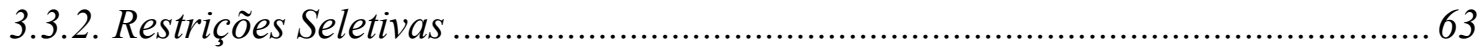

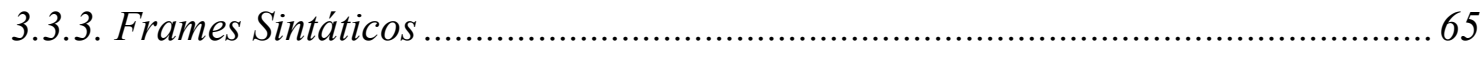

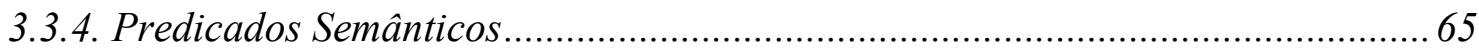

3.3.5. Extensões da VerbNet às classes básicas de Levin (1993)................................... 66

3.3.6. Experimento com o português e a VerbNet ..................................................... 68

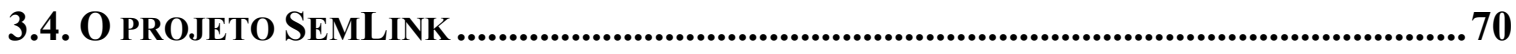

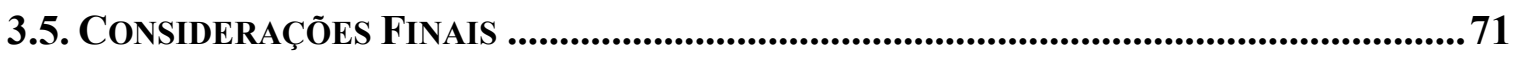

CAPÍTULO 4: ESTRUTURAS DE SUBCATEGORIZAÇÃO.................73

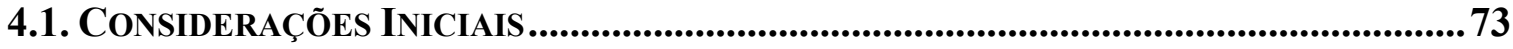

4.2. SiSTEMAS DE EXTRAÇÃO DE ESTRUTURAS DE SUBCATEGORIZAÇÃO PARA O INGLÊS E

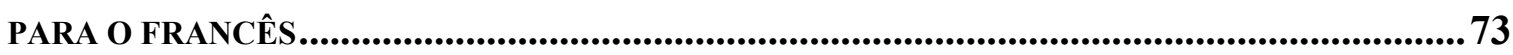


4.3. EXTRATOR DE ESTRUTURAS DE SUbCATEgorizaÇÃo PARA O PORTUGUÊS do

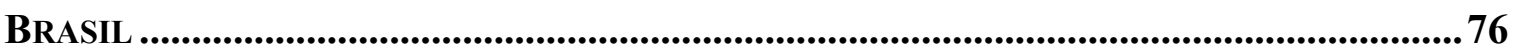

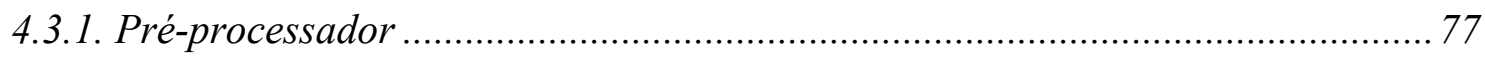

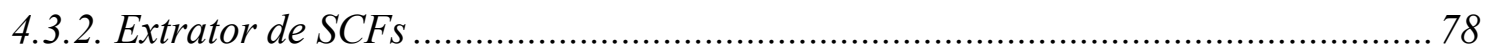

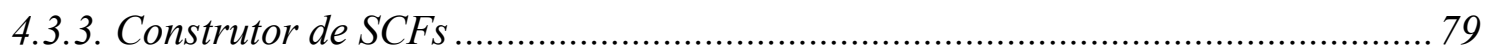

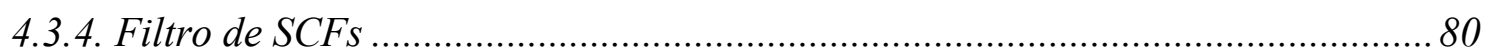

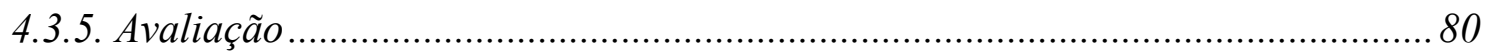

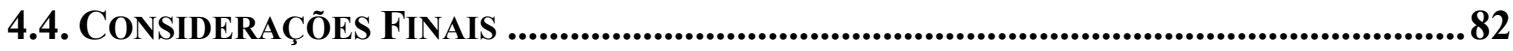

CAPÍTULO 5: TRABALHOS COMPUTACIONAIS COM CLASSES

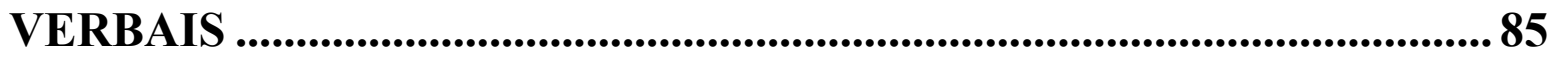

5.1. CONSIDERAÇÕES INICIAIS..................................................................................................... 85

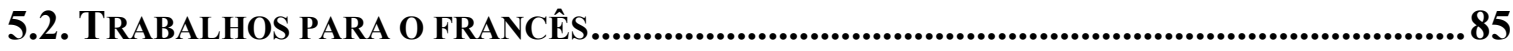

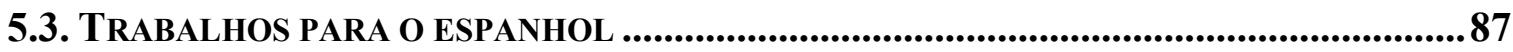

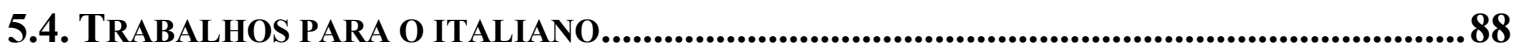

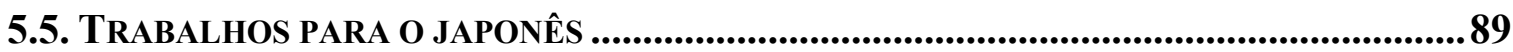

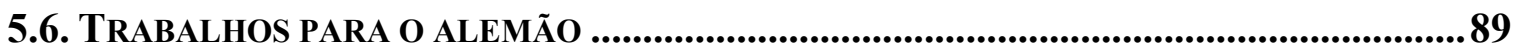

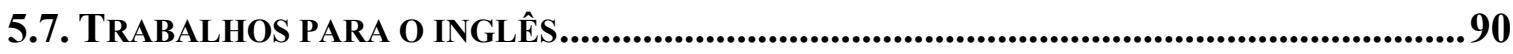

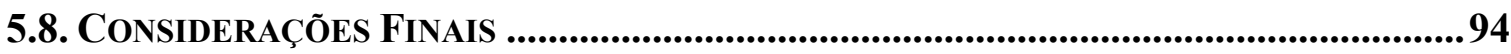

PARTE III: PROJETO DE PESQUISA...................................................97

CAPÍTULO 6: O MÉTODO DE CONSTRUÇÃO DA VERBNET.BR ...97

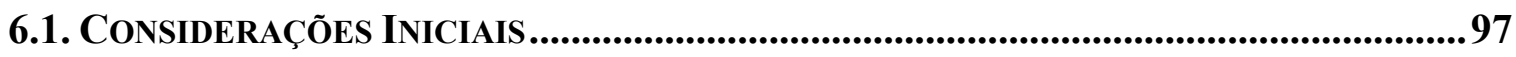

6.2. ConSTRUÇÃo SEMIAUTOMÁtiCA dA VERBNET.BR...............................................97 
6.2.1. Etapa 1: Definição das alternâncias sintáticas do português para cada classe presente na VerbNet

6.2.2. Etapa 2: Busca das alternâncias sintáticas em córpus etiquetado 101

6.2.3. Etapa 3: Definição dos candidatos a membros 102

6.2.4. Etapa 4: Escolha dos membros

6.3. CONSIDERAÇÕES FINAIS

CAPÍTULO 7:AVALIAÇÃO DO RECURSO VERBNET.BR 111

7.1. CONSIDERAÇÕES INICIAIS

7.2. PANORAMA DOS EXPERIMENTOS

7.3. AvaliaÇão da VerbNet.BR

7.3.1 Gold Standard para o português do Brasil..... 112

7.3.2 Análise da VerbNet.Br em relação ao gold standard. 117

7.3.3 Análise comparativa com a tarefa de agrupamento de verbos 123

7.3.4. Avaliação Intrínseca Quantitativa 129

7.4. Outras CONTRIBuições

7.4.1. Ferramenta de consulta à VerbNet.Br

7.4.2. PortLex: um portal para integração de trabalhos com léxicos no Brasil. 132

7.4.3. Revisão da WordNet.Br. 132

7.5. CONSIDERAÇÕES FINAIS 134

CAPÍTULO 8: CONCLUSÕES 137

8.1. CONTRIBUiÇÕeS 137

8.2. LiMitaÇÕES do TRABALHO 140

8.3. Trabalhos Futuros 141

REFERÊNCIAS 145

APÊNDICE A - CLASSES DA VERBNET.BR E RESULTADOS .......... 155 
APÊNDICE B - CLASSES DO GOLD STANDARD .................................... 195 APÊNDICE C - RESULTADOS DA AVALIAÇÃO DA VERBNET.BR

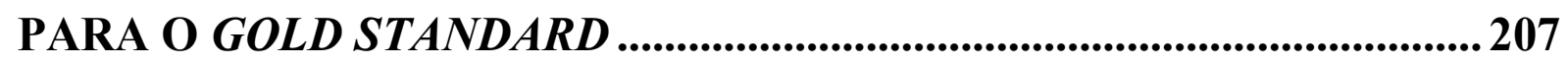
APÊNDICE D - RESULTADOS DA TAREFA DE AGRUPAMENTO DE VERBOS. 



\section{Parte I: Apresentação e}

\section{Fundamentação Téorica de Base}

\section{CAPÍTULO 1: Introdução}

\subsection{Contextualização e Motivação}

Dentre as atividades compreendidas pela área de Processamento de Língua Natural (PLN) encontram-se a criação e a disponibilização de recursos léxicos. Léxicos são fundamentais para analisar/processar e gerar a língua natural. Entretanto, para que eles possam ser utilizados em PLN, devem "[...] conter informações adequadas e codificadas para que o programa computacional ou o algoritmo possa 'compreendê-las' e utilizá-las" (Zavaglia, 2006, p. 1). Os recursos léxicos podem conter informações dos níveis morfológico, sintático, semântico ou discursivo. Exemplos desses recursos são as wordnets, os bancos sintáticos (treebanks), os bancos proposicionais como o PropBank ${ }^{1}$ (Palmer et al., 2005), e léxicos verbais que possuem mapeamentos para outros recursos léxicos, como a VerbNet ${ }^{2}$ (Kipper et al., 2000a; Kipper et al., 2000b; Kipper, 2005; Kipper et al., 2006). Estes recursos são fundamentais para trabalhos de diversas áreas. Em especial, recursos lexicais com informações sintáticas e/ou semânticas de verbos são importantes para tarefas como: recuperação e extração de informações (Croch e King, 2005), animações de instruções em língua natural (Allbeck et al., 2002), construção de parsers semânticos (Shi e Mihalcea, 2005), anotação de papéis semânticos (Yi e Palmer, 2004; Swier e Stevenson, 2004; Yi et al., 2007; Palmer et al., 2010), desambiguação do sentido de palavras (Girju et al., 2005; Abend et al., 2008; Chen e Di Eugenio, 2010; Brown et al., 2011), melhoria de outros recursos (McFate, 2010), dentre outras.

A construção e manutenção manual desses recursos são praticamente inviáveis dadas a grande carga de trabalho e a quantidade de tempo necessária para a realização dessas tarefas. Por isso, há um grande esforço para a criação desses recursos apoiada em

\footnotetext{
${ }^{1} \mathrm{http} / / /$ verbs.colorado.edu/ mpalmer/projects/ace.html

${ }^{2}$ http://verbs.colorado.edu/ mpalmer/projects/verbnet.html
} 
técnicas computacionais. Alguns métodos utilizam aprendizado de máquina. Como exemplo, pode-se citar: (i) a construção de taggers semânticos para papéis temáticos, conseguida via métodos de aprendizado de máquina supervisionados (Palmer et al., 2005; Palmer et al., 2010), para a criação de córpus ${ }^{3}$ anotados com papéis semânticos como o PropBank; (ii) extensão da VerbNet pelo uso de técnicas de aprendizado de máquina não supervisionados (Kipper et al., 2006); e (iii) agrupamento de verbos em classes sintáticosemânticas (Sun e Korhonen, 2009, Sun et al., 2010; Sun et al., 2011).

Outro método que viabiliza a criação de recursos é construí-los a partir de outros recursos já existentes. Nesta linha está o trabalho da wordnet do Brasil (WordNet.Br) (Dias-da-Silva et al., 2002; Dias-da-Silva, 2005; Dias-da-Silva et al., 2008; Dias-da-Silva, 2010) que foi alinhada com a WordNet de Princeton (aqui chamada de WordNet) (Miller et al., 1990; Fellbaum, 1998). Para cada synset (conjunto de palavras sinônimas) presente na WordNet.Br (criados a partir de dicionários) buscou-se alinhar um synset da WordNet. Assim, pode-se dizer que cada synset da WordNet.Br está alinhado com pelo menos um synset da WordNet de Princeton. Esse método permite que as relações semânticas da WordNet sejam herdadas automaticamente para a WordNet.Br, como foi feito no trabalho de Scarton e Aluísio (2009) para a relação semântica de hiperonímia e neste mestrado para as relações semânticas de troponímia e termos coordenados .

Nesta pesquisa, o tipo de recurso léxico que nos interessa é o que trata de verbos. As palavras classificadas como verbos possuem uma grande carga de informação sintática e semântica, afinal, a partir do conhecimento do comportamento de um verbo é possível saber como pode ser a construção da sentença. Em outras palavras, a partir de recursos verbais é possível identificar:

- A relação de verbos que admitem objetos diretos;

- A relação dos verbos que admitem objetos indiretos e quais as preposições admitidas pelos mesmos;

- A relação de verbos que admitem objetos diretos e indiretos simultaneamente;

\footnotetext{
${ }^{3}$ Neste trabalho escolheu-se o aportuguesamento da palavra corpus/corpora para córpus/córpus.
} 
- A relação de verbos que admitem objeto direto, mas podem ser usados intransitivamente (sem objeto), chamados de verbos inacusativos. Exemplos: Ele comeu maçã. / Ele comeu muito.

- A relação de verbos que admitem objeto direto, mas podem ser usados intransitivamente (sem objeto) com transferência do objeto para posição do sujeito, chamados de verbos inergativos. Exemplos: Eu queimei o bolo. / O bolo queimou.

- A relação dos verbos que admitem uso causativo. Exemplo: Eu envergonhei minha mãe. (causa: minha mãe envergonhar-se).

Saber estas e outras características verbais como os papéis temáticos, as restrições seletivas e os predicados semânticos, tem sido um limitante para as diversas atividades da área de PLN no Brasil, pois a língua portuguesa ainda é carente de recursos léxicos que agreguem informações semânticas e/ou sintáticas disponíveis de forma digital e pública (Lima et al., 2007).

A língua inglesa possui certa tradição na construção de léxicos. Um dos recursos léxicos mais conhecido e utilizado é a WordNet, que também pode ser considerada como uma abordagem para classificação de verbos. Porém, ela não possui algumas informações que são geralmente necessárias na área de PLN como, por exemplo, as alternâncias sintáticas $^{4}$ (alternâncias nas expressões dos argumentos, algumas vezes acompanhadas de mudança de sentido (Levin, 1993) - que são apresentadas brevemente no decorrer deste capítulo e com mais detalhes no Capítulo 2) que os verbos admitem (Kipper et al., 2000a e Kipper et al., 2000b). Outra abordagem para classificação de verbos são as classes de Levin (Levin, 1993) (que serão melhor apresentadas no Capítulo 2). Esta abordagem explicita características sintáticas, mas fica aquém da atribuição de componentes semânticos para cada classe. A hipótese fundamental de Levin é de que os frames sintáticos são um reflexo direto da semântica dos verbos (Kipper et al., 2000a e Kipper et al., 2000b).

Outros recursos da língua inglesa que podem ser citados são: PropBank, FrameNet (Baker et al., 1998) e VerbNet. Em especial, a VerbNet fornece informações semânticas e

\footnotetext{
${ }^{4}$ Outro termo encontrado na literatura é alternância de diátese.
} 
sintáticas dos verbos do inglês, é independente de domínio, e baseada nas classes verbais de Levin (Levin, 1993). Esse recurso possui também mapeamentos para a WordNet, suprindo assim as deficiências das duas abordagens de classificação de verbos citadas anteriormente. A VerbNet é disponibilizada livremente em formato XML (eXtensible Markup Language) e também possui uma interface $\mathrm{WEB}^{5}$ para acesso e pesquisa. Atualmente, a VerbNet conta com 270 classes, 200 subclasses, 5.257 verbos membros, 3.769 verbos e 1.420 frames com exemplos ${ }^{6}$.

Levin (1993) descreve as classes verbais como um conjunto de verbos que compartilham um ou mais componentes de significado e apresentam comportamento sintático similar. O comportamento de um verbo se refere às alternâncias sintáticas das quais um verbo participa. Algumas alternâncias sintáticas são: alternância locativa, alternância transitiva, alternância causativa, entre outras. Como exemplo, seguem as expressões (1) e (2), retiradas do trabalho de Levin (1993, p. 2), que apresentam a alternância locativa dos verbos em inglês spray e load.

(1) (a) Sharon sprayed water on the plants. (Sharon borrifou água sobre as plantas) (b) Sharon sprayed the plants with water. (Sharon borrifou as plantas com água)

(2) (a) The farmer loaded apples into the cart. (O fazendeiro carregou maçãs na carroça)

(b) The farmer loaded the cart with apples. (O fazendeiro carregou a carroça com maçãs)

Porém, verbos que são aparentemente relacionados com spray e load não possuem alternância locativa, como aparecem nas expressões (3), (4), (5) e (6) também retiradas do trabalho de Levin (1993, p. 2) (o sinal '*' representa agramaticalidade):

(3) (a) *Monica covered a blanket over the baby. (*Monica cobriu um cobertor sobre o bebê)

(b) Monica covered the baby with a blanket. (Monica cobriu o bebê com um cobertor)

\footnotetext{
${ }^{5} \mathrm{http}: / /$ verbs.colorado.edu/verb-index/

${ }^{6} \mathrm{http}: / /$ verbs.colorado.edu/verb-index/vn/reference.php
} 
(4) (a) *Gina filled lemonade into the pitcher. (*Gina encheu limonada no jarro)

(b) Gina filled the pitcher with lemonade. (Gina encheu o jarro com limonada)

(5) (a) Carla poured lemonade into the pitcher. (Carla despejou limonada no jarro)

(b) *Carla poured the pitcher with lemonade. (*Carla despejou o jarro com limonada)

(6) (a) The farmer dumped apples into the cart. (O fazendeiro despejou maçãs na carroça)

(b) *The farmer dumped the cart with apples. (* $\mathrm{O}$ fazendeiro despejou a carroça com maçãs)

Pode-se observar, então, que mesmo verbos com sentidos similares podem não possuir o mesmo comportamento. Por isso, é interessante agrupar verbos de maneira que respeite tanto significado quanto comportamento sintático. O trabalho de Levin (1993) é uma proposta de agrupamento de verbos respeitando os itens citados anteriormente.

Classes verbais são importantes para capturar generalizações que vão além da instância única do verbo, reduzindo o esforço necessário para a construção de léxicos e a probabilidade de erros quando um verbo é inserido na base (Kipper, 2005). Além dessa informação, na VerbNet foram introduzidos papéis temáticos para descrever a relação semântica subjacente entre os verbos da classe e seus argumentos em um frame. Para ilustrar a utilidade das classes verbais da VerbNet, podemos citar a tarefa de desambiguação de sentido de verbos (verb sense desambiguation) que tem utilizado fortemente essas classes (Girju et al., 2005; Abend et al., 2008; Chen e Di Eugenio, 2010; Brown et al., 2011).

Cada classe verbal da VerbNet é completamente descrita por um conjunto de membros, papéis temáticos para a estrutura predicado-argumento de seus membros, restrições seletivas para os argumentos e frames sintáticos (que descrevem, no nível da sintaxe, as diferentes combinações de argumentos que cada verbo pode apresentar - sendo as alternâncias sintáticas, alternâncias destes frames ${ }^{7}$ ) com uma breve descrição, um exemplo, uma descrição sintática e um conjunto de predicados semânticos com uma

${ }^{7}$ Frames sintáticos também são chamados neste mestrado de estruturas de subcategorização (subcategorization frames SCFs) ou, simplesmente, frames e serão discutidos no Capítulo 4. 
função temporal, conforme ilustrado na Tabela 1, em que parte da classe leave-52.1 ${ }^{8}$ é apresentada. Mais detalhes sobre a VerbNet são apresentados no Capítulo 3.

Tabela 1: Parte da classe leave-52.1 da VerbNet

\begin{tabular}{|l|l|l|}
\hline \multicolumn{5}{|c|}{ Leave-51.2 } \\
\hline Papéis temáticos e Restrições seletivas: Theme [+concrete] e Source [+location - region] \\
\hline Membros: abandon, split \\
\hline Frames:
\end{tabular}

Para o português do Brasil, várias iniciativas estão atualmente enfatizando a criação de recursos léxicos. Dentre elas há a criação da wordnet brasileira (WordNet.Br) (cujo método de criação foi apresentado anteriormente). Outros recursos na linha de wordnets são a MultiWordNet (Pianta et al., 2002), que possui uma versão para o português do Brasil, a WordNet.PT (Marrafa, 2002) (wordnet do português de Portugal) e o PAPEL (Gonçalo Oliveira et al., 2008; Santos et al., 2009) que apresenta as relações presentes em uma wordnet (sinonímia, antonímia, hiperonímia, hiponímia, dentre outras) para várias palavras do português de Portugal. Há também uma iniciativa para a construção de um PropBank para o Português do Brasil (PropBank.Br), no mesmo grupo de pesquisa do mestrado em tela, o NILC ${ }^{9}$, com sede no ICMC-USP ${ }^{10}$ (Duran et al., 2010a; Duran et al., 2010b; Duran e Aluísio, 2011; Duran e Aluísio, 2012). A primeira etapa deste trabalho consistiu da anotação de papéis semânticos (nos moldes do PropBank) de 6.142 instâncias da parte do Português do Brasil córpus Bosque (Afonso et al., 2002). Este córpus possui anotação sintática do parser PALAVRAS (Bick, 2000), corrigida manualmente. Atualmente, este trabalho tem enfoque na criação de frames files alinhados com os frames files do inglês. Outros trabalhos que merecem ser citados são a FrameNet Brasil ${ }^{11}$ (Salomão, 2009) que tem o objetivo de criar um recurso lexical online para o Português, baseado na semântica de frames e sustentado por evidência em córpus e o Projeto FrameCorp (Chishman et al., 2008 e Bertoldi e Chishman, 2009), uma proposta de

\footnotetext{
${ }^{8}$ A nomenclatura das classes da VerbNet seguem a nomenclatura de Levin (1993), seguida pelo número da seção em que a classe aparece no livro. Por exemplo, a classe leave-52.1 aparece na seção 52.1 de Levin(1993).

${ }^{9}$ NILC - Núcleo Interinstitucional de Linguística Computacional

${ }^{10}$ ICMC-USP - Insitituto de Ciências Matemáticas e de Computação da Universidade de São Paulo

${ }^{11} \mathrm{http}: / /$ www.framenetbr.ufjf.br/
} 
aplicação da semântica de frames à anotação de córpus e que, com este propósito, também utiliza a base de dados do Projeto FrameNet de Berkeley. Há também os mestrados de Fernando Alva Manchego (Alva-Manchego e Rosa, 2012a; Alva-Manchego e Rosa, 2012b) e Erick Rocha Fonseca (Fonseca e Rosa, 2012) e o doutorado de Murillo Guimarães Carneiro (também desenvolvidos no NILC) que propõem a anotação automática de papéis semânticos a partir de métodos de aprendizado de máquina, utilizando o córpus do PropBank.Br.

Apesar do grande esforço empenhado na construção desses recursos para o português, nenhum deles descreve as várias características das estruturas verbais na interface sintática-semântica. Alguns trabalhos de descrição do português apresentam estudos para o português de algumas das classes de Levin: Cançado (1996) trabalhou com verbos psicológicos (verbos que estão relacionados com estados emocionais, tais como "temer”, "preocupar", “acalmar" e "animar") classificando-os em quatro classes de acordo com alternâncias sintáticas e papéis semânticos; Chagas de Souza (2000) trabalhou com a alternância causativa-ergativa ${ }^{12}$ (alternância do frame sintático causativo (João quebrou o vaso - SN V SN) para o frame sintático ergativo (O vaso quebrou - SN V)) no português do Brasil; Chagas de Souza (2001) estudou uma construção própria da língua portuguesa, a construção adversativa (construções causativas que admitem a preposição "com" e denotam que algo foi afetado negativamente); Ávila (2006) trabalhou com alternâncias sintáticas para o português do Brasil apresentando um estudo para verbos relacionados ao verbo roubar; Círiaco (2007) apresentou um estudo de alternâncias causativo-ergativas; Moraes (2008) trabalhou com verbos de movimento e suas alternâncias e classes (verbos que denotam movimento, tais como "avançar", “chegar", “partir”, “derrapar” e "girar”); Perini (2008) estudou as valências verbais ${ }^{13}$ e os diversos frames sintáticos que compõem estas valências; Amaral (2010) trabalhou com a classe de verbos de modo de movimento (subclasse dos verbos de movimento) e Cançado et al. (2012) propõe a construção de um catálogo de verbos para o português do Brasil dividido em classes sintático-semânticas (mais detalhes sobre estes trabalhos são apresentados no Capítulo 2). Porém, esses e outros trabalhos tratam, geralmente, de um conjunto fechado de verbos e não disponibilizam os

\footnotetext{
${ }^{12}$ Os termos incoativo e anti-causativo também são utilizados na literatura com o mesmo sentido de ergativo.

${ }^{13}$ Segundo Perini (2008, p. 236), "a valência de um verbo é o conjunto de construções em ele pode ocorrer [...]". No trabalho de Perini (2008) o conceito de "construções" é o mesmo de frames sintáticos neste mestrado.
} 
resultados da análise em formato eletrônico ${ }^{14}$ para que possam ser distribuídos à comunidade gratuitamente e aproveitados computacionalmente.

No trabalho de Kipper (2005) há também um experimento para a língua portuguesa considerando o potencial cross-linguístico ${ }^{15}$ (cross linguistic) das classes de Levin (1993). Neste experimento, Kipper (2005) avalia a similaridade entre os verbos da classe Carry do inglês, com suas traduções para o português, obtendo um resultado promissor. Trabalhos para outras línguas também exploraram o potencial cross-linguístico das classes de Levin (1993). É o caso do trabalho de Merlo et al. (2002), para o italiano e Sun et al. (2010), para o francês. A existência do potencial cross-linguístico em estruturas semânticas superficiais, como é o caso da semântica das classes de Levin (1993), é também evidenciado em Jackendoff (1990).

Além da VerbNet, existem outros trabalhos que agrupam verbos em classes sintático-semânticas, porém realizam esta tarefa de forma automática. Para a língua inglesa pode-se citar os trabalhos de: (1) Merlo e Stevenson (2001), (2) Joanis e Stevenson (2003), (3) Kingsbury e Kipper (2003), (4) Sun et al. (2008), (5) Sun e Korhonen (2009) e (6) Sun e Korhonen (2011).

O primeiro utiliza uma abordagem supervisionada de aprendizado de máquina para a classificação de verbos considerando um conjunto de 59 verbos divididos em três classes (inergativos, inacusativos e que admitem perda de objeto) como base de treinamento. $\mathrm{O}$ segundo também utiliza uma abordagem supervisionada, porém com uma base de treinamento de 835 verbos divididos em 15 classes de Levin (1993). O terceiro utiliza uma abordagem não supervisionada para o agrupamento de verbos em classes, utilizando o córpus anotado no projeto PropBank para extrair os atributos e visa comparar os resultados com a VerbNet. O quarto explora uma abordagem não supervisionada de aprendizado de máquina e quatro abordagens supervisionadas para realização da tarefa. O interessante deste quarto trabalho é o uso de dezessete classes de Levin (1993), com doze membros cada classe, que são consideradas um gold standard. O quinto trabalho explora atributos

\footnotetext{
${ }^{14}$ Há uma iniciativa do Núcleo de Pesquisa em Semântica Lexical (NuPes), coordenado pela professora doutora Marcia Cançado, da Universidade Federal de Minas Gerais, em disponibilizar de forma mais acessível os dados gerados nos trabalhos dos membros do grupo (Márcia Cançado, 2011, comunicação pessoal). Além disso, em Cançado (2012) é afirmado que haverá a disponibilização do catálogo de verbos em um banco de dados eletrônico.

${ }^{15} \mathrm{O}$ termo cross-linguístico é uma tradução livre do termo em inglês cross-linguistic dado que desconhe-se uma tradução oficial para o português.
} 
semânticos na tarefa de agrupamento de verbos utilizando o gold standard do trabalho anterior como uma das bases de teste. Por fim, o sexto trabalho utiliza uma abordagem hierárquica para realizar o agrupamento de verbos (mais detalhes sobre estes trabalhos são apresentados no Capítulo 5). Vale comentar, que a maioria destes trabalhos utiliza SCFs como atributos.

Além do inglês, existem iniciativas de automatização da classificação de verbos para outras línguas. Para o francês, o trabalho de Sun et al. (2010) se baseia no trabalho de Sun e Korhonen (2009) para agrupar verbos do francês em classes sintático-semânticas. Para o italiano, o trabalho de Merlo et al. (2002) realiza aprendizado supervisionado com 59 verbos em italiano divididos em três classes: verbos que denotam mudança de estado, verbos que admitem perda de objeto e verbos psicológicos. Para o espanhol, o trabalho de Ferrer (2004) utiliza aprendizado não supervisionado para definir as classes verbais e compara o resultado com o trabalho manualmente desenvolvido de Vázquez et al. (2000). Para o japonês, o trabalho de Takeuchi et al. (2010) descreve a criação de um thesaurus que tem como base o compartilhamento de significados a partir da estrutura predicadoargumento. Por fim, para o alemão, o trabalho de Schulte im Walde (2006) utiliza uma abordagem não supervisionada de aprendizado de máquina para a tarefa de agrupamento de verbos em classes sintático-semânticas. Estes trabalhos serão detalhados no Capítulo 5.

\subsection{Objetivos e Hipóteses}

Neste mestrado, verificaram-se duas hipóteses:

(a) É possível a criação de um recurso léxico para o português de mesmas características da VerbNet (chamado VerbNet.Br (Scarton, 2011; Scarton e Aluisio,2012)), diretamente alinhado com a mesma, via um método semiautomático que se utiliza de recursos existentes (para o inglês e para o português), aproveitando-se do potencial cross-linguístico das classes de Levin, evidenciado em Jackendoff (1990), comprovado em Merlo et al. (2002) (para o italiano) e Sun et al., 2010 (para o francês) e testado para ao português em Kipper (2005); e

(b) a criação deste recurso léxico utilizando-se o método semiautomático e baseado em recursos já existentes produzirá resultados mais precisos do que um método 
baseado em agrupamento de dados, também desenvolvido nesta pesquisa, quando comparados a um gold standard.

O principal objetivo deste mestrado foi a criação da VerbNet.Br, que se deu com base em um método composto por quatro etapas: três automáticas (definição de candidatos a membros via alinhamentos e mapeamentos entre a VerbNet, WordNet e WordNet.Br e definição estruturas de subcategorização (SCFs ou frames) dos verbos via busca em córpus) e uma manual (definição dos frames sintáticos de cada classe para o português). Também foram realizados experimentos desconsiderando a etapa manual (mais detalhes sobre o método são apresentados no Capítulo 6).

Na Figura 1 é exemplificado o método de criação da VerbNet.Br (com a etapa manual). A primeira etapa foi manual (Etapa 1 da Figura 1). Ela consistiu da tradução dos frames sintáticos das classes da VerbNet que puderam ser diretamente traduzidas do inglês para o português. A segunda foi uma etapa automática (Etapa 2 da Figura 1) e consistiu da busca em córpus para construir uma lista de verbos e suas possíveis estruturas de subcategorização (utilizou-se a ferramenta de Zanette et al. (2012) para extração dos SCFs). A terceira etapa, também automática (Etapa 3 da Figura 1), aproveitou-se do alinhamento existente entre a WordNet e a WordNet.Br e do mapeamento entre a WordNet e a VerbNet (como se pode observar na Figura 1). Desta forma, tentou-se alinhar cada membro de uma classe da VerbNet com pelo menos um synset da WordNet.Br. Os verbos dos synsets alinhados aos membros de uma classe na VerbNet foram definidos como candidatos a membros da classe correspondente na VerbNet.Br. O resultado das três etapas anteriores alimentou a quarta etapa (automática - Etapa 4 da Figura 1) que consistiu de verificar se os candidatos a membros (definidos na terceira etapa) participavam das alternâncias sintáticas da classe (definidas na primeira etapa) a partir da lista de SCFs por verbo, obtida na segunda etapa. 


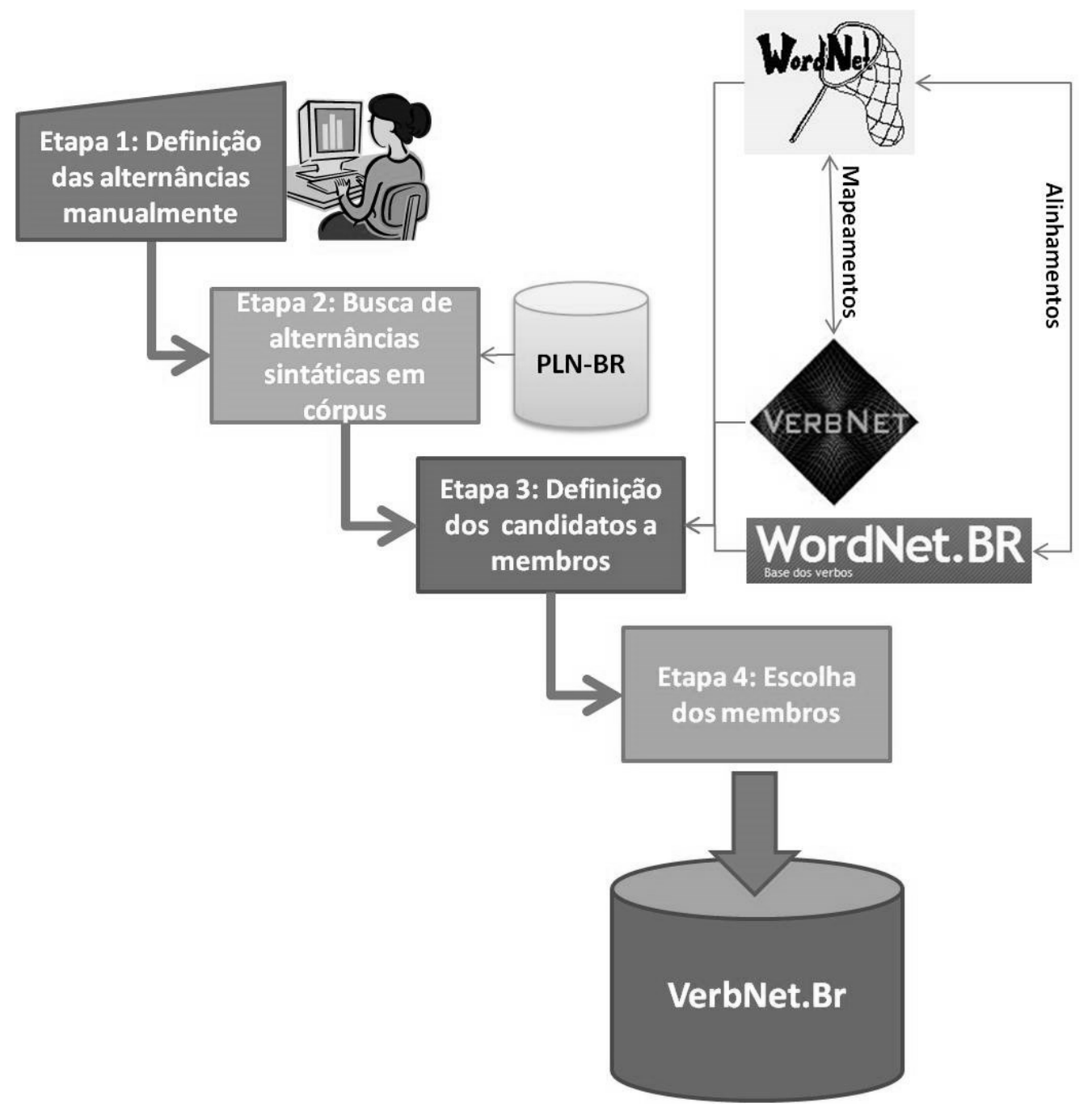

Figura 1: Esquematização do método de criação da VerbNet.Br a partir de outros recursos

No caso dos experimentos sem considerar a etapa manual (Etapa 1), na Etapa 4 são considerados somente os SCFs que os verbos candidatos (Etapa 3) apresentam no córpus (Etapa 2). Os verbos foram, então, selecionados da seguinte forma: escolheu-se o frame mais frequente para os verbos candidatos e selecionaram-se todos os verbos que apresentavam este frame como membros. Na Tabela 2 é apresentada uma classe do gold standard da VerbNet.Br, na qual é possível observar que os papéis temáticos e predicados semânticos são herdados da VerbNet. 
Tabela 2: Classe put-9.1 na VerbNet.Br

\begin{tabular}{|c|c|c|c|}
\hline \multicolumn{4}{|c|}{ Put-9.1 - VerbNet.Br } \\
\hline \multicolumn{2}{|c|}{$\begin{array}{l}\text { Papéis temáticos e Restrições } \\
\text { Destination[+location - region] }\end{array}$} & seletivas: $\quad$ Agent $[+a$ & imate] Theme[+concrete] \\
\hline \multicolumn{4}{|c|}{$\begin{array}{l}\text { Membros: cravar, posicionar, mergulhar, situar, inserir, depositar, introduzir, meter, guardar, } \\
\text { instalar, montar, pôr, colocar, botar, implantar, incluir, enterrar, fincar, fixar, plantar, dispor, } \\
\text { encaixar, estacionar, intercalar, semear. }\end{array}$} \\
\hline \multicolumn{4}{|c|}{ Frames: } \\
\hline Nome & Exemplo & Sintaxe & Semântica \\
\hline $\begin{array}{l}\text { SN } \quad \mathrm{V} \quad \mathrm{SN} \\
\text { SP.destination }\end{array}$ & $\begin{array}{l}\text { I put the rook } \\
\text { on/under/near the } \\
\text { table. } \\
\text { "Eu coloquei o livro } \\
\text { em/sobre/sob a mesa." }\end{array}$ & $\begin{array}{l}\text { Agent V Theme } \\
\{\{+l o c\}\} \text { Destination } \\
+ \text { loc: em, sobre, } \\
\text { sob, entre }\end{array}$ & $\begin{array}{ll}\text { - } & \text { motion(during(E), Theme) } \\
\text { - } & \text { not(Prep(start(E), Theme, } \\
& \text { Destination)) } \\
\text { - } & \text { Prep(end(E), } \\
& \text { Destination) } \\
\text { - } & \text { cause(Agent, E) }\end{array}$ \\
\hline $\begin{array}{l}\text { SN V } \\
\text { ADVP }\end{array}$ & $\begin{array}{l}\text { put the book } \\
\text { here/there. } \\
\text { "Eu coloquei o livro } \\
\text { aqui/lá." }\end{array}$ & $\begin{array}{l}\text { Agent V Theme Desti } \\
\text { nation }<+a d v \_l o c>\end{array}$ & $\begin{array}{ll}\text { - } & \text { motion(during(E), Theme) } \\
\text { - } & \text { not(Prep(start(E), Theme, } \\
& \text { Destination)) } \\
\text { - } & \text { Prep(end(E), } \\
& \text { Destination) } \\
\text { - } & \text { cause(Agent, E) }\end{array}$ \\
\hline
\end{tabular}

Um objetivo secundário foi contribuir para a correção da base de verbos da WordNet.Br. Como este recurso foi utilizado na construção da VerbNet.Br, seria ideal que ele estivesse corrigido e revisado. A proposta de colaboração com o pesquisador responsável pela WordNet.Br, o professor Bento Carlos Dias da Silva, dividiu-se em duas fases:

(a) correção automática de erros de definição na base de verbos da WordNet.Br, como apresentado na Seção 7.4.2; e

(b) desenvolvimento de uma interface de busca da WordNet.Br ${ }^{16}$.

Outro objetivo secundário foi a divulgação deste recurso e do método de criação via um portal para divulgação de trabalhos teóricos e computacionais sobre a VerbNet (chamado de PortLex ${ }^{17}$ ).

\subsection{Organização do Trabalho}

Este trabalho está organizado em três partes. A primeira parte contém a apresentação do trabalho e a fundamentação teórica de base, sendo composta pelos Capítulos 1 e 2. No Capítulo 2, são apresentados conceitos base para esta pesquisa. Na Seção 2.2 é apresentado o conceito de Papel Temático, com alguns exemplos. Na Seção

\footnotetext{
${ }^{16} \mathrm{http}: / /$ nilc.icmc.usp.br/wordnet

${ }^{17}$ www2.nilc.icmc.usp.br/portlex/
} 
2.3 é apresentada a hipótese de Levin (1993) para o agrupamento dos verbos em inglês. A Seção 2.4 traz a apresentação das alternâncias sintáticas proposta no estudo de Levin (1993). Por fim, na Seção 2.5 são apresentados os trabalhos relacionados ao trabalho de Levin (1993), para o português do Brasil: Cançado (1996), Chagas de Souza (2000), Chagas de Souza (2001), Ávila (2006), Ciríaco (2007), Moraes (2008), Perini (2008), Amaral (2010) e Cançado et al. (2012).

A segunda parte desta dissertação contém a fundamentação teórica computacional que norteia este trabalho. Os capítulos desta segunda parte vão de 3 a 5 . No Capítulo 3 é apresentada a VerbNet, sua estrutura e componentes, e os trabalhos relacionados, tanto para o inglês, quanto para o português do Brasil. Na Seção 3.2 são apresentados os trabalhos relacionados a VerbNet: wordnets, PropBank e FrameNet e suas versões para o Português do Brasil (WordNet.Br, PropBank.Br e FrameCorp/FrameNet Brasil, respectivamente). Na Seção 3.3 é apresentada a VerbNet principal objeto desta pesquisa. Na Seção 3.4 é apresentado o projeto SemLink (Loper et al., 2007) que visa o mapeamento de diversos recursos lexicais (WordNet, FrameNet, PropBank e VerbNet) para conseguir aproveitar as características individuais de cada recurso em uma só ferramenta. No Capítulo 4, são apresentados trabalhos relacionados com estruturas de subcategorização. $\mathrm{Na}$ Seção 4.2 são apresentados os trabalhos para a língua inglesa e para a língua francesa. Na Seção 4.3 é apresentado o trabalho de Zanette (2010), para o português. No Capítulo 5, são apresentados trabalhos computacionais com classes verbais sintático-semânticas. Na Seção 5.2 são apresentados os trabalhos para o francês. Na Seção 5.3 são apresentados os trabalhos para o espanhol. Na Seção 5.4 são apresentados os trabalhos para o italiano. Na Seção 5.5 são apresentados os trabalhos para o japonês. Na Seção 5.6 são apresentados os trabalhos para o alemão. Por fim, na Seção 5.7 são apresentados trabalhos para a língua inglesa, que tratam de agrupamento de verbos em classes sintático-semânticas de forma automática.

A terceira parte deste trabalho contempla a descrição do projeto de pesquisa deste mestrado, sendo dividida nos capítulos de 6 a 8. No Capítulo 6, é apresentado o projeto de mestrado em questão. A Seção 6.2 contém a definição do método de construção da VerbNet.Br, bem como a definição do uso do método (considerando todas as etapas, ou desconsiderando a etapa manual). No Capítulo 7 são apresentados os resultados e a 
avaliação da VerbNet.Br. Na Seção 7.2 são apresentados os resultados gerais. Na Seção 7.3 são apresentadas as avaliações intrínseca qualitativa e intrínseca quantitativa da VerbNet.Br. Na Seção 7.4 são apresentadas as outras contribuições deste mestrado (PortLex e WordNet.Br). Por fim, no Capítulo 8 são apresentadas as conclusões e as limitações deste mestrado e os trabalhos futuros relacionados a este mestrado. 


\section{CAPÍTULO 2: Papéis Temáticos, as alternâncias sintáticas e as classes de Levin}

\subsection{Considerações Iniciais}

Neste capítulo são tratados os conceitos e teorias que nortearam este mestrado. A Linguística Computacional (LC) e o Processamento de Língua (ou Linguagem) Natural (PLN) são denominações de áreas de pesquisa usadas indistintamente atualmente que remetem a uma área interdisciplinar envolvendo a Ciência da Computação e a Linguística. Estas tratam da modelagem computacional de aspectos das línguas naturais visando seu tratamento em programas de computador. Há algum tempo atrás era comum se fazer a distinção entre LC e PLN, porém até hoje é difícil concluir o que as tornavam distintas. Uma visão bastante aceita até então é que enquanto na LC se modelam computacionalmente teorias linguísticas conhecidas, em PLN não há compromisso com teorias linguísticas, podendo ser usados modelos empíricos, como os estatísticos ou baseados em regras. Em outras palavras, o que as distinguiria seria uma perspectiva mais linguística em LC e mais computacional em PLN. Por isso, para os cientistas da computação, muitas vezes se faz necessária uma definição e um estudo formal da parte linguística desta área. $\mathrm{Na}$ Seção 2.2, é apresentado o conceito de papel temático. $\mathrm{Na}$ Seção 2.3 apresenta-se o conceito de alternâncias sintáticas. Na Seção 2.4 são apresentadas as classes de Levin. Na Seção 2.5 são apresentados os trabalhos no Brasil relacionados com o trabalho de Levin. Por fim, na Seção 2.6 são apresentadas as considerações finais.

\subsection{Papéis Temáticos}

Papéis temáticos descrevem a relação semântica subjacente entre um verbo e seus argumentos e são usados para descrever padrões léxicos e semânticos no comportamento dos verbos (Kipper, 2005). No exemplo em (7), retirado de Cançado (2005, p. 3), pode-se observar que o verbo quebrar atribui o papel de agente a João, de paciente ao vaso e de instrumento ao martelo.

(7) João quebrou o vaso com o martelo. 
Segundo Kipper (2005) e Cançado (2005) não existe um consenso sobre o conjunto de papéis necessários para caracterizar os argumentos de um verbo e não há nenhum critério claro para determinar quais papéis devem ser aplicados a um argumento em particular e as definições para estes papéis são vagas. Perini (2008) defini os papéis temáticos como "um problema espinhoso, que requer discussão" (Perini, 2008, p.181). Kipper (2005) apresenta uma lista do que ela chama de "papéis temáticos comuns":

- Agente: um executor de uma ação ou evento.

- Paciente: um participante que é submetido a um processo ou é afetado por uma ação.

- Tema: um participante que está localizado em um lugar ou que se move de um lugar para outro.

- Experienciador: um participante caracterizado como ciente de algo ou experimentando algo.

- Estímulo: evento ou objeto que acarreta uma resposta psicológica de um experienciador.

- Instrumento: uma força física ou um objeto que faz a mudança de algo, usualmente, por entrar em contato direto com este algo.

- Posição: um participante que expressa uma posição.

- Fonte: um participante que representa o ponto de partida de um movimento.

- Meta: um participante para o qual o movimento segue.

- Receptor: participante que é o alvo da transferência de uma entidade (concreta ou abstrata).

- Beneficiário: entidade beneficiada por alguma ação.

Os papéis temáticos podem ser independentes da realização sintática do verbo:

(8) (a) John hit Bill. (John golpeou Bill)

(b) Bill was hit by John. (Bill foi golpeado por John) 
Nos dois casos apresentados em (8a) e (8b), retirados de Kipper (2005, p. 10), Bill tem o papel temático de paciente e John o de agente, mesmo alternando sintaticamente.

Vale comentar que existem outras teorias de papéis temáticos e, como não há um consenso, cada pesquisador decide por um conjunto próprio ou seja alguma vertente. Como este mestrado trata de um recurso léxico computacional, vale comentar as teorias utilizadas pelos recursos léxicos relacionados que apresentam anotação de papéis temáticos (somente PropBank e FrameNet, pois a WordNet não possui esta informação).

Os papéis semânticos do PropBank são argumentos numerados do tipo: Arg0, Arg1, Arg2, etc. Estes argumentos podem assumir papéis temáticos diferentes, dependendo da sentença em questão. Por exemplo, em uma sentença o Arg0 pode estar representando um agente, já em outra pode estar no lugar de um experienciador. O Arg1 em uma sentença pode ser um tema e em outra ou local. E assim acontece para os demais argumentos (Arg2, Arg3,...). Além dos argumentos numerados, o PropBank possui uma anotação para os adjuntos, os ArgMs. Os adjuntos podem denotar local, causa, tempo, modo, direção, verbos modais, entre outros. Esta notação é útil para tarefas de aprendizado de máquina, pois possui um alto grau de generalização.

Já a FrameNet possui papéis específicos para cada verbo. Por exemplo, os argumentos do verbo to buy devem receber como papéis semânticos Buyer (comprador), Seller (vendedor), Money (dinheiro) e Goods (mercadorias). Essa notação é muito específica, e pode não ser muito útil para tarefas de aprendizado de máquina. Porém, é muito rica e pode ser utilizada para melhoria de sistemas em PLN.

\subsection{Alternâncias sintáticas}

Como mencionado na seção anterior, alternâncias sintáticas (ou alternâncias de diátese) são alternâncias nas expressões de argumentos, algumas vezes acompanhadas de mudança de significado. Levin (1993) apresenta, detalhadamente, as alternâncias das quais os verbos em inglês participam (parte I, página 25). Parte da VerbNet (Capítulo 3) é baseada nestas alternâncias, por isso o conhecimento delas se faz necessário neste projeto de mestrado.

Levin (1993) descreve oito grandes classes de alternâncias de diátese (o sinal * indica agramaticalidade): 
- alternâncias de transitividade: envolvem mudança na transitividade do verbo da forma 'SN V SN' mudando para 'SN V' ou 'SN V SN' mudando para 'SN V SP'. Nesta classe se encontram a alternância causativa-ergativa, melhor apresentada na Seção 2.5;

- alternâncias envolvendo argumentos sem sintagmas verbais: não envolvem mudança na transitividade do verbo. Participam destas alternâncias verbos transitivos que permitem mais de uma maneira de expressar seus argumentos. É o caso da alternância dativa que alterna da forma 'SN1 V SN2 to SN3' para a forma 'SN1 V SN3 SN2', ou seja, o sintagma nominal que é objeto da preposição to no sintagma preposicional alterna para o primeiro objeto na construção com dois objetos (Bill sold a car to Tom - Bill vendeu um carro para Tom / Bill sold Tom a car - *Bill vendeu Tom um carro);

- alternâncias de sujeito oblíquo: não envolvem mudança na transitividade, porém envolvem mudanças no número de sintagmas nominais encontrados com o verbo. Como é o caso da alternância com sujeito que denotam força natural (I dried the clothes in the sun - Eu sequei as roupas no sol / The sun dried the clothes - $\mathrm{O}$ sol secou as roupas);

- alternâncias de diátese reflexiva: apresentam mudanças de significado que resultam do uso de pronomes reflexivos como objetos de alguns verbos. É o caso da alternância reflexiva de aparição em que o sujeito dos verbos dessa classe (na construção com um objeto reflexivo) possui a mesma relação semântica para com o verbo do que objeto da forma transitiva comum ( $I$ presented a solution to the problem yesterday - Eu apresentei uma solução para o problema ontem / A solution to the problem presented itselfyesterday - Uma solução para o problema se apresentou ontem);

- alternâncias passivas: engloba verbos que admitem voz passiva (The cook sliced the mushrooms - $\mathrm{O}$ cozinheiro fatiou os cogumelos / The mushrooms were sliced by the cook - Os cogumelos foram fatiados pelo cozinheiro). 
- alternâncias envolvendo sujeitos pós-verbais: construções em que o sujeito do verbo ocorre depois do verbo. É o caso da alternância de inversão locativa que é caracterizada por um sintagma preposicional antes do verbo e um sintagma nominal depois do verbo que denotam a mesma semântica que o sujeito da variante transitiva (An old man lives in the woods - Um velho homem vive na floresta / In the woods lives an old man - Na floresta vive um velho homem)

- outras construções: inclui uma variedade de outras construções que envolvem propriedades de argumentos de verbos. Como é o caso da alternância de interpretação não intencional com objeto reflexivo, em que o sujeito dos verbos que a admitem, embora sejam usualmente classificados como agentes, não tem a intenção de executar uma ação nele mesmo (Pauline cut herself-Pauline se cortou).

- verbos que requerem diáteses especiais: inclui verbos que apresentam restrições especiais em seu comportamento. Como é o caso de verbos que obrigatoriamente ocorrem na voz passiva (It is rumored that he left townHá rumores de que ele deixou a cidade).

Vale lembrar que estas alternâncias são dedicadas à língua inglesa e que algumas delas não apresentam compatibilidade com o português. Um exemplo é a alternância dativa (apresentada anteriormente), que alternada forma SN V SN to SN (Bill sold a car to TomBill vendeu um carro para Tom) para SN V SN SN (Bill sold Tom a car - *Bill vendeu Tom um carro). No português, no entanto, essa alternância não é apresentada pelo verbo correspondente a to sell (vender). O mesmo acontece para o verbo "enviar" (to send), que no inglês é possível dizer I sent Tom an e-mail (*Eu enviei Tom um e-mail). Porém, neste mestrado, considerou-se o que há de comum entre as línguas, o que justifica o estudo destas alternâncias.

\subsection{As classes de Levin}

O trabalho de Beth Levin (Levin, 1993) é, sem dúvida, um referencial no estudo de verbos. Ela agrupou os verbos do inglês em 51 grandes classes (com diversas subclasses) de acordo com as características sintáticas e semânticas que esses verbos compartilham. 
Segundo ela, o conhecimento que um falante de uma língua possui sobre itens lexicais sugere que há mais conhecimento lexical do que conhecimento de propriedades idiossincráticas específicas de palavras. No caso de verbos, um falante de uma dada língua é capaz de identificar em quais alternâncias sintáticas um determinado verbo pertencente à língua participa.

A hipótese para o agrupamento dos verbos é que a base da habilidade dos falantes de uma língua em determinar o comportamento de um verbo está relacionada com o significado deste verbo. Assim, os verbos de um mesmo grupo compartilham tanto características sintáticas quanto aspectos semânticos.

Para exemplificar esta afirmação, Levin apresenta um estudo de caso com os verbos break (quebrar), cut (cortar), hit (golpear) e touch (tocar). Todos estes verbos são transitivos, tomando dois argumentos: um como sujeito e outro como objeto, como podemos observar nos exemplos a seguir (todos os exemplos desta seção são retirados de Levin (1993, p. 6-7)):

(9) Margaret cut the bread. (Margaret cortou o pão.)

(10) Janet broke the vase. (Janet quebrou o vaso.)

(11) Terry touched the cat. (Terry tocou o gato.)

(12) Carla hit the door. (Carla golpeou a porta.)

Porém, estes verbos não participam das mesmas alternâncias sintáticas. Somente cut e break participam da alternância medial (um tipo de alternância de transitividade) cuja variante intransitiva é caracterizada pela ausência de um tempo de referência específico e por um agente conhecido, porém não explicitado (o sinal * indica agramaticalidade):

(13) The bread cuts easily. (O pão corta(-se) facilmente.)

(14) Crystal vases break easily. (Vasos de cristal quebram(-se) facilmente.)

(15) *Cats touch easily.

(16) *Door frames hit easily.

Já cut e hit participam da alternância conativa (outro tipo de alternância de transitividade) em que o objeto do verbo na variante transitiva aparece na variante 
intransitiva como o objeto da preposição no sintagma preposicional iniciado pela preposição at. $\mathrm{Na}$ variante com preposição há a tentativa de realização da ação, o que a diferencia do significado da variante transitiva. Os demais verbos não participam desta alternância:

(17) Margaret cut at the bread. (*Margaret cortou no pão.)

(18) * Janet broke at the vase.

(19) * Terry touched at the cat.

(20) Carla hit at the door. (*Carla golpeou na porta.)

Por fim, os verbos cut, hit e touch participam da alternância de alçamento de parte do corpo (um tipo de alternância envolvendo argumentos sem sintagma verbal) que é caracterizada pela mudança na expressão de uma parte do corpo: a parte do corpo pode ser expressa como objeto direto (sentenças (a)s de (21) a (24)) ou a pessoa (possuidora da parte do corpo) pode ser expressa como objeto do verbo e a parte do corpo expressa em um sintagma preposicional (sentenças (b)s de (21) a (24)):

(21) (a) Margaret cut Bill's arm. (Margaret cortou o braço de Bill.)

(b) Margaret cut Bill on the arm. (Margaret cortou Bill no braço.)

(22) (a) Janet broke Bill's finger. (Janet quebrou o dedo de Bill.)

(b) * Janet broke Bill on the finger.

(23) (a) Terry touched Bill's shoulder. (Terry tocou o ombro de Bill.)

(b) Terry touched Bill on the shoulder. (Terry tocou Bill no ombro.)

(24) (a) Carla hit Bill's back. (Carla golpeou as costas de Bill.)

(b) Carla hit Bill on the back. (Carla golpeou Bill nas costas.)

Pode ser observado na Tabela 3 (adaptada de Levin (1993)), que cada verbo possui um comportamento peculiar. 
Tabela 3: Comportamento dos verbos touch, hit, cut e break

\begin{tabular}{|l|l|l|l|l|}
\hline & touch & hit & cut & break \\
\hline conativa & Não & Sim & Sim & Não \\
\hline alçamento de parte do corpo & Sim & Sim & Sim & Não \\
\hline medial & Não & Não & Sim & Sim \\
\hline
\end{tabular}

Esses quatro tipos de comportamento sugerem que os verbos touch, hit, cut e break estão agrupados em classes diferentes:

Verbos break: break, crack, rip shatter, snap,...

Verbos cut: cut, hack, saw, scratch, slash,...

Verbos touch: pat, stroke, tickle, touch,...

Verbos hit: bash, hit, kick, pound, tap whack,...

Porém, segundo Levin, os verbos dessas classes não compartilham somente comportamento sintático, compartilham também aspectos de significado. Olhando para a alternância de alçamento de parte do corpo, o que difere os verbos cut (21), hit (23) e touch (24) que participam desta alternância do verbo break (22) que não participa é que os três primeiros obrigatoriamente envolvem contato. Já o verbo break é um verbo que carrega o sentido de mudança de estado não sendo necessário haver contato.

Para distinguir o verbo touch (19) dos verbos cut (17) e hit (20), basta olhar para a participação na alternância conativa. Somente cut e hit participam desta alternância que denota verbos que envolvem componentes de contato e movimento. O verbo touch é somente de contato e o verbo break (18) não denota nem contato nem movimento. Por isso, ambos não participam da alternância conativa.

Por fim, para distinguir entre cut (13) e hit (16) analisa-se a alternância medial. Esta alternância é apresentada por verbos que envolvem mudança de estado. Porém, o verbo hit e o verbo touch (15) não envolvem mudanças de estado, enquanto que break (14) e cut envolvem.

Resumindo, o que diferencia os quatro verbos e, consequentemente, as quatro classes é: break é um verbo que denota, unicamente, mudança de estado; cut denota mudança de estado por meio de contato por meio de movimento; hit denota contato por movimento e; touch denota, puramente, contato. 
Levin também afirma que a existência de relação entre o comportamento verbal e o significado verbal não é privilégio da língua inglesa. Alternâncias aparecem em diversas línguas com verbos de mesmos tipos semânticos. Como exemplo, sabe-se que o português possui a alternância causativa-ergativa (um tipo de alternância em que o objeto da forma transitiva é o sujeito da forma intransitiva) assim como ocorre no inglês. O exemplo (25) apresenta a alternância causativa no inglês e no português.

(25) (a) Carla broke the window. (Carla quebrou a janela.)

(b) The window broke. (A janela quebrou.)

A semântica também permanece a mesma nas duas línguas. Os verbos que admitem essa construção são verbos que denotam mudança de estado ou mudança de posição (exceto a classe descrita por Amaral (2010) detalhada na Seção 2.5.7).

Porém, existem alternâncias que não são compatíveis entre inglês e português. Como é o caso da alternância conativa, dos exemplos (17) e (20), que só ocorre para a língua inglesa e da alternância adversativa, apresentada na Seção 2.5.3, que só ocorre para o português.

\subsection{Trabalhos com verbos no Brasil}

Para o português do Brasil, diversos trabalhos foram realizados seguindo a linha de pesquisa de Levin. Porém, estes trabalhos apresentam resultados iniciais e trabalham com pequenas classes de verbos.

Na Seção 2.5.1 é apresentado o trabalho de Cançado (1996) que trabalhou com verbos psicológicos. Na Seção 2.5.2 é apresentado o trabalho de Chagas de Souza (2000) que trabalhou com a alternância causativa no português do Brasil. Na Seção 2.5.3 é apresentado o trabalho de Chagas de Souza (2001) que define uma construção própria do português do Brasil, a construção adversativa. $\mathrm{Na}$ Seção 2.5.4 é apresentado o trabalho de Ávila (2006) que estudou as propriedades semânticas e sintáticas dos verbos em português do Brasil, aplicadas ao conjunto de verbos relacionados ao verbo roubar. Na Seção 2.5.5 é apresentado o trabalho de Ciríaco (2007) que trabalhou com a alternância causativoergativa no português do Brasil. Na Seção 2.5.6 é apresentado o trabalho de Moraes (2008) que estudou verbos de movimento. Na Seção 2.5.7 é apresentado o trabalho de Perini 
(2008) que estudou as valências verbais no português do Brasil. Na Seção 2.5.8 é apresentado o trabalho de Amaral (2010) que estudou verbos de modo de movimento. Na Seção 2.5.9 é apresentado o catálogo de verbos para o português do Brasil compilado por Cançado et al. (2012). Por fim, na Seção 2.5.10 são apresentados outros trabalhos, além dos detalhados nas seções 2.5.1, 2.5.2, 2.5.3, 2.5.4, 2.5.5, 2.5.6, 2.5.7, 2.5 .8 e 2.5.9, e algumas considerações sobre estes trabalhos.

\subsubsection{Verbos psicológicos (Cançado, 1996)}

Em Cançado (1996), é realizado um estudo detalhado dos verbos psicológicos existentes no português do Brasil. Segundo Cançado (1996, p. 1), verbos psicológicos “[...] denotam um estado emocional e têm, obrigatoriamente, um argumento experienciador; apresentam interessantes propriedades relacionadas à organização da estrutura argumental e à ligação de anáforas [...]”.

Os verbos psicológicos possuem propriedades especiais, o que, segundo a autora do trabalho, justifica seu estudo: primeiro, o argumento que recebe o papel temático de experienciador pode aparecer como sujeito ou como objeto. Observam-se os exemplos retirados de Cançado (1996, p. 2):

(26) Mário teme fantasmas. (Mário é o experienciador)

(27) Fantasmas assustam Mário. (Mário é o experienciador)

Em segundo lugar, está a característica presente em casos com o experienciador no objeto, em que "[...] a anáfora localizada no sujeito pode ser ligada, ou pode tomar como antecedente, o objeto desse verbo" (Cançado, 1996, p.3). Seguem os exemplos retirados de Cançado (1996, p. 3):

(28) Estórias sobre si mesma agradam muito Maria.

(29) Falatórios sobre si mesmo incomodam João.

Em (28) e em (29) a anáfora (si mesma / si mesmo) aparece antes do sintagma nominal que resolve esta anáfora (Maria / João). Este caso excepcional ocorre somente com verbos que apresentam o experienciador como objeto.

Cançado dividiu os verbos psicológicos em quatro classes de acordo com seis características: (a) a capacidade do verbo aceitar construções ergativas; (b) a capacidade do 
verbo aceitar causativização com a promoção do terceiro argumento para a posição de sujeito; (c) a capacidade do verbo aceitar a inversão dos dois últimos argumentos; (d) se o verbo apresenta passivização sintática ou adjetiva; (e) se o verbo possui uma interpretação arbitrária quando temos um pronome na terceira pessoa do plural como sujeito da sentença e; (f) se o verbo permite orações causativas encabeçadas (utilizando o operador fazer).

Os verbos da classe 1 são representados pelo verbo temer (José teme o cachorro pelo seu tamanho), e:

- Não admitem (a) (*O cachorro se teme pelo seu tamanho)

- Não admitem (b) (*O tamanho teme o cachorro)

- Admitem (c) (José teme o tamanho do cachorro)

- Admitem a passivização sintática, mas não a adjetiva (d) (O cachorro é temido por José / $*$ O cachorro ficava temido com José)

- Admitem (e) (Temem o cachorro pelo seu tamanho)

- Admitem (f) (O amigo faz José temer o cachorro)

Os verbos da classe 2 são representados pelo verbo preocupar (Rosa preocupa a mãe com sua arrogância), e:

- Admitem (a) (A mãe se preocupava com a arrogância de Rosa)

- Admitem (b) (A arrogância de Rosa preocupava a mãe)

- Não admitem (c) (*Rosa preocupava a arrogância da mãe)

- Não admitem passiva sintática, mas admitem a adjetiva (d) (*A mãe foi preocupada por Rosa / A mãe ficava preocupada com a arrogância de Rosa)

- Não admitem (e) (*Preocupavam a mãe com aquela arrogância)

- Não admitem (f) (*O pai fazia Rosa preocupar a mãe)

Os verbos da classe 3 são representados pelo verbo acalmar (A polícia acalma a multidão com seus cacetetes), e:

- Admitem (a) (A multidão se acalma com os cacetetes da polícia) 
- Admitem (b) (Os cacetetes da polícia acalmam a multidão)

- Não admitem (c) (*A polícia acalma os cacetetes da multidão)

- Admitem passiva sintática, mas não admitem a adjetiva (d) (A multidão foi acalmada pela polícia / *A multidão ficou acalmada com os cacetetes da polícia)

- Admitem (e) (Acalmaram a multidão com aquelas ameaças)

- Admitem (f) (O coronel fez a polícia acalmar a multidão)

Por fim, a classe 4 é representada pelo verbo animar (Maria animou José com seus argumentos), e:

- Admitem (a) (José se animou com os argumentos de Maria)

- Admitem (b) (Os argumentos de Maria animaram José)

- Não admitem (c) (*Maria animou os argumentos de José)

- Admitem (d) (José foi animado por Maria / José ficou animado com os argumentos de Maria)

- Admitem (e) (Animaram José com aqueles argumentos)

- Admitem (f) (João fez Maria animar José com seus argumentos)

Além da classificação dos verbos em quatro classes de acordo com características sintáticas, Cançado também realiza um estudo semântico de cada classe identificando os papéis temáticos envolvidos. Assim, ela reforça a hipótese de que as características sintáticas dos verbos carregam traços semânticos.

Para os verbos da classe 1 (temer) o primeiro argumento é o experienciador (está em um estado psicológico) e o segundo argumento é o objetivo (entra em relação com o verbo que não acarreta nenhuma mudança de estado). No exemplo "José teme o cachorro", José é o experienciador e cachorro é o objetivo.

Para a classe 2 (preocupar) o primeiro argumento recebe o papel causa (tem um papel no desencadeamento do processo) e o segundo argumento é o experienciador. No exemplo "Rosa preocupava a mãe", Rosa é a causa e a mãe é o experienciador. 
A classe 3 (acalmar) pode apresentar o sujeito como causa e o objeto como experienciador, assim como a classe 2 ("A chegada da polícia acalma a multidão", $a$ chegada da polícia é a causa e a multidão é o experienciador). Porém, os verbos desta classe podem apresentar, também, um agente ("A polícia acalma a multidão com seus cacetetes", a polícia é o agente e a multidão é o experienciador) ou um instrumento ("Os cacetetes da polícia acalmaram a multidão, os cacetetes da polícia" são os instrumentos e a multidão é o experienciador) na posição de sujeito.

Por fim, a classe 4 (animar) não se diferencia da classe 3 em relação aos possíveis papéis temáticos, somente em relação à sintaxe como apresentado anteriormente. Portanto, os verbos dessa classe podem apresentar para o sujeito os papéis causa ("A chegada de Maria animou José”), agente (Maria animou José) ou instrumento (Um chá animou Maria).

\subsubsection{A alternância causativa no português do Brasil (Chagas de Souza, 2000)}

A tese de doutorado de Chagas de Souza (2000) apresenta uma análise aprofundada da ocorrência da alternância causativa no português do Brasil. Esta alternância corresponde a um evento causando outro evento.

Segundo Levin (1993), a alternância causativa é admitida por verbos que envolvem tanto o uso transitivo como intransitivo, em que o uso transitivo do verbo pode ser parafraseado para a forma intransitiva como nos exemplos (30), (31) e (32), para língua inglesa, retirados de Levin (1993, p. 29-31).

(30) (a) Janet broke the cup. (Janet quebrou o copo)

(b) The cup broke. (O copo quebrou)

(31) (a) Sylvia jumped the horse over the fence. (*Sylvia pulou o cavalo sobre a cerca)

(b) The horse jumped over the fence. (O cavalo pulou sobre a cerca)

(32) (a) The visitor rang the bell. (O visitante tocou a campainha)

(b) The bell rang. (A campainha tocou) 
Levin (1993) também define que os verbos que participam desta alternância são verbos que denotam mudança de estado ou mudança de posição.

O trabalho de Chagas de Souza (2000) se difere do de Levin (1993), pois Chagas de Souza avalia aspectos da alternância causativa mais profundos do que a simples mudança na sintaxe. Ele afirma, por exemplo, que os verbos que admitem a alternância causativa devem ser subespecificados quanto ao evento causador, ou seja, o evento causador da ação não precisa estar explicitamente definido ${ }^{18}$. Nos exemplos (33) e (34), retirados de Chagas de Souza (2000, p. 106), é possível observar que "se o sujeito for uma pessoa, ela pode usar as mãos, os pés, sentar no objeto ou nem mesmo fazer nada diretamente relacionado ao objeto para produzir o efeito de dobrar/curvar (bend) ou quebrar (break)" (Chagas de Souza, 2000, p. 106). Já no exemplo (35) é possível observar uma construção em que o evento causador da ação é especificado.

(33) He carefully bent the mattress to fit it in the car. (Ele dobrou cuidadosamente um colchão para que ele coubesse no carro)

(34) The archeologist broke the glued plates when he dropped his shovel on them. (O arqueólogo quebrou os pratos colados quando deixou cair sua pá sobre eles)

(35) João quebrou o galho com as mãos.

Outro ponto relacionado à semântica é a polissemia dos verbos. Chagas de Souza (2000, p. 117, grifos do autor) também apresenta uma discussão detalhada sobre esse tema reforçando que

[...] a alternância causativa não está associada a todos os sentidos dos verbos que a admitem, ou seja, a alternância não é algo que se determina simplesmente no léxico, com base num conjunto fixo de papéis temáticos atribuídos ou relações entre os argumentos de um verbo. O que importa é o significado específico que o verbo assume, o que pode envolver a aktionsart (um estado tem um comportamento sintático diferente de um accomplishment), o acarretamento de agentividade ou causatividade, ou o fato de o verbo denotar um evento psicológico ou não.

\footnotetext{
${ }^{18}$ A noção de sub-especificação é usada em vários campos da linguística. Pustejovsky (1995) apresenta o verbo usar como verbo leve, ou seja, sub-especificado quanto ao tipo de ação denotada. Por exemplo, Eu usei a faca denota a ação de cortar.
} 
Chagas de Souza (2000, p. 124) também discorre sobre a forma da alternância causativa na língua portuguesa, que pode ser transitiva, reflexiva ou intransitiva, como é o caso dos exemplos (36) e (37).

(36) (a) Eu quebrei o prato.

(b) O prato (se) quebrou.

(a) Eu abri a porta.

(b) A porta (se) abriu.

Porém, nem todos os verbos causativos apresentam essas três formas. No exemplo (38) apresenta-se um caso em que o verbo admite somente a alternância entre uso transitivo e uso reflexivo. Por fim, no exemplo (39) apresenta-se um caso em que o verbo admite somente a alternância entre o uso transitivo e o uso intransitivo (exemplos retirados de Chagas de Souza (2000, p. 124)).

(a) O vento aproximou o barco da praia.

(b) O barco se aproximou da praia.

(c) * O barco aproximou da praia.

(39) (a) O frio aumentou a incidência de doenças respiratórias.

(b) * A incidência das doenças respiratórias se aumentou.

(c) A incidência das doenças respiratórias aumentou.

Chagas de Souza (2000, p. 145) conclui que a alternância default para o português do Brasil é a transitivo-reflexiva, pois, para ele, o português do Brasil se encontra em uma fase em que o clítico pode ou não ser usado nas construções, ou seja, “[...] os verbos que alternam podem tanto ocorrer com ele quanto sem ele, alternando na forma $[\ldots]$ "..

\subsubsection{A construção adversativa (Chagas de Souza, 2001)}

Chagas de Souza (2001) descreve uma construção própria do português do Brasil, chamada por ele de alternância adversativa. "Trata-se da construção dos verbos que admitem a forma causativa construída com o auxílio da preposição com“. No exemplo (40) é possível observar esta construção. 
(40) (a) $\mathrm{O}$ motorista arrebentou o carro na batida.

(b) O motorista arrebentou com o carro na batida.

Neste exemplo, a preposição com não tem o significado comum de companhia/acompanhamento, como é o caso do exemplo (41) em que Maria saiu na companhia de João.

(41) Maria saiu com João.

Nem todos os verbos causativos admitem esta alternância, como é possível observar no exemplo (42). A maioria dos verbos que assumem esta alternância está relacionada com eventos em que algo é afetado negativamente.

(42) (a) Ele limpou a casa.

(b) * Ele limpou com a casa.

As classes verbais que admitem esta construção são:

- Membros da classe do verbo arrebentar (algo teve sua integridade, física ou funcional, alterada, podendo resultar em destruição): acabar, aniquilar, arrebentar, desmontar, despedaçar, destroçar, detonar, esbagaçar, esborrachar, escangalhar, esfacelar, esfarelar, esfarinhar, esfarrapar, esfrangalhar, esmigalhar, estilhaçar, estourar, estraçalhar, estragar, estrepar, estrumbicar, explodir, implodir;

- Membros da classe do verbo ferrar (alguém foi prejudicado): danar, desgraçar, estrepar, ferrar, foder, lascar;

- Membros da classe do verbo escrachar (alguém expressou uma opinião negativa sobre algo/alguém): achincalhar, anarquizar, desancar, enxovalhar, escrachar, esculachar, esculhambar, espinafrar; e

- Alguns verbos aspectuais: acabar, parar e prosseguir.

\subsubsection{Estudo dos verbos relacionados com o verbo roubar (Ávila, 2006)}

O trabalho de mestrado de Ávila (2006) apresenta uma rica revisão sobre o estudo da relação entre as propriedades semânticas e as alternâncias sintáticas de um verbo. Ela 
reproduz o estudo de Levin para uma pequena classe de verbos do português relacionados ao verbo roubar (verbos do synset 3741 da WordNet.Br). Outro objetivo deste trabalho foi, também, definir um método para refinar os synsets da WordNet.Br de acordo com estas características sintáticas e semânticas.

O synset 3741 (significado: apoderar-se de algo sem consentimento do proprietário) se assemelha à classe Steal Verbs (verbos que descrevem a remoção de algo de posse de alguém) de Levin (1993). Os verbos desta classe de Levin descrevem a remoção de algo de algum lugar ou da posse de alguém para o benefício de alguém.

Primeiramente, Ávila realiza uma "filtragem" do synset de estudo para eliminar verbos que são informais, estão em sentido figurado ou representam regionalismo ou gírias. Assim, o synset de estudo das alternâncias sintáticas é definido pela autora como synset 3741R: \{comer; despojar; escamotear; escorchar; furtar; rapinar; ratonear; roubar; safar; saquear; subtrair; tirar; tomar\}. Utilizando frases-exemplo adaptadas do dicionário Michaelis, do córpus NILC e da WEB, o synset 3741R foi dividido em quatro synsets de acordo com as alternâncias sintáticas dos verbos:

- Synset 3741a: \{furtar, rapinar, roubar\}

Alternância: Variante Intransitiva

Papéis temáticos: Agente (sujeito) V

Exemplos: Aquelas crianças só roubavam. / Maria não furtou mais. / $\underline{\text { Bush }}$ rapina nos EUA, na Europa, na África, na Ásia e nas Américas Central e do Sul.

- Synset 3741b: \{despojar, furtar, saquear, roubar\}

Alternância: Variante transitiva com objeto Local

Papéis temáticos: Agente (sujeito) V Local (objeto)

Exemplos: Um grupo de quatro indivíduos agrediu e roubou um rapaz. / Polícia prendeu ontem Silvia Helena da Silva, que furtou 50 residências. I

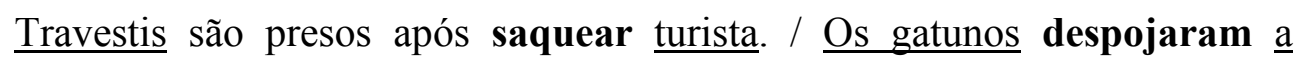
igreja. 
- Synset 3741c: \{comer, escamotear, furtar, rapinar, roubar saquear, subtrair, tirar, tomar\}

Alternância: Variante transitiva com objeto Localizado

Papéis temáticos: Agente (sujeito) V Localizado (objeto)

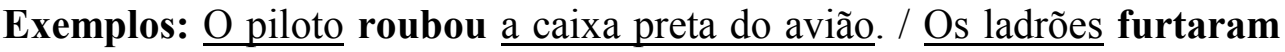
os computadores. / Eles tiraram meu dinheiro, deixando minha carteira vazia. / Eles tomaram meu dinheiro. / Michael Jackson, por exemplo, rapinou as poções. / Tropas da UNITA saquearam os bens da população. / O PRI subtraiu US\$120 milhões. / Algumas empreiteiras comeram muito dinheiro público. / Os ladrões escamotearam uma carteira.

- Synset 3641d: $\{$ roubar, subtrair, safar\}

Alternância: Variante transitiva com os objetos Local e Localizado Papéis temáticos: Agente (sujeito) V Local (objeto) Localizado (objeto)

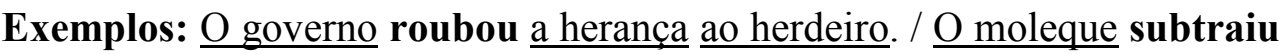
uma maçã ao quitandeiro. / Os gatunos safaram a carteira ao transeunte.

Observa-se com este estudo o refinamento de um synset da WordNet.Br por meio da análise de alternâncias sintáticas e papéis temáticos.

\subsubsection{A alternância causativo-ergativa no português do Brasil (Ciríaco, 2007)}

Ciríaco (2007) estudou a alternância causativo-ergativa no português brasileiro. Esta alternância expressa uma mudança de transitividade (Ciríaco, 2007, p. 46 e p. 58):

(a) Maria quebrou o espelho.

(b) O espelho quebrou.

(44) (a) O barulho acordou o neném.

(b) O neném acordou.

Mais detalhadamente, Círiaco (2007, p. 46) discorre que verbos que participam desta alternância variam da forma transitiva " [...] que ilustra a perspectiva causativa de um 
evento no mundo (algo/alguém causou a mudança de estado em um objeto/pessoa) [...]" (sentenças (a) de (43) e (44)) para a forma intransitiva “[...] que ilustra a perspectiva ergativa (algo/alguém mudou de estado)" (sentenças (b) de (43) e (44)) e vice-versa.

Ciríaco define, também, o conceito de verbos basicamente transitivos e verbos basicamente intransitivos. Os basicamente transitivos possuem a propriedade de ser o "desencadeador do processo", “[...] independentemente do contexto sentencial em que aparecem [...]" (Ciríaco e Cançado, 2009, p. 225) enquanto que os basicamente intransitivos não apresentam esta propriedade. Por exemplo, o verbo causativo quebrar é basicamente transitivo, pois tem um desencadeador. Já o verbo acordar é basicamente intransitivo, pois não apresenta a propriedade de desencadeador. Sendo assim, os verbos em (43) e (44) apresentam alternâncias diferentes. Em (43), como quebrar é basicamente transitivo, a sentença (a) é a básica e, para gerar a sentença (b), o verbo alterna de uma construção tipicamente causativa para uma construção processual (ergativa). Em (44), como acordar é basicamente intransitivo, a sentença (b) é a básica e, para gerar (a), o verbo alterna de uma construção processual para uma construção causativa. Ciríaco trabalha somente com o processo de ergativização.

As construções ergativas são um tipo de construção com alçamento de complemento $y$ da construção $x \mathrm{~V} y$ (em que $x$ e $y$ são argumentos do verbo $\mathrm{V}$ ) que expressam o mesmo evento da sentença causativa, porém, olhando sob a perspectiva do afetado. As construções ergativas podem ser divididas em duas classes: ergativas canônicas e ergativas cindidas. As canônicas são o caso mais frequente já apresentado em (43) em que o objeto é alçado para a posição de sujeito. Já nas cindidas, como em (45) retirado de Ciríaco (2007, p. 65), apenas parte do objeto é alçada como sujeito.
(a) João quebrou o ponteiro do relógio.
(b) O relógio quebrou o ponteiro.

\subsubsection{O estudo dos verbos de movimento (Moraes, 2008)}

Moraes (2008) definiu duas subclasses de verbos em português do Brasil baseadas nas subclasses 51.1 e 51.3.1 de Levin. A subclasse 51.1 trata de verbos com deslocamento inerentemente direcionado e a subclasse 51.3.1 trata de verbos com padrões de movimento que são característicos de entidades inanimadas. Para definir as classes para o português, 
Moraes utilizou a WordNet.Br e seus alinhamentos com a WordNet (trabalho similar a nossa proposta). Ele seguiu o seguinte método: (a) identifica-se a lista de verbos das classes de Levin; (b) busca-se estes verbos na WordNet e identificam-se os synsets dos quais estes verbos participam, eliminando manualmente aqueles que não condizem com o significado da classe; (c) identifica-se na base da WordNet.Br os synsets que estão alinhados com os synsets da WordNet e; (d) descrevem-se as propriedades dos verbos em português enquanto membro da classe equivalente ao inglês.

Para os verbos da Subclasse 1' (avançar, descer, cair, chegar, despencar, entrar, fugir, ir partir, recuar, sair, subir, vir, voltar) (equivalente à subclasse 51.1) as propriedades são: (a) todos os verbos descrevem o movimento e a direção desse movimento; (b) nenhum dos verbos descreve o modo do movimento e; (c) não há um padrão de expressão da origem, meta ou trajetória do movimento. Além disso, todos os verbos da Subclasse 1' compartilham a propriedade semântica de intransitividade. O papel temático Tema realizase sempre como sujeito e os papéis Meta e/ou Origem, quando presentes, são objetos. Alguns verbos desta subclasse (avançar, vir, subir, ir, sair, descer, entrar, cair, despencar, recuar, voltar) permitem a realização de um sintagma nominal que expressa a medida do desenvolvimento do evento, como no exemplo (46), retirado de Moraes (2008, p. 140):

(46) Ele avançou alguns metros puxando o cabresto do cavalo.

Como há verbos que não admitem este sintagma nominal que expressa medida (como é o caso de chegar, partir e fugir), a Subclasse 1' deve ser dividida em duas subclasses. Moraes também identificou que além de apresentarem a diferença sintática quanto ao sintagma que expressa medida, estes verbos também possuíam características semânticas distintas. Assim, as subclasses geradas foram: "a subclasse dos verbos que lexicaliza 'percurso' e, assim, permite a construção com 'sintagma medida', e a subclasse que lexicaliza uma mudança de estado baseada em uma oposição contraditória, que não admite a construção com o 'sintagma medida"” (Moraes, 2008, p. 142).

Para os verbos da Subclasse 3a' (derrapar, deslizar, espiralar, girar, oscilar, quicar, rodar, rodopiar, rolar, tremular, vibrar, virar, voltar) (equivalente à subclasse 51.3.1) temse as propriedades: (a) todos os verbos descrevem movimento e o modo ou meio do movimento; (b) podem descrever o deslocamento, mas não a especificação da direção do deslocamento; (c) os verbos da classe podem ser classificados em dois tipos, em “[...] 
função da existência ou não de um eixo em torno do qual o movimento denotado pelo verbo se realiza [...]" (Moraes, 2008, p. 143); (d) o movimento afeta entidades inanimadas; (e) quando ocorre, a especificação da direção realiza-se na sintaxe por meio de um sintagma preposicional e; (vi) todos os verbos participam da alternância TransitivoCausativa / Intransitiva-Ergativa ("a forma transitiva expressa o mesmo significado da forma intransitiva, acrescido do componente semântico 'causalidade"') (Moraes, 2008, p. 150), como aparece em (47).
(a) Mario rolou a bola (para o gol).
(b) A bola rolou (para o gol).

\subsubsection{As valências verbais (Perini, 2008)}

O trabalho de Perini (2008) é, junto com o de Cançado apresentado na Seção 2.5.9, um dos mais importantes estudos sobre os verbos e seus frames sintáticos ${ }^{19}$ para o português do Brasil. Ele definiu uma lista com 90 frames sintáticos apresentados por verbos do português brasileiro. As valências verbais são definidas de acordo com os frames sintáticos. Segundo Perini (2008, p. 236), “a valência de um verbo é o conjunto de construções em ele pode ocorrer [...]". Ele também define o conceito de diátese como “ uma construção que vale para a subcategorização de verbos" (Perini, 2008, p.236). Perini (2008) não utiliza uma abordagem baseada em córpus, apesar de utilizar alguns exemplos reais de jornal e rádio. Além disso, a definição dos frames sintáticos são baseadas no português falado, mas especificamente no "dialeto" mineiro. Portanto, construções como (48) (retirada de Perini (2008, p. 325)), que para a linguagem formal estaria incorreta pela ausência do clítico se, são aceitas como corretas.

(48) A criança assustou com o palhaço.

Ele descreve as diátese utilizando uma notação simbólica. Em (49) é apresentado um exemplo da construção ergativa na notação adotada por Perini (2008) (exemplo retirado de Perini (2008, p.378)).

\footnotetext{
${ }^{19}$ Perini (2008) nomeia de "construções" o que aqui é chamado de "frame sintático".
} 
(49) Zezé engordou.

Definição:

$\mathrm{H} \quad \mathrm{V}$

Paciente

Neste exemplo, 'H' representa o sintagma nominal indentificado como sujeito ou o sufixo de pessoa-número do verbo em casos de sujeito elíptico, como em (50) (retirado de Perini (2008, p. 106)).

(50) Belisquei a menina.

Já V representa o verbo (no caso de (49), engordar). Além disso, Perini (2008) defini papéis temáticos aos SNs associados ao verbo. No caso do exemplo, o SN recebeu o papel temático de Paciente. A lista de papéis temáticos de Perini (2008) se assemelha a lista usada na VerbNet no que tange a informação fornecida por eles (ambos conjuntos apresentam aproximadamente o mesmo nível de descrição). Portanto, há uma intersecção entre os papéis utilizados, tais como, Agente, Paciente, Tema, Lugar, entre outros.

Perini (2008) não separa os verbos em classes, somente lista as diátese e apresenta alguns verbos que podem participar de cada diátese (ele não faz um levantamento de todos os verbos que apresentam determinada diátese em um córpus, por exemplo). A construção transitiva, segundo Perini (2008), é apresentada na Figura (retirada de Perini(2008, p.373)). É possível observar na Figura 2 que o autor também prevê subtipos para as diáteses. No exemplo, a diátese transitiva possui um subtipo, que é a diátese transitiva de contato. Ele identificou como necessária a divisão, pois enquanto $\mathrm{C} 1$ denota mudança de estado, $\mathrm{C} 1.2$ não denota. Porém, em ambas as situações, o objeto direto é analisado como Paciente.

Outro ponto interessante neste trabalho é que ele considera complementos e adjuntos com o mesmo peso na diátese. Para Perini (2008) não é possível distinguir estes dois elementos de forma que não haja dúvidas sobre as construções que apresentam complementos e as construções que apresentam adjuntos. 


\section{CONSTRUÇÕES DA FORMA H V SN}

\section{C1. Transitiva}

Zezé comeu a pizza

Definição:

H $\quad$ V $\quad$ SN

$\mathrm{Ag}$

Com mudança de estado do Paciente

comer, fazer, consertar, escrever, quebrar ... (muitos verbos)

Subtipo:

\section{C1.2. de Contato}

Zezé tocou a parece

A mãe acariciou o bebê

Apesar de não haver mudança de estado, geralmente o objeto é analisado como Paciente. Inclui: de objeto cognato (ele dormiu um sono tranquilo); de contato (ele tocou a parede); de movimentação (Sílvia empurrou o armário) - neste caso, a movimentação é inferida pragmaticamente, mas pode não ter ocorrido; portanto, deve outro caso de contato.

tocar, acariciar, lamber, coçar, empurrar, ...

\section{Figura 2: Diátese Transitiva (Perini, 2008, p. 373)}

Ele também não trata da frequência das diáteses identificadas, apesar de enunciar a importância deste conhecimento:

"Uma coisa que nos interessa, portanto, é a frequência de determinados verbos e diáteses no léxico da língua. Não se trata de frequência conjunta dos verbos e suas diáteses, mas antes simplesmente da frequência de cada diátese particular, assim como das associações de várias diáteses. Isso é importante para efeitos de perspectiva: queremos saber quais são as grandes linhas da estrutura, e um dos aspectos a levar em conta é justamente a importância relativa de cada uma das diáteses ou das associações de diáteses.” (Perini, 2008, p.369)

Apesar do trabalho de Perini (2008) ser inicial e não descrever a maioria dos verbos, ele é de extrema importância para o avanço desta área, pois é um dos primeiros a sistematizar a escolha das diáteses a serem descritas. No livro há informações sobre o porque considerar ou não considerar um frame sintático como uma diátese de acordo com o estudo dos verbos. Por exemplo, não é necessário considerar as construções negativas ou interrogativas como diáteses, pois elas não são distintivas para os verbos do português (todos os verbos apresentam essas construções). 


\subsubsection{O estudo dos verbos de modo de movimento (Amaral, 2010)}

Um estudo recente sobre verbos de movimento realizado no mestrado de Amaral (2010) também merece ser citado. Na realidade, Amaral (2010, p. 6) utiliza em seu estudo uma subclasse dos verbos de movimento, os verbos de modo de movimento "[...] que descrevem o movimento de um objeto pelo ponto de vista do modo como se dá esse movimento, sem que haja a descrição de uma trajetória" e não descrevem a direção do movimento (nem implicitamente). Outra característica é que "o objeto que sofre o movimento não tem necessariamente controle sobre o evento" (Amaral, 2006, p. 6). Exemplos dessa classe de modo de movimento são apresentados em (51), retirado de Amaral (2006, p. 6). Já exemplos de verbos que denotam trajetória são apresentados em (52), retirado de Amaral (2006, p. 7).

(51) (a) A empregada sacudiu os tapetes.

(b) O menino quicou a bola.

(c) O participante girou a roleta.

(52) (a) O brinquedo caiu no chão.

(b) A menina foi para a casa da amiga.

(c) Maria voltou de Nova York.

No caso de (51) é possível observar que um objeto pode executar qualquer uma das ações sem mudar de lugar.

Os verbos dessa classe participam da alternância da forma transitivo-intransitiva, como é o caso do exemplo (53), retirado de Amaral (2010, p. 8).

(a) O vento sacudiu a cortina.

(b) A cortina sacudiu.

Amaral (2010) argumenta que apesar da semelhança sintática com a tradicional alternância causativo-ergativa (que também é um tipo de alternância transitivointransitiva), como é o caso do exemplo (43) da Seção 2.5.5, a alternância contemplada por verbos da classe de modo de movimento possui uma semântica diferente. Enquanto a alternância causativo-ergativa denota mudança de estado na forma intransitiva, os verbos de modo de movimento não denotam mudança de estado, em outras palavras, "em um 
evento descrito por um verbo de modo de movimento, o objeto não muda de estado, apenas sofre um movimento" (Amaral, 2010, p.8).

Apesar da semelhança entre as construções do exemplo (51), Amaral (2010) também define peculiaridades semânticas em cada caso. Ela divide esta classe de verbos em duas subclasses:

- verbos que denotam atividade: “[...] denotam um movimento oscilatório em que o provocador desse movimento pode ser um ser animado ou um fenômeno da natureza com força própria" (Amaral, 2010, p. 28); e

- verbos causativos: denotam movimento giratório em que o provocador do movimento pode ser um ser animado, fenômenos naturais com força própria ou eventos.

O que diferencia este trabalho do trabalho de Moraes (2008) é a abordagem empregada. Amaral (2010) segue uma linha totalmente linguística, enquanto que Moraes (2008) está inserido na área de PLN. Em outras palavras, Moraes (2008) estava interessado em melhorar um recurso de PLN já existente, a WordNet.Br.

\subsubsection{Catálogo de verbos do português do Brasil (Cançado et al., 2012)}

A construção de um catálogo de verbos do português do Brasil é um trabalho coordenado pela professora Márcia Cançado da Universidade Federal de Minas Gerais (UFMG). Este projeto consiste da construção (baseada em intuição linguística e não com base em córpus) de um catálogo com informações lexicais e semânticas de verbos que será disponibilizado nas versões impressa e digital.

O catálogo é dividido em volumes, com cada volume agrupando verbos de acordo com propriedades semânticas. O primeiro volume (cuja versão impressa será publicada em breve) foi descrito em Cançado et al. (2012) e conta com 861 verbos de mudança (verbos que denotam algum tipo de mudança), com 5.500 sentenças. As autoras se basearam na hipótese de Levin (1993) e dividiram os verbos em quatro classes: mudança de estado, mudança de estado locativo, mudança de local e mudança de posse. 
Para cada classe, uma lista de verbos é apresentada, e as propriedades sintáticas e/ou semânticas da classe são descritas para cada verbo. Exemplos de descrição para o verbo "quebrar" (pertencente à classe de mudança de estado) são apresentados a seguir (exemplos adaptados de Cançado et al. (2012 p.439):

(54) O João quebrou o vaso.

(alternância causativa com um agente como sujeito)

(55) A queda quebrou o vaso.

(alternância causativa com uma causa como sujeito)

(56) O vaso (se) quebrou.

(alternância transitiva incoativa com se opcional)

(57) O vaso (se) quebrou com a queda.

(alternância transitiva incoativa com se opcional e a causa na posição de adjunto)

O João quebrou o vaso com um martelo.

(alternância causativa com um instrumento na posição de adjunto)

Se algum verbo não possui alguma das propriedades sintáticas e/ou semânticas inerentes da classe, são apresentadas sentenças com sinal de agramaticalidade $(*)$ para estas construções.

Os exemplos foram criados pelos linguistas com base em observações para cada verbo. Não foram utilizados córpus para a extração dos exemplos, pois as autoras acreditam que trabalhos baseados em córpus não conseguem abarcar todas as possibilidades existentes na língua, uma vez que não existe um córpus grande o suficiente que represente toda uma língua. A divisão de verbos por classe é de: 685 verbos para a classe de mudança de estado, 68 verbos para a classe de mudança de estado locativo, quinze verbos para a classe de mudança de local e 93 verbos para a classe de mudança de posse.

As autoras utilizaram a teoria de decomposição de predicados (seguindo Levin e Rappaport Hoav, 2005) para representar os componentes semânticos dos verbos. Exemplos 
para as estruturas dos verbos de mudança são apresentados a seguir (adaptados de Cançado et al. (2012)):

$\left[\left[\mathrm{X}_{(\mathrm{VOLITION})}\right.\right.$ CAUSE [BECOME Y (STATE) $\left.]\right]$

(mudança de estado - verbos: “quebrar", “abrir”, "machucar”)

[ [ $\mathrm{X}_{(\text {VOLITION) }}$ CAUSE [BECOME Y (STATE) IN Z] ]

(mudança de estado locativo - verbos: "acomodar", "esconder", "pendurar")

\section{$\left[\mathrm{X}_{(\mathrm{VOLITION})} \mathrm{CAUSE}[\mathrm{BECOME} \mathrm{Y}(\mathrm{PLACE})]\right]$}

(mudança de local - verbos: “engaiolar”, “engarrafar”, “ensacar”)

\section{$\left[\mathrm{X}_{(\mathrm{VOLITION})} \mathrm{CAUSE}[\mathrm{BECOME} \mathrm{Y}\right.$ WITH $\left.(\mathrm{THING})]\right]$}

(mudança de posse - verbos: "aparelhar", "amanteigar", "colorir”)

É possível observar que todas as classes apresentam o componente BECOME (característico dos verbos relacionados com mudança). Com esse tipo de estrutura, as autoras afirmam ser possível verificar as semelhanças e diferenças entre as classes e entre as subclasses. Além disso, diversas informações sintáticas e semânticas podem ser extraídas dessas representações (tais como: papéis temáticos, tipos das alternâncias, etc.).

Por fim, as autoras mencionam como será a interface digital do catálogo: serão disponibilizadas buscas por verbo, papéis temáticos, propriedades sintáticas, etc. Elas apresentam um exemplo de busca por estrutura passiva, retornando todos os verbos que apresentam esta estrutura.

\subsubsection{Outros trabalhos e considerações}

Além dos trabalhos para o português detalhados nesta seção, também existem outros trabalhos interessantes que merecem ser citados. Whitaker-Franchi (1989) (um dos trabalhos pioneiros no Brasil na área de alternâncias sintáticas, anterior inclusive a Levin (1993)) explorou as construções ergativas que são por ela definidas por duas características: (a) são admitidas por verbos que podem ser intransitivos ou transitivos e (b) o sujeito da forma intransitiva é o objeto direto da forma transitiva, ambos com a mesma função temática. Pode-se observar no exemplo (63) que o papel temático do objeto direto 
da forma transitiva (63b) é o mesmo papel assumido pelo sujeito da forma intransitiva (63a).
(a) João quebrou a janela. (João = Agente e janela = Paciente $)$
(b) A janela quebrou. (janela $=$ Paciente)

No trabalho de mestrado de Menezes (2005) foram estudados verbos de trajetória com detalhamento das preposições admitidas por esses verbos. Em (64), retirado de Menezes (2005, p. 44) é possível observar exemplos de verbos dessa classe.

(64) (a) João afastou o filho do carro. (o carro é o ponto inicial da trajetória)

(b) Maria leva as crianças da casa até a escola. (a casa é o ponto inicial da trajetória e a escola é o ponto final)

(c) João chegou à faculdade (a faculdade é o ponto final da trajetória)

(d) João chegou (o ponto inicial da trajetória é o local em que o falante está)

Também há o trabalho de Lima (2007) que estudou verbos que pertencem a uma classe definida por ele como "vitória e derrota" que são verbos que assumem: (a) o conflito direto (“[...] pressuposição de conflito direto entre dois argumentos envolvidos no processo") (Lima, 2007, p. 59), (b) a simetricidade (“[...] a relação de pressuposição de igualdade de condições dos dois contendores em relação ao início do conflito" (Lima, 2007, p. 61), ou seja, o resultado poderia ser o oposto); e (c) o resultado do conflito (é possível perceber claramente quem foi o vitorioso e quem foi o perdedor). Todas estas características estão presentes no exemplo (65), retirado de Lima (2007, p. 61). Como é possível observar, a definição da classe de "vitória e derrota" se baseia na semântica e não na sintaxe-semântica como nos outros casos.

$$
\text { O Vasco venceu o Flamengo. }
$$

Neste trabalho, Lima (2007) refuta, em partes, a hipótese de Levin: "Não existe nenhuma diátese comum a todos os verbos de vitória e derrota. Esta observação vai de encontro à hipótese de Levin." (Lima, 2007, p. 125). Porém, pode-se observar que a classe escolhida por Lima (2007) não é uma classe típica do trabalho feito por Levin (1993). Além disso, o próprio autor admite que mais estudos precisam ser realizados para que a hipótese possa ser considerada refutada. 
Outro trabalho que merece ser citado é o de Godoy (2009) que explorou a classe de verbos recíprocos do português do Brasil. Exemplos de verbos recíprocos são os verbos “concordar", "conversar", "trombar" e "flertar", como nos exemplos apresentados de (66) a (69).

(66) (a) João e Maria concordaram.

(b) João concordou com Maria.

(67) (a) João e Maria conversaram.

(b) João conversou com Maria.

(68) (a) João e Maria trombaram.

(b) João trombou com Maria.

(69) (a) João e Maria flertaram.

(b) João flertou com Maria.

Por fim, um último trabalho que também merece ser citado, é a dissertação de mestrado de Ribeiro (2010) que explorou o uso do clítico se na alternância causativa do português do Brasil, aprofundando o trabalho de Chagas de Souza (2000) (detalhado na Seção 2.5.2).

Escolhemos para detalhamento nesta seção os trabalhos de Cançado (1996), Chagas de Souza (2000), Chagas de Souza (2001), Ávila (2006), Ciríaco (2007), Moraes (2008), Perini (2008), Amaral (2010) e Cançado et al. (2012) por apresentarem bons resultados de estudos com alternâncias sintáticas e classes de Levin para o português.

O trabalho de Cançado (1996) é interessante, pois propõe uma classificação verbal, baseada na semântica, mas que busca exibir as características sintáticas semelhantes às classes definidas semanticamente. Este processo é inverso ao processo proposto neste mestrado que segue a linha de Levin (1993): espera-se que verbos que são considerados de uma mesma classe por compartilhar comportamento sintático compartilhem, também, comportamento semântico. Na mesma linha do trabalho de Cançado (1996) está o trabalho de Godoy (2009). 
Chagas de Souza (2000), Whitaker-Franchi (1989) e Ciríaco (2007) tratam da alternância causativa-ergativa. Escolheu-se o trabalho de Chagas de Souza (2000) por se tratar de um trabalho semanticamente profundo quando contrastado com Levin (1993). Além disso, ele descreve sucintamente a forma desta alternância, apontando a forma transitivo/reflexiva como a mais comum na língua portuguesa. Já o trabalho de Ciríaco (2007) foi escolhido por estudar profundamente a face ergativa desta alternância, além de analisar o uso transitivo e intransitivo de um verbo.

Chagas de Souza (2001) descreve uma alternância própria da língua portuguesa, a alternância adversativa. A existência desta e outras alternâncias para o português sem existência para o inglês e também o oposto (como é o caso da alternância conativa para o inglês que não existe para o português - exemplos (17), (18), (19) e (20)) é um limitante para a pesquisa descrita neste trabalho que propõe se aproveitar de fatores crosslinguísticos entre o português e o inglês. Porém, esta e outras alternâncias próprias da língua podem ser identificadas por linguistas especialistas e inseridas na base da VerbNet.Br. Além disso, a tarefa de extração de estruturas de subcategorização também pode ajudar a identificar estas propriedades do português.

Ávila (2006) realiza uma ampla revisão bibliográfica do tema de classes verbais e ainda propõe um refinamento dos synsets da WordNet.Br a partir desse tipo de estudo verbal. O interessante deste trabalho é a relação da WordNet.Br com as classes verbais de Levin (1993) o que reforça nossa hipótese de existir um fator cross-linguístico entre inglês e português.

Menezes (2005), Moraes (2008) e Amaral (2010) estudaram a classe de verbos de movimento. Em Moraes (2008) há uma perspectiva de PLN, usando a WordNet.Br como objeto de trabalho para definição das classes verbais para o português, o que em muito se assemelha com uma das fases deste mestrado. Já Amaral (2010) analisa os verbos com uma perspectiva puramente linguística.

Perini (2008) definiu uma lista de frames sintáticos para o português do Brasil. Este trabalho, apesar da riqueza, não foi desenvolvido com foco em PLN e, portanto, não pode ser diretamente usado para tarefas dessa área. Além disso, há diversas colocações pertinentes no trabalho de Perini (2008) sobre a situação da linguística atual. Um exemplo é quando ele diz que o estágio atual da linguística pode ser chamado de "história natural", 
dizendo que a linguística está "mais ou menos na situação da física antes de Newton, quando ainda não havia um paradigma que norteasse a interpretação dos fatos observados" (Perini, 2008, p. 14). Ele também critica (em vários momentos) abordagens baseadas em teorias de outras línguas. Na página 15 do livro (Perini, 2008) ele afirma que:

“É urgente elaborar estudos amplos de grandes fatias da estrutura das línguas. Esses estudos devem se concentrar em línguas particulares, sem ceder à tentação de aplicar a uma língua análise de outra. A comparação entre as línguas, assim como a procura de universais, é um empreendimento válido, mas só pode ser realizado em um segundo momento."

De certa forma, este mestrado vai contra essa posição, uma vez que foi proposta a construção de um recurso léxico para o português com base em outro recurso para a língua inglesa. Porém, dado o sucesso de trabalhos como a EuroWordNet, a WordNet.Br (apresentadas no Capítulo 3), que foram construídas baseadas em e alinhadas com a WordNet; e os estudos preliminares para o francês e para o italiano com as classes da VerbNet (apresentados no Capítulo 5), que apresentaram compatibilidades entre as línguas para essa classificação, acredita-se que abordagens cross-língue sejam úteis e necessárias. Sabe-se que não é possível utilizar todas as informações e definições de uma língua em outra, porém, trabalhar com as compatibilidades pode ser um caminho prático para se iniciar um estudo. Portanto, conclui-se que Perini (2008) defende uma abordagem bottomup, em que primeiro se devem definir as peculiaridades da língua para, posteriormente, identificar universais. Já este mestrado utilizou uma abordagem top-down em que partiu-se da hipótese da existência de um potencial cross-linguístico das classes de Levin, identificou-se as relações comuns às duas línguas e, como trabalho futuro de cunho linguístico, será necessária uma validação e descrição das peculiaridades do português. Apesar de Perini (2008) discordar da abordagem top-down, este trabalho prova sua utilidade, atingindo uma f-measure de $60 \%$ na VerbNet.Br (discussão apresentada no Capítulo 7).

Além disso, Perini (2008) também apresenta críticas ao trabalho de Levin (1993). Algumas críticas são enunciadas e discutidas a seguir: 
a) "Não explicita a capacidade distintiva dos frames sintáticos". Perini (2008) tem razão ao realizar esta afirmação. Enquanto em seu trabalho, ele tomou o cuidado em definir o porque descrever ou não descrever uma determinada diátese; Levin (1993) não explicita esta parte (apesar de não incluir na lista de alternâncias construções negativas e interrogativas, por exemplo, que são gerais para todos os verbos);

b) "Realiza muitas distinções entre os frames sintáticos". Pode-se concluir que esta crítica é consequência da crítica anterior. Como não há uma definição prévia do que deve ou não deve ser considerado como alternância, muitas distinções podem ter sido realizadas desnecessariamente. A crítica é válida para este mestrado, pois, sistemas de PLN deve ser capazes de generalização e um alto nível de detalhamento prejudica essa capacidade;

c) "Propõe classes pouco homogêneas". É verdade que as classes de Levin contém muitas exceções, o que as torna pouco homogêneas. Porém, na VerbNet, é considerado o uso das subclasses propostas por Korhonen e Briscoe (2004), o que trata de algumas exceções nas classes de Levin (mais sobre esse assunto é apresentado na Seção 3.3), tornando as classes mais homogêneas;

d) "Agrupa os verbos de acordo com alternâncias". Essa crítica tem cunho especificamente linguístico e, pode-se concluir que usar a abordagem de Levin ou a de Perini (2008) (que considera somente os frames sintáticos, sem pensar na alternância) é uma discussão que está fora do escopo deste mestrado em PLN;

e) "Não analisa, sintática e semanticamente, as alternâncias definidas". Mais uma vez é uma crítica válida: a análise sintática e semântica das alternâncias de Levin é superficial e não está sistematizada. Porém, a VerbNet possui um esquema sistematizado para definir a realização sintática do frame sintático e também os papéis temáticos associados a estes frames. Portanto, a crítica de Perini (2008) vale somente para as classes de Levin (1993), não para a VerbNet;

Ele também apresenta alguns frames sintáticos apresentados no trabalho de Levin (1993) como distintivos e que ele considera não terem a mesma função no português. É o caso da distinção entre a construção ergativa e a construção média. Levin (1993) afirma que a diferenciação destes dois frames sintáticos é necessária, dado que existem muitos verbos do inglês que apresentam uma delas, mas não apresentam a outra. Perini (2008) argumenta que no português os verbos que apresentam a construção média, sempre apresentam a ergativa e vice-versa. Como discussões de cunho linguístico fogem aos escopo deste mestrado (que possui foco em PLN), não identificou-se a necessidade de aprofundar-se nessa crítica. O que vale salientar, no entanto, é que neste mestrado propôsse trabalhar com as similaridades da teoria da Levin (1993) no inglês e no português, pois acredita-se que é possível partir das similaridades para depois identificar as peculiaridades.

Por fim, Cançado et al. (2012) propõe a criação de um catálogo de verbos do português do Brasil. Este catálogo, como as próprias autoras reconhecem, possui 
semelhanças com a VerbNet. Porém, pode-se considerar que este recurso é bem mais rico, dado que vem sendo construído manualmente. Porém, a capacidade de generalização das regras contidas neste recurso é limitada, uma vez que não está sendo construído com foco em PLN. Mesmo assim, há grande intersecção deste trabalho com o trabalho da VerbNet.Br. Em conversa com a professora Dra. Márcia Cançado da UFMG, pretendemos unir esforços para melhorar ambos os recursos (a VerbNet.Br poderia, por exemplo, servir de base para o trabalho linguístico efetuado pelos pesquisadores da UFMG).

\subsection{Considerações Finais}

Neste capítulo foram discutidos os conceitos base para a pesquisa de mestrado. Os papéis temáticos, as classes de Levin e as alternâncias sintáticas, apesar de serem estudos para o inglês, foram o grande pilar desta pesquisa dada a importância destes conceitos na construção da VerbNet.

Os trabalhos para a língua portuguesa apresentados na Seção 2.5 têm grande valor linguístico, porém, todos estes trabalhos tratam de um conjunto pequeno de verbos e não estão armazenados em uma grande base que possa ser utilizada em projetos de PLN. Vale comentar, que o Núcleo de Pesquisa em Semântica Lexical $(\mathrm{NuPes})^{20}$, coordenado pela professora doutora Márcia Cançado, da Universidade Federal de Minas Gerais, tem um projeto de disponibilizar os dados dos seus trabalhos com classes verbais em um formato computável $^{21}$ (assim como mencionado em Cançado et al. (2012)). Porém, vale lembrar, que este mestrado visou à construção de um recurso para ser utilizado em aplicações em de PLN.

\footnotetext{
${ }^{20} \mathrm{http} / / /$ www.letras.ufmg.br/nucleos/nupes/index.asp?file=index

${ }^{21}$ Márcia Cançado, 2011, comunicação pessoal.
} 


\section{Parte II: Fundamentação Téorica Computacional}

\section{CAPÍTULO 3: Recursos Léxicos e a VerbNet}

\subsection{Considerações Iniciais}

Neste capítulo, apresenta-se a fundamentação teórica para o tópico principal de pesquisa deste mestrado, a VerbNet. A VerbNet é um projeto que fornece informações semântica e sintática dos verbos do inglês explicitamente, é independente de domínio, e se baseia nas classes verbais de Levin (Levin, 1993). Também são apresentados trabalhos relacionados como wordnets, FrameNet e PropBank, em especial a WordNet e a WordNet.Br que também são objetos de estudo deste trabalho (Seção 3.1). Na Seção 3.2, são apresentados os trabalhos relacionados à VerbNet. Na Seção 3.3 são descritas a estrutura e os componentes da VerbNet. Na Seção 3.4 é apresentado o projeto SemLink, sendo desenvolvido na Universidade do Colorado, pela equipe de Martha Palmer. Por fim, na Seção 3.5 apresentam-se as considerações finais.

\subsection{Trabalhos relacionados: wordnets, FrameNet e PropBank}

Sendo a VerbNet um repositório lexical de verbos que contem características sintáticas e semânticas destes verbos, a apresentação de recursos semelhantes se faz necessária para justificar a criação de um novo recurso. Além disso, este mestrado utilizou a WordNet.Br e a WordNet, o que justifica um estudo sobre recursos desta natureza. Na Seção 3.2.1 é apresentado o conceito de wordnet, os principais projetos, a wordnet pioneira (WordNet), e um dos objetos deste trabalho de mestrado, a WordNet.Br. Na Seção 3.2.2 é apresentado o recurso FrameNet e seu projeto no Brasil. Por fim, na Seção 3.2.3 é apresentado o recurso PropBank e a versão brasileira PropBank.Br. 


\subsubsection{Wordnets}

Uma wordnet pode ser entendida como uma base de dados que sistematiza o conjunto dos verbos, substantivos, adjetivos e advérbios de um dado idioma em termos de uma rede de quatro relações: sinonímia, antonímia, hiponímia/hiperonímia e meronímia/holonímia (Cruse, 1986). Esta seção foi dividida em quatro subseções dada a quantidade de trabalhos importantes com wordnets. Na Seção 3.2.1.1 é apresentada a WordNet de Princeton. Na Seção 3.2.1.2 é apresentada a EuroWordNet. Na Seção 3.2.1.3 é apresentada a MultiWordNet. Por fim, na Seção 3.2.1.4 é apresentada a wordnet brasileira, a WordNet.Br.

\subsubsection{A WordNet de Princeton}

A WordNet de Princeton é a pioneira em recursos deste tipo (com 11.306 verbos e 13.508 synsets de verbos ${ }^{22}$ ). Seu projeto foi uma proposta para uma combinação efetiva entre a tradicional informação lexicográfica e os avanços computacionais. A ideia inicial era fornecer uma ajuda para realizar buscas em dicionários de forma conceitual, e não alfabética. Como esta tarefa se mostrou não trivial, nasceu a WordNet (Miller et al., 1990).

Segundo seus criadores (Miller et al., 1990), a principal relação semântica da WordNet (o que deve se estender para qualquer wordnet) é a sinonímia, afinal é baseada nestas relações que os synsets são criados. Além disso, é por causa da sinonímia que a WordNet (e também as demais wordnets) é dividida em: substantivos, verbos, adjetivos e advérbios. Como os conceitos são representados por synsets e os sinônimos devem ser substituíveis, palavras de diferentes classes sintáticas não podem ser sinônimas. Esta sinonímia que ocorre nas wordnets é chamada de sinonímia fraca, pois uma expressão é sinônima de outra em um contexto $X$ se a substituição de uma pela outra não altera $\mathrm{o}$ significado de $X^{23}$.

A WordNet possui uma interface $\mathrm{WEB}^{24}$ e uma aplicação desktop ${ }^{25}$. Na Figura 3 é apresentada a tela de entrada da versão 3.1 (atual) da ferramenta online da WordNet. Como se pode observar, trata-se de uma interface simples de busca, com somente uma opção:

\footnotetext{
$22 \mathrm{http}$ //wordnet.princeton.edu/wordnet/man2.0/wnstats.7WN.html

${ }^{23}$ Mais informaçãoo pode ser encontrada em (Cruse, 1986), capítulo 12

${ }^{24}$ Para acessar a WordNet: http://wordnetweb.princeton.edu/perl/webwn

${ }^{25}$ Para baixar a WordNet: http://wordnet.princeton.edu/wordnet/download/
} 
busca por palavra. Pode-se também selecionar algumas opções de visualização (como frequência da palavra, por exemplo).

\section{WordNet Search -3.1 \\ - WordNet home page - Glossary - Help}

Word to search for: Search WordNet

\section{Display Options: (Select option to change) $\rightarrow$ Change}

Figura 3: Tela de Entrada da WordNet (versão WEB)

\subsubsection{A EuroWordNet}

EuroWordNet ${ }^{26}$ é uma base de dados multilíngue composta de várias wordnets de idiomas Europeus que é estruturada nos mesmos moldes da WordNet (Vossen, 2002). Cada uma das wordnets da EuroWordNet é uma rede semelhante das relações entre os significados de palavras em um idioma específico. As relações semânticas são, portanto, consideradas relações internas do idioma. Além destas relações, cada synset é também ligado com o synset mais próximo da WordNet (versão 1.5).

Para armazenar as várias wordnets em uma única base de dados multilingual, os synsets da WordNet funcionam como um índice inter-lingual (ILI) (Vossen, 2004). Assim é possível acessar um synset de uma wordnet através do synset de outra wordnet, desde que ambos os synsets estejam ligados ao mesmo conceito da WordNet. Uma base de dados multilíngue é útil para recuperação de informação entre os idiomas, transferência de informação de uma wordnet para outra e a comparação de diferentes wordnets.

A arquitetura do banco de dados da EuroWordNet permite manter as características específicas de cada idioma e também a relação entre as diversas wordnets através do índice da WordNet. Inicialmente, a EuroWordNet implementou quatro wordnets dos idiomas: holandês, italiano, espanhol e inglês. Como extensão do projeto, foram incluídos os idiomas: alemão, estoniano, francês e tcheco. Todas as wordnets são limitadas a substantivos e verbos ${ }^{27}$.

\footnotetext{
${ }^{26} \mathrm{http}: / /$ www.illc.uva.nl/EuroWordNet/

${ }^{27}$ Informações retiradas de um documento datado de 2004 [Vossen, 2004], nenhuma referência mais atual foi encontrada
} 


\subsubsection{A MultiWordNet}

A MultiWordNet ${ }^{28}$ também é um recurso composto de várias wordnets (Pianta et al., 2002). Porém, é diferente da EuroWordNet na metodologia adotada para sua elaboração. Enquanto a EuroWordNet consiste de wordnets independentes para, numa fase posterior, tentar encontrar correspondências entre elas, a MultiWordNet construiu wordnets de linguagens distintas mantendo, na medida do possível, as relações semânticas disponíveis na WordNet. Isto é feito pela criação de um novo synset com correspondência com um synset da WordNet. Este novo synset herda as relações semânticas que há entre os synsets da WordNet.

Neste modelo, procedimentos automáticos podem ser concebidos para acelerar tanto a construção de synsets correspondentes quanto à detecção de divergências entre a WordNet e a wordnet sendo construída. A MultiWordNet corresponde a wordnets de sete idiomas: inglês, português, italiano, espanhol, hebreu, latim e romeno ${ }^{29}$.

\subsubsection{A WordNet.Br}

A WordNet.Br é a wordnet para o português do Brasil e foi a partir de seus alinhamentos com a WordNet que a VerbNet.Br foi criada. Por isso, este recurso foi de extrema importância para esta pesquisa e merece ser detalhado.

A construção da base de relações da WordNet.Br (Dias-da Silva et al., 2008) e (Dias-da Silva, 2005) é feita (e já foi concluída para verbos) por meio de um alinhamento com a WordNet (Fellbaum, 1998). O linguista começa o procedimento selecionando uma palavra em português. Então é realizada uma busca em um dicionário bilíngue (Português do Brasil - Inglês) e a palavra selecionada é relacionada com sua versão em inglês. Buscase, então, na WordNet o synset que corresponde à palavra com o sentido esperado pelo linguista. Assim como na MultiWordNet e na EuroWordNet, os verbos são relacionados utilizando o índice da WordNet (ILI). Neste ponto do método, o linguista deve decidir qual tipo de relação o novo synset da WordNet.Br terá com o synset da WordNet. Seguindo o modelo proposto pelos criadores da EuroWordNet, são possíveis quatro tipo de relações:

\footnotetext{
${ }^{28} \mathrm{http}: / /$ multiwordnet.fbk.eu/english/home.php

${ }^{29}$ Para acessar a MultiWordNet: http://multiwordnet.itc.it/english/home.php
} 
EQ_SYNONYM, EQ_NEAR_SYNONYM,

EQ_HAS_HYPERONYM (detalhadas na Tabela 4).

Tabela 4: Lista das possíveis relações entre a WordNet.Br com a WordNet

\begin{tabular}{|l|l|}
\hline \multicolumn{1}{|c|}{ Relação } & \multicolumn{1}{c|}{ Descrição } \\
\hline EQ_SYNONYM & $\begin{array}{l}\text { Relação direta entre um synset da WordNet.Br com um synset da } \\
\text { WordNet }\end{array}$ \\
\hline EQ_NEAR_SYNONYM & $\begin{array}{l}\text { Quando mais de um synset da WordNet.Br está relacionado com } \\
\text { um synset da WordNet ou vice-versa }\end{array}$ \\
\hline EQ_HAS_HYPONYM & $\begin{array}{l}\text { Quando um synset da WordNet é hipônimo de um synset da } \\
\text { WordNet.Br }\end{array}$ \\
\hline EQ_HAS_HYPERONYM & $\begin{array}{l}\text { Quando um synset da WordNet é hiperônimo de um synset da } \\
\text { WordNet.Br }\end{array}$ \\
\hline
\end{tabular}

Como exemplo da relação direta EQ_SYNONYM, tem-se o synset 1003 \{atender, corresponder, cumprir, realizar, satisfazer) (com o sentido: 'atender as necessidades ou expectativas') da WordNet.Br alinhado com o synset 02591336 \{satisfy, fulfill, fulfil, live up to\} (com sentido: 'fulfil the requirements or expectations of' - 'atender as necessidades ou expectativas') da WordNet. Como se pode observar, ambos synsets possuem sentidos diretamente equivalentes o que justifica o uso de EQ_SYNONYM.

Já como exemplo da relação EQ_HAS_HYPERONYM, tem-se o synset 1120 \{desinchar, desinflamar\} (com sentido: 'deixar de estar inflamado') da WordNet.Br alinhado com o synset 00096441 \{heal\} (com sentido: 'get healthy again' - 'fica saudável novamente'). É possível observar que o sentido do synset da WordNet é mais geral do que o sentido do synset da WordNet.Br. Portanto, a relação ideal entre estes synsets é de EQ_HAS_HYPERNONYM ${ }^{30}$.

Atualmente, a WordNet.Br possui a base de verbos criada, faltando apenas à validação dos synsets e dos alinhamentos. No trabalho de Scarton e Aluísio (2009), foram herdadas automaticamente as relações de hiperonímia da WordNet para a WordNet.Br a partir dos alinhamentos entre as bases. Na Figura 4 (retirada do trabalho de Di Felipo e Dias-da-Silva (2007)) é apresentado um exemplo de alinhamento entre um synset da WordNet.Br e um synset da WordNet e a ilustração da herança automática das relações de hiperonímia. Como é possível observar, o synset \{try, seek, attempt, essay, assay\} da WordNet aparece alinhado com o synset \{tentar, ensaiar, experimentar\} da WordNet.Br. Os synsets $\{$ risk, put on the line,... \} e \{arriscar, expor\} também estão alinhados. Como há

\footnotetext{
${ }^{30}$ Vale comentar que as relações de EQ_NEAR_SYNONYM, EQ_HAS_HYPERONYM e EQ_HAS_HYPONYM só ocorrem quando o linguista não consegue estabelecer a relação ótima de EQ_SYNONYM
} 
uma relação de hiperonímia entre os synsets da WordNet (o synset de try é hiperônimo do synset de risk) e estes synsets estão alinhados com os synsets da WordNet.Br é possível herdar a relação de hiperonímia entre o synset de 'tentar' e o synset de 'arriscar'.

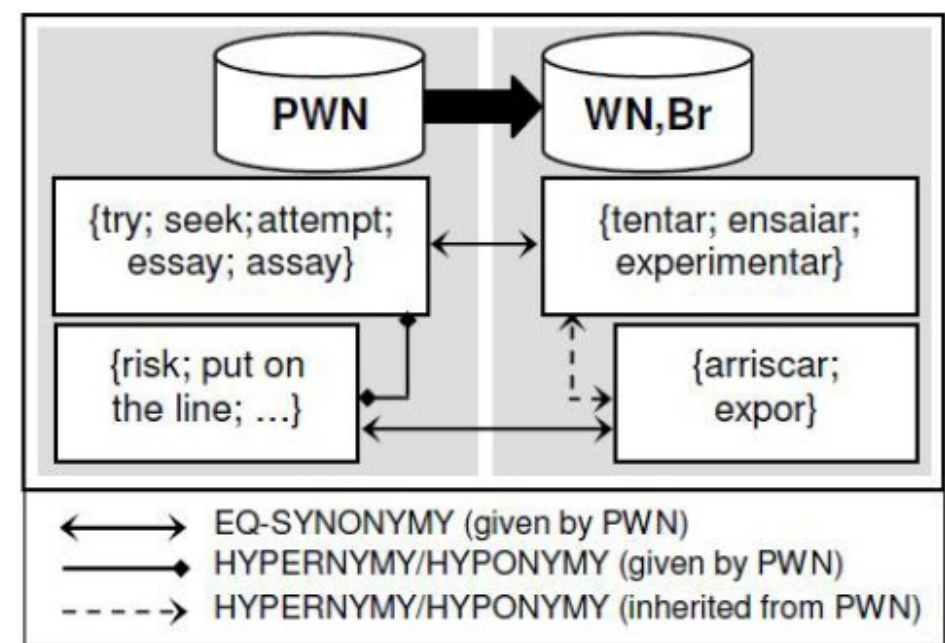

Figura 4: Exemplo de um alinhamento entre a WordNet.Br e a WordNet (Di Felipo e Dias-da Silva, 2007) - PWN: WordNet; WN,Br: WordNet.Br

Além disso, neste mesmo trabalho de herança automática das relações de hiperonímia, foi desenvolvido um protótipo de ferramenta de consulta da WordNet. $\mathrm{Br}^{31}$ na WEB que foi reestruturada neste mestrado (Capítulo 7, Seção 7.4.3). As demais relações semânticas (Troponímia e Termos Coordenados) também foram herdadas durante este mestrado.

\subsubsection{FrameNet}

A FrameNet ${ }^{32}$ (desenvolvida em Berkeley) é um recurso léxico para a língua inglesa baseado na Semântica de frames de Fillmore (Baker et al., 1998). Seu desenvolvimento ainda está em curso e o objetivo é criar uma base de conhecimentos lexicais apoiada por um córpus semanticamente anotado. Os domínios semânticos sendo cobertos são: healthy care (saúde), chance (chance), perception (percepção), communication (comunicação), transaction (transação), time (tempo), space (espaço), body (corpo), motion (movimento), life stages (estágios da vida), social context (contexto social), emotion (emoção) e cognition (cognição).

\footnotetext{
${ }^{31} \mathrm{http}: / /$ nilc.icmc.usp.br/wordnet

${ }^{32} \mathrm{https}: / /$ framenet.icsi.berkeley.edu/fndrupal/
} 
Os resultados do projeto são: (a) um recurso lexical chamado de FrameNet database e; (b) ferramentas de software de apoio. O FrameNet database é composto por três componentes principais:

- Léxico: com os componentes: (a) dados de um dicionário convencional; (b) fórmulas que definem os modos morfossintáticos em que os frames semânticos podem ser realizados nas sentenças ou frases construídas com a palavra; (c) links para exemplos de sentenças semanticamente anotadas que ilustram cada uma das realizações em potencial, identificadas pela fórmula e; (d) links para a base de frames e para outros recursos como a WordNet.

- Base de Frames: contém descrições da estrutura conceitual básica de cada frame e nomeia e descreve os elementos que participam destas estruturas.

- Exemplos de sentenças anotadas: são marcações para exemplificar a semântica e a morfossintaxe dos itens lexicais.

Como exemplo, considera-se a busca da palavra buy (to buy - comprar) na ferramenta WEB da FrameNet na Figura 5.

FrameNet Data Search for buy
Frame search results: No Frame Results
Lexical unit search results: Closest match is buy
\begin{tabular}{|l|l|}
\hline Lexical Unit & Frame \\
\hline buy.v & Commerce_buy \\
\hline buyer.n & Commerce_scenario \\
\hline
\end{tabular}

Figura 5: Exemplo do resultado da FrameNet na busca pela palavra buy

São retornadas duas unidades lexicais, uma que representa o verbo (buy.v comprar) e outra que representa um substantivo (buyer.n - comprador). Também são retornados os frames que as unidades lexicais participam. No caso do verbo, o frame semântico é o Commerce_buy. Na Figura 6, apresenta-se a descrição apresentada para o frame semântico Commerce_buy. 


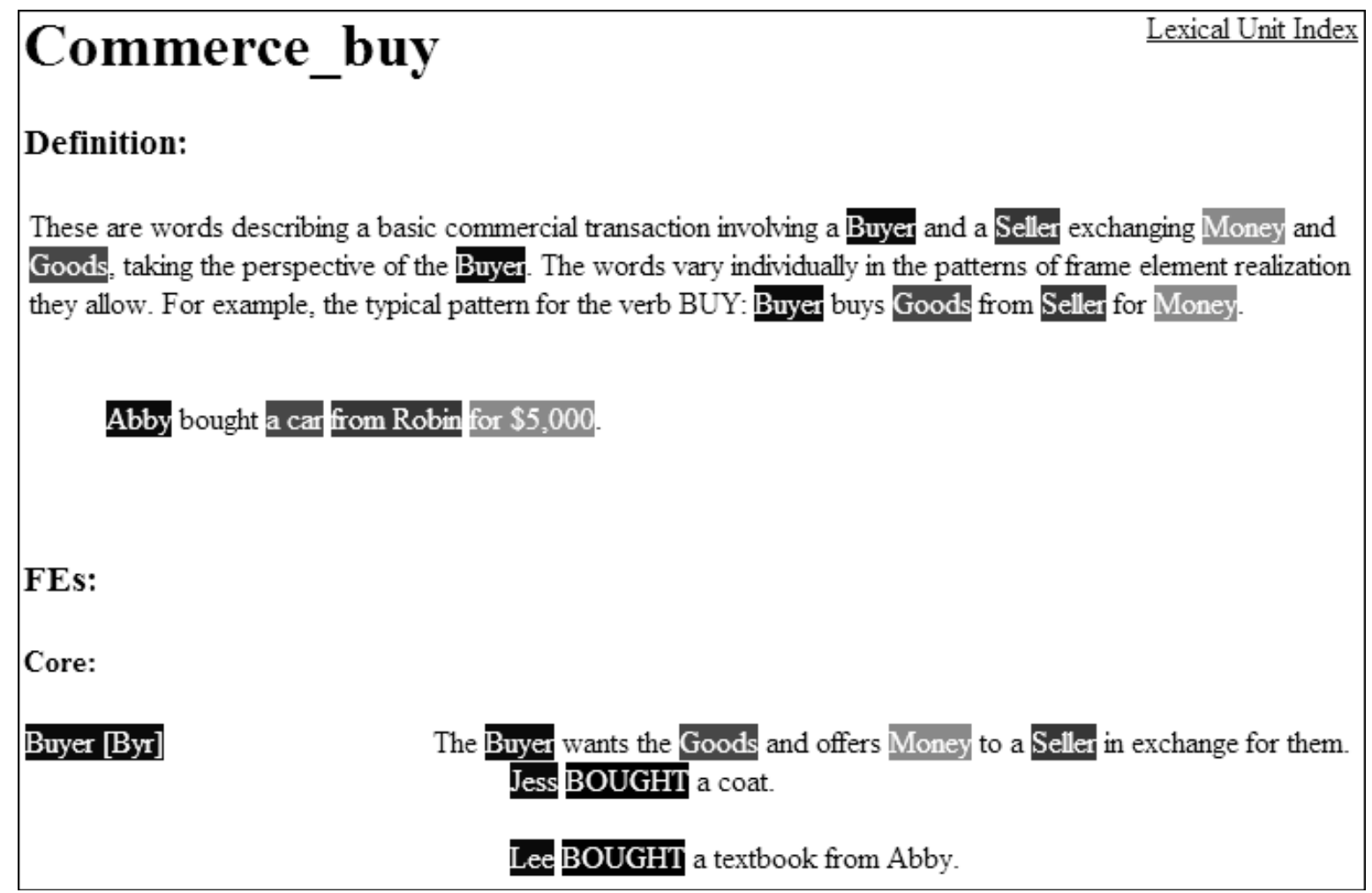

Figura 6: Descrição do frame Commerce_buy

Na definição, apresentada na Figura 6, tem-se para o verbo to buy (comprar) que os papéis dos argumentos podem ser Buyer (comprador), Seller (vendedor), Money (dinheiro) e Goods (mercadorias). O padrão típico do frame sintático é Buyer compra Goods do Seller por Money (um determinado valor).

A FrameNet oferece perspectivas para várias aplicações, tanto baseadas em PLN quanto para Lexicografia (Atkins et al., 2003).

O trabalho de Chishman et al. (2008) (FrameCorp) é uma iniciativa de anotação semântica para o português do Brasil. Neste projeto, antes de se construir frames adequados para a língua, iniciou-se a anotação semântica de um córpus com as etiquetas dos frames construídos para o inglês. Embora isso tenha gerado algumas dificuldades, foi um importante passo para aquisição de conhecimento na área.

Há também o trabalho de Salomão (2009), a FrameNet Brasil ${ }^{33}$, que visa à criação de um recurso lexical online para o Português do Brasil, baseado na semântica de frames e sustentado por evidência em córpus. Tanto o FrameCorp quanto a FrameNet Brasil utilizam a semântica de frames de Fillmore e a base de dados da FrameNet de Berkeley

\footnotetext{
${ }^{33} \mathrm{http}: / /$ www.framenetbr.ufjf.br/
} 
para suas pesquisas. A diferença é que o primeiro pratica anotações em texto corrido e o segundo anotações lexicográficas (Salomão, 2009). Porém, há um esforço para que os trabalhos caminhem juntos. Um exemplo de frame semântico para a unidade lexical “comprar" na FrameNet Brasil é apresentado na Figura 7.

\title{
Comércio_comprar [Commerce_buy]
}

\author{
Definição \\ Trata-se de palavras que descrevem uma transação comercial básica envolvendo um Comprador e um \\ Vendedor, trocando Dinheiro e Mercadorias sob a perspectiva do Comprador.
}

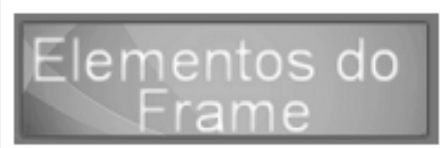

\section{Nucleares (Core)}
Comprador o Comprador quer as Mercadorias e oferece Dinheiro para um Vendedor em troca Buyer] delas.

-Não consigo me lembrar daquele dia.Mas lembrome de um dia quando tinha cinco anos e meu pai me COMPROU um sorvete

Mercadorias O EF Mercadorias é qualquer coisa (incluindo trabalho ou tempo, por exemplo) que é [Goods] trocado por Dinheiro em uma transação.

- Na verdade, minha mãe tem as conexões. Marsh Warner COMPROU uma peça dela no verão passado.

Figura 7: Exemplo da unidade lexical "abandonar" na FrameNet Brasil

Pode-se observar que o frame Comércio_comprar (apresentado na Figura 7) é alinhado com o frame Commerse_buy (apresentado na Figura 6).

\subsubsection{PropBank}

O PropBank ${ }^{34}$ foi criado, para a língua inglesa, a partir da anotação de um córpus com papéis semânticos, incluindo os papéis vistos como argumentos e como adjuntos. Este projeto possui duplo propósito: determinar a frequência da variação sintática na prática e também a criação de sistemas automáticos de reconhecimento de papéis semânticos,

\footnotetext{
${ }^{34} \mathrm{http}: / /$ verbs.colorado.edu/ mpalmer/projects/ace.html
} 
utilizando métodos baseados em aprendizado de máquina (Palmer et al., 2005). O PropBank é composto por rolesets (um roleset é um conjunto de papéis semânticos de um sentido de um verbo), framesets (um frameset compreende a um roleset mais os frames semânticos que um verbo participa) e frame files (coleção de framesets de um verbo). $\mathrm{O}$ córpus utilizado foi o Penn TreeBank (Marcus et al., 1993) e a estratégia utilizada foi partir dos verbos mais frequentes e construir frames files para eles, localizando, no córpus, exemplos das diversas manifestações desses verbos. Uma vez criados os frames files, a equipe do PropBank utilizou as classes verbais da VerbNet para complementá-los.

Na Figura 8 tem-se um exemplo de um frameset do PropBank (o frameset kick.01). Neste frameset o verbo kick tem o sentido de "conduzir ou empurrar com o pé", porém o instrumento não precisa ser necessariamente "o pé”. Pode-se observar na Figura 8 que o verbo admite três argumentos em que o Arg0 é o Kicker (quem chuta), Arg1 é a Thing kicked (coisa que foi chutada) e o Arg2 é o Instrument (instrumento usado para chutar, no caso, o instrumento default é o pé). Neste caso, o Arg0 é um agente, o Arg1 é um paciente e o Arg2 é um instrumento. O exemplo da Figura 8 também apresenta duas construções possíveis para o verbo kick no sentido descrito anteriormente. O primeiro exemplo apresenta uma construção com todos os argumentos, porém o instrumento não é “o pé” (o Arg2 é "with the embarrassing failure of Citicorp and Chase Manhattan Corp. to deliver $\$ 7.2$ billion in bank financing for a leveraged buy-out of United Airlines parent UAL Corp”). Já no segundo exemplo é apresentada uma construção sem o instrumento (somente com $\operatorname{Arg} 0$ e Arg1).

Frameset kick.01 "drive or impel with the foot"

Arg0: Kicker

Arg1: Thing kicked

Arg2: Instrument (defaults to foot)

Ex1: [ArgM-DIS But] [Arg0 two big New York banks ${ }_{i}$ ] seem $\left[\right.$ Arg0 ${ }^{*} \operatorname{trace}_{i}{ }_{i}$ ] to have kicked [Arg1 those chances] [ArgM-DIR away], [ArgM-TMP for the moment], [Arg2 with the embarrassing failure of Citicorp and Chase Manhattan Corp. to deliver $\$ 7.2$ billion in bank financing for a leveraged buy-out of United Airlines parent UAL Corp]. (wsj_1619)

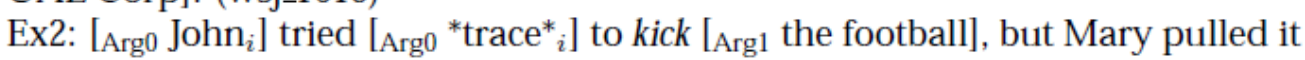
away at the last moment.

Figura 8: Exemplo de um frameset do PropBank (retirado de Palmer et al. (2005))

Para o português do Brasil, o trabalho de pós-doutorado da doutora em linguística Magali Sanches Duran (PropBank.Br) (Duran et al., 2010a; Duran et al., Duran e Aluísio, 
2011; Duran e Aluísio, 2012), desenvolvido no NILC sob mesma orientação da aluna deste mestrado em tela, prevê a criação de um recurso léxico nos moldes do PropBank. No primeiro ano de trabalho foi anotado um córpus de textos simplificados com perguntas aos verbos (tarefa relacionada com a anotação de papéis semânticos e que serviu de base para a criação de um etiquetador automático de perguntas aos verbos (Amâncio et al., 2010)). No segundo ano de pós-doutorado, o córpus Bosque foi anotado com as etiquetas do PropBank e alguns frame files foram construídos. Atualmente, no terceiro ano de pós-doutorado, está prevista a construção de frame files para todo o córpus Bosque. Assim como ocorreu no PropBank, este trabalho pode ser beneficiado diretamente pela construção de uma VerbNet para o português do Brasil e pretende-se alinhar os dois recursos. $\mathrm{O}$ alinhamento dos dois recursos será dado pelo alinhamento entre PropBank e PropBank.Br (que está sendo construído com esta preocupação), pelo alinhamento entre VerbNet e VerbNet.Br (trabalho deste mestrado) e pelo alinhamento entre PropBank e VerbNet. O alinhamento entre PropBank e VerbNet ocorre entre os rolesets e as classes. A tarefa de alinhamento entre o PropBank e o PropBank.Br está sendo desenvolvida pelo aluno de Iniciação Científica Jhonata Martins e será de extrema importância para a criação dos frame files para o português.

Outros trabalhos relacionados estão sendo desenvolvidos nos mestrados de Fernando Alva Manchego e Erick Fonseca, também desenvolvidos no NILC e orientados pelo Prof. Dr. João Luis Garcia Rosa. O primeiro propõe um método semissupervisionado para a anotação automática de papéis semânticos, seguindo os rótulos do Propbank. O segundo trabalho propõe o uso de redes neurais para a anotação automática de papéis semânticos com atributos mais simples (somente lexicais), o que exclui a necessidade do córpus conter anotação sintática. Há, também, o doutorado de Murillo Guimarães Carneiro (também orientando do Prof. Dr. João Luis Garcia Rosa) que propõe a anotação automática de papéis semânticos usando algoritmos evolutivos.

\subsection{VerbNet}

A VerbNet é um léxico verbal, para o inglês, com informações sintáticas e semânticas, que se utiliza das classes de Levin (1993) e possui mapeamentos com a WordNet, Xtag (XTAG Research Group, 2001) e FrameNet. Este recurso foi desenvolvido durante o doutorado de Karin Kipper (Kipper, 2005). Classes verbais são importantes para 
capturar generalizações que vão além da instância única do verbo, reduzindo assim o esforço necessário para a construção de léxicos e também a probabilidade de erros quando um verbo é inserido na base (Kipper, 2005). A VerbNet é estruturada em classes que agrupam verbos da maneira proposta por Levin (1995), mas não segue totalmente a esta proposta. Kipper utilizou a base da proposta de Levin (191 classes verbais) e algumas extensões para melhor representar os verbos.

Cada classe verbal da VerbNet é completamente descrita por um conjunto de membros, papéis temáticos para a estrutura predicado-argumento de seus membros, restrições seletivas para os argumentos e frames sintáticos com uma breve descrição, um exemplo, uma descrição sintática e um conjunto de predicados semânticos com uma função temporal. Na Tabela 1 do Capítulo 1 (copiada a seguir) pode-se observar parte da classe leave-52.1, ilustrando os papéis temáticos, as restrições seletivas e os frames. Nesta tabela, a primeira linha apresenta o nome da classe (leave-52.1). A segunda linha contém os papéis temáticos e as restrições seletivas. Neste caso, os papéis temáticos são: Theme (Tema) (refere-se a participantes em um lugar ou submetidos a uma mudança de lugar) e Source (Fonte) (ponto de origem do movimento). Theme possui a restrição seletiva [+animate] que define que este papel temático deve ser algo animado. Source possui duas restrições seletivas: [+location -region] que definem que o papel temático é um local mas que não aceita frases com expressões preposicionais. A partir da quarta linha há a apresentação de um frame. Para este frame, na linha seis, podemos observar seu nome (Basic Transitive) que define o comportamento transitivo para os verbos desta classe. Também há um exemplo para este frame na linha seis, coluna dois (We abandoned the area). Na terceira coluna da linha seis há a definição sintática para este frame (Theme $V$ Source), ou seja, este frame pede um Tema seguido de um verbo que é seguido por uma Fonte. Por fim, na ultima coluna da linha seis, são apresentados os predicados semânticos (usados para denotar relações entre participantes e eventos). Neste caso, o predicado utilizado é motion (movimento) com o função temporal during $(E)$ e o participante Theme. $\mathrm{O}$ evento during $(E)$ significa que durante o evento ocasionado pelo verbo o participante (Theme) estará em movimento (motion). 
Tabela 1: Parte da classe leave-52.1 da VerbNet

\begin{tabular}{|l|l|l|l|}
\hline \multicolumn{5}{|c|}{ Leave-51.2 } \\
\hline Papéis temáticos e Restrições seletivas: Theme [+concrete] e Source [+location - region] \\
\hline Membros: abandon, split \\
\hline Frames:
\end{tabular}

Como mencionado no início desta seção, a VerbNet possui mapeamentos para os synsets da WordNet (se eles existirem). Estes mapeamentos são feitos para cada membro de cada classe. Na Figura 9 é apresentado um trecho do arquivo XML da classe escape51.2 do VerbNet. Nesta figura pode-se observar os membros desta classe e seu mapeamento para a WordNet (apresentados com as etiquetas “wn").

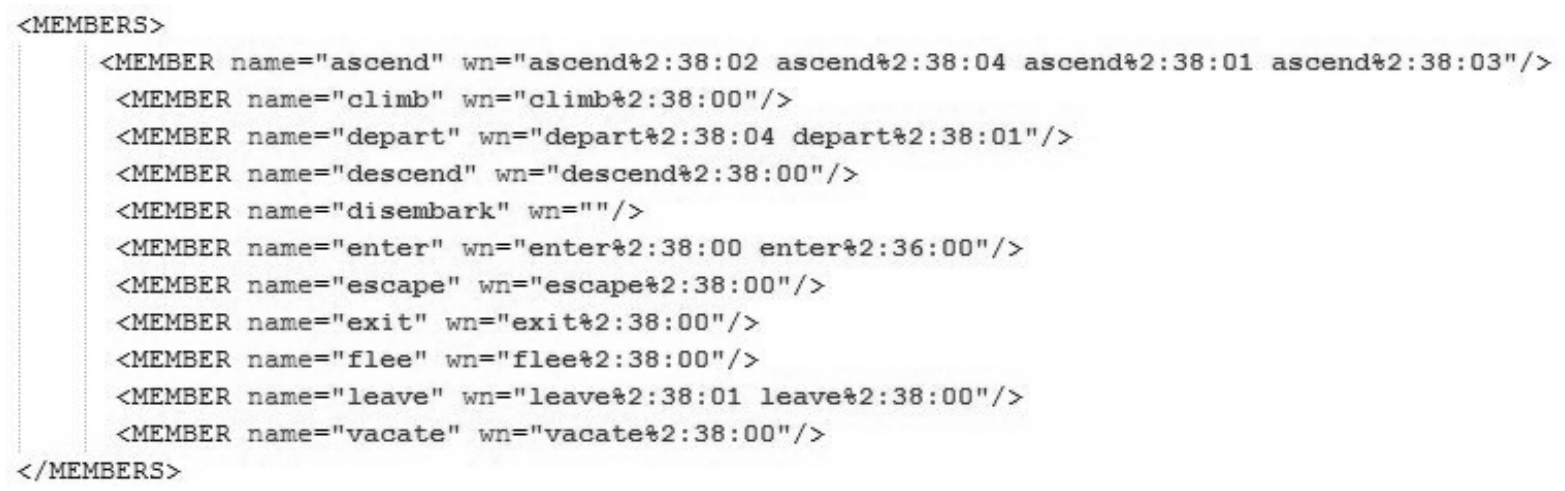

Figura 9: Membros da classe escape-51.2

O procedimento seguido neste mestrado para a criação da Verbnet.Br foi buscar os synsets da WordNet.Br alinhados com os synsets da WordNet que aparecem para cada membro. Assim, foi possível associar estes synsets as características sintáticas e semânticas presentes na VerbNet. Este procedimento é detalhado no Capítulo 6.

Cada componente da VerbNet será melhor detalhado nas próximas seções. $\mathrm{Na}$ Seção 3.3.1 são apresentados os papéis temáticos da VerbNet. Na Seção 3.3.2 são apresentadas as restrições seletivas. Na Seção 3.3.3 são apresentados os frames sintáticos. $\mathrm{Na}$ Seção 3.3.4 são apresentados os predicados semânticos. $\mathrm{Na}$ Seção 3.3.5 são apresentadas extensões propostas por Kipper (2005) para as classes básicas de Levin 
(1993). Por fim, na Seção 3.3.6 é apresentado um experimento realizado por Kipper (2005) considerando semelhanças entre as classes verbais do inglês com o português.

\subsubsection{Papéis Temáticos}

A VerbNet possui 23 papéis temáticos que foram criados para mapear os argumentos dos verbos de todas as classes. Embora Kipper (2005) discuta que é difícil determinar um bom conjunto de papéis temáticos, a meta do projeto da VerbNet foi fornecer o máximo de informação possível sobre a classe. A escolha de usar papéis temáticos ao invés de argumentos numerados se justifica, pois os papéis fornecem parte da descrição semântica para a classe o que não seria possível com os argumentos numerados. A informação extra contida nos papéis temáticos (em oposição ao uso de argumentos numerados) fica mais clara quando se olha para exemplos de classes que apresentam o mesmo frame sintático. Os exemplos (70) e (71) foram retirados de Kipper (2005, p. 30):

(70) The tourists admired the paintings.

Experienciador V Tema

(71) Paula hit the ball

Agente V Paciente

Por exemplo, a classe admire-31.2 (uma classe de verbos psicológicos) utiliza os papéis experienciador e tema (58), enquanto que a classe hit-18.1 (uma classe de verbos de contato) utiliza os papéis agente e paciente (59) para o mesmo frame transitivo.

Kipper (2005) também afirma que para os 5.200 sentidos de verbos da VerbNet, este conjunto de 23 papéis temáticos é suficiente para prover as informações necessárias. A seguir, é apresentada uma lista de alguns papéis temáticos utilizados na VerbNet:

- Ator: usado para algumas classes de comunicação quando ambos os argumentos podem ser considerados simétricos (a mudança na ordem dos argumentos não afeta o sentido da sentença).

- Agente: sujeito humano ou animado. Usualmente utilizado como agente volitivo, porém, na VerbNet, este papel é, também, utilizado para sujeitos controlados internamente, tal como forças e máquinas. 
- Atributo: atributo de um paciente ou tema, se refere a algo que está mudando, como no exemplo: The price of oil soared, the price recebe o papel de atributo.

- Beneficiário: entidade que se beneficia de alguma coisa.

- Destino: o final de um movimento ou direção para qual o movimento é direcionado.

- Fonte: ponto inicial do movimento.

- Experienciador: usado em um participante que está ciente de algo ou está experimentando algo.

- Instrumento: usado em objetos que entram em contato com outro objeto e causam alguma mudança neste.

- Paciente: usado em participantes que são submetidos a um processo ou que foram afetados de alguma forma.

- Tema: usados em participantes que estão em uma localização ou submetidos a uma mudança de localização.

- Tópico: tema/tópico de uma conversa ou de uma mensagem transferida (usado em verbos de comunicação).

Como os papéis temáticos são atribuídos às classes, verbos que aparecem em mais de uma classe podem ter diferentes papéis. $\mathrm{O}$ fato dos verbos serem atribuídos às classes também garante que eles possam ser herdados para outra língua (já que as classes podem ser cross-linguísticas - vide exemplo no Capítulo 8).

\subsubsection{Restrições Seletivas}

As restrições seletivas da VerbNet são impostas aos papéis temáticos e, segundo Kipper, são baseadas na EuroWordNet. Elas são uma hierarquia, com múltiplas heranças e sem ciclos. Esta hierarquia é apresentada na Figura 10 (retirada de Kipper (2005, p. 36)).

Na Figura 10, é possível observar, por exemplo, que a restrição location (localização) é subdivida em três campos: 
- Region (região): para expressar construções preposicionais, tal como 'from under the rug' (debaixo do tapete).

- Place (lugar): para construções como 'in Paris' (em Paris) ou 'under the rug' (embaixo do tapete).

- Object (objeto): tal como 'on the table' (sobre a mesa) - o lugar é um objeto.

A restrição location (localização) pode aparecer em alguns papéis como [+location -region] para evitar construções como from under the rug. Se todas as construções de location são permitidas, a restrição aparece como [+location].

Os papéis temáticos podem apresentar restrições adicionais (como plural, por exemplo, na classe correspond-36.1 na qual o sujeito na construção intransitiva deve estar no plural - exemplos (72) e (73)).

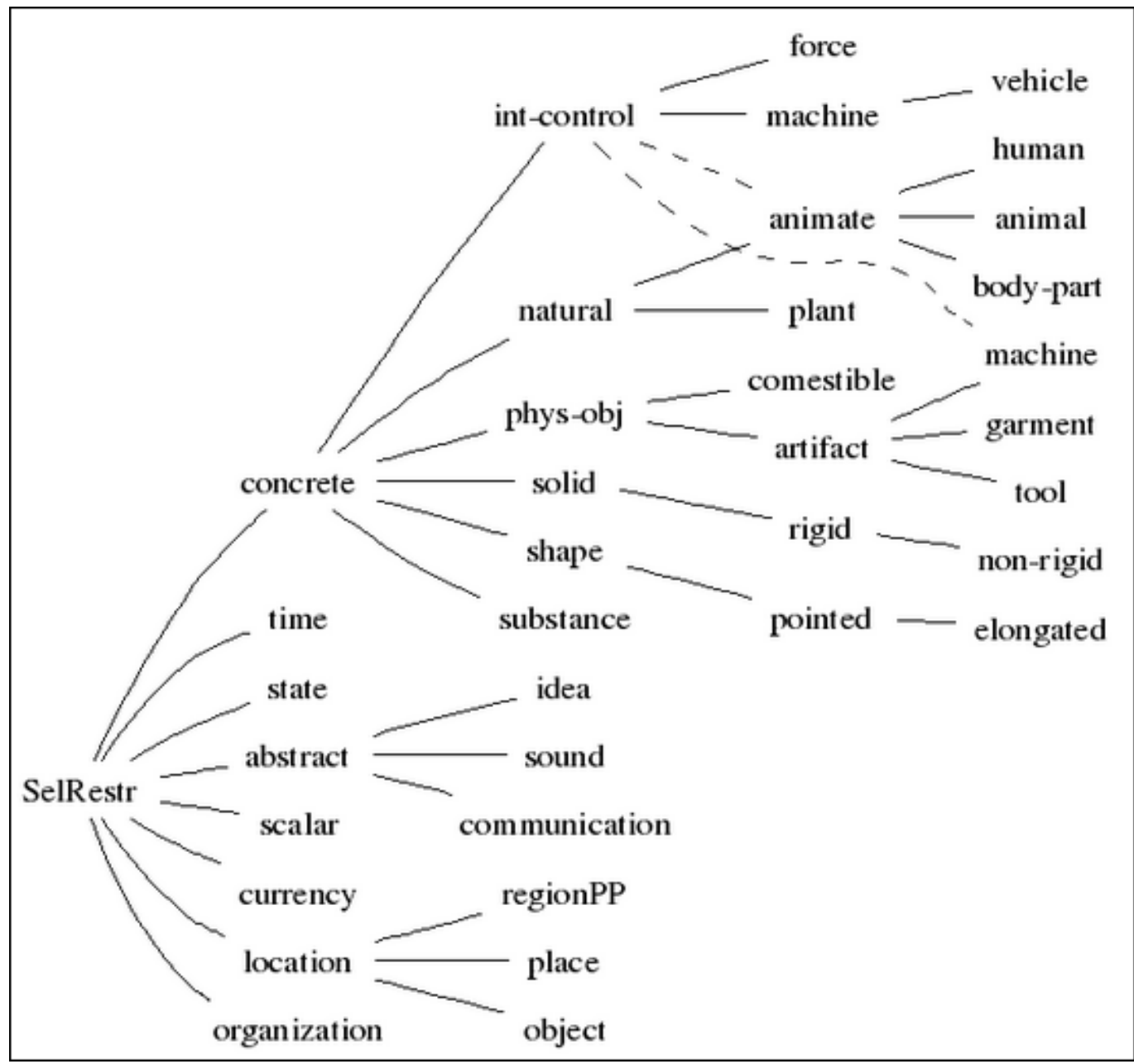

Figura 10: Hierarquia das restrições seletivas da VerbNet (Kipper, 2005) 


\subsubsection{Frames Sintáticos}

Os frames sintáticos descrevem construções como transitivas, intransitivas, frases preposicionais, e um grande conjunto das alternâncias propostas por Levin. Um frame sintático contém: os papéis temáticos, o verbo e outros itens lexicais necessários para construções e alternâncias em particular. Há também uma hierarquia de preposições, para especificar quais preposições estão presentes em um frame em particular. Exemplos de frames sintáticos são apresentados em (72), (73) e (74), retirados da classe correspond36.1 da VerbNet:

$$
\text { Agent[+plural] V (Agente[+plural] V) }
$$

They agreed. (Eles concordaram.)

$$
\text { Agent[+plural] V \{about\} Theme[-sentential] (Agente[+plural] V \{sobre\} }
$$
Tema[-sentencial]

They agreed about it. (Eles concordaram sobre isso.)

Agent V \{with Co-Agent \{about\} Theme[-sentential] (Agente V \{com\} Co-Agent \{sobre\} Tema[-sentencial])

They agreed with him about it. (Eles concordaram com ele sobre isso.)

\subsubsection{Predicados Semânticos}

Os predicados semânticos fornecem as relações entre participantes e eventos e são responsáveis por definir os componentes de significado de cada classe. Kipper também incluiu uma função de tempo nos predicados semânticos para fornecer informações sobre quando cada um dos predicados é aplicado. Esta função de tempo especifica se o predicado é verdadeiro no início do evento $(\operatorname{start}(E))$, na preparação do evento $(\operatorname{during}(E))$, no final do evento $(\operatorname{end}(E))$ ou no resultado do evento $(\operatorname{result}(E))$. Os predicados semânticos são divididos em quatro classes:

- Predicados gerais: inclui predicados como motion (movimento) e cause (causa) e são genéricos em uma grande quantidade de classes e, também, em várias línguas. 
- Predicados variáveis: predicados cujo significado admite uma relação umpor-um com um conjunto de palavras em uma língua.

- Predicados específicos: carregam um sentido verbal específico.

- Predicados para múltiplos eventos: são predicados usados para expressar relações entre eventos.

Os argumentos dos predicados semânticos são:

- Event: o evento (E) ou uma subparte dele $(\operatorname{start}(E)$, during $(E)$, end(E), result(E)), descrevendo para qual parte no evento o predicado semântico continua válido.

- Constant: especifica uma propriedade da classe, mas não é um dos papéis temáticos.

- ThemRole: inclui os papéis temáticos presentes no frame sintático.

- Verb Specific: para argumentos que são instanciados diferentemente pelos verbos da classe.

Na última linha da Tabela 1 (quarta coluna) há um exemplo de quatro predicados semânticos para o frame transitivo da classe leave-51.2:

- motion(during(E), Theme) - durante o evento o Tema está em movimento.

- location(start(E), Theme, Initial_Location) - no início do evento o Tema está em um lugar inicial.

- $\operatorname{not}(\operatorname{location}(\mathrm{end}(\mathrm{E})$, Theme, Initial Location) $)$ - no fim do evento o Tema não está no lugar inicial (está em qualquer outro lugar).

- direction(during(E), from, Theme, Initial_Location) - durante o vento a direção do movimento parte do lugar inicial.

\subsubsection{Extensões da VerbNet às classes básicas de Levin (1993)}

Uma das primeiras extensões realizadas na VerbNet foi o refinamento das classes com o intuito de deixá-las coerentes com seus componentes (papéis temáticos, restrições seletivas, frames sintáticos e predicados semânticos). Este refinamento adicionou 194 
subclasses à versão original. Uma subclasse herda toda a informação da classe e adiciona informações aos seus membros (que os distingue do resto da classe). Essas informações adicionais podem incluir restrições seletivas aos papéis temáticos, adição de frames sintáticos ou adição de predicados semânticos. Vale comentar que esta extensão não altera o número de classes básicas de Levin (1993) (linha 2 da Tabela 6).

Outra atividade que resultou em melhoria para a VerbNet foi o experimento com o PropBank. A cobertura sintática da VerbNet foi avaliada considerando os frames sintáticos encontrados no córpus anotado do PropBank. O resultado desta avaliação levou ao aperfeiçoamento da VerbNet incluindo 54 novos verbos (o trabalho de Levin (1993) possui 4.173 verbos) (linha 3 da Tabela 6).

Kipper (2005) também considerou o trabalho de Korhonen e Briscoe (2004) no qual propuseram uma extensão das classes originais de Levin (1993) com 57 novas classes. As novas classes foram extraídas de córpus com o intuito de aumentar a cobertura das classes de Levin (1993) e torna-las mais compreensíveis (uma vez que muitas classes eram ambíguas e/ou com regras pouco definidas). Estas classes consideram verbos não tratados no trabalho de Levin (1993), como é o caso de verbos que aceitam frases adjetivas ou adverbiais. Porém, o trabalho de Korhonen e Briscoe (2004) não é somente uma extensão do trabalho de Levin (1993), pois há conflitos entre os dois trabalhos. Em outras palavras, Korhonen e Briscoe (2004) não só identificaram novos membros, como também identificaram subclasses das classes já existentes e novas grandes classes. Por isso, das 57 novas classes, duas foram desconsideradas, 35 foram incorporadas diretamente como novas classes da VerbNet, sete foram incorporadas diretamente como novas subclasses da VerbNet, doze foram combinadas com classes já existentes e uma foi inserida com necessidade de reestruturação das classes existentes (linha 4 da Tabela 6). Um exemplo de uma classe incluída por esta abordagem (confess-37.10) é apresentado na Tabela 5. Esta classe foi inserida na grande classe de Levin "Verbos de Comunicação" (classe 37).

Outra extensão considerou o recurso léxico LCS Database (Dorr, 2001) que também está organizado em uma versão modificada das classes de Levin (1993), sendo que o conjunto de papéis temáticos utilizados para a descrição sintática é similar aos utilizados na VerbNet. A compatibilidade entre os recursos foi responsável pela inclusão de 429 novos verbos (426 lemas) ao léxico da VerbNet (linha 5 da Tabela 6). 
Tabela 5: Classe confess-37.10 inserida na VerbNet de acordo com o trabalho de Korhonen e Briscoe (2004)

\begin{tabular}{|c|c|c|c|}
\hline \multicolumn{4}{|c|}{ Confess-37.10 } \\
\hline \multicolumn{2}{|c|}{$\begin{array}{l}\text { Papéis temáticos e Restrições } \\
\text { [+animate|+organization] e Topic }\end{array}$} & seletivas: Agente $[-$ & mate|+organization], Recipiente \\
\hline \multicolumn{4}{|c|}{ Membros: acknowledge, admit, confess, proclaim, reveal } \\
\hline \multicolumn{4}{|c|}{ Frames: } \\
\hline Nome & Exemplo & Sintaxe & Semântica \\
\hline $\begin{array}{l}\text { SN } \\
\text { SP.recipient }\end{array}$ & They confessed to us. & Agent $\mathrm{V}$ \{to\} Recipient & $\begin{array}{ll}\text { - } & \text { transfer_info(during(E), } \\
\text { Agent, Recipient, ?Topic) } \\
\text { - } \quad \text { cause(Agent, E) }\end{array}$ \\
\hline
\end{tabular}

Por fim, Kipper (2005) também utilizou duas técnicas automáticas para ampliar a VerbNet. A primeira utilizou agrupamento de verbos no córpus do PropBank e comparou o resultado com as classes da VerbNet (tarefa apresentada com mais detalhes no Capítulo 5). Desta comparação foi possível inserir 47 novos verbos (10 lemas) às classes da VerbNet (linha 6 da Tabela 6). A segunda técnica utilizou os mapeamentos com a WordNet para buscar novos membros às classes. Como quase todo membro da VerbNet está alinhado a um synset da WordNet, os membros desses synsets também foram considerados candidatos a membros. Após esta atividade 255 verbos (208 lemas) foram inseridos na VerbNet (linha 7 da Tabela 6).

A Tabela 6 sintetiza a evolução da VerbNet após cada extensão proposta.

Tabela 6: Evolução da VerbNet (retirada do trabalho de Kipper(2005))

\begin{tabular}{|l|c|c|c|}
\hline & Verbos & Lemas & Classes \\
\hline VerbNet + subclasses & 4173 & 3007 & 191 \\
\hline VerbNet + PropBank & 4227 & 3007 & 191 \\
\hline VerbNet + Korhonen e Briscoe (2004) & 4526 & 3175 & 237 \\
\hline VerbNet + LCS & 4955 & 3601 & 237 \\
\hline VerbNet + agrupamento & 5002 & 3611 & 237 \\
\hline VerbNet + WordNet & 5257 & 3819 & 237 \\
\hline
\end{tabular}

\subsubsection{Experimento com o português e a VerbNet}

No trabalho de Kipper (2005) há um experimento promissor que apresenta as similaridades diretas entre uma classe de Levin (1993) - Carry verbs- e sua tradução para o português.

Na primeira etapa, Kipper (2005) considerou as traduções diretas de cada verbo da classe Carry e concluiu que os verbos são, naturalmente, subdivididos em duas subclasses de acordo com a alternância conativa (conative alternation) e a alternância de separação (apart alternation). Além disso, todos os verbos dessa classe (tanto em inglês quanto em 
português) admitem as preposições de caminho (path prepositions), como from/de e to/para.

A alternância conativa em inglês, para os verbos da classe Carry, utiliza a preposição at ou against (por exemplo: Nora pushed at/against the chair). Já para os verbos em português a preposição utilizada é principalmente 'contra'. (por exemplo: 'Nora empurrou contra a cadeira').

A alternância de separação em inglês utiliza a palavra apart (por exemplo: I pulled the twig and the branch apart). Já em português a palavra utilizada é separando (por exemplo: 'Eu puxei o ramo e o galho separando-os'). Na Tabela 7 é apresentada a separação da classe Carry em duas subclasses, valendo tanto para verbos em inglês quanto para verbos em português.

Tabela 7: classe Carry - compatibilidade entre verbos do inglês e português (retirada do trabalho de

\begin{tabular}{|l|l|c|c|c|}
\hline \multicolumn{1}{|c|}{ Inglês } & \multicolumn{1}{|c|}{ Português } & Conativa & Separação & Preposições de Caminho \\
\hline Carry & Levar & Não & Não & Sim \\
Haul & Fretar & Não & Não & Sim \\
Heft & Levantar com dificuldade & Não & Não & Sim \\
Hoist & Içar & Não & Não & Sim \\
Lug & Levar com dificuldade & Não & Não & Sim \\
Tote & Levar facilmente & Não & Não & Sim \\
Tow & Rebocar & Não & Não & Sim \\
\hline Shove & Empurrar com violência & Não & Não & Sim \\
Push & Empurrar & Sim & Sim & Sim \\
Draw & Puxar & Sim & Sim & Sim \\
Pull & Puxar & Sim & Sim & Sim \\
Kick & Chutar & Sim & Sim & Sim \\
Tug & Puxar com força & Sim & Sim & Sim \\
Yank & Arrancar & Sim & Sim & Sim \\
\hline
\end{tabular}

Uma subclasse é composta de verbos que não apresentam a alternância conativa, nem a alternância de separação (verbos presentes na segunda linha da Tabela 7). Já os verbos da outra subclasse apresentam as duas alternâncias (verbos presentes na terceira linha da Tabela 7). 
Kipper (2005) conclui o experimento com duas questões para investigação. A primeira considera que, como o experimento foi realizado com traduções de verbos do inglês para o português, devem existir outros verbos que também pertençam à classe (além dos verbos traduzidos). A segunda considera que uma tradução do inglês para o português pode ser muitos-para-muitos e a compatibilidade das alternâncias da classe em inglês vai depender da tradução escolhida para o português.

\subsection{O projeto SemLink}

O projeto SemLink ${ }^{35}$ une diversos recursos semânticos através de mapeamentos entre eles. Até o momento, dois mapeamentos foram concluídos: VerbNet/PropBank e VerbNet/FrameNet. Vale lembrar que a VerbNet já possui mapeamentos para a WordNet.

O mapeamento entre a VerbNet e o PropBank foi feito em duas partes: um mapeamento lexical e um classificador de instâncias. O mapeamento lexical especifica, para cada palavra, os possíveis mapeamentos entre o PropBank e a VerbNet. Já o classificador de instâncias determina quais mapeamentos devem ser utilizados para uma dada ocorrência da palavra (Loper et al., 2007). Em outras palavras, a tarefa consistiu em definir para cada sentido no PropBank, qual mapeamento com a VerbNet deve ser utilizado.

O mapeamento entre a VerbNet e a FrameNet também foi feito em duas partes. Uma parte com mapeamentos do tipo muitos-para-muitos entre as classes da VerbNet e os frames da FrameNet (uma unidade lexical da FrameNet pode ser mapeada para mais de um membro da VerbNet e vice-versa). A segunda parte consiste do mapeamento entre os papéis temáticos da VerbNet os elementos dos frames da FrameNet ${ }^{36}$.

Este projeto é importante, pois visa à ligação de diversos recursos lexicais que foram desenvolvidos com diferentes métodos e propósitos e, por isso, cada um possui uma riqueza diferente. Consequentemente, uma ligação entre esses recursos pode combinar o que há de melhor em cada um e ser de grande utilidade para a área de PLN.

Vale comentar que a necessidade de construção de uma VerbNet para o português do Brasil foi identificada no interesse de construir um SemLink para o esta língua. Como já

\footnotetext{
${ }^{35} \mathrm{http}: / /$ verbs.colorado.edu/semlink/

${ }^{36}$ Informações encontradas em: http://verbs.colorado.edu/semlink/semlink1.1/vn-fn/README.TXT
} 
existem trabalhos para o português relacionados a WordNet, ao PropBank e a FrameNet, o caminho natural seria dar continuidade a estes trabalhos construindo uma rede tal qual o SemLink. Porém, a VerbNet é o recurso central do projeto SemLink, é através dela que os outros recursos se relacionam. Portanto, a construção de uma VerbNet para o português do Brasil era fundamental.

Além disso, vale ressaltar que a VerbNet.Br já foi construída alinhada com a WordNet.Br e o PropBank.Br já está sendo construído com o intuito de facilitar o alinhamento com a VerbNet.Br (que deve ser feito de forma automática, utilizando-se os alinhamentos entre PropBank e VerbNet). Portanto, uma primeira versão do SemLink para o português do Brasil, com alinhamentos entre WordNet.Br, VerbNet.Br e PropBank.Br poderá ser construída sem muito custo.

\subsection{Considerações Finais}

Neste capítulo foram apresentados a estrutura e os componentes do recurso VerbNet que é o modelo de recurso lexical de verbos deste projeto. É neste recurso que esta pesquisa é baseada, com vistas à criação de um recurso semelhante para o português, via a proposta de um método de criação que também é resultado da pesquisa. Além disso, foram apresentadas as extensões deste recurso em relação às classes básicas propostas por Levin (1993). Por fim, foi apresentado um experimento realizado por Kipper (2005), considerando as semelhanças entre a classe Carry do inglês e a tradução de seus membros para o português.

Foram apresentados, também, os recursos relacionados com a VerbNet (wordnets, FrameNet e PropBank) e os trabalhos relacionados para o português do Brasil (WordNet.Br, o projeto de FrameNet para o Brasil e o PropBank.Br). Vale lembrar que a WordNet.Br e a WordNet são de extrema importância para este projeto, dado que seus alinhamentos serão aproveitados para construir a VerbNet.Br.

Também foi apresentado o projeto SemLink que visa o mapeamento entre diversos recursos lexicais. Este projeto é interessante, pois visa tornar prática a interligação entre recursos com características e conteúdos diferentes.

Na Tabela 8 é apresentada uma comparação entre os quatro recursos apresentados neste capítulo. A comparação se dá em cinco aspectos: classes gramaticais que o recurso 
engloba, extração de classes verbais, definição da estrutura predicado-argumento, status do projeto e status do projeto para o português. O recurso mais abrangente é a WordNet, que engloba quatro classes gramaticais. $\mathrm{O}$ único recurso que apresenta a estrutura de classes verbais diretamente e a estrutura predicado-argumento é a VerbNet (nos demais recursos é necessário inferir classes verbais de acordo com os demais relacionamentos entre os verbos e retirar a estrutura predicado-argumento do córpus). A WordNet é mais indicada quando se deseja trabalhar com semântica profunda, tal como, sinonímia, antonímia, hiperonímia, troponímia, etc. O PropBank é útil quando se deseja inferir os papéis semânticos dos argumentos dos verbos. Apesar dos papéis do ProbBank não serem intuitivos (Arg0, Arg1, etc.), esta abordagem é muito útil para aprendizado de máquina. A FrameNet contém uma rica descrição linguística de frames semânticos e é útil quando se deseja saber de quais frames um verbo participa, quais os papéis que ele admite, qual a estrutura sintática padrão para o verbo, etc. Já a VerbNet é útil para saber qual a interface sintático-semântica dos verbos, quais são as realizações sintáticas que levam a uma determinada semântica e como os papéis são posicionados em cada frame.

Tabela 8: Comparação entre os recursos WordNet, PropBank, FrameNet e VerbNet

\begin{tabular}{|c|c|c|c|c|c|}
\hline Recurso & $\begin{array}{c}\text { Classes } \\
\text { gramaticais }\end{array}$ & $\begin{array}{l}\text { Classes } \\
\text { verbais }\end{array}$ & $\begin{array}{l}\text { Estrutura } \\
\text { Predicado - } \\
\text { Argumento }\end{array}$ & Status & Português \\
\hline WordNet & $\begin{array}{l}\text { substantivos, } \\
\text { adjetivos, } \\
\text { advérbios, } \\
\text { verbos }\end{array}$ & indireta & superficial & $\begin{array}{l}\text { Concluída a } \\
\text { classe de } \\
\text { verbos; } \\
\text { classe de } \\
\text { substantivos } \\
\text { em } \\
\text { andamento }\end{array}$ & $\begin{array}{l}\text { em andamento } \\
\text { (WordNet.Br); classe } \\
\text { de verbos terminada e } \\
\text { em fase de avaliação }\end{array}$ \\
\hline PropBank & verbos & indireta & indireta & concluído & $\begin{array}{l}\text { em andamento } \\
\text { (PropBank.Br); } \\
\text { anotação do córpus } \\
\text { Bosque completa e em } \\
\text { fase de criação de } \\
\text { frame files }\end{array}$ \\
\hline FrameNet & $\begin{array}{l}\text { substantivos, } \\
\text { verbos }\end{array}$ & indireta & indireta & $\begin{array}{l}\text { em } \\
\text { andamento }\end{array}$ & $\begin{array}{l}\text { em andamento } \\
\text { (FrameCorp } \\
\text { FrameNet Brasil) }\end{array}$ \\
\hline VerbNet & verbos & direta & direta & concluída & $\begin{array}{lr}\text { primeira } & \text { versão } \\
\text { apresentada } & \text { neste } \\
\text { mestrado (VerbNet.Br) }\end{array}$ \\
\hline
\end{tabular}




\section{CAPÍTULO 4: Estruturas de Subcategorização}

\subsection{Considerações Iniciais}

Neste capítulo, são apresentados trabalhos relacionados à extração e à construção de léxicos com informações de estruturas de subcategorização (subcategorization frames SCFs). Este capítulo traz detalhes importantes, pois na Etapa 2 deste mestrado utilizou-se a ferramenta de extração de SCFs para o Português do Brasil, desenvolvida por Zanette (2010). SCFs são importantes para a melhoria de diversas tarefas de PLN, como, por exemplo, classificação automática de verbos (Ferrer, 2004; Sun and Korhonen, 2009; Sun et al., 2010; Sun et al., 2011) que é apresentada no Capítulo 5. Na Seção 4.2 são apresentados os principais trabalhos (para o inglês e para o francês) que nortearam a construção do sistema para o português. Na Seção 4.3 é apresentado o sistema de extração de SCFs para o Português do Brasil. Por fìm, na Seção 4.4 são apresentadas as considerações finais do capítulo.

\subsection{Sistemas de extração de estruturas de subcategorização para o inglês e para o francês}

Como a abordagem de extração de estruturas de subcategorização para o português do Brasil foi baseada nos sistemas de Briscoe e Carroll (1997) (para o inglês) e Messiant (2008) (para o francês), a descrição destes sistemas se faz necessária. Além disso, dado que os principais sistemas de agrupamento de verbos (Capítulo 5) para o inglês e para o francês utilizam léxicos com informações de SCFs (que foram construídos com os sistemas que são apresentados), uma apresentação destes léxicos também se faz necessária. Na Seção 4.2.1 são apresentados o sistema de Briscoe e Carroll (1997) e o léxico gerado a partir deste sistema para o inglês (Korhonen et al., 2006). Na Seção 4.2.2 são apresentados o sistema de Messiant (2008) e o léxico gerado para o francês (Messiant et al., 2008).

\subsubsection{Estruturas de subcategorização para o inglês}

Geralmente, um sistema de extração de SCFs trata de verbos, não diferencia sentidos de verbos e tratam de aspectos sintáticos dos frames (tipo, número e/ou frequência relativa dos SCFs para um dado verbo) (Korhonen et al., 2006). O trabalho de Briscoe e 
Carroll (1997) é o mais utilizado na tarefa de extração de estruturas de subcategorização para a língua inglesa. Este sistema pode ser dividido em seis partes:

1. Tagger;

2. Lematizador;

3. Parser probabilístico;

4. Extrator de conjunto de padrões - responsável por extrair os SCFs para cada verbo;

5. Classificador de padrões - classifica os SCFs em classes de subcategorização (subcategorization classes) pré-definidas (ou rejeita padrões que não são classificados);

6. Analizador de padrões - avalia os SCFs selecionados para cada verbo, filtrando os SCFs candidatos de acordo com a probabilidade desses SCFs.

Dado que o tagger, o lematizador e o parser utilizados foram ferramentas consolidadas, as três últimas partes são as de interesse.

O extrador de conjunto de padrões recebe a saída do parser e identifica o verbo e os argumentos (sujeito e o objetos) de cada sentença. As construções passivas são marcadas separadamente. Esta etapa informa o verbo, o frame, a construção preposicional (se houver) e os núcleos dos argumentos.

As 160 classes utilizadas pelo classificador de padrões foram, em sua maioria, extraídas dos dicionários sintáticos ANLT (Boguraev e Briscoe., 1987) e COMLEX (Grishman et al., 1994) - construídos manualmente - e cerca de 30 classes foram definidas após análise manual dos padrões que não puderam ser classificados pelas demais classes. Estas classes definem os padrões de SCFs possíveis para os verbos (por exemplo, dois padrões para o verbo "comprar" seriam SN V SN e SN V SN SP, com o SP podendo ser parametrizado com a preposição "para”).

$\mathrm{O}$ analisador de padrões avalia os SCFs identificados de acordo com o número de vezes que cada padrão aparece relacionado com cada verbo (considerando as probabilidades de ocorrência de cada SCF). 
Para avaliar o sistema desenvolvido, Briscoe e Carroll (1997) utilizaram o córpus Susanne (Sampson, 1995), com 1,2 milhões de palavras e escolheram de forma aleatória quatorze verbos para análise comparativa com os dicionários ANLT e COMLEX e, destes quatorze verbos, selecionaram sete para análise manual no córpus (dado que nem todas as classes de subcategorização foram derivadas dos dicionários). Calcularam precisão (porcentagem de classes de subcategorização corretas para todas as classes) e abrangência (porcentagem de classes corretas nos dicionários ou no córpus). A precisão e abrangência para os quatorze verbos considerando os dicionários foram de 65,7\% e 35,5\%, respectivamente. Já a precisão de abrangência para os sete verbos considerando a análise manual do córpus foram de $76,6 \%$ e $43.4 \%$, respectivamente.

O sistema de Briscoe e Carroll (1997), com as alterações semânticas propostas por Korhonen (2002) e Korhonen e Preiss (2003), foi utilizado para a construção do VALEX, um léxico de subcategorização (de verbos) para o inglês (Korhonen et al., 2006). Foram selecionados 6.433 verbos dos quais: 5.583 aparecem no COMLEX ou no ANLT e 850 são os verbos mais frequentes do British National Corpus (BNC) (Leech, 1992). Para extrair as informações de SCFs foram utilizados cinco córpus: BNC, The North American News Text Corpus (NANT) (Graff, 1995), The Guardian ${ }^{37}$ corpus, The Reuters corpus (Rose et al., 2002) e os dados utilizados para as duas Text Retrieval Evaluation Conferences ${ }^{38}$ (TREC-4 e TREC-5). Foram selecionadas, pelo menos, 250 sentenças por verbo. Nos casos em que apareceram menos de 250 sentenças em todos os córpus, foram extraídas sentenças adicionais da WEB. Ao final, o léxico contém 212.741 SCFs (33 SCFs por verbo, na média). Assim como na avaliação do trabalho de Briscoe e Carroll (1997), foi realizada uma análise manual de dados do córpus (183 verbos no total). O melhor resultado obtido de $f$-measure foi de $87,3 \%$ com precisão e abrangência de $93,1 \%$ e $82,2 \%$, respectivamente para o caso dos 183 verbos. Quando os resultados foram comparados com os do ANLT e do COMLEX o melhor resultado de $f$-measure foi de $57,3 \%$ com precisão e abrangência de $58,6 \%$ e $56 \%$, respectivamente.

\footnotetext{
${ }^{37} \mathrm{http}: / /$ www.guardian.co.uk/

${ }^{38} \mathrm{http}: / /$ trec.nist.gov/data/docs_eng.html
} 


\subsubsection{Estruturas de subcategorização para o francês}

Messiant (2008) adaptou o trabalho de Briscoe e Carroll (1997) para o francês. Este sistema é dividido em quatro partes:

1. Primeiramente, o córpus cru é etiquetado (utilizando um tagger) e depois é fornecido como entrada para um parser sintático.

2. Depois, o extrator de padrões seleciona os verbos com mais de 200 ocorrências e busca os padrões sintáticos de cada verbo.

3. O construtor de SCFs define as categorias sintáticas de cada parte dos padrões sintáticos (por exemplo, sintagmas nominais). Assim, este módulo define os SCFs e calcula a frequência de cada SCF e de cada par verbo+SCF. Como não existia um dicionário de frames para o francês (assim como existia para o inglês), não foi implementada a etapa do classificador de padrões (como no sistema de Briscoe e Carroll (1997)).

4. Por fim, a etapa de filtro de SCFs seleciona os SCFs de acordo com a medida Maximum likelihood (MLE). Esta medida é a razão entre a frequência de ocorrência do par verbo+SCF e a frequência do verbo.

Este sistema deu origem ao LexSchem: léxico de subcategorização (de verbos) para o francês (Messiant et al., 2008). Para a criação deste léxico, foi utilizado o córpus LeMonde com 200 milhões de palavras. Para avaliação foi construído um gold standard com 20 verbos. A f-measure obtida foi de $65 \%$, com $79 \%$ de precisão e $55 \%$ de abrangência.

\subsection{Extrator de estruturas de subcategorização para 0 português do Brasil}

O sistema desenvolvido por Zanette (2010) é baseado nos sistemas de Briscoe e Carroll (1997) (utilizando a versão utilizada em Korhonen et al., 2006 para a construção do VALEX) e Messiant (2008). O sistema de Zanette (2010) foi desenvolvido utilizando a linguagem Python ${ }^{39}$ e o sistema gerenciador de banco de dados MySQL ${ }^{40}$. Este sistema já

\footnotetext{
${ }^{39} \mathrm{http} / / / \mathrm{www} \cdot$ python.org/

${ }^{40} \mathrm{http}: / /$ www.mysql.com/
} 
passou por alterações (algumas específicas para este mestrado) como as descritas em Zanette et al. (2012) e Zilio et al. (2012). Aqui é apresentada a versão atual. Assim como o sistema de Messiant (2008), o sistema de Zanette (2010) é dividido em quatro módulos, apresentados nas próximas seções, seguida da avaliaçao do sistema.

\subsubsection{Pré-processador}

O pré-processador recebe um córpus cru e processa cada texto morfossintaticamente. Nesta etapa, foi utilizado o parser PALAVRAS (Bick, 2000). A saída do parser utilizada foi a flat, com informações de dependência. Um exemplo desta saída é apresentado na Figura 11 para a sentença: "O mesmo espírito irrequieto e empreendedor caracteriza José Reis e Ennio Candotti." (retirada do córpus Lácio-Ref ${ }^{41}$ (Aluísio et al., 2004)).

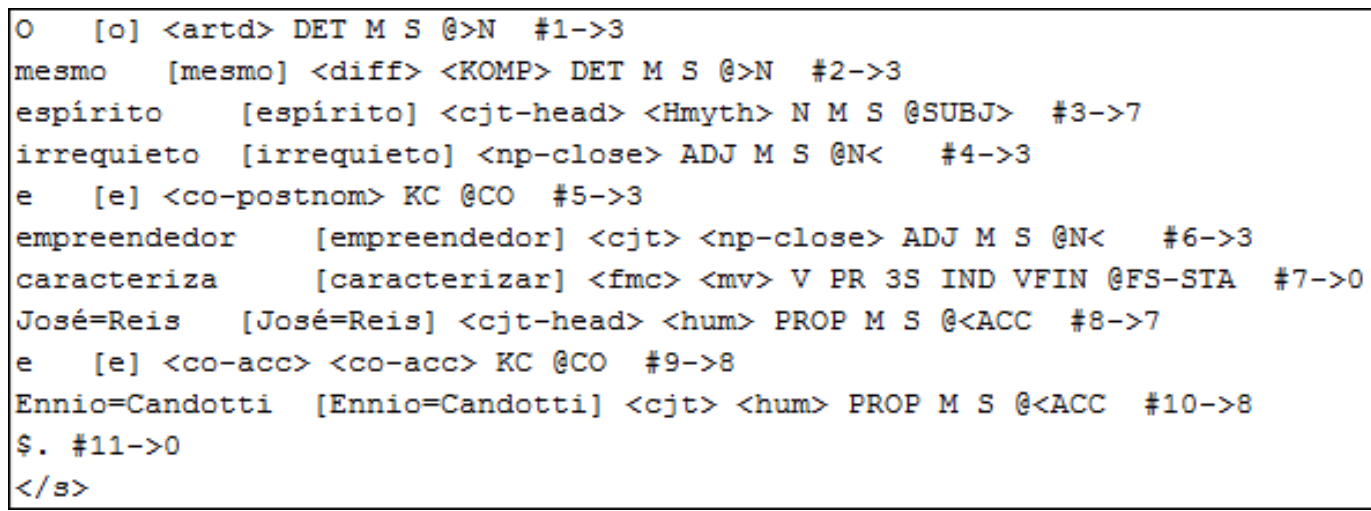

Figura 11: Saída Flat do parser PALAVRAS

É possível observar que cada linha da Figura 11 representa um token da sentença (alguns tokens são agrupados, como é o caso de José=Reis e Ennio=Candotti que são entidades mencionadas ${ }^{42}$ ). A frente do token é apresentada a análise morfossintática e as dependências (marcadas após o símbolo “\#”). A partir destas marcações de dependências, é possível construir uma árvore de dependências. A árvore de dependências para a sentença da Figura 11 é apresentada na Figura 12.

\footnotetext{
${ }^{41} \mathrm{http}: / /$ www.nilc.icmc.usp.br/lacioweb/index.htm

${ }^{42}$ Entidades mencionadas (Named Entities) são unidades que representam nomes (pessoas, organizações ou lugares) ou expressões numéricas (tempo, data, dinheiro e porcentagens) (Nadeau e Sekine, 2007).
} 


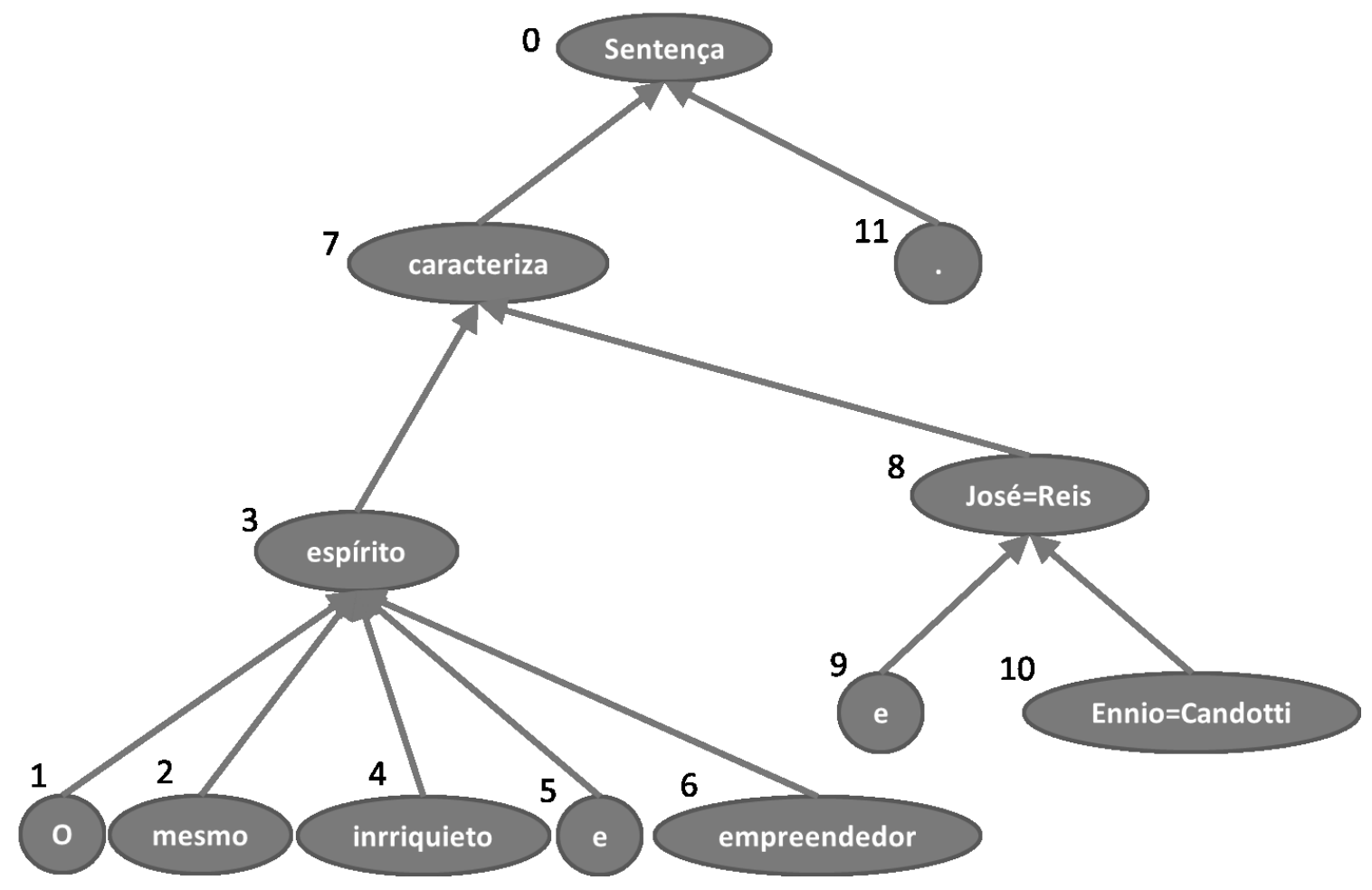

Figura 12: Árvore de dependências

É possível observar na Figura 12 que os tokens "espírito" e "José=Reis" estão diretamente ligadas ao verbo "caracterizar" que está ligado à raiz da sentença. Na Figura 11, observando as anotações após o símbolo “@” para os tokens "espírito" e "José=Reis", tem-se que o primeiro possui a etiqueta “@SUBJ>” que indica o núcleo do sujeito do verbo e o segundo possui a etiqueta “@<ACC” que indica o núcleo do argumento do verbo.

A partir destas informações morfossintáticas e de dependência é que o Extrator de SCFs extrai os frames.

\subsubsection{Extrator de SCFs}

O Extrator de SCFs retira os itens da árvore de dependências que posteriormente poderão se tornar SCFs. Algumas ressalvas sobre esta etapa:

- Todos os verbos do córpus são considerados (não somente alguns verbos alvo, como nos trabalhos de Korhonen et al., 2006 e Messiant, 2008);

- Não é feita distinção entre complementos verbais e adjuntos adverbais (assim como em Messiant, 2008), porque não existe um estudo consolidado nesta área para o português. 
Para fazer a extração, primeiramente, identifica-se o verbo e depois se busca pelos constituintes ligados a este verbo. Os constituintes ligados ao verbo serão posteriormente analisados pelo Construtor de SCFs. Nesta etapa, informações sobre o verbo e suas ocorrências no córpus são armazenadas no banco de dados.

\subsubsection{Construtor de SCFs}

O Construtor de SCFs utiliza os constituintes identificados pelo Extrator de SCFs para a construção do frame. Lembrando que os argumentos dos verbos são todos os constituintes que estiverem ligados ao verbo e marcados como "ACC", no caso de objeto direto ou "PIV", no caso de objeto indireto. Também são considerados o lema da preposição e o complemento do sintagma preposicional. Logo, os constituintes podem ser (Zanette et al., 2012):

- $\mathrm{V}[\mathrm{x}]$ : o verbo principal, com as ênclises definidas - por exemplo: "me" em "dá-me o livro";

- SUBJ[SN]: sujeito da sentença com um sintagma nominal como núcleo;

- SUBJ[oculto]: sujeito da sentença é oculto;

- SN: sintagmas nominais;

- ADJP: sintagmas adjetivos;

- SP[prep]: sintagmas preposicionados - prep é a preposição núcleo do sintagma.

Informações sobre o frame e as ocorrências do mesmo são armazenadas no banco de dados. Exemplos de frames para o verbo "comprar" são apresentados na Tabela 9 (os exemplos são retirados do córpus PLN-BR ${ }^{43}$ (Bruckschen et al., 2008)).

Tabela 9: Exemplos de frames para o verbo "comprar"

\begin{tabular}{|l|l|}
\hline \multicolumn{1}{|c|}{ Frame } & \multicolumn{1}{c|}{$\begin{array}{c}\text { Sentença } \\
\text { "Os iranianos, com maior entusiasmo, compraram uma fábrica } \\
\text { de bicicletas." }\end{array}$} \\
\hline SUBJ[SN]_V_SN_SP[para] & $\begin{array}{l}\text { "Depois de o garçom, Jan comprou outros brinquedos para o } \\
\text { filho." }\end{array}$ \\
\hline SUBJ[SN]_V_SN_SP[por] & $\begin{array}{l}\text { "Empresário compra Monza GLS por Cr\$5,3 milhões, mas } \\
\text { empresa só dá recibo de Cr\$4,2 milhões." }\end{array}$ \\
\hline SUBJ[oculto]_V_SN & "Comprei camisas do Flamengo e do Santos." \\
\hline
\end{tabular}

\footnotetext{
${ }^{43}$ http://www.nilc.icmc.usp.br/plnbr/
} 
Os argumentos e informações sobre os argumentos do verbo, tais como, posição na sentença, tipo do argumento (objeto direto, objeto indireto ou sujeito) e classificação sintática, também são armazenados.

\subsubsection{Filtro de SCFs}

Como todos os passos do sistema são automáticos, o Construtor de Frames produz muitos resultados espúrios. Seguindo a hipótese de Messiant (2008), de que "argumentos verdadeiros tendem a ocorrer em posições de argumentos mais frequentemente do que adjuntos" (Zanette, 2010 p. 34), espera-se que os frames de alta frequência sejam os corretos. Consequentemente, existem filtros (que são definidos como parâmetros do sistema) para eliminar as entradas de baixa frequência:

- Filtro de frequência absoluta de verbos: elimina verbos com baixa frequência;

- Filtro de frequência absoluta de frames: elimina frames com baixa frequência;

- Filtro de frequência relativa de frames: elimina frames com baixa frequência considerando os verbos.

Neste mestrado, foram utilizados os filtros de frequência absoluta de verbos e frames (foram considerados verbos com frequência superior a dez e frames com frequência superior a cinco). Apesar de os valores dos filtros serem pequenos, seguiu-se os resultados de Korhonen et al. (2003) que, em alguns casos, os ruídos dos frames podem conter informações úteis (assim como observado por Korhonen et al. (2003) para agrupamento de verbos).

\subsubsection{Avaliação}

A primeira versão da ferramenta (apresentada em Zanette (2010)), considerava o formato de árvores deitadas do PALAVRAS para a extração dos frames. Esta escolha foi tomada, inicialmente, para utilizar o córpus BOSQUE da Floresta Sintá(c)tica (Afonso et al., 2002). O autor decidiu por este córpus, pois ele possui anotação automática pelo PALAVRAS, corrigida manualmente por linguistas. Portanto, a avaliação da ferramenta seria menos penalizada com os possíveis erros do parser. 
Para a avaliação, foi necessário, também, utilizar uma lista de referências com informações de SCFs. Dado que inexiste para o português uma lista específica com estas características, foi utilizado o Léxico do NILC (Muniz, 2004) que contém mais de 1,5 milhões de entradas flexionadas para o português. Para cada entrada, há informações sobre as categorias que os verbos podem apresentar (INT: intransitivo, TD: transitivo direto, TI: transitivo indireto e BI: bitransitivo) e sobre as preposições que os sintagmas preposições (se houver) podem assumir. Na Figura 13 (retirada de Zanette (2010) p.27) é apresentada a entrada do verbo "armar" neste léxico.

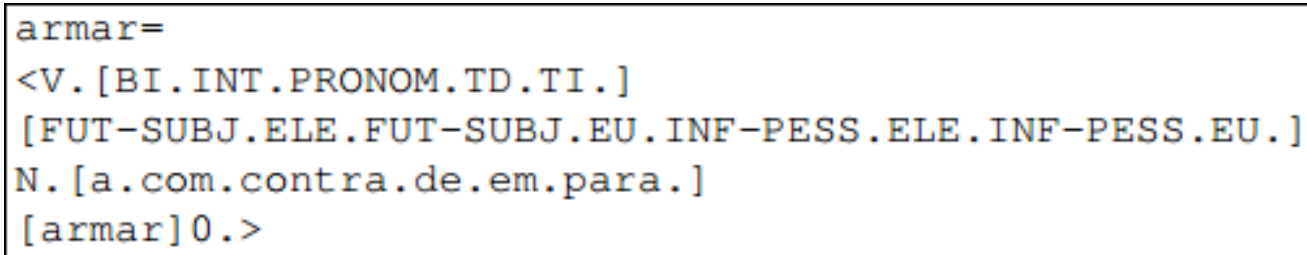

Figura 13: Exemplo de entrada para o verbo "armar" no Léxico do NILC (retirada de Zanette (2010) p.27)

É possível observar na Figura 123que o verbo armar possui as quatro classes (INT, TD, TI e BI). Assim sendo, as possíveis combinações de argumentos (desconsiderando a informação de sujeito), podem ser (Figura 14 retirada de Zanette (2010) p. 40):

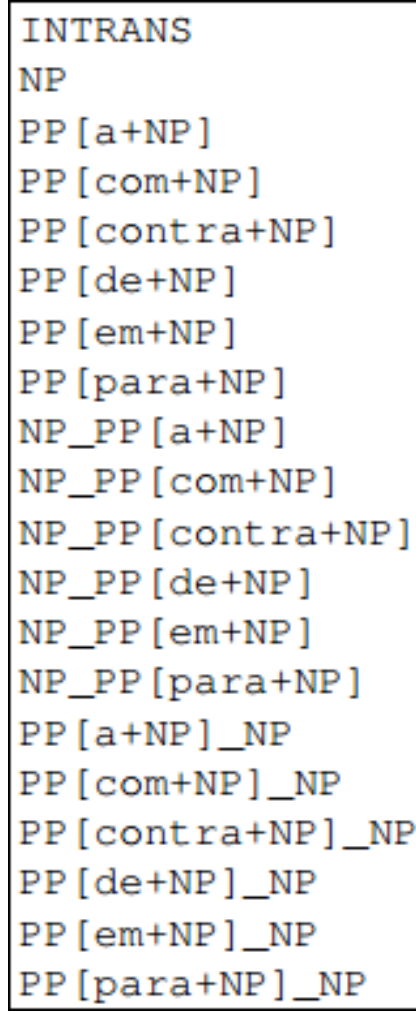

Figura 14: Lista de possíveis argumentos (objetos) do verbo "armar" 
$\mathrm{Na}$ Figura 14, considere SP[prep+SN] igual a SP[prep]_SN. Logo, é possível observar que existem 20 possíveis SCFs para o verbo armar.

A avaliação foi realizada nos seguintes cenários: (1) sem filtragem; (2) filtro de frequência absoluta dos verbos; (3) filtro de frequência absoluta dos frames; e (4) filtro de frequência relativa dos frames. O melhor resultado para $f$-measure foi de $28 \%$ no quarto cenário. Considerando somente os 20 verbos mais frequentes no córpus, a $f$-measure foi de $41,3 \%$. Realizando uma filtragem nos verbos auxiliares, a f-measure subiu para $50,6 \%$.

\subsection{Considerações Finais}

Neste capítulo foram apresentados sistemas de extração de estruturas de subcategorização que motivaram a construção do sistema de extração de SCFs para o português. Sabe-se que existem mais trabalhos nesta área: como os pioneiros Brent (1993), Ushioda et al. (1993) e Manning (1993) para o inglês e o novo método proposto por Lippincott et al. (2012) também para o inglês, porém, dado que esta literatura é extensa e não é o foco principal deste mestrado, decidiu-se focar somente nas ferramentas e recursos diretamente relacionados com a ferramenta desenvolvida por Zanette.

Um trabalho que merece ser citado é o de McCarthy e Korhonen (1998) que propõem a identificação de alternâncias sintáticas utilizando estruturas de subcategorização e preferências seletivas. As estruturas de subcategorização são obtidas seguindo o método de Briscoe e Caroll (1997). As preferências seletivas são identificadas para os verbos calculando association scores - calculados a partir da frequência de substantivos ocorrendo com o verbo em questão e ocorrendo independente do verbo. No doutorado de McCarthy (2001) é explorada mais profundamente esta tarefa. No caso deste mestrado, contudo, não havia tempo hábil para um estudo completo como o de McCarthy (2001), o que justifica a simplificação da tarefa, que foi considerar somente os frames sintáticos identificados pela ferramenta para a Etapa 2.

Outro trabalho que também merece ser citado é a ferramenta IRASubCat (Altamirano e Alonso i Alemany, 2010). Os autores propõem a extração de estruturas de subcategorização para qualquer língua, a partir de córpus, com informações formatadas no padrão XML, exigido pela ferramenta. As informações são flexíveis e a única informação obrigatória é a anotação do verbo. Caso somente esta informação seja fornecida, o sistema 
identifica os SCFs de acordo com a forma das palavras. Caso mais informações sejam fornecidas, o sistema utiliza estas informações para identificar os SCFs. Vale comentar que estas informações podem ser de qualquer tipo, tais como, morfológicas, sintáticas, semânticas, entre outras. O usuário é responsável por definir quais informações utilizar. Além disso, o usuário também pode definir os limiares para selecionar os SCFs, os verbos que serão utilizados, entre outros filtros. Os autores também propõem uma solução para distinção de adjuntos e complementos baseada na frequência destes constituintes. Constituintes mais frequentes tem maior probabilidade de serem complementos, enquanto que adjuntos são menos frequentes. O melhor resultado obtido para esta ferramenta foi de $74 \%$ de $f$-measure, avaliada no córpus SenSem (Catellón et al., 2006), considerando os 20 verbos mais frequentes e anotações manuais para comparação. Decidimos por utilizar o trabalho de Zanette (2010) e não este, pois Zanette desenvolveu uma ferramenta específica para o português. Além disso, dado o tempo e escopo deste mestrado, a ferramenta de Zanette (2010) se tornou a escolha mais simples. Primeiro, porque recebe como entrada com texto processados pelo parser PALAVRAS sem necessitar de pré-processamento. Segundo, porque se estabeleceu uma parceria com o aluno de mestrado Adriano Zanette (criador da ferramenta) e o aluno de doutorado Leonardo Zilio (responsável pelas definições teóricas da ferramenta), ambos da Universidade Federal do Rio Grande do Sul (UFRGS). Esta parceria foi fundamental para o uso da ferramenta e melhoria da mesma ${ }^{44}$.

\footnotetext{
${ }^{44}$ Esta parceria com pesquisadores da UFRGS foi viabilizada graças à visita técnica financiada pela FAPESP
} 


\section{CAPÍTULO 5: Trabalhos computacionais com classes verbais}

\subsection{Considerações Iniciais}

Neste capítulo é reservado um espaço para a discussão de trabalhos com classes verbais para outras línguas além do inglês. Como os trabalhos aqui apresentados em sua maioria diferem do método e da organização proposta por Kipper (2005), uma seção sobre trabalhos para o inglês seguindo métodos diferentes também se fez necessária. Na Seção 5.2 são apresentados os trabalhos para a língua francesa. Na Seção 5.3 são apresentados os trabalhos para o espanhol. Na Seção 5.4 são apresentados os trabalhos para o italiano. Na Seção 5.5 são apresentados os trabalhos para a língua japonesa. Na Seção 5.6 são apresentados os trabalhos para o alemão. Na Seção 5.7 são apresentados os trabalhos para a língua inglesa que seguem métodos diferentes do trabalho de Kipper (2005). Por fim, na Seção 5.8 são apresentadas as considerações finais.

\subsection{Trabalhos para o francês}

O trabalho de Saint-Dizier (1996) reformula o trabalho de Levin (1993) com foco em PLN. A noção de 'alternâncias' de Levin (1993) é substituída pelo conceito de 'contexto' (context). Um contexto é um frame que usa a categoria e algumas informações sintáticas para representar a forma e posição que os argumentos de um verbo devem ter em uma sentença. As classes verbais são formadas pelo conjunto de verbos que compartilham os mesmos contextos.

Saint-Dizier (1996) justifica o uso de contextos no lugar de alternâncias, pois com eles não é necessária a definição de uma forma básica da qual as alternâncias são derivadas e também não é necessário estabelecer as relações entre a forma básica e as alternâncias. Além disso, com contextos não é necessário levar em conta as mudanças de sentidos provocadas pelas alternâncias. Os contextos são encontrados através de busca em córpus.

Para a divisão de verbos em classes, Saint-Dizier (1996) considera que para os verbos pertencerem a uma mesma classe eles devem aceitar, exatamente, o mesmo conjunto de contextos. Esta classificação se difere da classificação proposta por Levin 
(1993), pois nela as classes verbais são constituídas de subconjuntos de alternâncias, selecionadas intuitivamente. A classificação semântica das classes é similar à classificação proposta na WordNet.

Outro trabalho para a língua francesa que merece ser citado é o de Sun et al. (2010). Neste trabalho há a proposta da construção de uma VerbNet para o francês utilizando técnicas de agrupamento de dados e um gold standard composto de dezessete classes de Levin (1993) (para a língua inglesa), cada classe possuindo doze membros cujos sentidos predominantes (segundo a WordNet) pertencem a classe.

O gold standard é utilizado para avaliar qualitativamente os grupos de dados, para isso foi necessário um método de criação desse gold standard para o francês a partir do trabalho de Sun et al. (2008) que propôs um gold standard para o inglês com dezessete classes de Levin (1993), cada classe com doze membros. O método utilizado é apresentado a seguir:

- Primeiro, traduziu-se todos os membros para o francês, considerando todas as possíveis traduções;

- Para cada verbo candidato, foram identificadas as alternâncias sintáticas buscando seguir o critério de Levin (1993): as alternâncias sintáticas devem levar a um mesmo sentido verbal ou a um sentido estendido;

- Somente verbos que compartilhavam as mesmas alternâncias sintáticas foram mantidos na classe.

Seguindo este método, $40 \%$ das traduções foram descartadas, pois não apresentavam todas as alternâncias sintáticas. $\mathrm{Na}$ versão final, o gold standard para o francês possui 171 verbos em dezesseis classes, em que a menor classe inclui sete verbos e a maior classe dezesseis.

Para o experimento de agrupamento de verbos foram considerados atributos (léxicos, sintáticos e semânticos) extraídos de um córpus em francês (a base LexSchem (Messiant et al., 2008) com estruturas de subcategorização para 3.297 verbos em francês). O método de agrupamento utilizado foi o spectral clustering (que já havia sido utilizado para o inglês e para o alemão). O melhor desempenho foi de $64,5 \%$ de $f$-measure que, segundo os autores, é inferior aos resultados para o inglês (para a língua inglesa, tem-se 
$80,35 \%$ de $f$-measure com o mesmo algoritmo, porém com uma base de dados cerca de duas vezes maior - a base VALEX (Korhonen et al., 2006) 6.397 verbos em inglês).

\subsection{Trabalhos para o espanhol}

O trabalho de Vázquez et al. (2000) é uma compilação dos verbos em espanhol, classificados de acordo com suas alternâncias sintáticas, seguindo a mesma hipótese de Levin (1993). Apesar de ser um trabalho realizado manualmente (como o trabalho de Levin (1993)), ele merece ser citado por dois motivos: primeiro porque se assemelha ao trabalho de Levin (1993) e é um dos únicos trabalhos completos para uma língua diferente do inglês; segundo, pois ele é usado como recurso de avaliação para o trabalho de Ferrer (2004) que propõe o uso de agrupamento para a classificação de verbos.

No trabalho de Ferrer (2004) são utilizadas estruturas de subcategorização como recurso para extração de atributos para a tarefa de agrupamento de verbos. A hipótese que rege o trabalho é semelhante à hipótese dos demais trabalhos de classificação verbal: a descrição dos verbos em termos de seus comportamentos sintáticos é útil para alcançar suas propriedades semânticas.

Os atributos utilizados no trabalho foram as probabilidades de ocorrência das estruturas de subcategorização de cada verbo. Para extrair esses atributos, foi realizada uma busca por padrões compostos de verbos e os constituintes que co-ocorrem com esses verbos considerando dois córpus da língua espanhola. Porém, nem todos os padrões correspondem aos padrões desejados para as estruturas de subcategorização. Primeiro, porque alguns padrões contêm adjuntos no lugar de constituintes. Segundo, porque alguns padrões contêm elementos que não estão relacionados com o verbo. Por fim, porque o processo de extração ou o córpus utilizado pode conter erros. Portanto, é necessário filtrar os dados extraídos. Neste trabalho foi utilizada a medida Maximum Likelihood Estimate $(M L E)$ que consiste na razão da soma verbo ${ }_{i}+$ padrão $_{i}$ pela frequência de verbo ${ }_{i}$. Em que verbo $_{i}$ é a frequência de um dado verbo e padrão ${ }_{i}$ é a frequência de um dado padrão.

Após a extração das probabilidades das estruturas de subcategorização de cada verbo, estas são utilizadas como atributos para a tarefa de agrupamento de dados. A intenção do trabalho foi chegar a uma divisão natural dos dados que concordasse com a classificação dos verbos do trabalho de Vázquez et al. (2000). A autora utilizou duas 
medidas para avaliação do trabalho. A primeira foi a Adjusted Rand measure que mede a concordância de duas partições: uma que é dada pelo processo de agrupamento de dados e outra que é dada por critérios externos. Os valores dessa medida variam de 1 a -1 em que 1 significa total concordância entre as partições e -1 significa total discordância. No caso do trabalho de Ferrer (2004) a partição externa são as classes definidas manualmente no trabalho de Vázquez et al. (2000). A segunda medida foi a Silhouette measure que serve para indicar a consistência dos grupos obtidos, independente da divisão dos dados na versão manual. $\mathrm{O}$ melhor desempenho apresentou 0,07 para adjusted rand measure e 0,37 para silhouette measure. Segundo os autores, estes resultados são inferiores aos resultados apresentados para o alemão em Schulte im Walde (2003) (0,15 para adjusted rand measure) e comparáveis com os resultados para o inglês de Stevenson e Joanis (2003) $(0,04$ e 0,07 para adjusted rand measure $)$.

\subsection{Trabalhos para o italiano}

O trabalho de Merlo et al. (2002) descreve um método para a classificação supervisionada de verbos, seguindo uma abordagem proposta para o inglês (Merlo e Stevenson, 2001). Neste trabalho, é realizado um experimento considerando três classes do inglês: verbos que expressam mudança de estado (change of state), verbos que possuem a alternância de perda de objeto (object drop) e verbos psicológicos (psych verbs) que correspondem a três grandes classes de Levin (1993) (45, 26 e 31, respectivamente). Para cada classe foram selecionados 20 verbos em italiano que correspondessem às classes. Como atributos, foram considerados: definição se o sujeito é animado ou não (ANIM), frequência relativa do uso transitivo do verbo (TRANS) e uso do verbo em construções causativas (CAUS). Estes atributos foram retirados de um córpus da língua italiana. O algoritmo de aprendizado supervisionado utilizado foi o C5.0 (uma nova versão do tradicional algoritmo de árvores de decisão C4.5) com os métodos de treinamento e teste crossvalidation e leave-one-out.

O melhor resultado para a classe de verbos psicológicos foi de $89 \%$ de $f$-measure considerando todos os atributos. O melhor resultado para a classe de verbos de mudança de estado foi de $93 \%$ de $f$-measure considerando todos os atributos. E o melhor resultado para a classe de verbo de perda de objeto foi de $81 \%$ de $f$-measure também considerando todos os atributos. O resultado para a classe de verbos que admitem perda de objeto pode ser 
comparado com o resultado para o inglês de Merlo e Stevenson (2001) que foi inferior ao apresentado para o italiano (64,9\% de $f$-measure) .

\subsection{Trabalhos para o japonês}

O trabalho de Takeuchi et al. (2010) descreve a criação de um thesaurus que tem como base o compartilhamento de significados a partir da estrutura predicado-argumento. $\mathrm{Na}$ estrutura proposta, uma classe verbal (que é uma classe conceitual) possui verbos que compartilham o significado. Uma classe 'pai' possui conceitos da classe 'filha', sendo a classe 'filha' uma concretização dos verbos da classe 'pai'.

A metodologia de construção utilizou duas abordagens. A primeira bottom up utilizou sentidos verbais definidos em um dicionário como os sentidos mais refinados da hierarquia, e agrupou os verbos que poderiam compartilhar algum sentido. A segunda top down considerou três classes: state, change of state e activity como as classes de mais alto nível na hierarquia.

As classes no nível intermediário da hierarquia foram definidas agrupando sentidos verbais com base na categoria aspectual (ação, estado,...), no tipo de argumento (físico, mental,...) e em aspectos mais detalhados dependendo da categoria aspectual.

Para cada classe verbal foram incorporadas estruturas para descrever as relações semânticas que são sintaticamente motivadas e significados vinculados que poderiam expandir o thesaurus.

Neste trabalho, os autores descrevem uma comparação do thesaurus com um córpus anotado manualmente para descobrir como o recurso proposto cobre os sentidos presentes em notícias de jornal e o resultado foi de $84,32 \%$ para abrangência.

\subsection{Trabalhos para o alemão}

O trabalho de Schulte im Walde e Brew (2002) apresenta experimentos iniciais com classes verbais para o alemão. Neste trabalho, foram classificados 57 verbos em quatorze classes (utilizando agrupamento de verbos) que foram comparadas com classes anotadas manualmente.

Uma extensão deste trabalho é apresentada em Schulte in Walde (2006). Neste trabalho é feito um experimento considerando a tarefa de agrupamento comparada com 
186 verbos classificados em 53 classes (um gold standard anotado manualmente baseado na classificação para o inglês proposta por Levin (1993) e de acordo com a classificação de verbos do alemão proposta por Schumacher (1986)).

Como atributos para a tarefa de agrupamento de verbos foi utilizado um modelo estatístico de gramática. São consideradas as distribuições de três níveis de características verbais: (a) a definição puramente sintática das estruturas de subcategorização, (b) a definição sintático-semântica das estruturas de subcategorização e das preferências preposicionais, e (c) a definição sintático-semântico das estruturas de subcategorização com preferências preposicionais e preferências seletivas. $\mathrm{O}$ algoritmo de agrupamento de dados utilizado foi o tradicional $k$-means. A autora realiza diversos experimentos considerando os três níveis de características verbais e outros fatores que influenciam na tarefa (a discussão dos resultados obtidos está fora do escopo deste mestrado).

\subsection{Trabalhos para o inglês}

Pesquisas para a língua inglesa são tradicionais na área de PLN. Como foi apresentado no Capítulo 3, existe uma grande quantidade de recursos léxicos verbais para esta língua. Da mesma forma, existem diversos trabalhos com classes verbais para o inglês. Um deles, apresentado na Seção 2.4 do Capítulo 2, é o estudo das classes verbais de Levin (1993). Porém, Levin realizou um estudo manual e existem diversas iniciativas para automatizar este tipo de tarefa. Outro trabalho, obviamente, é a VerbNet que se utilizou das classes de Levin (1993) para construir um recurso léxico verbal, mas também foi realizado, em grande parte, manualmente. Mas, existem outras iniciativas para o inglês que merecem ser citadas e nesta seção são apresentadas algumas delas.

O trabalho de Merlo e Stevenson (2001) propõe a classificação automática de verbos baseada na distribuição estatística da estrutura argumental. As autoras consideraram as três grandes classes dos verbos opcionalmente intransitivos no inglês: inergativo (unnergative), inacusativo (unaccusative) e perda de objeto (object-drop). Como atributos foram considerados: o número de vezes que o verbo aparecia na forma transitiva ou intransitiva, o número de vezes que o verbo aparecia na voz ativa ou na voz passiva, o número de usos do verbo no particípio passado ou no passado simples, o número de usos do verbo de forma causativa ou não causativa e o número de vezes que o sujeito do verbo 
era animado ou não. Foram considerados 59 verbos (quase 20 para cada classe) para treinamento e o algoritmo utilizado foi o C5.0 (que é uma nova versão do tradicional algoritmo de árvore de decisão $\mathrm{C} 4.5$ ). $\mathrm{O}$ treinamento e o teste foram feitos seguindo dois métodos: 10-fold-cross-validation e single hold-out. O melhor resultado foi apresentado utilizando o método 10-fold-cross-validation e considerando todos os atributos $(69,8 \%$ de acurácia). Considerando as três classes, os melhores resultados obtidos foram $78,1 \%$ de $f$ measure para classe dos verbos inergativos, $75,7 \%$ de $f$-measure para a classe de verbos inacusativos e $64,9 \%$ de $f$-measure para a classe de verbos que admitem perda de objeto. Vale comentar que as autoras definem como trabalho futuro a inclusão de atributos que considerem os papéis semânticos dos argumentos dos verbos.

O trabalho de Joanis e Stevenson (2003) propõe uma extensão ao trabalho de Merlo e Stevenson (2001). Os autores consideraram os atributos: frequência dos slots sintáticos que contém argumentos de verbos (sujeito, objeto direto ou indireto e sintagmas preposicionais), sobreposição desses slots de acordo com a parte I do livro de Levin (1993), número de vezes que o verbo aparecia na voz ativa ou na voz passiva, número de usos do verbo no particípio passado ou no passado simples, tempo verbal, contagem de verbos auxiliares ou advérbios que influenciam na voz e no aspecto verbal, e animacidade dos argumentos do verbo. Utilizaram 835 verbos em quinze classes de Levin (1993) como dados de treinamento. $\mathrm{O}$ algoritmo de aprendizado de máquina supervisionado utilizado foi o C5.0 (uma nova versão do tradicional algoritmo de árvore de decisão C4.5). O método de treinamento e teste utilizado foi 10-fold-cross-validation. Obteve-se um resultado de $58,6 \%$ de acurácia considerando todos os atributos.

Kingsbury e Kipper (2003) utilizaram o algoritmo k-means para medir a similaridade entre as classes da VerbNet e os grupos de verbos. Para geração dos grupos de verbos foi utilizado o córpus do PropBank e os frames sintáticos definidos neste córpus. Em (75) e (76), retirados de Kipper (2005), é possível observar como é a forma dos frames.

Arg0.rel.Arg1

John felt a bump (John sentiu um solavanco)

(76) Arg1.rel

The butter softened (A manteiga amoleceu) 
Como dado de entrada para o algoritmo de agrupamento de dados é dada uma matriz com o sentido do verbo e a frequência com que ele participa dos frames. Na Figura 15 é apresentado um trecho exemplo da matriz de entrada (figura retirada do trabalho de Kipper (2005)). Vale comentar que somente os sentidos que aparecem mais de dez vezes no córpus foram considerados.

\begin{tabular}{|l|r|r|r|r|}
\hline verb sense & Arg0.rel.Arg1 & rel.Arg1 & Arg1.rel & Arg0.rel.Arg1.Arg2 \\
\hline soften.01 & 0.3684 & 0.1578 & 0.4736 & 0.0000 \\
put.01 & 0.0592 & 0.0069 & 0.0034 & 0.0000 \\
feel.02 & 0.9610 & 0.0129 & 0.0000 & 0.0000 \\
feel.03 & 0.5000 & 0.3571 & 0.0000 & 0.0000 \\
break.08 & 0.6250 & 0.0625 & 0.2500 & 0.0000 \\
crowd.01 & 0.0000 & 0.2500 & 0.2500 & 0.0000 \\
\hline
\end{tabular}

Figura 15: Matriz de entrada para o algoritmo de agrupamento de dados (retirado de Kipper (2005))

Na primeira coluna da Figura 15 têm-se os sentidos dos verbos no PropBank e nas demais colunas estão os frames sintáticos extraídos do PropBank e a frequência com que o sentido aparece na forma do respectivo frame.

Foram realizados testes com a quantidade de grupo de dados variando de três a 150 . $\mathrm{O}$ experimento com 90 grupos de dados foi o que apresentou melhores resultados. $\mathrm{Na}$ comparação com a VerbNet, alguns grupos de dados apresentam mais membros do que as classes. Por exemplo, a classe meet-36.3 da VerbNet contém verbos que denotam encontros com combate (como exemplo, fight (lutar)). No grupo de dados correspondente a essa classe apareceu, também, o verbo hedge (limitar) que, no sentido de proteger-se (de), pode ser considerado um membro desta classe, como no exemplo (77), retirado de Kingsbury e Kipper (2003).

(77) But some investors might prefer a simple strategy than hedging their individual holdings. (Mas alguns investidores devem preferir uma estratégia simples a limitar suas participações individuais)

Como mencionado do Capítulo 3, no trabalho de Kipper (2005) foi apresentada uma fase com base no trabalho de Kingsbury e Kipper (2003) para inserir novos membros na VerbNet. Porém, o algoritmo escolhido foi o EM (Expectation Maximization). Como dados para entrada no algoritmo foram usados 1.278 verbos que ocorrem mais de dez vezes no córpus do PropBank. Destes verbos, somente 484 estavam associados com uma 
única classe na VerbNet. Para estes verbos, informações sobre a classe foram inseridas como atributos para a tarefa de agrupamento de dados. Isso foi feito para que o algoritmo reproduzisse as classes da VerbNet. A partir desta tarefa foi possível inserir 47 novos verbos (10 lemas) às classes da VerbNet.

O trabalho de Sun et al. (2008) explora quatro algoritmos de aprendizado de máquina supervisionados (K-NN, Máxima Entropia, SVM e Modelo Gaussiano) e um algoritmo não supervisionado (Pairwise Clustering) para a tarefa de classificação de verbos. Os autores seguem a taxonomia proposta por Levin (1993) e utilizam de estruturas de subcategorização como atributos para o treinamento. Para o treinamento foram selecionadas dezessete classes de Levin (1993), com doze membros para cada classe. Utilizaram dois métodos para treinamento e teste: leave one out e re-sampling. O melhor resultado obtido foi de $62,5 \%$ de $f$-measure considerando o modelo Gaussiano.

O trabalho de Sun e Korhonen (2009) adiciona atributos semânticos (preferências seletivas) na tarefa de classificação de verbos. Também consideram a taxonomia de Levin (1993). Utilizaram dezessete conjuntos de atributos que fornecem informações do contexto léxico dos verbos, das preferências lexicais dos argumentos dos verbos, estruturas de subcategorização e preferências seletivas. Os autores utilizaram dois métodos de agrupamento de dados: pairwise clustering e spectral clustering. Utilizaram dois conjuntos de verbos: um com 205 verbos em quinze classes de Levin (1993) retirados do trabalho de Joanis et al. (2008) e outro com 204 verbos em dezessete classes de Levin (1993) retirados do trabalho de Sun et al. (2008). O melhor resultado foi de $80,35 \%$ de $f$-measure com o algoritmo spectral clustering e com os dados do trabalho de Sun et al. (2008).

O trabalho de Sun e Korhonen (2011) utiliza um método hierárquico para a tarefa de agrupamento de verbos (Hierarchical Graph Factorization Clustering). A vantagem do uso de um método hierárquico é a possibilidade de representar os dados e os resultados de acordo com uma dada taxonomia (como é o caso das classes da VerbNet). Os autores utilizaram três conjuntos de teste: (1) um gold standard baseado no trabalho de (Stevenson e Joanis, 2003); (2) um grande gold standard hierárquico das classes da VerbNet; e (3) um subconjunto de (2), com a remoção das classes únicas (classes no nível mais alto da hierarquia que não se dividem em subclasses). Os atributos utilizados foram: SCFs e suas frequências relativas aos verbos, SCFs parametrizados por preposições, SCFs 
parametrizados por sujeitos (de acordo com o parser) e SCFs parametrizados por objetos (também de acordo com o parser). Para o conjunto de testes (1), o resultado obtido foi de $41,2 \%$ de acurácia, para (2) o melhor resultado foi de $40 \%$ de $f$-measure e para (3) o melhor resultado obtido foi de $92 \%$ de $f$-measure.

\subsection{Considerações Finais}

Apesar do trabalho proposto neste mestrado não estar diretamente relacionado com nenhum dos trabalhos citados neste capítulo, a apresentação dos mesmos é útil para contrastar o que vem sendo feito na área de classificação de verbos com a proposta aqui apresentada. Sem dúvida, o trabalho que mais se assemelha ao proposto neste mestrado é o de Sun et al. (2010) (apresentado na Seção 4.2) que propõe a criação de uma VerbNet para o francês. Mas as semelhanças param neste ponto. O método utilizado por esses autores (como o método utilizado pelos outros autores apresentados neste capítulo) é complemente diferente do proposto. Porém, conhecer os trabalhos para outras línguas e os diferentes métodos empregados é de grande valia para o enriquecimento deste trabalho. A partir deste estudo, foi possível incluir como etapa de avaliação um experimento com agrupamento de verbos para tentar verificar se a proposta de construção da VerbNet.Br a partir de outros recursos é mais precisa do que o uso de aprendizado não supervisionado, dado que o uso de métodos de agrupamento de dados é bastante comum para a tarefa de classificação de verbos (esta atividade será melhor apresentada no capítulo 5).

Na Tabela 10 é apresentado um resumo de algumas características dos trabalhos apresentados neste capítulo: língua de trabalho, método utilizado para classificação de verbos e a relação com este mestrado. Como é possível observar na última coluna da Tabela 8, o trabalho de Saint-Dizier (1996) e o trabalho de Ferrer (2004) têm semelhança média, pois utilizam busca em córpus pela estrutura de argumentos, semelhante ao que foi feito na etapa 2 deste mestrado (descrita na Seção 5.2.2). Já os trabalhos de Merlo et al. (2002), Schulte im Walde (2006), Joanis e Stevenson (2003) e Sun e Korhonen (2011) também são considerados com relação média, pois utilizam a mesma abordagem que foi utilizada neste mestrado para as classes de verbos: a taxonomia de Levin (1993). Por fim, os trabalhos de Kingsbury e Kipper (2003), Kipper (2005), Sun et al. (2008), Sun e Korhonen (2009) e Sun et al. (2010), possuem alta relação com este mestrado. Em relação aos dois primeiros, pois um trabalho futuro é realizar experimentos com base nestes 
trabalhos para melhorar os resultados da VerbNet.Br. Os demais trabalhos tem alta relação, pois parte da avaliação intrínseca (que analisou os resultados da VerbNet.Br contra os resultados da tarefa de agrupamento de verbos - Capítulo 7) é baseada nestes trabalhos. Além disso, o método de criação do gold standard para o francês (apresentado em Sun et al., 2010) possui características semelhantes ao método de criação da VerbNet.Br proposto neste mestrado. A diferença é que o método aqui proposto se utilizará dos alinhamentos entre WordNet e WordNet.Br e do mapeamento entre WordNet e VerbNet para definição dos candidatos a membros das classes da VerbNet.Br, enquanto que, no trabalho de Sun et al. (2010), foram realizadas traduções a partir do inglês. Vale comentar que o gold standard para o português também foi criado seguindo a metodologia proposta para o francês.

Tabela 10: Resumo dos trabalhos apresentados no Capítulo 4

\begin{tabular}{|c|c|c|c|}
\hline Trabalho & Língua & Método & $\begin{array}{c}\text { Semelhança com a } \\
\text { VerbNet.Br }\end{array}$ \\
\hline Saint-Dizier (1996) & Francês & Busca em córpus por contexto & Média \\
\hline Sun et al. (2010) & Francês & $\begin{array}{l}\text { Agrupamento de dados: } \\
\text { spectral clustering }\end{array}$ & Alta \\
\hline Vázquez et al. (2000) & Espanhol & Definição manual & Baixa \\
\hline Ferrer (2004) & Espanhol & $\begin{array}{lr}\begin{array}{l}\text { Agrupamento } \\
\text { bottom-up }\end{array} & \text { de } \text { dados: } \\
\text { clustering } & \text { hierarquical } \\
\end{array}$ & Média \\
\hline Merlo et al. (2002) & Italiano & C5.0 (supervisionado) & Média \\
\hline Takeuchi et al. (2010) & Japonês & $\begin{array}{l}\text { Duas abordagens: bottom-up e } \\
\text { top-down }\end{array}$ & Baixa \\
\hline $\begin{array}{l}\text { Schulte in Walde } \\
(2006)\end{array}$ & Alemão & $\begin{array}{l}\text { Agrupamento de dados: } k- \\
\text { means }\end{array}$ & Média \\
\hline $\begin{array}{l}\text { Merlo e Stevenson } \\
(2001)\end{array}$ & Inglês & C5.0 (supervisionado) & Baixa \\
\hline $\begin{array}{lll}\text { Joanis e Stevenson } \\
(2003)\end{array}$ & Inglês & C5.0 (supervisionado) & Média \\
\hline $\begin{array}{lll}\text { Kingsbury e } \\
(2003)\end{array}$ & Inglês & Custering: k-means & Alta \\
\hline Kipper (2005) & Inglês & Agrupamento de dados: EM & Alta \\
\hline Sun et al. (2008) & Inglês & 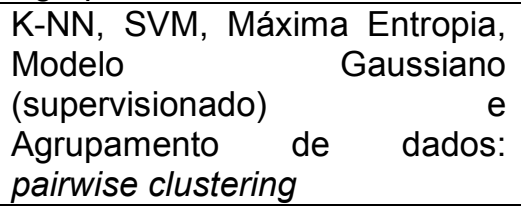 & Alta \\
\hline Sun e Korhonen (2009) & Inglês & $\begin{array}{l}\text { Agrupamento de dados: } \\
\text { spectral clustering e pairwise } \\
\text { clustering }\end{array}$ & Alta \\
\hline Sun e Korhonen (2011) & Inglês & $\begin{array}{lr}\text { Agrupamento de dados: } \\
\text { Hierarquical } \\
\text { Factorization Clustering } & \text { Graph } \\
\end{array}$ & Média \\
\hline
\end{tabular}




\section{Parte III: Projeto de Pesquisa}

\section{CAPÍTULO 6: O Método de Construção da VerbNet.Br}

\subsection{Considerações Iniciais}

Neste capítulo, são apresentadas as etapas de desenvolvimento do projeto VerbNet.Br (Scarton, 2011; Scarton e Aluísio, 2012). Na Seção 6.2, é apresentado o método semiautomático de construção da VerbNet.Br. Por fim, na Seção 6.3 são apresentadas as considerações finais do capítulo.

\subsection{Construção semiautomática da VerbNet.Br}

Como mencionado no Capítulo 1, a construção da VerbNet.Br foi realizada de forma semiautomática, considerando conhecimentos linguísticos e técnicas computacionais como ocorre naturalmente em muitas aplicações de PLN. A Seção 6.2.1 contém a descrição da primeira etapa da construção da VerbNet.Br que consiste da definição das alternâncias sintáticas do português para cada classe da VerbNet e foi realizada via tradução direta. Na Seção 6.2.2 é apresentada a tarefa de busca de alternâncias sintáticas em córpus (utilizando a ferramenta de extração de estruturas de subcategorização apresentada em Zanette et al. (2012)), que foi utilizada para validar os membros das classes da VerbNet.Br. A Seção 6.2.3 mostra como a VerbNet, a WordNet e a WordNet.Br foram utilizadas para a construção da VerbNet.Br. Por fim, na Seção 6.2.4 é apresentado o método para seleção dos membros das classes da VerbNet.Br.

\subsubsection{Etapa 1: Definição das alternâncias sintáticas do português para cada classe presente na VerbNet}

Como as classes de Levin não são totalmente independentes de língua, previu-se que não seria possível a herança completamente automática de todos os componentes da VerbNet para a VerbNet.Br. Para realizar a escolha dos membros automaticamente (Etapa 
4) o método de criação semiautomático previu a necessidade de se ter os frames sintáticos do português para cada classe da VerbNet pré-definidos (posteriormente, na apresentação dos experimentos no Capítulo 7, serão mostrados os casos para os quais esta etapa não foi utilizada).

Esta etapa consistiu da tradução direta dos frames sintáticos do inglês para o português (quando era possível traduzir diretamente) e foi realizada pela aluna em questão com apoio de linguistas do NILC. Partiu-se do princípio enunciado por Levin de que os falantes nativos de uma língua são capazes de avaliar o uso correto do verbo com seus argumentos. Como esta tarefa foi superficial, pois caso não houvesse tradução direta o frame equivalente para o português simplesmente não era traduzido, somente $o$ conhecimento nativo da língua foi suficiente para executá-la. Utilizou-se como ferramentas de apoio o dicionário on-line Michaellis ${ }^{45}$ e a ferramenta Google Translate $^{46}$ (para definir algumas traduções), a VerbNet com os mapeamentos para a WordNet (para interpretação do sentido dos verbos) e a WordNet.Br (caso houvesse alinhamento, para auxílio com o sentido no português).

Como exemplo, considera-se o verbo to jump nas sentenças em 78 (retirados de Levin (1993 p. 266)).

(a) The horse jumped over the fence. (O cavalo pulou sobre a cerca.)

(b) Tom jumped the horse over the fence. (*Tom pulou o cavalo sobre a cerca.)

(alternância de indução de ação - tipo de alternância causativa)

Não existe tradução direta para a sentença em (78b), portanto o frame sintático (SN V SN SP[over]) desta sentença não seria traduzido para o português, ou seja, não seria incluído na base da VerbNet.Br. Somente o frame de (78a) (SN V SP[over]) seria traduzido para SN V SP[sobre], sendo incluído na VerbNet.Br.

A inserção de alternâncias específicas para o português foi deixada para trabalhos futuros, pois, neste trabalho, o foco foi trabalhar com as intersecções entre as línguas portuguesa e inglesa. Além disso, a tarefa de definição de alternâncias específicas para o

\footnotetext{
${ }^{45} \mathrm{http}: / /$ michaelis.uol.com.br/

${ }^{46} \mathrm{http}: / /$ translate.google.com/
} 
português é de cunho linguístico e foge da competência da aluna em questão. Porém, as estruturas de subcategorização identificadas na Etapa 2 poderão servir como insumo para esta tarefa, uma vez que estas estruturas são identificadas a partir de córpus do português.

Vale comentar que este trabalho só considerou as classes originalmente propostas por Levin (1993), mais as grandes classes propostas nas extensões da VerbNet que foram inseridas entre as classes de Levin (1993). Em outras palavras, consideramos todas as classes da VerbNet com índices entre 9.1 (primeira classe de Levin, put-9.1) até 57 (última classe de Levin, weather-57). As classes com índices maiores do que 57 não foram consideradas. As subclasses também não foram consideradas, pois se acredita que estas sejam mais dependentes de língua do que as grandes classes, já que as subclasses contêm verbos da classe que compartilham uma alternância a mais ou uma alternância a menos do que a grande classe. Portanto, para criar a VerbNet.Br, considerou-se 191 classes originais de Levin (1993) mais 22 grandes classes inseridas por Kipper (2005), totalizando 213 classes (contra as 274 da VerbNet original). Mais adiante, será discutida a razão da exclusão de onze classes, restando 202 classes nesta primeira versão da VerbNet.Br. A lista com as 202 classes (com as informações de aceitação dos membros) é apresentada no Apêndice A.

Inicialmente, pensou-se em realizar esta etapa editando os arquivos em XML (Extensible Markup Language) da VerbNet, inserindo uma nova etiqueta para as alternâncias traduzidas. Porém, dado o custo desta tarefa e a ausência de um editor para apoiá-la, decidiu-se utilizar um Sistema Gerenciador de Banco de Dados (SGBD) com uma interface de administração para edição e armazenamento dos dados. Foi escolhido o MySQL $^{47}$ como SGBD e a ferramenta MySQL Query Browser ${ }^{48}$ como interface para edição. A partir desse tipo de armazenamento, é possível extrair os dados para qualquer formato desejado (podendo retorná-los para a proposta inicial em XML).

Foi definida uma tabela no banco de dados para armazenar todas as informações necessárias para a futura recuperação dos dados e alinhamentos com a VerbNet. Como exemplo da realização desta etapa, foi escolhida a classe put-9.1. Na Figura 16 são apresentados os frames da classe put-9.1 na VerbNet.

\footnotetext{
${ }^{47} \mathrm{http}: / /$ www.mysql.com/

${ }^{48} \mathrm{http}: / /$ downloads.mysql.com/archives.php?p=mysql-query-browser
} 


\begin{tabular}{|c|c|c|}
\hline FRAMES & & REF $\widehat{K E Y}$ \\
\hline \multicolumn{3}{|c|}{ NP V NP PP.DESTINATION } \\
\hline EXAMPLE & "I put the book on/under/near the table." & \\
\hline SYNTAX & 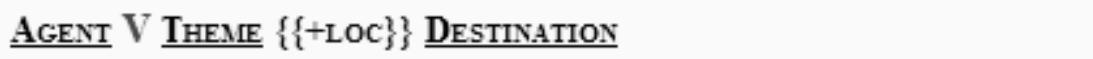 & \\
\hline SEMANTICS & $\begin{array}{l}\text { Motion(during(E), Theme) not(Prep(stakt(E), Theme, Destination)) } \\
\text { Prep(end(E), Theme, Destination) Cause(AGent, E) }\end{array}$ & \\
\hline \multicolumn{3}{|c|}{ NP V NP ADVP } \\
\hline EXAMPLE & "I put the book here/there." & \\
\hline SYNTAX & 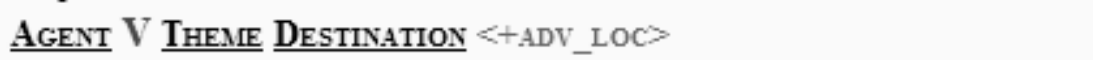 & \\
\hline SEMANTICS & $\begin{array}{l}\text { Motion(during(E), Theme) not(Prep(start(E), Theme, Destination)) } \\
\text { Prep(end(E), Theme, Destination) Cause(Agent, E) }\end{array}$ & \\
\hline
\end{tabular}

Figura 16: Frames da classe put-9.1 na VerbNet ${ }^{49}$

Na Figura 16, é possível observar que há dois frames para a classe put-9.1: SN V SN SP e SN V SN ADVP. Para facilitar a comparação de padrões na Etapa 4, excluímos os sintagmas nominais (SNs) antes do verbo (sujeitos). Tomou-se esta decisão, pois tanto a língua inglesa quanto a língua portuguesa raramente apresentam sujeito posposto em suas construções (nas classes traduzidas da VerbNet não foi encontrada nenhuma ocorrência).

Consequentemente, os padrões foram traduzidos nos casos em que havia tradução direta. No caso de frames com preposições (como o primeiro frame da Figura 16), foram consideradas duas traduções: uma que apresenta apenas o sintagma preposicional (SP) e outra que parametriza a preposição núcleo do sintagma preposicional (SP[prep]). Na Tabela 11 são apresentadas as traduções para os frames da Figura 16.

Tabela 11: Frames traduzidos para o português para a classe put-9.1

\begin{tabular}{|l|l|l|l|}
\hline $\begin{array}{c}\text { Frame da } \\
\text { VerbNet }\end{array}$ & \multicolumn{1}{|c|}{ Padrão SP } & \multicolumn{1}{|c|}{ Padrão SP[prep] } & \multicolumn{1}{c|}{ Frase exemplo } \\
\hline SN V SN SP & V_SN_SP & V_SN_SP[em/entre/sobre/sob] & $\begin{array}{l}\text { Eu coloquei o livro sobre } \\
\text { a mesa. }\end{array}$ \\
\hline SN V SN ADVP & V_SN_ADVP & V_SN_ADVP & Eu coloquei o livro aqui. \\
\hline
\end{tabular}

Na terceira coluna da segunda linha da Tabela 11, é possível observar que se tentou identificar todas as preposições previstas para esta construção.

Como era de se esperar, houve casos em que não foi possível efetuar a tradução de nenhum frame para o português. Estes casos foram marcados com uma etiqueta "all", e a decisão para a última etapa foi a seleção de todos os candidatos. A ausência de traduções dos frames para o português se deu em dois casos. No primeiro, a classe não apresentava frames para a classe principal (caso da classe eat-39.1). No segundo, a classe não

\footnotetext{
${ }^{49}$ Imagem retirada de: http://verbs.colorado.edu/verb-index/vn/put-9.1.php
} 
apresentava frames que eram passíveis de tradução direta (caso da classe gorge-39.6 que possui um único frame $\mathrm{SN} V \mathrm{SP}[\mathrm{on}]$ que não possui correspondência direta para o português, como exemplo, Cynthia gorged on peaches (*Cynthia devorou em pêssegos))

\subsubsection{Etapa 2: Busca das alternâncias sintáticas em córpus etiquetado}

Esta tarefa consistiu em identificar frames sintáticos para verbos em córpus, a fim de comparar estes frames com os frames traduzidos na Etapa 1. Para isso, utilizou-se a ferramenta de Zanette et al. (2012). Esta ferramenta, como apresentada no Capítulo 4, extrai frames sintáticos de verbos do português a partir de córpus etiquetados com o parser PALAVRAS (a Tabela 9 do Capítulo 4, Seção 4.3, apresenta exemplos de frames para o verbo "comprar").

Uma vez selecionada a ferramenta de extração, era necessário escolher um córpus. Inicialmente, pensou-se em utilizar somente o córpus PLN-BR-FULL (aproximadamente 29 milhões de palavras), compilado no âmbito do projeto PLN-BR. Posteriormente, decidiu-se usar o córpus Lácio-Ref (aproximadamente nove milhões de palavras), compilado no âmbito do projeto Lácio-Web. Esta decisão é justificada pela diversidade de gêneros $^{50}$ do córpus Lácio-Ref (jornalístico/informativo, literário, jurídico, instrucional e científico) enquanto que o PLN-BR-FULL contém somente o gênero jornalístico/informativo.

Contudo, durante a realização da atividade de agrupamento de verbos (utilizada para avaliação da VerbNet.Br, apresentada na Seção 6.3), identificou-se a necessidade de utilizar um córpus maior. Sabe-se que existem córpus de grandes proporções para o português do Brasil, como é o caso do Corpus Brasileiro ${ }^{51}$, com 1 bilhão de palavras. Porém, estes córpus não disponibilizam textos para processamento (somente para consultas de frequências, por exemplo). Como era necessário utilizar os textos crus, decidiu-se juntar três córpus, cujo acesso foi viabilizado: PLN-BR-FULL, Lácio-Ref e um córpus com textos da Revista Pesquisa FAPESP ${ }^{52}$ compilado por Aziz e Specia (2011). Na Tabela 12 são apresentados alguns detalhes dos córpus utilizados. Ao final, obteve-se um córpus com

\footnotetext{
${ }^{50}$ http://www.nilc.icmc.usp.br/lacioweb/classificacoes.htm

${ }^{51} \mathrm{http}: / /$ corpusbrasileiro.pucsp.br/cb/Inicial.html

52 http://revistapesquisa.fapesp.br/
} 
aproximadamente 41 milhões de palavras. Vale comentar que havia uma intersecção entre o córpus PLN-BR-FULL e o córpus Lácio-Ref: alguns textos jornalísticos do ano de 1994. Por essa razão, foram eliminados os textos repetidos.

Tabela 12: Informações sobre os córpus utilizados

\begin{tabular}{|l|c|c|c|}
\hline \multicolumn{1}{|c|}{ Corpus } & Número de textos & $\begin{array}{c}\text { Número de palavras } \\
\text { (valores aproximados) }\end{array}$ & Palavras/Textos \\
\hline Lácio-Ref & 2236 & 9 milhões & 4025,04 \\
\hline PLN-BR-FULL & 103080 & 29 milhões & 252,23 \\
\hline Revista FAPESP & 3840 & 6 milhões & 366,45 \\
\hline
\end{tabular}

Os dados extraídos pela ferramenta de extração de frames também foram armazenados em um banco de dados no SGBD MySQL. Foram identificados 3.779 lemas de verbos (com frequência superior a dez ocorrências), 408 frames sem parametrização por preposição e 3.578 frames com parametrização (descartando os frames com frequência inferior a cinco ocorrências).

Para exemplificar, considere o verbo "instalar" candidato a membro da classe put9.1 (a definição dos candidatos a membros das classes da VerbNet.Br é apresentada na Seção 6.2.3). Na Tabela 13 são apresentados alguns dos frames com frequência superior a cinco encontrados para o verbo "instalar".

Tabela 13: Frames para o verbos instalar

\begin{tabular}{|l|l|}
\hline \multicolumn{1}{|c|}{ Frame } & \multicolumn{1}{|c|}{ Exemplo } \\
\hline SP[em]_SUBJ[SN]_V_SN & $\begin{array}{l}\text { "SP[Em a entrega], SUBJ[técnicos] V[instalam] SN[o } \\
\text { equipamento] e ensinam a tirar a bebida, como no caso da } \\
\text { Brahma." }\end{array}$ \\
\hline SUBJ[SN]_V_SN & $\begin{array}{l}\text { SUBJ[Os homens] V[instalam] SN[fábricas], cortam árvores e } \\
\text { terminam vítimas de seus próprios artefatos. }\end{array}$ \\
\hline SUBJ[SN]_V_SN_SP[em] & "SUBJ[Perdigão] V[instala] SN[abatedouro] SP[em Goiás]." \\
\hline SUBJ[SN]_V_SN_SP[para] & $\begin{array}{l}\text { "SUBJ[A rainha Elizabeth] V[instalou] SN[um aquecedor] SP[para } \\
\text { a almofada do trono] utilizada em cerimônias oficiais [...]" }\end{array}$ \\
\hline
\end{tabular}

Vale reforçar que a ferramenta de extração de frames não faz distinção entre adjuntos e complementos (conforme discussão apresentada no Capítulo 4).

\subsubsection{Etapa 3: Definição dos candidatos a membros}

Como mencionado na Seção 3.2.1.4, a WordNet.Br possui alinhamentos com a WordNet. Esses alinhamentos podem ser de diversos tipos como apresentado na Tabela 4 do Capítulo 3. O alinhamento ideal é o de EQ_SYNONYM em que um synset da WordNet.Br é alinhado diretamente com um synset da WordNet. Outro alinhamento que 
está próximo do ideal é o de EQ_NEAR_SYNONYM. Por isso, nesta etapa, trabalhou-se somente com esses dois casos.

A VerbNet possui mapeamentos de seus membros para os synsets da WordNet (se eles existirem). Estes mapeamentos são feitos para cada membro de cada classe (como apresentado na Seção 3.3). Na Figura 9 da Seção 3.3 é apresentado um trecho do arquivo XML da classe escape-51.2 da VerbNet. Nessa figura, pode-se observar os membros dessa classe e seu mapeamento para a WordNet (apresentados com as etiquetas “wn”).

O método para definição dos candidatos a membros foi realizado seguindo o algoritmo:

1. Para cada classe da VerbNet faça:

a. Para cada membro da classe faça:

i. Buscar os ILIs (índices inter-lingual) dos synsets da WordNet relacionados com o membro

ii. Para cada ILI encontrado faça:

1. Buscar os synsets correspondentes na WordNet.Br

2. Para cada synset da WordNet.Br faça:

a. Definir todos os verbos do synset como candidatos a membro da classe em questão

Na Figura 17 pode-se observar a ilustração deste processo.

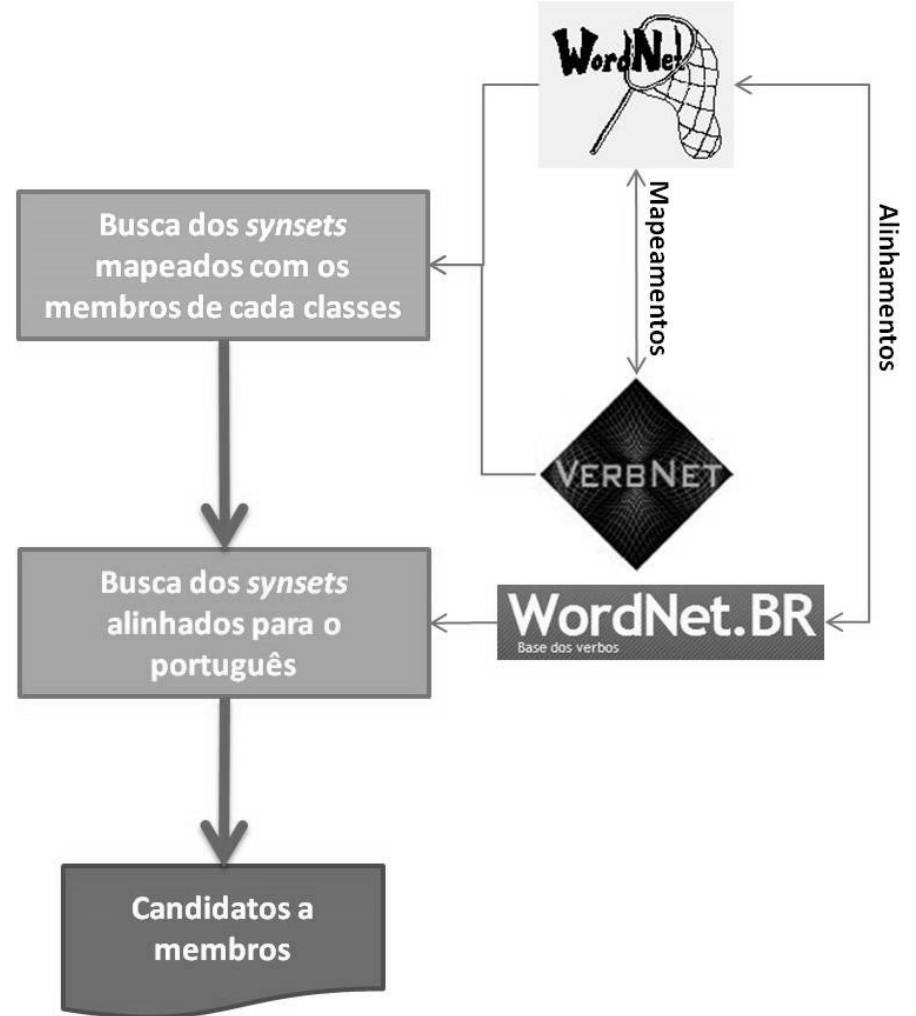

Figura 17: Esquema da tarefa de definição dos candidatos a membros da VerbNet.Br 
Nesta etapa, foram identificados 4.298 lemas de verbos para 254 classes, com uma média de dezesseis verbos por classe (aqui foram trazidas informações para todas as 274 classes da VerbNet - na etapa de validação (Etapa 4) é que foram consideradas apenas 213 classes). Das 213 classes consideradas para a primeira versão da VerbNet.Br, dez não apresentaram alinhamentos com a WordNet.Br e por isso foram descartadas, são elas: pelt17.2, floss-41.2.1, ferret-35.6, mine-10.9, subjugate-42.3, masquerade-29.6, register-54.1, flinch-40.5, calve-28 e promise-37.13. Vale comentar que esta etapa foi implementada na linguagem C\#.NET, dada a facilidade de se lidar com arquivos em XML (formato da VerbNet) e com o SGBD MySQL nesta linguagem (no qual está armazenada a base de dados da WordNet.Br).

Como exemplo, apresenta-se a classe put-9.1. Na Tabela 14 são apresentados os membros da classe e os ILIs (com os respectivos synsets) correspondentes aos alinhamentos com a WordNet.Br.

Tabela 14: Membros da classe put-9.1 da VerbNet

\begin{tabular}{|c|c|}
\hline Membros & ILls \\
\hline Arrange & 01422386 (arrange, set_up) \\
\hline Immerse & 01534101 (immerse, plunge1) \\
\hline Implant & $\begin{array}{l}01486477 \text { (implant, engraft, embed, imbed, plant1), } 01252425 \text { (implant2) } \\
\text { e } 00710590 \text { (plant, implant) }\end{array}$ \\
\hline Lodge & 01485763 (lodge, wedge1, stick2, deposit) \\
\hline Mount & 01303684 (mount) e 00395465 (mount1) \\
\hline Position & 01452069 (put, set, place, pose2, position, lay1) \\
\hline Situate & 01532141 (situate, fix1, posit, deposit1) \\
\hline Sling & 01472007 (sling, catapult1) \\
\hline Station & 01054384 (station, post, base, send, place) \\
\hline Superimpose & Não possui mapeamento para a WordNet \\
\hline Bury & $\begin{array}{l}02085555 \text { (bury), } 02382555 \text { (bury, entomb, inhume, inter, lay_to_rest), } \\
01197062 \text { (bury), } 01538803 \text { (immerse1, swallow, swallow_up, bury2, } \\
\text { eat_up) e } 01487754 \text { (bury1, sink) }\end{array}$ \\
\hline Deposit & 02243919 (deposit, bank) \\
\hline Embed & 01486477 (implant, engraft, embed, imbed, plant1 ) \\
\hline Insert & 01380907 (insert, infix1, enter3, introduce) \\
\hline Install & 01526111 (install, instal, put_in, set_up2) \\
\hline Park & 01451150 (park) e 01878451 (park) \\
\hline Plant & $\begin{array}{l}01523846 \text { (plant, set9), } 02255657 \text { (plant), } 01331003 \text { (plant6) e } 00710590 \\
\text { (plant, implant) }\end{array}$ \\
\hline Stash & 02238982 (hoard1, stash, cache, lay_away, hive_up, squirrel_away) \\
\hline Stow & Não possui mapeamento para a WordNet \\
\hline
\end{tabular}

$\mathrm{Na}$ Tabela 15 são apresentados os alinhamentos dos ILIs definidos na Tabela 14 com os synsets da WordNet.Br. 
Tabela 15: Membros da classe put-9.1 e os synsets da WordNet.Br

\begin{tabular}{|c|c|c|}
\hline Membros & ILIs & Alinhamentos com a WordNet.Br \\
\hline Arrange & 01422386 & $\begin{array}{l}\text { Synset } 1606 \text { (coordenar, dispor); Synset } 312 \text { (arrumar, estivar); } \\
\text { Synset } 314 \text { (aconchegar, ajeitar, compor, conchegar) }\end{array}$ \\
\hline Immerse & 01534101 & Sem alinhamentos com a WordNet.Br \\
\hline \multirow{3}{*}{ Implant } & 01486477 & Synset 1781 (cravar-se, embeber-se, fixar-se) \\
\hline & 01252425 & Sem alinhamentos com a WordNet.Br \\
\hline & 00710590 & $\begin{array}{l}\text { Synset } 3220 \text { (arraigar, cravar, estranhar, implantar, introduzir, } \\
\text { radicar) }\end{array}$ \\
\hline Lodge & 01485763 & Synset 1778 (arraigar, enfincar, enraizar, fincar, fixar) \\
\hline \multirow{2}{*}{ Mount } & 01303684 & Sem alinhamentos com a WordNet.Br \\
\hline & 00395465 & Sem alinhamentos com a WordNet.Br \\
\hline Position & 01452069 & $\begin{array}{l}\text { Synset } 1232 \text { (encaixar); Synset } 3314 \text { (colocar, localizar, situar); } \\
\text { Synset } 3932 \text { (botar1, colocar, depor, depositar, meter, pôr, } \\
\text { postar); Synset } 3975 \text { (antepor, prepor); Synset } 796 \text { (botar1, pôr); } \\
\text { Synset } 797 \text { (botar1, calçar, pôr) }\end{array}$ \\
\hline Situate & 01532141 & Sem alinhamentos com a WordNet.Br \\
\hline Sling & 01472007 & Sem alinhamentos com a WordNet.Br \\
\hline Station & 01054384 & Sem alinhamentos com a WordNet.Br \\
\hline \multirow{5}{*}{ Bury } & 02085555 & Sem alinhamentos com a WordNet.Br \\
\hline & 02382555 & Synset 337A (enterrar, sepultar) \\
\hline & 01197062 & Synset 1376 (encovar, enterrar) \\
\hline & 01538803 & $\begin{array}{l}\text { Synset } 1974 \text { (absorver, afundar, engolir, sorver, submergir, } \\
\text { tragar); Synset 337B (soterrar, subterrar) }\end{array}$ \\
\hline & 01487754 & Sem alinhamentos com a WordNet.Br \\
\hline Deposit & 02243919 & Sem alinhamentos com a WordNet.Br \\
\hline Embed & 01486477 & Synset 1781 (cravar-se, embeber-se, fixar-se) \\
\hline Insert & 01380907 & $\begin{array}{l}\text { Synset } 1688 \text { (empatar); Synset } 1864 \text { (embutir-se, encaixar-se, } \\
\text { entrar); Synset } 3138 \text { (incluir, inserir, meter); Synset } 3911 \\
\text { (embeber, encaixar, engastar, inserir, intercalar, introduzir, } \\
\text { intrometer, pôr) }\end{array}$ \\
\hline Install & 01526111 & Synset 3906 (instalar, ligar, pôr) \\
\hline \multirow{2}{*}{ Park } & 01451150 & Sem alinhamentos com a WordNet.Br \\
\hline & 01878451 & Synset 2038 (encostar, estacionar, parar, parquear) \\
\hline \multirow{4}{*}{ Plant } & 01523846 & $\begin{array}{l}\text { Synset } 3857 \text { (cultivar, plantar, semear); Synset } 525 \text { (arraigar-se, } \\
\text { arreigar-se, cravar-se, entranhar-se, introduzir-se) }\end{array}$ \\
\hline & 02255657 & Sem alinhamentos com a WordNet.Br \\
\hline & 01331003 & Sem alinhamentos com a WordNet.Br \\
\hline & 00710590 & $\begin{array}{l}\text { Synset } 3220 \text { (arraigar, cravar, entranhar, implantar, introduzir, } \\
\text { radicar) }\end{array}$ \\
\hline Stash & 02238982 & Sem alinhamentos com a WordNet.Br \\
\hline
\end{tabular}

Portanto, todos os 62 verbos que aparecem na coluna 3 da Tabela 15 são candidatos a membros da classe put-9.1 (somente os verbos com partícula "-se" foram desconsiderados). São eles: absorver, aconchegar, afundar, ajeitar, antepor, arraigar, arrumar, botar, calçar, colocar, compor, conchegar, coordenar, cravar, cravejar, cultivar, depor, depositar, dispor, embeber, empatar, encaixar, encastoar, encastrar, encostar, encovar, enfincar, engastar, engolir, enraizar, enterrar, entranhar, entrar, estacionar, estivar, fincar, fixar, implantar, incluir, inserir, instalar, intercalar, introduzir, intrometer, ligar, 
localizar, meter, parar, parquear, plantar, pôr, postar, prepor, radicar, semear, sepultar, situar, sorver, soterrar, submergir, subterrar e tragar.

\subsubsection{Etapa 4: Escolha dos membros}

$\mathrm{Na}$ etapa final da construção da VerbNet.Br foram escolhidos automaticamente os membros para cada classe da VerbNet.Br, considerando os resultados das etapas anteriores. Foram utilizadas duas abordagens. A primeira segue o esquema apresentado na Figura 18.

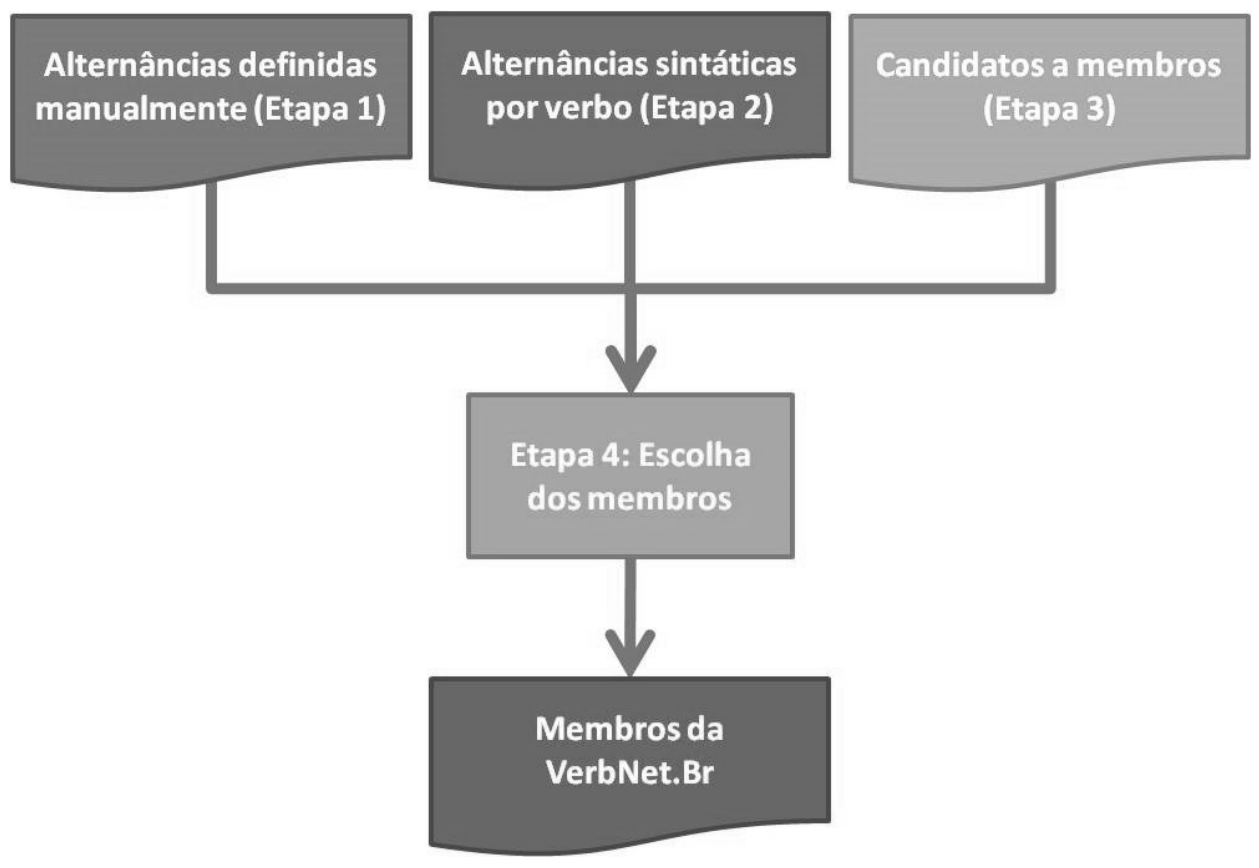

Figura 18: Descrição da tarefa de definição dos membros das classes da VerbNet.Br

Como é possível observar no esquema da Figura 18, para cada candidato a membro (definidos na Etapa 3) buscou-se os respectivos frames sintáticas correspondentes ao verbo candidato (alternâncias encontradas na Etapa 2). Compararam-se frames do candidato com frames definidos para a classe (definidas na Etapa 1) a qual ele é candidato a membro. Se o verbo possuía pelo menos o teto de $10 \%$ (valor definido empiricamente - a discussão da escolha deste valor é apresentada no Capítulo 7) dos frames definidos para a classe ele se tornava membro da classe. Caso contrário, o candidato foi marcado como não membro. Foram realizados dois experimentos: considerando os sintagmas preposicionais com parametrização por preposição (experimento 1 - EXP1) e sem parametrização (experimento 2 - EXP2). Algoritmicamente: 
1. Para cada classe da VerbNet.Br faça:

a. Para cada verbo candidato a membro da classe faça:

i. Buscar os frames identificados na Etapa 2 para o verbo

ii. Comparar os frames definidos manualmente para a classe (Etapa 1) com os frames encontrados na Etapa 2:

1. Se o verbo apresenta no córpus pelo menos o teto ${ }^{53}$ de $10 \%$ dos frames definidos para a classe na Etapa 1:

a. Selecionar o verbo

b. Caso contrário, não selecionar o verbo

Esta etapa atenuou o erro inserido pela base da WordNet.Br sem revisão. A hipótese que tinhamos era que os verbos que não existem na língua (embora uma língua seja dinâmica e inclua novas palavras com o passar do tempo) seriam eliminados, pois não seriam encontradas alternâncias no córpus (embora a amostra da língua que tínhamos não era muito grande). Já os verbos que estejam erroneamente alocados em um synset ou que apresentem alinhamentos com a WordNet equivocados, provavelmente não seriam considerados, pois somente os verbos que possuíam as alternâncias requeridas pela classe (definidas na Etapa 1) foram aceitos. O erro só pode ter permanecido para os casos das classes em que nenhuma alternância foi definida em português.

$\mathrm{Na}$ segunda abordagem, pensando em avaliar a real necessidade da etapa manual (Etapa 1), decidiu-se experimentar um método que desconsiderasse essa etapa. Com esse objetivo, foi utilizada uma estratégia gulosa para seleção de membros, selecionando-os de acordo com as alternâncias mais frequentes (retiradas de córpus) para cada verbo de cada classe. Esta estratégia é considerada gulosa, pois se baseia nas informações locais (no caso o frame sintático mais frequente) para decisão dos membros (sem reconsiderar após a seleção) (Ziviani, 2005). Com base nos resultados da Etapa 2, verificou-se qual frame era o mais frequente entre os verbos candidatos. Selecionou-se, então, o frame mais frequente e os verbos que o apresentavam foram considerados membros da classe (a escolha de somente um frame foi decidida empiricamente - a discussão da escolha deste valor é apresentada no Capítulo 7). Nesta abordagem, também foram considerados frames parametrizados (experimento 3 - EXP3) e não parametrizados (experimento 4 - EXP 4). Algoritmicamente:

\footnotetext{
${ }^{53}$ A função teto é definida como: $\lceil x\rceil=$ a identificação do menor inteiro maior ou igual a x (Graham et al. 1994). Como exemplo, considere $\mathrm{x}=1,2$. $\mathrm{O}$ teto de $\mathrm{x}$ seria definido por $[1,2\rceil=2$.
} 
1. Para cada classe da VerbNet.Br faça:

a. Para cada verbo candidato a membro da classe faça:

i. Buscar os frames identificados na Etapa 2 para o verbo

ii. Verificar qual o frame mais frequente:

1. Selecionar o frame mais frequente e os verbos do frame mais frequente

a. Selecionar os verbos que apresentam este frame

Esta etapa foi implementada na linguagem python $^{54}$ e os resultados foram armazenados no SGBD MySQL.

Para exemplificar, tomando a classe put-9.1 como exemplo, tem-se 62 candidatos a membros com 43 verbos com frequência maior que dez (considerados na análise). De acordo com a primeira abordagem (considerando a Etapa 1), os verbos candidatos deveriam apresentar $10 \%$ das alternâncias definidas para a classe. Na Tabela 11 foram apresentadas as duas alternâncias definidas manualmente para a classe: V_SN_SP[em/entre/sob/sobre] e V_SN_ADVP. A segunda alternância foi desconsiderada, pois a ferramenta de extração de frames utilizada na Etapa 2 não considera sintagmas adverbiais. Assim sendo, somente uma alternância ficou definida para a classe (teto de $10 \%$ de um é igual a um). Os verbos candidatos (Etapa 3) deveriam, então, apresentar a alternância V_SN_SP[em/entre/sob/sobre] - no caso de parametrização por preposição (EXP1) - ou V_SN_SP - no caso sem parametrização (EXP2). Na Tabela 15 são apresentados os verbos selecionados e alternâncias apresentadas por eles nos dois casos. Foram selecionados 26 verbos considerando a parametrização por preposição e 28 , sem considerar a parametrização.

Como era de se esperar, o experimento sem parametrização seleciona mais verbos do que a abordagem com parametrização (vide Tabela 16). Considerar as preposições é uma estratégia problemática, pois elas podem ser ambíguas e, muitas vezes, podem ter sido esquecidas na etapa manual. Já a estratégia de não considerar preposições pode selecionar verbos que possuam a mesma estrutura com preposições diferentes e não aceitas pela classe. Na Tabela 16, os verbos "dispor" e "tragar" não apresentam a construção com uma das preposições definidas V_SN_SP[em/entre/sob/sobre] (com frequência superior a 5).

\footnotetext{
${ }^{54} \mathrm{http} / / /$ www.python.org/
} 
Porém, estes mesmos verbos apresentam a construção V_SN_SP com outras preposições. Isso ocorre, pois, a construção não parametrizada considera todas as construções em que aparecem um SP naquela posição, independente da preposição núcleo do SP.

Tabela 16: Verbos selecionados para a classe put-9.1 (considerando a Etapa 1)

\begin{tabular}{|l|c|c|}
\hline \multicolumn{1}{|c|}{ Verbo } & EXP1 & EXP2 \\
\hline absorver & V_SN_SP[em] & V_SN_SP \\
\hline arrumar & V_SN_SP[em] & V_SN_SP \\
\hline botar & V_SN_SP[em] & V_SN_SP \\
\hline colocar & V_SN_SP[em/entre/sobre/sob] & V_SN_SP \\
\hline compor & V_SN_SP[em] & V_SN_SP \\
\hline coordenar & V_SN_SP[em] & V_SN_SP \\
\hline cravar & V_SN_SP[em] & V_SN_SP \\
\hline cultivar & V_SN_SP[em] & V_SN_SP \\
\hline depor & V_SN_SP[em] & V_SN_SP \\
\hline depositar & V_SN_SP[em] & V_SN_SP \\
\hline dispor & & V_SN_SP \\
\hline encostar & V_SN_SP[em] & V_SN_SP \\
\hline engolir & V_SN_SP[em] & V_SN_SP \\
\hline enterrar & V_SN_SP[em] & V_SN_SP \\
\hline fincar & V_SN_SP[em] & V_SN_SP \\
\hline fixar & V_SN_SP[em] & V_SN_SP \\
\hline implantar & V_SN_SP[em] & V_SN_SP \\
\hline incluir & V_SN_SP[em/entre/sobre] & V_SN_SP \\
\hline inserir & V_SN_SP[em] & V_SN_SP \\
\hline instalar & V_SN_SP[em] & V_SN_SP \\
\hline introduzir & V_SN_SP[em] & V_SN_SP \\
\hline ligar & V_SN_SP[em] & V_SN_SP \\
\hline localizar & V_SN_SP[em] & V_SN_SP \\
\hline meter & V_SN_SP[em] & V_SN_SP \\
\hline parar & V_SN_SP[em] & V_SN_SP \\
\hline plantar & V_SN_SP[em] & V_SN_SP \\
\hline pôr & V_SN_SP[em] & V_SN_SP \\
\hline tragar & -- & V_SN_SP \\
\hline
\end{tabular}

Considerando a abordagem que elimina a Etapa 1, os frames selecionados para a classe put-9.1 foram: (SUBJ[SN])_V_SN considerando parametrização por preposição (EXP3) e (SUBJ[SN])_V_SN sem parametrização (EXP4), ou seja, a mesma alternância (os sujeitos também não foram considerados nesta etapa - incluiu-se a informação somente para ilustração). Os verbos selecionados (41 nos dois casos) foram: absorver, afundar, ajeitar, arrumar, botar, calçar, colocar, compor, coordenar, cravar, cultivar, depor, depositar, dispor, empatar, encaixar, encostar, engolir, enterrar, entrar, estacionar, fincar, fixar, implantar, incluir, inserir, instalar, intercalar, introduzir, ligar, localizar, meter, parar, plantar, pôr, semear, sepultar, situar, sorver, soterrar e tragar.

No Capítulo 7, quando da discussão dos resultados obtidos com um gold standard, reforçamos que o uso da Etapa 1 não acarreta em grande melhoria de precisão. Isto sugere 
que a seleção dos membros poderia ser feita somente por métodos automáticos (etapas 2, 3 e 4 do método). Porém, como será discutido posteriormente, isso acarreta a perda da possibilidade de herança automática de informações interessantes como, por exemplo, os predicados semânticos.

\subsection{Considerações Finais}

Neste capítulo, foi apresentado o método de criação da VerbNet.Br (Seção 6.2). Este método contém quatro etapas relativamente independentes (foi possível realizar a codificação de cada etapa automática sem a necessidade de esperar a conclusão da etapa anterior, com exceção da Etapa 4, final, que usa as anteriores). Por se tratar de um processo semiautomático, há uma etapa manual (Etapa 1), que se supunha ser necessária (mais discussões sobre este ponto estão no Capítulo 7).

Na Seção 6.2.1 foi apresentada a etapa manual. Esta etapa consistiu da tradução direta dos frames das classes da VerbNet para o português. A Etapa 2 (automática) foi apresentada na Seção 6.2.2 e consistiu da identificação dos frames sintáticos para os verbos do português do Brasil a partir de córpus, utilizando a ferramenta de extração de estruturas de subcategorização descrita em Zanette et al. (2012). Na Seção 6.2.3 foi apresentada outra etapa automática que consistiu na definição dos candidatos a membros da VerbNet.Br, a partir dos alinhamentos entre a VerbNet, a WordNet e a WordNet.Br. Por fim, na Seção 6.2.4, foi apresentada a última etapa, que combina as etapas anteriores, selecionando os verbos para as classes da VerbNet.Br. Esta seleção foi realizada de duas formas: considerando a etapa manual (comparando as alternâncias definidas para classe com as alternâncias que os verbos apresentaram em córpus) e sem considerar a etapa manual (utilizando uma estratégia gulosa, selecionando os verbos de acordo com os frames mais frequentes).

Por fim, o método merece destaque, pois pode ser utilizado para outras línguas. A única exigência é que estas línguas possuam uma wordnet alinhada com a WordNet e uma ferramenta de extração de estruturas de subcategorização (ou um léxico computacional com estas informações). Exemplos de línguas são: francês, espanhol e alemão que já possuem uma wordnet alinhada com a WordNet e também possuem trabalhos na linha de estruturas de subcategorização. 


\section{CAPÍTULO 7:Avaliação do Recurso VerbNet.Br}

\subsection{Considerações Iniciais}

Neste capítulo é apresentada avaliação do recurso VerbNet.Br. Na Seção 7.2 é apresentado o panorama de cada um dos experimentos apresentados na Seção 6.2.4. Na Seção 7.3 são apresentadas as formas de avaliação intrínseca: qualitativa e quantitativa. $\mathrm{Na}$ Seção 7.4 são apresentadas outras contribuições deste trabalho. Por fim, na Seção 7.5 são apresentadas as considerações finais do capítulo.

\subsection{Panorama dos Experimentos}

Como mencionado na Seção 6.2.1, foram selecionadas 213 classes da VerbNet para fazerem parte da primeira versão da VerbNet.Br. Destas 213 classes, dez não apresentaram alinhamentos com a WordNet.Br (como mencionado na Seção 6.2.3) e foram descartadas. A classe vehicle-51.4.1 que apresentava um único candidato a membro, o verbo "barquejar", também foi eliminada, pois o candidato não possuía frequência no córpus da Etapa 2. Assim, a versão inicial da VerbNet.Br, utilizada nos quatro experimentos, conta com 202 classes e 1893 lemas de verbos como candidatos, sendo que cada classe possui 23 verbos candidatos, em média. Na Tabela 17 são apresentados os resultados gerais para cada experimento.

Tabela 17: Resultados Gerais para cada experimento

\begin{tabular}{|l|c|c|}
\hline & $\begin{array}{c}\text { Número de verbos } \\
\text { (lemas) aceitos }\end{array}$ & $\begin{array}{c}\text { Número médio de } \\
\text { verbos por classe }\end{array}$ \\
\hline EXP1 & 1766 & 21 \\
\hline EXP2 & 1786 & 21 \\
\hline EXP3 & 1691 & 21 \\
\hline EXP4 & 1703 & 21 \\
\hline
\end{tabular}

Como é possível observar na Tabela 17, o EXP3 foi o experimento que selecionou menos verbos (1691 lemas de verbos) e o EXP2 foi o que selecionou mais verbos (1786 lemas de verbos), o que era esperado uma vez que o uso de preposições restringe mais a seleção dos verbos. Porém, todos os experimentos possuem o mesmo número médio de verbos por classe (21 verbos por classe), o que indica que os experimentos foram compatíveis. Além disso, se considerarmos todos os verbos candidatos, sem os 
experimentos (somente com um filtro de frequência maior do que dez), a média de verbos por classe é de 23, o que não está longe dos resultados dos experimentos.

\subsection{Avaliação da VerbNet.Br}

A VerbNet.Br foi avaliada de forma intrínseca qualitativa em duas fases. A primeira fase consistiu da análise de dezesseis classes da VerbNet.Br, comparando os resultados dos verbos selecionados com um gold standard para o português do Brasil. A segunda, consistiu da comparação dos resultados das mesmas dezesseis classes com resultados de um método de agrupamento de verbos (totalmente automático e baseado em córpus). A criação do gold standard para o português do Brasil é apresentada na Seção 7.3.1; a primeira fase da avaliação intrínseca qualitativa é apresentada na Seção 7.3.2; e a segunda é apresentada na Seção 7.3.3. Já na Seção 7.3.4 são apresentados os resultados da avaliação intrínseca quantitativa.

\subsubsection{Gold Standard para o português do Brasil}

A primeira tarefa a ser considerada na atividade de agrupamento de verbos é a construção de um gold standard para a língua em questão. O gold standard é importante para a viabilidade da avaliação quantitativa dos grupos de verbos da tarefa de agrupamento de verbos. Além disso, o gold standard para o português também foi utilizado para a avaliação qualitativa das classes da própria VerbNet.Br. No trabalho de Sun et al. (2010) foi criado um gold standard das classes da VerbNet para o francês a partir do gold standard definido para o inglês em Sun (2007). Neste trabalho seguiu-se a mesma metodologia definida para o francês para a criação do gold standard para o português.

Primeiro, realizou-se a tradução dos verbos do gold standard definido para o inglês em Sun (2007) (constituído de dezessete classes com dezesseis verbos em cada classe Figura 19). Depois, analisaram-se as classes da VerbNet, definindo as alternâncias sintáticas para o português do Brasil. E por fim, foram selecionados os verbos que apresentavam essas alternâncias.

A primeira versão do gold standard para o português do Brasil foi criado pela Dra. Karin Kipper Schuler - pesquisadora responsável pela VerbNet (graça à parceria estabelecida por intermédio da Profa. Dra. Anna Korhonen, da Universidade de Cambridge, UK, e da Profa. Dra. Martha Palmer, da Universidade do Colorado, Estados 
Unidos). Além da Dra. Karin Kipper Schuler ser a criadora da VerbNet, com conhecimento avançado das classes de Levin, ela também é falante nativa do português do Brasil. Para realizar a tradução dos verbos, ela utilizou a ferramenta Google Translate ${ }^{55 .}$ As alternâncias sintáticas para cada classe foram definidas por ela (dado o conhecimento das classes de Levin e da língua portuguesa).

\begin{tabular}{|c|c|c|}
\hline $\begin{array}{l}\text { Class } \\
\text { label }\end{array}$ & Description & Verbs \\
\hline 10.1 & REMOVE & $\begin{array}{l}\text { remove, abolish, discharge, extract, deduct, eradicate, sever, evict, } \\
\text { eject, subtract, retract, delete }\end{array}$ \\
\hline 11.1 & SEND & $\begin{array}{l}\text { ship, post, send, transport, transmit, transfer, deliver, slip, dis- } \\
\text { patch, forward, mail, shunt }\end{array}$ \\
\hline 13.5 .1 & GET & $\begin{array}{l}\text { win, gain, earn, buy, get, book, reserve, fetch, attain, pick, charter, } \\
\text { conserve }\end{array}$ \\
\hline 18.1 & HIT & $\begin{array}{l}\text { beat, slap, bang, knock, pound, batter, hammer, lash, bash, } \\
\text { smack, whack, bump }\end{array}$ \\
\hline 22.2 & AMALGAMATE & $\begin{array}{l}\text { integrate, match, coincide, incorporate, compare, unite, contrast, } \\
\text { affiliate, unify, overlap, correlate, alternate }\end{array}$ \\
\hline 29.2 & CHARACTERIZE & $\begin{array}{l}\text { envisage, portray, regard, treat, identify, define, depict, diagnose, } \\
\text { enlist, reinstate, picture, class }\end{array}$ \\
\hline 30.3 & PEER & $\begin{array}{l}\text { listen, stare, look, glance, gaze, peer, peek, squint, snoop, gape, } \\
\text { leer, peep }\end{array}$ \\
\hline 31.1 & AMUSE & $\begin{array}{l}\text { stimulate, threaten, shock, confuse, upset, overwhelm, scare, dis- } \\
\text { appoint, delight, exhaust, intimidate, frighten }\end{array}$ \\
\hline 36.1 & CORRESPOND & $\begin{array}{l}\text { cooperate, collide, concur, compromise, flirt, interact, dissent, } \\
\text { mate, banter, haggle, commiserate, elope }\end{array}$ \\
\hline 37.3 & $\begin{array}{l}\text { MANNER } \\
\text { SPEAKING }\end{array}$ & $\begin{array}{l}\text { shout, yell, whisper, mutter, murmur, snarl, moan, wail, mumble, } \\
\text { grunt, whimper, stutter }\end{array}$ \\
\hline 37.7 & SAY & $\begin{array}{l}\text { say, reply, mention, state, report, respond, announce, recount, } \\
\text { utter, exclaim, retort, confide }\end{array}$ \\
\hline 40.2 & $\begin{array}{l}\text { NONVERBAL EX- } \\
\text { PRESSION }\end{array}$ & $\begin{array}{l}\text { smile, laugh, grin, sigh, gasp, chuckle, frown, giggle, sneer, yawn, } \\
\text { sob, snore }\end{array}$ \\
\hline 43.1 & LIGHT EMISSION & $\begin{array}{l}\text { shine, flash, flare, glow, blaze, flicker, gleam, sparkle, glisten, twin- } \\
\text { kle, glitter, flame }\end{array}$ \\
\hline 45.4 & $\begin{array}{l}\text { OTHER CHANGE } \\
\text { OF STATE }\end{array}$ & $\begin{array}{l}\text { soften, weaken, strengthen, narrow, deepen, dampen, melt, mul- } \\
\text { tiply, sharpen, shorten, broaden, freeze }\end{array}$ \\
\hline 47.3 & $\begin{array}{l}\text { MODES OF BE- } \\
\text { GING WITH MO- } \\
\text { TION }\end{array}$ & $\begin{array}{l}\text { quake, falter, sway, swirl, teeter, flutter, wobble, waft, quiver, } \\
\text { wiggle, vibrate, oscillate }\end{array}$ \\
\hline 51.3 .2 & RUN & $\begin{array}{l}\text { swim, fly, walk, slide, run, travel, stroll, glide, jog, march, trot, } \\
\text { gallop }\end{array}$ \\
\hline 9.1 & PUT & $\begin{array}{l}\text { bury, place, install, mount, put, deposit, position, set, situate, } \\
\text { immerse, insert, stash }\end{array}$ \\
\hline
\end{tabular}

Figura 19: Gold Standard criado para a língua inglesa (retirado de Sun (2007))

A primeira versão do gold standard possuía 203 verbos divididos em dezesseis classes (a classe peer-30.3 foi removida por não ser compatível com o português). A partir

\footnotetext{
${ }^{55} \mathrm{http}: / /$ translate.google.com/
} 
dessa versão, decidiu-se pesquisar mais traduções nos dicionários Collins (Collins, 2010) e Michaellis ${ }^{56}$ e na WordNet.Br, com objetivo de inserir mais verbos nas classes. Ao final do processo, foram inseridos mais dezenove verbos nas classes do gold standard para o português do Brasil (222 verbos no total). Outros dicionários podem servir de suporte para a validação da VerbNet.Br.

Porém, para a tarefa de agrupamento de verbos foi necessário selecionar os verbos frequentes e, também, os frames frequentes. Utilizando os córpus apresentados na Seção 6.2.2, considerando a frequência de verbos maior do que dez e a frequência de frames maior do que cinco, obtivemos um total de 185 verbos divididos em dezesseis classes. Esse resultado consistiu a segunda versão do gold standard (utilizada para a tarefa de agrupamento de verbos). As maiores classes dessa versão foram amuse-31.1 e say-37.7 com 23 membros e as menores classes foram hit-18.1 e modes_of_being_with_motion-47.3 com quatro membros. Os verbos da segunda versão do gold standard aparecem na Tabela 15 (verbos que foram descartados aparecem em negrito).

Durante a etapa de avaliação das classes da VerbNet.Br pelo gold standard (Seção 7.3.2), foi necessária a inclusão de mais verbos para o correto cálculo de precisão e abrangência (verbos em negrito na Tabela 18). Esta inclusão foi efetuada pela aluna (com base em exemplos do córpus) e melhorada (para algumas classes) pela Dra. Magali Sanches Duran. A linguista analisou os candidatos a membros que não faziam parte do gold standard e validou parte deles com exemplos da internet, incluindo, além disso, verbos equivalentes aos membros de cada classe da VerbNet. Na nova versão do gold standard foram incluídos 463 verbos e eliminados oito verbos, resultando em um total de 540 verbos divididos em dezesseis classes. A maior classe foi other_cos_45.4 com 117 verbos e a menor classe foi light-emission-43.1 com nove membros. Essa é considerada a terceira versão do gold standard (utilizada na análise da VerbNet.Br).

As classes da VerbNet selecionadas para o gold standard, suas respectivas definições semânticas e as restrições, definidas pela Dra. Karin Kipper, para que o verbo pertença à classe são apresentadas no Apêndice $\mathrm{B}$. Na Tabela 18, os membros do gold standard do português são apresentados sumarizados; em negrito aparecem os verbos que foram adicionados posteriormente, durante a análise apresentada na Seção 7.3.2.

\footnotetext{
${ }^{56} \mathrm{http}: / /$ michaelis.uol.com.br/
} 
Tabela 18: Gold standard para o português do Brasil

\begin{tabular}{|c|c|}
\hline Classe & Membros \\
\hline amalgamate-22.2 (26 verbos) & $\begin{array}{l}\text { unificar, alternar, contrastar, combinar, juntar, comparar, } \\
\text { casar, reunir, bater, integrar, ligar, prender, aderir, aliar, } \\
\text { atar, atrelar, combinar, coordenar, grudar, harmonizar, } \\
\text { interligar, mesclar, misturar, relacionar, somar, ornar }\end{array}$ \\
\hline amuse-31.1 (117 verbos) & $\begin{array}{l}\text { frustar, chatear, alarmar, escandalizar, aterrorizar, } \\
\text { amedrontar, deliciar, apavorar, alegrar, decepcionar, } \\
\text { aborrecer, encantar, ofender, espantar, chocar, contrariar, } \\
\text { abalar, agradar, assustar, confundir, estimular, ferir, } \\
\text { ameaçar, abater, acalmar, afetar, animar, atrair, } \\
\text { atrapalhar, cegar, comover, consolar, desanimar, } \\
\text { desgraçar, deslumbrar, divertir, emocionar, empolgar, } \\
\text { excitar, fascinar, iludir, impressionar, incomodar, } \\
\text { indignar, induzir, inquietar, inspirar, intimidar, intrigar, } \\
\text { irritar, prejudicar, preocupar, revoltar, afligir, aliviar, } \\
\text { atormentar, cativar, confortar, constranger, contentar, } \\
\text { deprimir, desagradar, desapontar, descontentar, } \\
\text { desencorajar, desestimular, desonrar, distrair, } \\
\text { embaraçar, encorajar, enfurecer, entreter, entusiasmar, } \\
\text { envergonhar, horrorizar, humilhar, incendiar, inflamar, } \\
\text { penalizar, perturbar, sensibilizar, tranquilizar, satisfazer, } \\
\text { agitar, arrasar, cansar, enfraquecer, estremecer, } \\
\text { maravilhar, serenar, sossegar, torturar, acabrunhar, } \\
\text { acalentar, alucinar, aprazer, arrepiar, comprazer, } \\
\text { debilitar, deleitar, desconfortar, desesperar, desgostar, } \\
\text { enfadar, entristecer, esmorecer, exaltar, exaurir, exultar, } \\
\text { fatigar, impacientar, importunar, magoar, oprimir, } \\
\text { tolher, vexar, zangar }\end{array}$ \\
\hline characterize-29.2 (37 verbos) & $\begin{array}{l}\text { diagnosticar, pintar, retratar, encarar, classificar, identificar, } \\
\text { definir, representar, tratar, aceitar, adotar, caracterizar, } \\
\text { reconhecer, conceber, conhecer, considerar, dar, } \\
\text { entender, ter, tomar, ver, imaginar, interpretar, julgar, } \\
\text { olhar, recordar, rememorar, reproduzir, supor, } \\
\text { visualizar, perceber, tomar, conhecer, enxergar, } \\
\text { lembrar, taxar, achar }\end{array}$ \\
\hline correspond-36.1 (28 verbos) & $\begin{array}{l}\text { pechinchar, flertar, simpatizar, colidir, cooperar, interagir, } \\
\text { namorar, colaborar, unir, concordar, debater, discutir, } \\
\text { brigar, conviver, discordar, acordar, ajustar, combinar, } \\
\text { compactuar, comunicar, conciliar, conspirar, disputar, } \\
\text { negociar, pactuar, paquerar, relacionar, reunir. }\end{array}$ \\
\hline get-13.5.1 (18 verbos) & $\begin{array}{l}\text { arranjar, colher, reservar, adquirir, pegar, obter, buscar, } \\
\text { comprar, ganhar, conseguir, alugar, contratar, arrendar, } \\
\text { conquistar, angariar, apanhar, arrematar, capturar }\end{array}$ \\
\hline hit-18.1 (16 verbos) & $\begin{array}{l}\text { martelar, esmagar, espancar, bater, golpear, alvejar, } \\
\text { amassar, coçar, comprimir, cutucar, esbarrar, chutar, } \\
\text { chicotear, esbofetear, pisotear, socar }\end{array}$ \\
\hline light_emission-43.1 (9 verbos) & $\begin{array}{l}\text { resplandecer, raiar, cintilar, piscar, brilhar, refletir, alumiar, } \\
\text { faiscar, lucilar }\end{array}$ \\
\hline $\begin{array}{l}\text { manner_of_speaking-37.3 } \\
\text { verbos) }\end{array}$ & $\begin{array}{l}\text { cochichar, rosnar, sussurrar, berrar, resmungar, balbuciar, } \\
\text { bradar, murmurar, queixar, gritar, assobiar, cantar, ciciar, } \\
\text { gaguejar, grunhir, vociferar, confidenciar, gemer, } \\
\text { segredar, soprar }\end{array}$ \\
\hline $\begin{array}{l}\text { modes_of_being_with_motion-47.3 } \\
\text { (18 verbos) }\end{array}$ & $\begin{array}{l}\text { boiar, flutuar, vibrar, oscilar, agitar, balançar, brandir, } \\
\text { dançar, girar, pairar, palpitar, pulsar, sacudir, tremer, } \\
\text { inclinar, ondular, pender, rebolar }\end{array}$ \\
\hline
\end{tabular}




\begin{tabular}{|c|c|}
\hline Classe & Membros \\
\hline $\begin{array}{l}\text { nonverbal_expression-40.2 } \\
\text { verbos) }\end{array}$ & $\begin{array}{l}\text { bocejar, arfar, roncar, soluçar, suspirar, sorrir, chorar, rir, } \\
\text { assobiar, choramingar, delirar, fungar, gargalhar, } \\
\text { gemer, ofegar, ressonar, tossir, piscar }\end{array}$ \\
\hline other_cos-45.4 (117 verbos) & $\begin{array}{l}\text { suavizar, encurtar, afrouxar, alargar, estreitar, derreter, } \\
\text { dissipar, congelar, dissolver, afundar, enfraquecer, } \\
\text { aprofundar, contrair, fundir, intensificar, ampliar, abaixar, } \\
\text { abrandar, acalmar, acordar, afiar, afinar, agigantar, } \\
\text { alagar, alegrar, alisar, alongar, alvejar, amaciar, } \\
\text { amortecer, amplificar, apagar, aperfeiçoar, aplacar, } \\
\text { apressar, aprimorar, arrebentar, arrefecer, arrombar, } \\
\text { atenuar, avolumar, avultar, azedar, caiar, cegar, } \\
\text { cicatrizar, clarear, comprimir, condensar, corar, } \\
\text { cristalizar, curar, debilitar, degenerar, deprimir, } \\
\text { desacelerar, desandar, desatar, descentralizar, } \\
\text { desdobrar, desenrolar, desequilibrar, desestabilizar, } \\
\text { desfiar, destravar, dilatar, diluir, dourar, encurtar, } \\
\text { endurecer, entreabrir, envelhecer, enxugar, equilibrar, } \\
\text { escurecer, esfriar, estabilizar, estalar, esticar, estourar, } \\
\text { estrangular, expandir, explodir, fortalecer, furar, gelar, } \\
\text { inundar, manchar, matizar, melar, molhar, nivelar, } \\
\text { reacender, reanimar, reavivar, recrudescer, refrescar, } \\
\text { ressecar, secar, solidificar, sujar, umedecer, vergar, } \\
\text { abalar, abrir, acelerar, acender, agravar, apontar, } \\
\text { aquecer, despertar, detonar, encher, encolher, } \\
\text { engrossar, esquentar, fechar, lotar }\end{array}$ \\
\hline put-9.1 (25 verbos) & $\begin{array}{l}\text { cravar, posicionar, mergulhar, situar, inserir, depositar, } \\
\text { introduzir, meter, guardar, instalar, montar, pôr, colocar, } \\
\text { botar, implantar, incluir, enterrar, fincar, fixar, plantar, } \\
\text { dispor, encaixar, estacionar, intercalar, semear }\end{array}$ \\
\hline remove-10.1 (29 verbos) & $\begin{array}{l}\text { extirpar, erradicar, subtrair, descarregar, remover, extrair, } \\
\text { arrancar, recolher, eliminar, cortar, liberar, retirar, tirar, } \\
\text { isolar, destituir, excluir, expulsar, separar, abolir, } \\
\text { afastar, apagar, demitir, derrubar, despedir, destacar, } \\
\text { exonerar, exterminar, extinguir, sacar, suprimir }\end{array}$ \\
\hline run-51.3.2 (35 verbos) & $\begin{array}{l}\text { galopar, perambular, escorregar, deslizar, marchar, nadar, } \\
\text { passear, voar, caminhar, andar, correr, avançar, desfilar, } \\
\text { flutuar, pular, saltar, subir, vagar, engatinhar, escalar, } \\
\text { galgar, mergulhar, boiar, esvoaçar, mancar, cambalear, } \\
\text { cavalgar, escalar, esgueirar-se, rastejar, saltitar, } \\
\text { sonambular, trotar, ziguezaguear, gatinhar }\end{array}$ \\
\hline say-37.7 (40 verbos) & $\begin{array}{l}\text { recontar, segredar, reportar, retrucar, proclamar, exprimir, } \\
\text { replicar, formular, noticiar, narrar, mencionar, confiar, expor, } \\
\text { relatar, alegar, descrever, declarar, anunciar, responder, } \\
\text { falar, apresentar, afirmar, dizer, comunicar, contar, } \\
\text { ordenar, propor, citar, divulgar, informar, lembrar, } \\
\text { repetir, sugerir, confidenciar, notificar, reiterar, } \\
\text { exclamar, insinuar, verbalizar, revelar }\end{array}$ \\
\hline send-11.1 (14 verbos) & $\begin{array}{l}\text { despachar, transportar, remeter, desviar, emitir, transmitir, } \\
\text { transferir, enviar, mandar, deslocar, trazer, encaminhar, } \\
\text { expedir, remeter }\end{array}$ \\
\hline
\end{tabular}




\subsubsection{Análise da VerbNet.Br em relação ao gold standard}

Nesta seção é apresentada uma análise das classes do gold standard (terceira versão), em comparação com os resultados da VerbNet.Br. Foram utilizadas as medidas de precisão, abrangência e f-measure para análise. Para a tarefa de classificação em aprendizado de máquina, classes binárias são muitas vezes consideradas como positivas (classe de maior interesse) ou negativas. Os resultados, então, são analisados como: (i) verdadeiros positivos (VP): exemplos verdadeiros da classe positiva; (ii) verdadeiros negativos (VN): exemplos verdadeiros da classe negativa; (iii) falsos positivos (FP): exemplos classificados erroneamente como positivos; e (iv) falsos negativos (FN): exemplos classificados erroneamente como negativos. $\mathrm{O}$ interesse nesta abordagem é lidar com os erros (falsos positivos e negativos) e analisar o impacto deles na tarefa. Para avaliar a VerbNet.Br, considerou-se:

- VP: verbos de uma dada classe do gold standard que foram selecionados corretamente para esta classe;

- VN: verbos fora de uma dada classe do gold standard que foram descartados corretamente;

- FP: verbos selecionados erroneamente para uma dada classe do gold standard;

- FN: verbos descartados erroneamente para uma dada classe do gold standard.

As medidas de precisão e abrangência são, então, calculadas em termos de VP, FP e FN, conforme apresentado nas Fórmulas 1 e 2, respectivamente.

$$
\text { Precisão }=\frac{V P}{V P+F P}
$$

Fórmula 1: Cálculo da Precisão

$$
\text { Abrangência }=\frac{V P}{V P+F N}
$$

Fórmula 2: Cálculo da Abrangência

A f-measure é calculada de acordo com a Fórmula 3.

$$
F-\text { measure }=2 \frac{\text { precisão } * \text { abrangência }}{\text { precisão }+ \text { abrangência }}
$$

Fórmula 3: Cálculo da $f$-measure 
A precisão mede se todos os exemplos classificados como positivos são realmente positivos, ou seja, mede a relevância dos verbos que foram selecionado como positivos. A abrangência mede se foi classificada como positivos todos os exemplos que são positivos, em outras palavras, mede se todos os verbos relevantes (verbos que estão no gold standard) foram selecionados. A f-measure é uma média harmônica da precisão e abrangência.

Também foram calculadas a precisão, abrangência e f-measure globais (macro). Para isso, considerou-se as Fórmulas 4, 5 e 6 (em que $c$ representa cada classe).

$$
\begin{aligned}
& \text { Precisão } o_{\text {global }}=\frac{\sum \text { Precisão } o_{c}}{\text { número de classes }} \\
& \text { Fórmula 4: Cálculo da Precisão Global } \\
& \text { Abrangência }_{\text {global }}=\frac{\sum \text { Abrangência }_{c}}{\text { número de classes }} \\
& \text { Fórmula 5: Cálculo da Abrangência Global } \\
& F-\text { measure }=2 \frac{\text { Precisão }_{\text {global }} * \text { Abrangência }}{\text { global }}
\end{aligned}
$$

\section{Fórmula 6: Cálculo da $f$-measure Global}

É possível observar que a precisão global e a abrangência global (Fórmulas 4 e 5) são a média das precisões e abrangências de cada classe. Já a f-measure é calculada com base nessas médias (é diferente da média das f-measures de cada classe).

Primeiramente, calculou-se a precisão, abrangência e $f$-measure considerando todos os verbos selecionados na Etapa 3 com uma única restrição: ter frequência maior do que dez no córpus da Etapa 2. Estes resultados foram chamados de EXP0 (resultados apresentados junto com os resultados dos demais experimentos e considerado como baseline) e foram necessários para definir os valores empíricos de EXP1, EXP2, EXP3 e EXP4 (conforme apresentados no Capítulo 6). Para definir a taxa de aceitação de EXP1 e EXP2, verificou-se qual valor (variando de $10 \%$ a $70 \%$ ) maximizava a $f$-measure global. $\mathrm{O}$ valor de $10 \%$ foi o que apresentou melhor $f$-measure global e superou o resultado para EXP0. Logo, selecionar os verbos que apresentem pelo menos o teto de $10 \%$ dos frames da classe, significa aceitar pelo menos um frame, uma vez que não há classes com mais de dez frames definidos. Para EXP3 e EXP4, seguindo a mesma ideia, tentou-se maximar a $f$ - 
measure global variando os valores de número de verbos (entre dez e 20) e número de frames para seleção (variando entre um e cinco). $\mathrm{O}$ melhor resultado foi obtido para no máximo um frame (selecionado-se apenas um frame, não há necessidade de restringir o número de verbos).

Foram analisadas as classes para cada um dos quatro experimentos (EXP1 a EXP4). Detalhes sobre os verbos selecionados como VP, FP, VN e FN são apresentados no Apêndice C. Para verificar se havia diferença significativa entre os valores globais de precisão e abrangência, foi considerado o teste t-student com $p<0,05$. O mesmo cálculo foi realizado para a f-measure, porém vale comentar que a diferença significativa é calculada com base nas $f$-measures de cada classe e não reflete a diferença significativa das f-measures globais. Para verificar se havia diferença significativa entre os resultados de precisão e abrangência entre os experimentos (sem EXP0) utilizou-se o teste estatístico ANOVA, também com $p<0,05$. Utilizou-se o mesmo teste para a $f$-measure porém com a mesma resssalva feita para o teste $t$-student.

Os resultados de precisão para cada um dos experimentos (incluindo EXP0), considerando cada classe do gold standard (local) e precisão global, são apresentados na Tabela 19.

Tabela 19: Resultados de precisão para os experimentos considerando as classes do gold standard

\begin{tabular}{|l|l|l|l|l|l|}
\hline \multicolumn{5}{|c|}{ Precisão } \\
\hline & EXP0 & EXP1 & EXP2 & EXP3 & EXP4 \\
\hline amalgamate-22.2 & 29,27 & $\mathbf{2 9 , 2 7}$ & 29,27 & 29,85 & 29,85 \\
\hline amuse-31.1 & 42,57 & $\mathbf{4 2 , 2 8}$ & 42,74 & 42,22 & 42,22 \\
\hline characterize-29.2 & 35,62 & $\mathbf{7 2 , 7 3}$ & 46,00 & 36,62 & 36,62 \\
\hline correspond-36.1 & 36,84 & 35,56 & 38,46 & 35,56 & 34,78 \\
\hline get-13.5.1 & 20,90 & $\mathbf{2 1 , 8 8}$ & $\mathbf{2 1 , 8 8}$ & $\mathbf{2 1 , 8 8}$ & $\mathbf{2 1 , 8 8}$ \\
\hline hit-18.1 & 50,00 & 55,56 & 55,56 & 55,56 & 55,56 \\
\hline light_emission-43 & 45,00 & 45,00 & 45,00 & 43,75 & 43,75 \\
\hline manner_of_speaking-37.3 & 50,00 & 50,00 & 50,00 & 46,67 & 46,67 \\
\hline modes_of_being_with_motion-47.3 & 51,72 & 51,72 & 51,72 & 56,00 & 56,00 \\
\hline nonverbal_expression-40.2 & 36,00 & 37,50 & 36,00 & 45,00 & 45,00 \\
\hline other_cos-45.4 & 30,21 & 30,71 & 30,71 & 34,39 & 34,39 \\
\hline put-9.1 & 48,84 & 57,69 & 57,14 & 51,22 & 51,22 \\
\hline remove-10.1 & 39,13 & 40,91 & 40,91 & 40,91 & 40,91 \\
\hline run-51.3.2 & 35,94 & 36,51 & 35,94 & 40,74 & 40,74 \\
\hline say-37.7 & 40,68 & 41,07 & 41,07 & 41,07 & 41,07 \\
\hline send-11.1 & 71,43 & 71,43 & 71,43 & 71,43 & 71,43 \\
\hline GLOBAL & $\mathbf{4 1 , 5 1}$ & $\mathbf{4 4 , 9 9}$ & $\mathbf{4 3 , 3 6}$ & $\mathbf{4 3 , 3 0}$ & $\mathbf{4 3 , 2 6}$ \\
\hline
\end{tabular}

O experimento que maximizou a precisão (maior valor para a precisão global) foi o EXP1 (44,99\%). A classe get-13.5.1 apresentou a precisão mais baixa $(21,88 \%)$ em todos 
os experimentos, e a classe characterize-29.2 apresentou o maior valor de precisão no EXP1 (72,73\%). Todos os experimentos superaram a precisão de EXP0, porém não é possível afirmar que há diferença significativa entre os resultados dos quatro experimentos e o EXP0 quando aplicado o teste t-student. Também não é possível afirmar se há diferença significativa entre os experimentos EXP1 a EXP4 quando aplicado o teste ANOVA.

Na Tabela 20 são apresentados os resultados de abrangência (local e global).

Tabela 20: Resultados de abrangência para os experimentos considerando as classes do gold standard

\begin{tabular}{|l|l|l|l|l|l|}
\hline \multicolumn{5}{|c|}{ Abrangência } \\
\hline & EXP0 & EXP1 & EXP2 & EXP3 & EXP4 \\
\hline amalgamate-22.2 & 100 & $\mathbf{1 0 0}$ & $\mathbf{1 0 0}$ & $\mathbf{8 3 , 3 3}$ & $\mathbf{8 3 , 3 3}$ \\
\hline amuse-31.1 & 100 & $\mathbf{9 2 , 8 6}$ & $\mathbf{9 4 , 6 4}$ & $\mathbf{8 4 , 8 2}$ & $\mathbf{8 4 , 8 2}$ \\
\hline characterize-29.2 & 100 & $\mathbf{6 1 , 5 4}$ & $\mathbf{8 8 , 4 6}$ & $\mathbf{1 0 0}$ & $\mathbf{1 0 0}$ \\
\hline correspond-36.1 & 100 & $\mathbf{7 6 , 1 9}$ & $\mathbf{9 5 , 2 4}$ & $\mathbf{7 6 , 1 9}$ & $\mathbf{7 6 , 1 9}$ \\
\hline get-13.5.1 & 100 & $\mathbf{1 0 0}$ & $\mathbf{1 0 0}$ & $\mathbf{1 0 0}$ & $\mathbf{1 0 0}$ \\
\hline hit-18.1 & 100 & $\mathbf{9 0 , 9 1}$ & $\mathbf{9 0 , 9 1}$ & $\mathbf{9 0 , 9 1}$ & $\mathbf{9 0 , 9 1}$ \\
\hline light_emission-43 & 100 & $\mathbf{1 0 0}$ & $\mathbf{1 0 0}$ & $\mathbf{7 7 , 7 8}$ & $\mathbf{7 7 , 7 8}$ \\
\hline manner_of_speaking-37.3 & 100 & $\mathbf{1 0 0}$ & $\mathbf{1 0 0}$ & $\mathbf{8 7 , 5 0}$ & $\mathbf{8 7 , 5 0}$ \\
\hline modes_of_being_with_motion-47.3 & 100 & $\mathbf{1 0 0}$ & $\mathbf{1 0 0}$ & $\mathbf{9 3 , 3 3}$ & $\mathbf{9 3 , 3 3}$ \\
\hline nonverbal_expression-40.2 & 100 & $\mathbf{1 0 0}$ & $\mathbf{1 0 0}$ & $\mathbf{1 0 0}$ & $\mathbf{1 0 0}$ \\
\hline other_cos-45.4 & 100 & $\mathbf{9 7 , 4 1}$ & $\mathbf{9 7 , 4 1}$ & $\mathbf{9 3 , 1 0}$ & $\mathbf{9 3 , 1 0}$ \\
\hline put-9.1 & 100 & $\mathbf{7 1 , 4 3}$ & $\mathbf{7 6 , 1 9}$ & $\mathbf{1 0 0}$ & $\mathbf{1 0 0}$ \\
\hline remove-10.1 & 100 & $\mathbf{1 0 0}$ & $\mathbf{1 0 0}$ & $\mathbf{1 0 0}$ & $\mathbf{1 0 0}$ \\
\hline run-51.3.2 & 100 & $\mathbf{1 0 0}$ & $\mathbf{1 0 0}$ & $\mathbf{9 5 , 6 5}$ & $\mathbf{9 5 , 6 5}$ \\
\hline say-37.7 & 100 & $\mathbf{9 5 , 8 3}$ & $\mathbf{9 5 , 8 3}$ & $\mathbf{9 5 , 8 3}$ & $\mathbf{9 5 , 8 3}$ \\
\hline send-11.1 & 100 & $\mathbf{8 3 , 3 3}$ & $\mathbf{1 0 0}$ & $\mathbf{1 0 0}$ & $\mathbf{1 0 0}$ \\
\hline GLOBAL & $\mathbf{1 0 0}$ & $\mathbf{9 2 , 8 7}$ & $\mathbf{9 6 , 1 7}$ & $\mathbf{9 2 , 4 0}$ & $\mathbf{9 2 , 4 0}$ \\
\hline
\end{tabular}

No caso da abrangência, o experimento que maximizou os resultados foi o EXP2 (96,17\%). Todas as classes apresentaram abrangência superior a 70\% para todos os experimentos, o que pode ser explicado pelos fato de que os parametros definidos empiricamente são pequenos para diminuir a abrangência dos resultados. A classe amalgamate-22.2 apresentou 100\% de abrangência nos experimentos EXP1 e EXP2, o que era esperado, já que todos os candidatos a membros da classe foram selecionados (uma vez que a classe não apresenta alternâncias na Etapa1). EXP0 apresentou 100\% de abrangência para todas as classes, o que era esperado, pois todos os verbos candidatos foram selecionados neste primeiro experimento. Neste caso, há diferença significativa entre os resultados dos quatro experimentos e o EXP0, quando aplicado o teste $t$-student. Porém, não é possível afirmar que existe diferença significativa entre os valores de abrangência de EXP1 a EXP4, utilizando o teste ANOVA. 
Por fim, na Tabela 21, são apresentados os resultados de $f$-measure (local e global).

Tabela 21: Resultados de $f$-measure para os experimentos considerando as classes do gold standard

\begin{tabular}{|l|l|l|l|l|l|}
\hline \multicolumn{5}{|c|}{$\boldsymbol{f}$-measure } \\
\hline & $\mathrm{EXP} 0$ & $\mathrm{EXP} 1$ & $\mathrm{EXP} 2$ & $\mathrm{EXP} 3$ & EXP4 \\
\hline amalgamate-22.2 & 45,28 & 45,28 & 45,28 & 43,96 & 43,96 \\
\hline amuse-31.1 & 59,73 & 58,10 & 58,89 & 56,38 & 56,38 \\
\hline characterize-29.2 & 52,53 & 66,67 & 60,53 & 53,61 & 53,61 \\
\hline correspond-36.1 & 53,85 & 48,48 & 54,79 & 48,48 & 47,76 \\
\hline get-13.5.1 & 34,57 & $\mathbf{3 5 , 9 0}$ & $\mathbf{3 5 , 9 0}$ & $\mathbf{3 5 , 9 0}$ & $\mathbf{3 5 , 9 0}$ \\
\hline hit-18.1 & 66,67 & 68,97 & 68,97 & 68,97 & 68,97 \\
\hline light_emission-43 & 62,07 & 62,07 & 62,07 & 56,00 & 56,00 \\
\hline manner_of_speaking-37.3 & 66,67 & 66,67 & 66,67 & 60,87 & 60,87 \\
\hline modes_of_being_with_motion-47.3 & 68,18 & 68,18 & 68,18 & 70,00 & 70,00 \\
\hline nonverbal_expression-40.2 & 52,94 & 54,55 & 52,94 & 62,07 & 62,07 \\
\hline other_cos-45.4 & 46,40 & 46,69 & 46,69 & 50,23 & 50,23 \\
\hline put-9.1 & 65,63 & 63,83 & 65,31 & 67,74 & 67,74 \\
\hline remove-10.1 & 56,25 & 58,06 & 58,06 & 58,06 & 58,06 \\
\hline run-51.3.2 & $\mathbf{5 2 , 8 7}$ & 53,49 & 52,87 & 57,14 & 57,14 \\
\hline say-37.7 & 57,83 & $\mathbf{5 7 , 5 0}$ & 57,50 & 57,50 & 57,50 \\
\hline send-11.1 & 83,33 & $\mathbf{8 3 , 3 3}$ & $\mathbf{8 3 , 3 3}$ & $\mathbf{8 3 , 3 3}$ & $\mathbf{8 3 , 3 3}$ \\
\hline GLOBAL & $\mathbf{5 8 , 6 7}$ & $\mathbf{6 0 , 6 2}$ & $\mathbf{5 9 , 7 7}$ & $\mathbf{5 8 , 9 7}$ & $\mathbf{5 8 , 9 3}$ \\
\hline
\end{tabular}

$\mathrm{O}$ melhor resultado para $f$-measure global foi obtido pelo EXP1 (60,62\%). A classe send-11.1 obteve os melhores resultados individuais de $f$-measure $(83,33 \%)$ em todos os experimentos. A classe get-13.5.1 obteve os piores resultados em todos os experimentos $(35,90 \%)$. Porém, não há diferença significativa, entre as $f$-measures das classes, quando se compara os resultados dos experimentos com o EXP0, de acordo com o teste $t$-student. Também não é possível afirmar se há diferença significativa entre os resultados de EXP1 a EXP4, utilizando o teste ANOVA.

A Figura 20 apresenta graficamente os resultados de Precisão, Abrangência e $f$ measure global. 


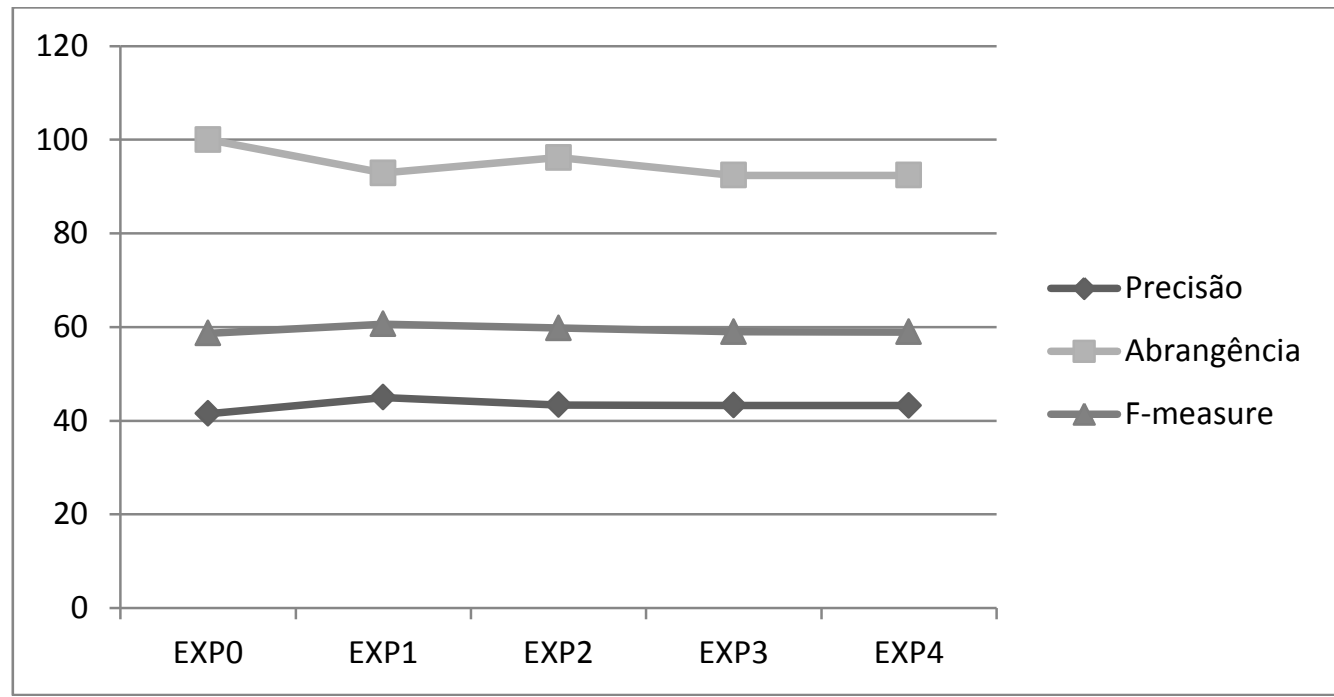

Figura 20: Precisão, Abrangência e $f$-measure global para todos os experimentos

Com os resultados apresentados nas Tabelas 19, 20 e 21, é possível concluir que a Etapa 1 do método pode ser descartada, uma vez que é possível obter resultados comparáveis sem considerá-la. Mais do que isso, toda a Etapa 4 poderia ser descartada, uma vez que não há diferença significativa entre os resultados de precisão de EXP0 e os resultados dos demais experimentos (além do que a abrangência é significativamente maior do que os demais experimentos). Porém, descartar a Etapa 1 implica perder os alinhamentos com os frames do inglês e, consequentemente, perder possíveis alinhamentos com os predicados semânticos (uma vez que esses estão definidos para cada frame). Portanto, como um requisito da VerbNet.Br era herdar a maior quantidade de informação da VerbNet (definido na hipótese (a)) e os resultados de precisão dos experimentos não são discrepantes, os resultados que se decidiu reportar no Apêndice A foram os resultados do EXP1 que apresentou os melhores resultados para precisão, abrangência (quando comparado aos demais experimentos) e $f$-measure.

Outra análise interessante que pode ser feita, utilizando os resultados dos experimentos EXP3 e EXP4 (experimentos que agrupam verbos de acordo com os frames mais frequentes dos candidatos) é que a hipótese de Levin se comprova, com certa precisão e cobertura, para o português. Das dezesseis classes, treze apresentaram $f$-measure superior a 50\% em EXP3 e EXP4. Isso significa que é possível agrupar os verbos do português também partindo da hipótese de Levin. 


\subsubsection{Análise comparativa com a tarefa de agrupamento de verbos}

Como observou-se no Capítulo 6, o método de criação da VerbNet.Br é linguisticamente motivado e com alto custo, dada a existência de uma etapa manual e dada a necessidade da pré-existência de outros recursos alinhados. Portanto, decidiu-se comparar os resultados desse método com resultados de um método completamente automático, baseado em córpus, como os métodos de agrupamento de verbos apresentados no Capítulo 5. A tarefa de agrupamento de verbos foi realizada sob orientação da Profa. Dra. Anna Korhonen da Universidade de Cambridge no Reino Unido, durante estágio de pesquisa no exterior ${ }^{57}$, realizado pela aluna em questão.

Para realizar a atividade de agrupamento de verbos, foi necessário ter como base um gold standard das classes a serem agrupadas (a tarefa é realizada considerando somente essas classes - sem considerar outras classes e outros verbos). Foi para essa etapa de agrupamento de verbos que o gold standard foi inicialmente construído pela Dra. Karin Kipper. Como a etapa de comparação com os resultados VerbNet.Br foi realizada após a conclusão da etapa de agrupamento de verbos, o gold standard aqui utilizado corresponde à segunda versão (verbos da Tabela 15 que não aparecem em negrito).

Para melhor realizar esta tarefa, algumas modificações foram feitas na ferramenta de Zanette et al. (2012), para que a mesma pudesse extrair mais informações úteis para os atributos da tarefa:

- Inclusão da informação de tempo e modo verbal extraídas das etiquetas do parser PALAVRAS,

- Armazenamento da posição dos argumentos na sentença,

- Armazenamento da posição do verbo na sentença,

- Armazenamento do frame sem preposições.

Como atributos, foram selecionados os sete atributos que obtiveram melhor desempenho na tarefa para o francês em Sun et al. (2010), considerando o tipo de atributo. Seguindo a nomenclatura reportada no referido artigo, os atributos selecionados foram:

\footnotetext{
${ }^{57}$ Estágio Financiado pela FAPESP, via bolsa BEPE.
} 
- Atributos com informações básicas dos SCFs:

- F1: SCFs e suas frequências relativas para cada verbo (sem considerar as preposições - por isso, não há colchetes em SP) Exemplo: A menina gosta de sorvete - SUBJ[SN] V SP

- F2: F1 com informações sobre o tempo verbal - esta informação foi retirada da saída do PALAVRAS

○ F3: F1 com a informação da preposição (por isso, observa-se uso de colchetes no exemplo) - Exemplo: A menina gosta de sorvete SUBJ[SN] V SP[de]

- Atributos com informações sobre o contexto lexical (co-ocorrências). Estes atributos foram selecionados de acordo com Li and Brew (2008). As palavras (collocations - COs) relacionadas são extraídas de uma janela de palavras imediatamente antes e/ou depois do verbo. Stop words são removidas antes do processo e foram considerados os lemas das palavras:

- F7: COs são extraídas de uma janela de seis palavras, considerando a posição relativa das palavras - Exemplos: A menina bonita gosta de sorvete de uva - COs: menina e bonita antes do verbo e sorvete e uva depois do verbo.

- Atributos com informações de preferências lexicais:

- F13: tipo e frequência de preposições na relação SP, combinado com o tipo e frequência de substantivos nas posições de sujeito, objeto direto ou indireto.

O F16: atributo F3 combinado com o atributo F13.

- Atributos com informações de restrições seletivas (selectional preferences):

○ F17: combinação de F3 com a informação de restrições seletivas.

Para a extração deste atributo de restrições seletivas foi necessário conhecer as restrições seletivas de cada verbo. Dado que não havia recurso com tais informações, adotou-se o mesmo método automático utilizado para o 
francês em Sun et al. (2010) e para o inglês em Sun e Korhonen (2009). Esse método realiza o agrupamento dos argumentos dos verbos, de acordo com sua função (Sujeito, Objeto direto ou indireto). O algoritmo consiste em:

i. identificar as relações gramaticais (Sujeito e Objeto) de todos os verbos;

ii. extrair o elemento principal dessas relações e;

iii. classificar os $\mathrm{N}$ mais frequentes elementos em $\mathrm{M}$ classes. Utilizou-se $\mathrm{N}$ igual a 20 e experimentou-se com $\mathrm{M}$ igual a 20 e a 30 e selecionou-se $\mathrm{M}=30$, pois este apresentou melhores resultados.

Primeiramente, utilizou-se o algoritmo K-means com a medida de distância de cossenos. Decidiu-se iniciar por este algoritmo, pois além de poder ser utilizado como baseline, era o algoritmo com o qual possuía-se maior familiaridade. Além disso, existe uma boa implementação desse algoritmo na biblioteca NLTK $^{58}$ para a linguagem Python, o que serviu como um bom motivo para aprendizado da linguagem Python.

Após adquirir os resultados de baseline, iniciaram-se experimentos com o algoritmo MNCut Spectral Cluster (Meila e Shi, 2001) - algoritmo utilizado para a mesma tarefa no inglês e no francês. Este algoritmo recebe como entrada uma matriz de similaridade e utiliza probabilidades para encontrar os melhores grupos de verbos. Foi utilizada uma implementação pronta do MNCut Spectral Cluster, desenvolvida por Lin Sun.

Após analisar alguns resultados promissores, testou-se um novo algoritmo, mais robusto do que o Spectral Cluster. O novo algoritmo, chamado DCD (Yang e Oja, 2012) utiliza métodos estocásticos para realizar a tarefa de agrupamento. Assim como no caso do MNCut Spectral Cluster, esse algoritmo foi desenvolvido por Lin Sun (apesar de aluna em questão ter ajudado a acertar alguns parâmetros do algoritmo).

Os resultados foram avaliados quantitativamente utilizando duas medidas (Sun et al., 2010):

- Modified Purity (mPur): medida global que avalia a precisão média dos grupos de verbos. Cada grupo de dados é a associado com a classe que mais aparece nele. $\mathrm{O}$ número de verbos num grupo de dados $\mathrm{K}$ que pertence a essa classe é representado por $\mathrm{n}_{\text {prevalent }}(\mathrm{K})$ e os outros verbos são

\footnotetext{
${ }^{58}$ http://nltk.org/
} 
considerados erros. Clusters com $\mathrm{n}_{\text {prevalent }}(\mathrm{K})=1$ são descartados para não incluir erros de grupos unitários (vide Fórmula 7).

$$
m \text { Pur }=\frac{\sum_{n_{\text {prevalent }}\left(k_{i}\right)>2} n_{\text {prevalent }}\left(k_{i}\right)}{\text { number of verbs }}
$$

Fórmula 7: Cálculo da medida mPur

- Weighted Class Accuracy (ACC): proporção de membros do grupo de dados dominante (DOM-CLUST $_{\mathrm{i}}$ ) em todas as classes (vide Fórmula 8).

$$
A C C=\frac{\sum_{i=1}^{C} \text { verbs in } D O M-C L U S T_{i}}{\text { number of verbs }}
$$

Fórmula 8: Cálculo da medida ACC

As medidas mPur e ACC podem ser consideradas como precisão e abrangência, respectivamente. Portanto, utilizamos estas medidas para o cálculo da f-measure (vide Fórmula 9).

$$
F=\frac{2 * m P u r * A C C}{m P u r+A C C}
$$

Fórmula 9: Cálculo da medida $f$-measure

Foram realizados experimentos variando-se o número de grupos de verbos entre dois e 25 (dado que todos os algoritmos necessitavam do número de grupos como parâmetro de entrada). Vale comentar que foram utilizados os sete atributos com os valores de frequência normalizados. Aqui são apresentados apenas os resultados considerando dezesseis grupos de verbos, os demais resultados são apresentados no Apêndice D. Na Tabela 22, é possível observar os resultados de $f$-measure considerando dezesseis grupos de dados, todos os atributos e para todos os algoritmos.

Tabela 22: Resultados de $\boldsymbol{f}$-measure para 16 classe
\begin{tabular}{|l|c|c|c|}
\hline \multicolumn{4}{|c|}{ f-measure (16 classes) } \\
\hline & K-means & Spectral & DCD \\
\hline F1 & 33,16 & $\mathbf{3 9 , 8 2}$ & 35,22 \\
\hline F2 & 27,73 & $\mathbf{3 7 , 1 0}$ & 36,64 \\
\hline F3 & 39,51 & 41,21 & $\mathbf{4 2 , 4 6}$ \\
\hline F7 & 33,13 & $\mathbf{3 8 , 7 5}$ & 35,86 \\
\hline F13 & 29,95 & 36,03 & $\mathbf{3 6 , 9 8}$ \\
\hline F16 & 32,10 & $\mathbf{3 8 , 7 0}$ & 35,85 \\
\hline F17 & 37,70 & $\mathbf{4 2 , 9 3}$ & 38,61 \\
\hline
\end{tabular}

É possível observar na Tabela 22 que o melhor desempenho foi alcançado com o algoritmo MNCut Spectral Cluster e com o atributo F17 (42,93\% de $f$-measure). Também 
é possível observar que o algoritmo DCD somente supera o Spectral Cluster em F3 (42,46\% de f-measure contra 41,21\% do Spectral Cluster) e em F13 (36,98\% de $f$-measure contra $36,03 \%$ do Spectral Cluster). Nos demais casos, o Spectral Cluster é melhor que o novo método. Também é importante dizer que ambos os métodos superaram o K-means, considerado como baseline.

Na Tabela 23, há uma comparação dos desvios padrão para cada atributo em cada algoritmo.

Tabela 23: Resultados de desvio padrão

\begin{tabular}{|l|c|c|c|}
\hline \multicolumn{4}{|c|}{ STD (2 to 25 classes) } \\
\hline & K-means & Spectral & DCD \\
\hline F1 & 7,163568 & 7,733457 & $\mathbf{6 , 6 2 8 6 4 8}$ \\
\hline F2 & 5,008798 & 6,89312 & $\mathbf{6 , 5 9 0 4 7 8}$ \\
\hline F3 & 7,293219 & 9,692708 & $\mathbf{9 , 4 6 4 6 0 4}$ \\
\hline F7 & 4,966054 & 9,65505 & $\mathbf{6 , 3 3 0 6 5 1}$ \\
\hline F13 & 6,054268 & 7,802301 & $\mathbf{7 , 6 0 2 2 5 4}$ \\
\hline F16 & 6,034365 & 8,527191 & $\mathbf{7 , 8 0 1 2 3 2}$ \\
\hline F17 & 7,2201 & 8,6522 & $\mathbf{7 , 9 4 2 8 3 1}$ \\
\hline
\end{tabular}

É interessante observar que o desvio padrão do DCD é menor do que o do Spectral Cluster em todos os cenários. Pode-se dizer, então, que os resultados do DCD são mais homogêneos.

Para comparar os resultados da tarefa de agrupamento de verbos com a VerbNet.Br, foi necessário repetir a tarefa para o novo gold standard. Como a intenção é fazer uma comparação justa, somente os atributos F1 e F3 foram considerados, pois são os mesmos atributos considerados nos experimentos EXP1, EXP2, EXP3 e EXP4. Escolheu-se, também, repetir os experimentos somente para os algoritmos MNCut Spectral Cluster e DCD. Para realizar esta tarefa, foi necessário decidir uma classe para verbos ambíguos, uma vez que, para realizar a tarefa de agrupamento, cada verbo só pode pertencer a uma classe. A decisão foi tomada intuitivamente (uma vez que não há córpus anotados com informações de sentido), tentando escolher o sentido mais geral. Na Tabela 24 são apresentados os verbos ambíguos (as classes escolhidas são apresentadas em negrito). 
Tabela 24: Verbos ambíguos no gold standard do português

\begin{tabular}{|l|l|}
\hline \multicolumn{1}{|c|}{ Verbo } & \multicolumn{1}{c|}{ Classes } \\
\hline acordar & correspond-36.1, other_cos-45.4 \\
\hline alegrar & amuse-31.1, other_cos-45.4 \\
\hline acalmar & amuse-31.1, other_cos-45.4 \\
\hline assobiar & manner_speaking-37.3, nonverbal_exprression-40.2 \\
\hline abalar & amuse-31.1, other_cos-45.4 \\
\hline confidenciar & say-37.7, manner_speaking-37.3 \\
\hline apagar & remove-10.1, other_cos-45.4 \\
\hline agitar & amuse-31.1, modes_of_being_with_motion-47.3 \\
\hline comunicar & correspond-36.1, say-37.7 \\
\hline bater & hit-18.1, amalgamate-22.2 \\
\hline alvejar & hit-18.1, other_cos-45.4 \\
\hline flutuar & modes_of_being_with_motion-47.3, run-51.3.2 \\
\hline mergulhar & run-51.3.2, put-9.1 \\
\hline piscar & nonverbal_exprression-40.2, light_emission-43.1 \\
\hline relacionar & amalgamate-22.2, correspond-36.1 \\
\hline gemer & manner_speaking-37.3, nonverbal_exprression-40.2 \\
\hline boiar & modes_of_being_with_motion-47.3,run-51.3.2 \\
\hline reunir & amalgamate-22.2, correspond-36.1 \\
\hline comprimir & hit-18.1, other_cos-45.4 \\
\hline lembrar & characterize-29.2, say-37.7 \\
\hline esvoaçar & modes_of_being_with_motion-47.3, run-51.3.2 \\
\hline combinar & amalgamate-22.2, correspond-36.1 \\
\hline deprimir & amuse-31.1, other_cos-45.4 \\
\hline debilitar & amuse-31.1, other_cos-45.4 \\
\hline unir & amalgamate-22.2, correspond-36.1 \\
\hline cegar & amuse-31.1, other_cos-45.4 \\
\hline enfraquecer & \\
\hline &
\end{tabular}

Comparou-se os resultados da VerbNet.Br com os resultados da atividade de agrupamento de verbos considerando a f-measure, precisão e abrangência globais (como apresentado na Tabela 25) - escolheu-se o resultado dos atributos F1 e F3, pois tem como base os SCFs que também são parte do método utilizado para seleção dos membros da VerbNet.Br. Além disso, F3 foi o atributo que apresentou melhores resultados para a tarefa de agrupamento de verbos.

Tabela 25: Comparação dos resultados da VerbNet.Br com os resultados da tarefa de agrupamento de verbos

\begin{tabular}{|l|c|c|c|c|c|c|c|c|c|}
\hline & \multicolumn{4}{|c|}{ Agrupamento de verbos } & \multicolumn{5}{c|}{ VerbNet.Br } \\
\hline & Spec & Spec & DCD & DCD & EXP0 & EXP1 & EXP2 & EXP3 & EXP4 \\
& F3 & F1 & F3 & & & & & \\
\hline f-measure & 37,56 & 41,61 & 47,10 & 49,07 & 58,67 & $\mathbf{6 0 , 6 2}$ & 59,77 & 58,97 & 58,93 \\
\hline Precisão & 37,99 & 40,89 & 42,01 & 44,21 & 41,51 & $\mathbf{4 4 , 9 9}$ & 43,36 & 43,30 & 43,26 \\
\hline Abrangência & 37,14 & 42,36 & 53,58 & 55,13 & $\mathbf{1 0 0}$ & 92,87 & 96,17 & 92,40 & 92,40 \\
\hline
\end{tabular}

$\mathrm{O}$ melhor resultado para $f$-measure foi apresentado pelo EXP1 da VerbNet.Br, seguido pelo EXP2. Todos os resultados de precisão, abrangência e f-measure da VerbNet.Br foram melhores dos que os resultados da tarefa de agrupamento. A melhor 
precisão foi obtida pelo EXP1 $(44,99 \%)$ e a melhor abrangência foi obtida em EXP0 (como era de se esperar).

Apesar de a VerbNet.Br apresentar melhores resultados do que a tarefa de agrupamento, não é possível concluir que o método semiautomático e linguisticamente motivado é melhor do que o método completamente automático. O que se pode inferir é que, numa possível extensão do método de agrupamento, a VerbNet.Br possa se beneficiar dos seus resultados. Além disso, pode-se observar que o uso do novo gold standard atingiu melhores resultados de f-measure no algoritmo $\mathrm{DCD}$, o que mostra que esse ainda é um campo a ser explorado para o português.

\subsubsection{Avaliação Intrínseca Quantitativa}

A abordagem quantitativa foi realizada considerando-se os membros das classes. Para isso, foi calculada a taxa de membros aceitos de acordo com a Fórmula 10 (considerando cada classe: Taxa de $\operatorname{aceitos}_{\mathrm{m}}(\mathrm{i})$ ) e com a Fórmula 11 (considerando a

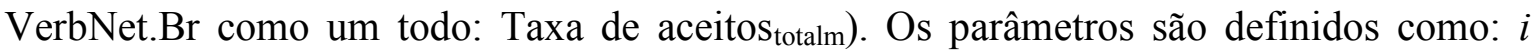
representa cada classe $(i>0) ; m_{i}$ é o número de membros aceitos da classe $i, n_{i}$ é o número total de candidatos a membros da classe $i$, e $t$ é o número total de classes.

$$
\text { Taxa de } \operatorname{aceitos}_{m}(i)=\frac{m_{i}}{n_{i}}(i>0)
$$

Fórmula 10: Taxa de membros aceitos em cada classe

$$
\text { Taxa de aceitos } S_{\text {totalm }}=\frac{\sum_{0}^{t} m_{i}}{\sum_{0}^{t} n_{i}}(i>0)
$$

Fórmula 11: Taxa de membros aceitos em toda a VerbNet.Br

Os resultados para as classes do gold standard (considerando os quatro experimentos) são apresentados na Tabela 26 (os resultados para as demais classes são apresentados no Apêndice A). Nesta mesma tabela é apresentada a taxa de aceitação global. 
Tabela 26: Taxa de membros aceitos para cada classe do gold standard

\begin{tabular}{|l|c|c|c|c|}
\hline \multicolumn{1}{|c|}{ Classe } & \multicolumn{4}{c|}{ Taxa de membros aceitos } \\
& (por classe) \\
\hline & EXP1 & EXP2 & EXP3 & EXP4 \\
\hline amalgamate-22.2* & - & - & 81,71 & 81,71 \\
\hline amuse-31.1 & 93,54 & 94,30 & 85,56 & 85,55 \\
\hline characterize-29.2 & 30,14 & 68,49 & 97,26 & 97,26 \\
\hline correspond-36.1 & 78,95 & 91,23 & 78,95 & 80,70 \\
\hline get-13.5.1 & 95,52 & 95,52 & 95,52 & 95,52 \\
\hline hit-18.1 & 81,82 & 81,82 & 81,82 & 81,82 \\
\hline light_emission-43 & 100 & 100 & 80,00 & 80,00 \\
\hline manner_of_speaking-37.3 & 100 & 100 & 93,75 & 93,75 \\
\hline modes_of_being_with_motion-47.3 & 100 & 100 & 86,21 & 86,21 \\
\hline nonverbal_expression-40.2 & 96,00 & 100 & 80,00 & 80,00 \\
\hline other_cos-45 & 95,83 & 95,83 & 81,77 & 81,77 \\
\hline put-9.1 & 60,47 & 65,12 & 95,35 & 95,35 \\
\hline remove-10.1 & 95,65 & 95,65 & 95,65 & 95,65 \\
\hline run-51.3.2 & 98,44 & 100 & 84,36 & 84,36 \\
\hline say-37.7 & 94,92 & 94,92 & 94,92 & 94,92 \\
\hline send-11.1 & 100 & 100 & 100 & 100 \\
\hline GLOBAL & 89,82 & 91,48 & 89,99 & 90,13 \\
\hline
\end{tabular}

* a classe amalgamate-22.2 não apresenta taxa de aceitação em EXP1 e EXP2, pois não teve alternâncias traduzidas na Etapa 1.

É possível observar na Tabela 26, que a classe send-11.1 apresenta a maior aceitação $(100 \%)$ em todos os experimentos. Um resultado esperado era de que EXP2 apresentasse maiores valores do que EXP1, uma vez que EXP2 não especifica as preposições dos SPs. Essa expectativa se confirmou e EXP2 também apresentou a maior taxa de aceitação global $(91,48 \%)$ dentre todos os experimentos.

\subsection{Outras Contribuições}

Além da construção da VerbNet.Br, outras atividades complementares foram realizadas durante este mestrado. Na Seção 7.4.1 é apresentada a ferramenta de consulta a base de dados da VerbNet.Br. Na Seção 7.4.2 é apresentado o portal PortLex. Na Seção 7.4.3 é apresentada a atividade de criação de uma ferramenta para apoiar a revisão humana da base de verbos da WordNet.Br.

\subsubsection{Ferramenta de consulta à VerbNet.Br}

A ferramenta de consulta a base de dados da VerbNet.Br ${ }^{59}$ foi desenvolvida baseada na ferramenta de consulta da VerbNet ${ }^{60}$. Apesar de os resultados da VerbNet.Br ainda não estarem validados, a apresentação dos resultados preliminares é interessante para

\footnotetext{
${ }^{59}$ http://www.nilc.icmc.usp.br/verbnetbr

${ }^{60} \mathrm{http}$ ://verbs.colorado.edu/verb-index/
} 
a divulgação do recurso entre a comunidade de PLN com o intuito de atrair pesquisadores interessados em melhorar e trabalhar com este recurso. A versão apresentada na ferramenta online é resultado do EXP1 apresentado na Seção 6.2.4.

$\mathrm{Na}$ Figura 21 é apresentada a página inicial da ferramenta de consulta à VerbNet.Br. Nesta página, há informações sobre o projeto da VerbNet.Br e também sobre como utilizar o site.

\title{
VerbNet.Br 1.0
}

Home

\section{Bem-vindo à VerbNet.Br 1.0}

\begin{abstract}
Neste site, é possível consultar a primeira versão da VerbNet.Br (VerbNet.Br 1.0). Este recurso, baseado na VerbNet do inglês[1], contém informações sobre a interface sintático-semântica dos verbos do português do Brasil (de acordo com a teoria das classes de Levin[2]. A VerbNet.Br foi construída semiautomaticamente, a partir dos mapeamentos entre a VerbNet e a WordNet de Princeton [3] e dos alinhamentos entre a WordNet e a WordNet.Br (Wordnet do português do Brasil) [4]. A VerbNet.Br 1.o contém 202 classes (alinhadas com a VerbNet), 1.766 lemas de verbos e 4.333 sentidos de verbos.
\end{abstract}

Figura 21: Página inicial da VerbNet.Br

A busca na base pode ser realizada de três formas: (i) o usuário pode escolher uma letra e visualizar todos os verbos iniciados por essa letra; (ii) o usuário pode digitar parte de um verbo ou do nome de uma classe; ou (iii) o usuário pode visualizar todas as classes presentes na VerbNet.Br. A Figura 22 contém a página de busca da VerbNet.Br.

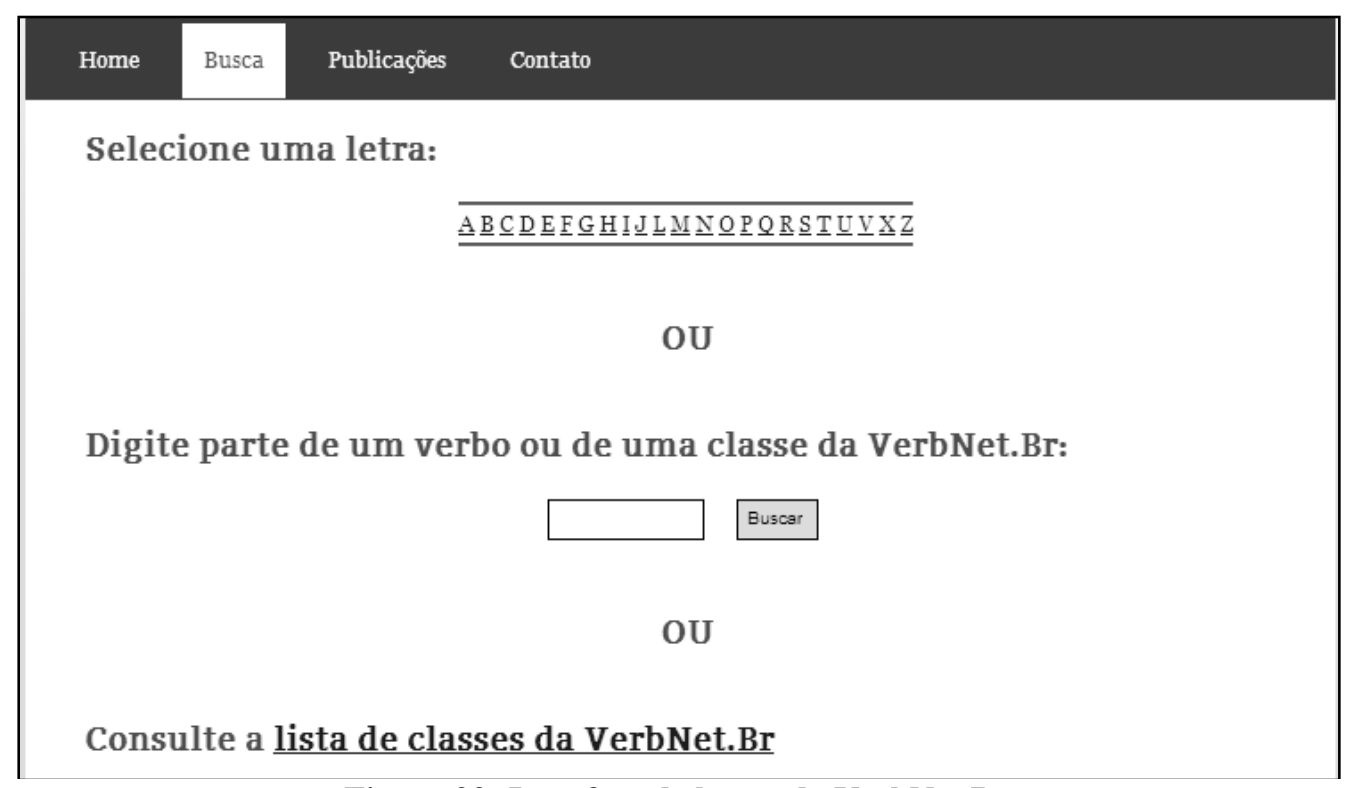

Figura 22: Interface de busca da VerbNet.Br 


\subsubsection{Portlex: um portal para integração de trabalhos com léxicos no Brasil}

Um portal para integração de trabalhos com léxicos computacionais do português foi desenvolvido no escopo deste mestrado. $O$ intuito desta ferramenta, chamada de PortLex, é disponibilizar de forma fácil e em um só lugar diversos recursos léxicos do português do Brasil. A ferramenta pode ser acessada em: http://www2.nilc.icmc.usp.br/portlex/ (Figura 23).

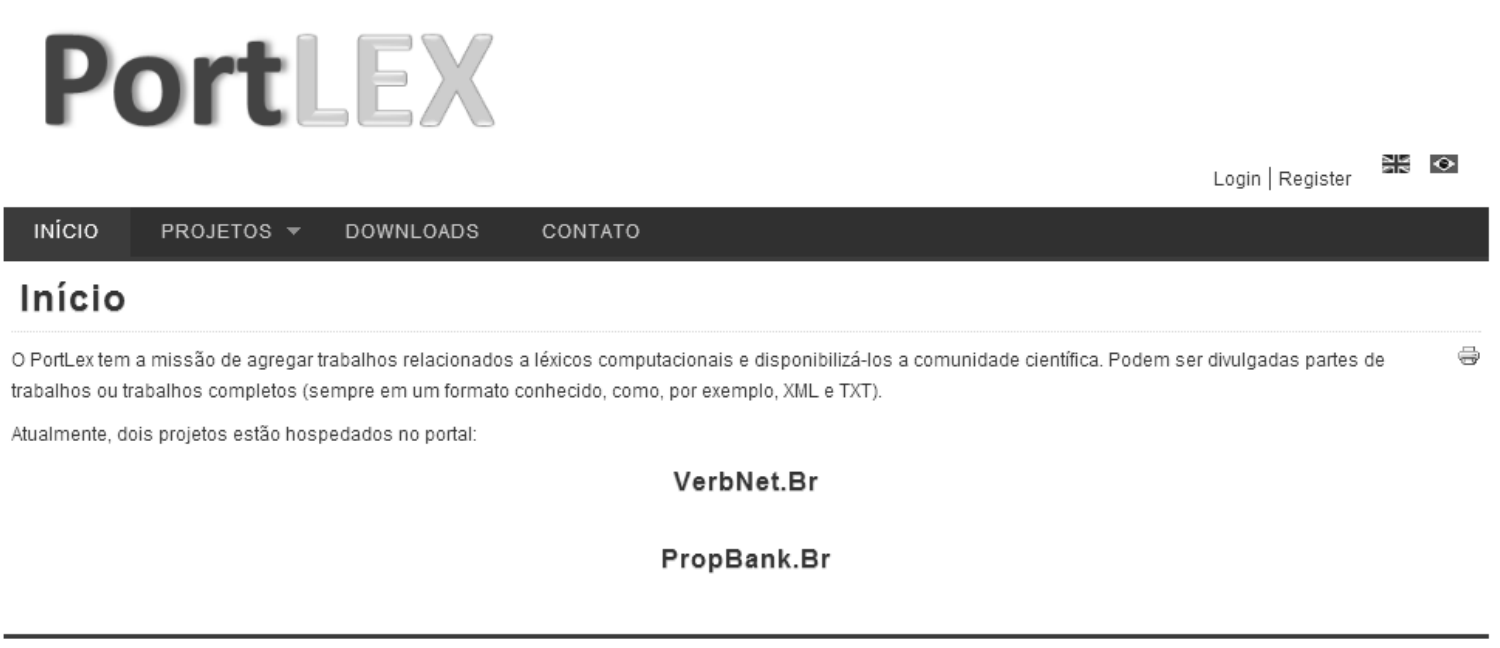

Figura 23: Interface do PortLex

Atualmente, dois projetos estão hospedados no portal: a VerbNet.Br e o PropBank.Br. Ambos disponibilizam recursos criados durante os respectivos projetos. Pretende-se divulgar este portal para que mais pesquisadores se interessem em divulgar seus dados e projetos nele.

Este recurso é importante, pois com ele será possível encontrar linguistas interessados em validar a VerbNet.Br e dar continuidade a pesquisas com ela. Além disso, será possível unir esforços para pesquisa em léxicos para o português.

\subsubsection{Revisão da WordNet.Br}

Como mencionado em vários capítulos desta dissertação, foram utilizados nesta pesquisa, três recursos léxicos já existentes: a WordNet de Princeton, a WordNet.Br e a VerbNet. Na Seção 3.2.1.1, foi apresentada a WordNet de Princeton. Na Seção 3.2.1.4, foi apresentada a WordNet.Br. Por fim, na Seção 3.3, foi apresentada a VerbNet. 
Na Seção 3.2.1.4, é possível observar que a WordNet.Br possui sua base de verbos completa, porém, ainda necessita de revisão humana. Por isso, foi desenvolvida neste mestrado uma ferramenta que apoia o trabalho linguístico de correção da WordNet.Br. Esta ferramenta esta disponível em: http://www.nilc.icmc.usp.br/wordnet (Figura 24).

\title{
WordNet.Br 1.0 - Base de Verbos
}

\section{Home}

\author{
Verbos \\ ILIs \\ Chaves \\ Glosas \\ Tipos semânticos
}

Publicações

Contato

\section{Bem-vindo a WordNet.Br - Base de Verbos}

Neste site é possível realizar buscas à primeira versão do Banco de Dados da WordNet.Br contando com 5860 verbos em 3713 synsets. A WordNet.Br é a wordnet do português do Brasil, construída completamente alinhada a versão 2.0 da WordNet de Princeton (WordNet.Pr).

Figura 24: Interface da WordNet.Br

Além da ferramenta de consulta (Figura 24), outras atividades foram realizadas para fornecer mais informação aos linguistas que revisarão a base e para corrigir algumas inconsistências teóricas que existiam na base antiga da WordNet.Br. Primeiramente, foi realizada uma correção automática na base da WordNet.Br devido a um erro de concepção: anteriormente a base de dados da WordNet.Br não considerava, adequadamente, polissemia e homonímia. Segundo Jurafsky e Martin (2009), homonímia é a relação entre palavras com a mesma forma, porém com sentidos completamente opostos (como em manga (fruta) e manga (parte da camisa)). Já a polissemia é a relação entre palavras com a mesma forma e que compartilham algum tipo de traço semântico (como em banco (entidade financeira) e banco (banco de areia) - ambos servem para depositar alguma coisa). Os verbos homônimos devem ser distinguidos dos polissêmicos inserindo números em suas ocorrências. Por exemplo, o verbo decorar deveria receber um número no sentido de memorizar e outro no sentido de enfeitar, por se tratarem de verbos homônimos. Estas informações já tinham sido anotadas pelos linguistas responsáveis pela WordNet.Br (em documentos da ferramenta Microsoft Word). Porém, quando da criação da base de dados em um Sistema de Banco de Dados Relacional, esta informação não foi corretamente armazenada: decorarl e decorar2, por exemplo, foram armazenados apenas como decorar. Portanto, a tarefa de correção consistiu da identificação destes casos e correto 
armazenamento. Na versão atual da WordNet.Br, após a correção automática que foi implementada neste mestrado, decorarl é o verbo decorar no sentido de enfeitar e decorar2 possui o sentido de memorizar. Já o verbo dormir não recebe marcação numérica nos sentidos de adormecer e pernoitar, por se tratar, neste caso, de polissemia. Além desta correção, os nomes das tabelas do banco de dados e de seus atributos também foram alterados para ficarem mais coerentes com o que representam.

A relação de hiperonímia para a WordNet.Br havia sido herdada da WordNet no trabalho de Scarton e Aluísio (2009). Neste trabalho realizamos a herança das relações de Troponímia e Termos Coordenados.

Todas as etapas da revisão da WordNet.Br foram realizadas em parceria com (e sob supervisão de) o Professor Doutor Bento Carlos Dias da Silva e seus alunos.

\subsection{Considerações Finais}

Neste capítulo, foram apresentados os resultados e a avaliação da VerbNet.Br. Também foram apresentadas as contribuições extras produzidas durante a realização deste mestrado.

Na Seção 7.3.1 foi apresentada a criação do gold standard para dezesseis classes da VerbNet, com base nos trabalhos de Sun (2007), Sun e Korhonen (2009) e Sun et al. (2010). O gold standard foi posteriormente aumentado de acordo com os resultados obtidos pela VerbNet.Br.

$\mathrm{Na}$ Seção 7.3.2 foi apresentada a análise dos resultados da VerbNet.Br, considerando os quatro experimentos realizados. As classes analisadas foram as do gold standard e o melhor resultado global foi obtido pelo experimento 2 (esta avaliação é parte da avaliação intrínseca qualitativa).

Na Seção 7.3.3 foi apresentada a tarefa de agrupamento de verbos para o português do Brasil, bem como a comparação dos resultados desta tarefa com os resultados da VerbNet.Br. Os resultados globais da VerbNet.Br, para os quatro experimentos, superaram os resultados da tarefa de agrupamento de verbos (esta avaliação é parte da avaliação intrínseca qualitativa). 
Na Seção 7.3.4 foi apresentada a avaliação intrínseca quantitativa, que trata da taxa de aceitação dos verbos candidatos a membros. Nesta avaliação, constatou-se que o experimento 2 apresentou a maior taxa de aceitação.

Na Seção 7.4 são apresentados a interface de consulta à VerbNet.Br, o PortLex e a interface de busca da WordNet.Br, contribuições extras deste mestrado.

Pode-se concluir deste capítulo que o experimento que apresenta os melhores resultados para a avaliação intrínseca qualitativa é o EXP1. Portanto, os resultados deste experimento foram apresentados no Apêndice A e serão disponibilizados na WEB (no portal PortLex). Já na avaliação intrínseca quantitativa, o melhor resultado foi para EXP2.

Apesar de os resultados da VerbNet.Br, construída via método semiautomático, serem mais precisos do que a tarefa de agrupamento, não é possível dizer precisamente se o método da VerbNet.Br é melhor do que uma atividade completamente automática. Algumas ressalvas que devem ser feitas são: o gold standard utilizado na tarefa de agrupamento era relativamente pequeno, o córpus utilizado não era suficientemente grande comparado com os córpus utilizados nos demais trabalhos da literatura e as ferramentas utilizadas para extração dos atributos (parser e extrator de SCFs) contém diversos erros que afetam a precisão dos atributos. 


\section{CAPÍTULO 8: Conclusões}

\subsection{Contribuições}

O objetivo principal deste mestrado, a criação da VerbNet.Br a partir de recursos já existentes e córpus, foi concluído, uma vez que apresentou-se uma primeira versão dos resultados. Após a conclusão da VerbNet.Br é possível dizer que as classes herdam informações da VerbNet. Na Tabela 27 apresenta-se a classe put-9.1 da VerbNet.Br, considerando EXP2.

Tabela 27: Classe put-9.1 na VerbNet.Br

\begin{tabular}{|c|c|c|c|}
\hline \multicolumn{4}{|c|}{ Put-9.1 - VerbNet.Br } \\
\hline \multicolumn{2}{|c|}{$\begin{array}{l}\text { Papéis temáticos e Restrições } \\
\text { Destination[+location - region] }\end{array}$} & \multicolumn{2}{|c|}{ seletivas: Agent[+animate] } \\
\hline \multicolumn{4}{|c|}{$\begin{array}{l}\text { Membros: localizar, fincar, cravar, instalar, arrumar, introduzir, botar, inserir, enterrar, depositar, } \\
\text { plantar, colocar, compor, dispor, parar, ligar, implantar, depor, tragar, coordenar, incluir, meter, } \\
\text { cultivar, absorver, engolir, pôr, fixar, encostar. }\end{array}$} \\
\hline \multicolumn{4}{|c|}{ Frames: } \\
\hline Nome & Exemplo & Sintaxe & Semântica \\
\hline $\begin{array}{l}\text { SN } \quad \mathrm{V} \quad \mathrm{SN} \\
\text { SP.destination }\end{array}$ & $\begin{array}{l}\text { I put the book } \\
\text { on/under/near } \\
\text { the } \\
\text { "Eu coloquei o livro } \\
\text { em/sobre/sob a mesa." }\end{array}$ & $\begin{array}{l}\text { Agent V Theme } \\
\{\{+l o c\}\} \text { Destination } \\
+ \text { loc: em, sobre, } \\
\text { sob, entre }\end{array}$ & $\begin{array}{ll}\text { - } & \text { motion(during(E), Theme) } \\
\text { - } & \text { not(Prep(start(E), Theme, } \\
& \text { Destination)) } \\
\text { - } & \text { Prep(end(E), } \\
& \text { Destination) } \\
\text { - } & \text { cause(Agent, E) } \\
\end{array}$ \\
\hline $\begin{array}{l}\text { SN V } \\
\text { ADVP }\end{array}$ & $\begin{array}{l}\text { put the book } \\
\text { here/there. } \\
\text { "Eu coloquei o livro } \\
\text { aqui/lá." }\end{array}$ & $\begin{array}{l}\text { Agent V Theme Desti } \\
\text { nation <+adv_loc }>\end{array}$ & $\begin{array}{ll}\text { - } & \text { motion(during(E), Theme) } \\
\text { - } & \text { not(Prep(start(E), Theme, } \\
& \text { Destination)) } \\
\text { - } & \text { Prep(end(E), } \\
& \text { Destination) } \\
\text { - } & \text { cause(Agent, E) }\end{array}$ \\
\hline
\end{tabular}

Neste caso é possível observar que os papéis temáticos apresentados do inglês podem ser herdados para os verbos do português. Considere "colocar", o sujeito é "quem coloca", portanto Agente (Agent), um dos argumentos é "a coisa colocada", portanto, Tema (Theme) e outro argumento (opcional nesse caso) é "o local onde o Agente coloca o Tema", ou seja, o Destino (Destination) em que o Tema termina ao final da ação. Predicados semânticos (no caso dos frames alinhados) também podem ser herdados. No caso da classe put-9.1 o frame diretamente traduzido para o português foi o primeiro (Linha 5 da Tabela 27), definindo como preposição de local (+loc na Linha 5 da Tabela 27): em sobre, sob e entre. Assim, os predicados semânticos do frame do inglês também podem ser herdados para o português. A interpretação é como segue: 
- Motion(during(E), Theme): durante o evento E o Tema está em movimento.

- $\operatorname{Not}(\operatorname{Prep}(\operatorname{start}(\mathrm{E})$, Theme, Destination)): no início do evento E o Tema não está em/entre/sobre/sob o Destino.

- Prep(end(E), Theme, Destination): no fim do evento E o Tema está em/entre/sobre/sob o Destino.

- Cause(Agent, E): o que causa o evento E é o Agente.

Portanto, considerando a sentença "Eu coloquei o livro sobre a mesa", o sujeito "Eu" recebe o papel de Agente, o primeiro argumento "o livro" recebe o papel de "Tema" e o segundo argumento "a mesa" recebe o papel de "Destino". Além disso, durante o evento do verbo (o ato de colocar) "o livro" está em movimento, ele não está no Destino ("a mesa") antes do evento ser completada (somente no final da ação) e quem causa o evento é o Agente ("Eu”).

É possível concluir também que se comprovou a hipótese (a) "é possível a criação de um recurso léxico para o português de mesmas características da VerbNet, diretamente alinhado com a mesma, via um método semiautomático que se utiliza de recursos existentes (para o inglês e para o português), aproveitando-se do potencial crosslinguístico das classes de Levin”. Pode-se dizer que a primeira versão da VerbNet.Br foi criada, via VerbNet e demais recursos, com precisão de $44 \%$, abrangência de $92 \%$ e $f$ measure de $60 \%$.

Já a hipótese (b) "a criação deste recurso léxico (VerbNet.Br) utilizando-se o método semiautomático e baseado em recursos já existentes produzirá resultados mais precisos do que um método baseado em agrupamento de dados, a ser também desenvolvido nesta pesquisa, quando comparados a um gold standard", necessita ser melhor investigada. Apesar de os resultados da VerbNet.Br serem melhores em precisão, abrangência e f-measure a diferença não foi significativa. Além disso, o método de agrupamento de verbos não deve ser descartado, uma vez que consegue extrair resultados rapidamente. Vale comentar que um aumento do córpus utilizado e a melhoria da precisão da ferramenta de extração de frames, bem como do parser, poderiam alterar drasticamente os resultados apresentados para a tarefa de agrupamento de verbos, podendo fazer com que ela superasse os resultados da VerbNet.Br em precisão. 
Os objetivos secundários também foram atendidos. Como foi apresentado no Capítulo 7, tanto o PortLex, quando a interface de busca da WordNet.Br foram elaborados e criados neste metrado.

Outra conclusão interessante é que somente os alinhamentos entre VerbNet, WordNet e WordNet.Br já trazem muita informação significante e com alta precisão e abrangência (conforme apresentado no Capítulo 7 - 41,51\% de precisão, $100 \%$ de abrangência (o que é de se esperar, dado que todos os candidatos são selecionados) e $58,67 \%$ de $f$-measure). Isto evidencia mais uma vez o potencial cross-linguístico das classes de Levin, além de ser um indício de que os alinhamentos entre os recursos são de boa qualidade (mesmo os da WordNet.Br que ainda carecem de validação).

Por fim, o projeto VerbNet.Br é pioneiro no Brasil e de grande importância para a área de PLN. Além disso, como é possível inferir após a leitura do Capítulo 6, o método aqui proposto é inovador e trata de potenciais cross-linguísticos entre inglês e português. Um ponto importante a ser notado é que este método pode ser estendido para outras línguas, bastando que estas possuam uma wordnet alinhada com a WordNet e um extrator ou recurso léxico de SCFs.

A Tabela 28 compara os número da VerbNet com os números da VerbNet.Br.

Tabela 28: Comparação da VerbNet com a VerbNet.Br

\begin{tabular}{|l|c|c|c|}
\hline & VerbNet Original & VerbNet Extendida & VerbNet.Br \\
\hline Classes de principais & 191 & 274 & 202 \\
\hline $\begin{array}{l}\text { Número de sentidos } \\
\text { de verbos }\end{array}$ & 4656 & 5257 & 4333 \\
\hline $\begin{array}{l}\text { Número de lemas de } \\
\text { verbos }\end{array}$ & 3445 & 3769 & 1766 \\
\hline
\end{tabular}

É possível observar na Tabela 28 que a VerbNet.Br apresenta cerca de $74 \%$ das classes principais (classes que seguem as grandes classes de Levin) da VerbNet. Também é válido notar que a VerbNet.Br apresenta menos sentidos de verbos e menos lemas do que a VerbNet, o que é explicado pelo número inferior de classes e também porque a VerbNet.Br foi criada utilizando os recursos. Portanto, o número de verbos na VerbNet.Br é limitado ao número de verbos presente na WordNet.Br 


\subsection{Limitações do Trabalho}

Os resultados apresentados no Capítulo 7, podem conter diversos problemas oriundos do método apresentado no Capítulo 6. Um deles consiste na herança de erros dos recursos utilizados. Ou seja, se há erros na WordNet.Br, na WordNet ou na VerbNet estes erros podem ter sido herdados para o novo recurso. O grande problema aqui é conseguir avaliar o impacto destes recursos - tarefa que foi deixada para trabalhos futuros.

Outro problema considerado mais crítico, que afeta somente a abordagem manual, é o caso de classes que compartilham poucas alternâncias sintáticas (ou nenhuma) com o português. Em casos como este, somente alternâncias básicas (como a transitiva - SN V $\mathrm{SN}$ ) ou nenhuma alternância pode ser traduzida, o que selecionaria muitos verbos que não pertencem à classe. Por isso, foram realizados experimentos que desconsiderassem a etapa manual, tentando mensurar sua utilidade (conforme apresentado no Capítulo 7).

Há também problemas durante a extração de SCFs. Uma vez que utiliza-se as estruturas sintáticas identificadas pelo parser PALAVRAS, erros oriundos da anotação automática também podem ser herdados. Conforme já foi discutido no Capítulo 4, um problema é a não distinção entre argumentos e adjuntos. Tentou-se amenizar este problema filtrando os frames por frequência (somente frames com frequência superior a cinco foram considerados). Porém, o principal problema são os erros de anotação. Por exemplo, considere a sentença "Está concentrado desde segunda, realizando tratamento intensivo, mas o médico Joaquim Grava se mostrou sem esperanças.”, na Figura 25 é apresentada a anotação do PALAVRAS para esta sentença. O sobrenome do médico Joaquim Grava (que deveria ser reconhecido como uma entidade nomeada), é reconhecido como o verbo "gravar" (conforme parte em negrito). Assim, "o médico Joaquim" é considerado erroneamente como argumento (sujeito) de "Grava" no frame SUBJ[SN]_V.

Outros erros oriundos da anotação automática também são críticos, como por exemplo, a não anotação de um argumento e palavras desconhecidos do parser que ele considera como verbo. É possível também que haja outros erros que não foram identificados.

Portanto, é difícil definir o impacto destes erros na VerbNet.Br como um todo e, como não existem alternativas a essas ferramentas e recurso, deve-se lidar com estes erros. 


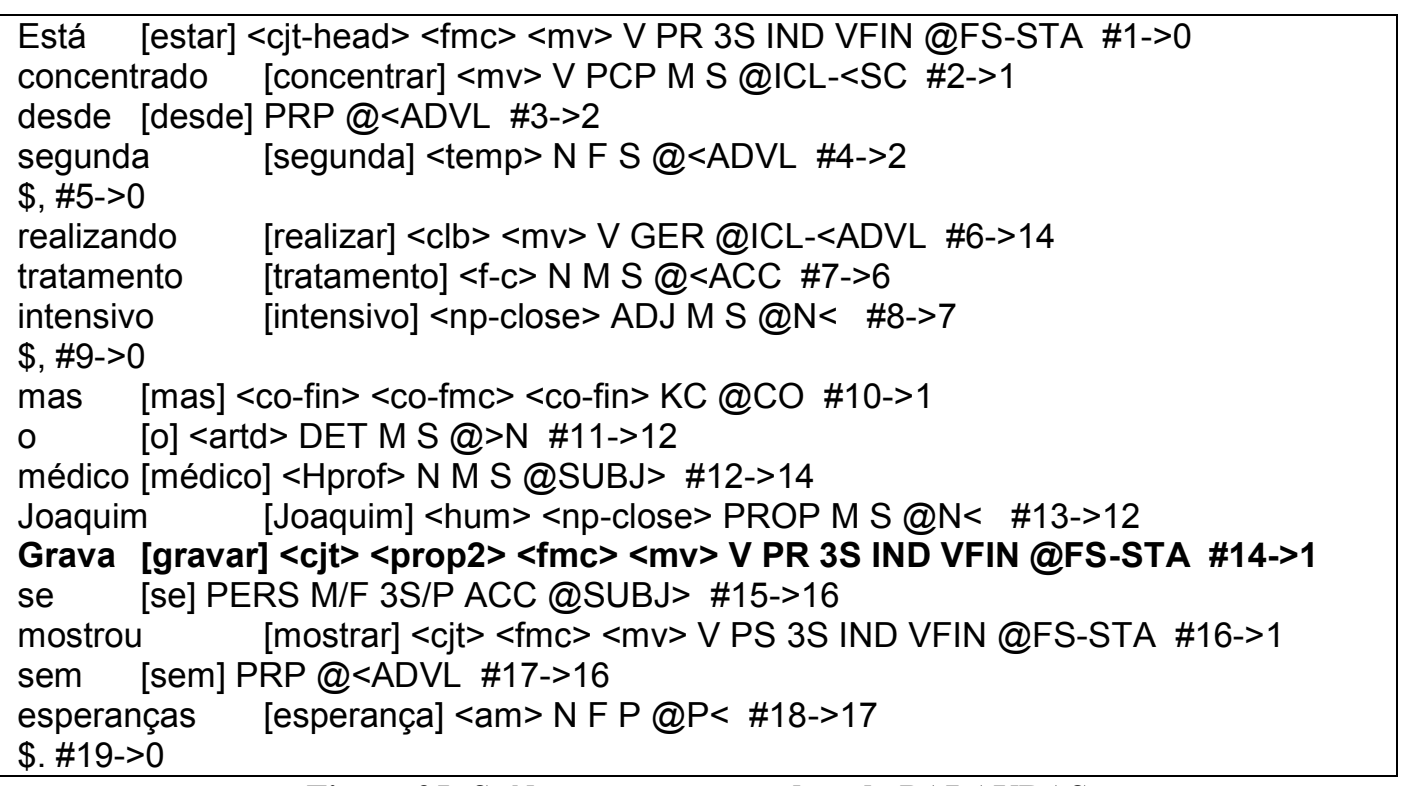

Figura 25: Saída com erros gerada pelo PALAVRAS

\subsection{Trabalhos Futuros}

É fato que a VerbNet.Br está limitada aos recursos utilizados para sua criação. Portanto, vislumbra-se três frentes de trabalho: validação do recursos criado, inclusão de características específicas da língua portuguesa em uso via agrupamento de dados e inclusão de características com riqueza linguística da língua portuguesa, como o trabalho de Cançado et al. (2012).

Como é possível observar nos resultados da VerbNet.Br, há a necessidade de validação linguística após a execução do método semiautomático. Os verbos em negrito na Linha 3 da Tabela 27 são os verbos selecionados erroneamente para a classe. Verbos neste caso necessitam ser revistos manualmente e, a decisão de mantê-los na classe ou removêlos dela não é simples. Portanto, é uma tarefa a ser realizada por linguistas. Para tanto, pretende-se, como atividade futura, estabelecer uma parceria com a profa. Dra. Márcia Cançado da Universidade Federal de Minas Gerais (UFMG) e seu grupo de pesquisa. Uma vez que eles trabalham com a descrição de verbos do português em classe verbais motivadas sintática e semanticamente, eles também podem ser beneficiados dos resultados da VerbNet.Br.

Além disso, desde a criação do Penn TreeBank (Marcus et al., 1993), acredita-se que a tarefa de crítica e validação é mais eficiente do que a tarefa de criação a partir do zero (scratch). O uso de córpus e resultados computacionais, auxiliam a cognição humana 
na identificação de ocorrências corretas. Durante a revisão do gold standard das classes da VerbNet para uso neste mestrado, a Dra. Magali Duran também reconheceu o processo de revisão como uma excelente metodologia e verificou que muitos verbos que apareciam no córpus dificilmente seriam identificados como membros somente pela intuição. Um exemplo é o verbo "bater" que possui como usos principais "bater em alguém", "bater em alguma coisa", "bater palmas" e "bater claras em neve, bater bolo". Porém, este verbo foi selecionado para a classe amalgamate-22.2, que agrupa verbos com sentido de "coincidir". Inicialmente, este verbo poderia ser considerado um erro, porém, ao buscar exemplos na WEB, a linguista identificou a sentença (79) na qual o verbo "bater" realmente possui o sentido de "coincidir".

(79) "Sua versão dos fatos não bate com a dela."

Com isso, pode-se dizer que abordagens hibridas que unem intuição e a realização da língua em córpus podem apresentar melhores resultados da língua em uso e o seu dinamismo, como (Klavans e Resnik, 1996) já tinha evidenciado.

Outo ponto que necessita de revisão são os frames. É certo que existem frames próprios da língua portuguesa e que poderiam ser inseridos na base. Como trabalho futuro, também se pretende estudar os frames obtidos em córpus para cada membro selecionado e verificar se eles podem ser inseridos na VerbNet.Br, bem como realizar parcerias com linguistas dispostos a realizar uma análise mais profunda das classes de Levin e não baseada somente em observações de córpus (trabalho já realizado pela equipe da profa. Dra. Márcia Cançado).

Outro trabalho futuro consiste da melhoria do método de seleção, para torná-lo mais preciso e robusto. Um caminho a ser seguido é a combinação dos experimentos considerando as traduções manuais, com os experimentos que só consideram as frequências de frames. Outro caminho é a melhoria da tarefa de agrupamento de verbos e combinação dela com o método semiautomático.

Uma análise interessante, também deixada para trabalhos futuros, é continuar explorando o potencial cross-linguístico das classes de Levin e tentar estendê-lo para outros recursos léxicos computacionais. Uma das atividades propostas no projeto de doutorado da aluna em questão é melhorar os resultados da VerbNet.Br utilizando os 
alinhamentos entre o PropBank e a VerbNet e entre o PropBank e o PropBank.Br (ainda em construção).

Por fim, analisar o impacto dos erros oriundos dos recursos e ferramentas utilizados também foi deixado como um trabalho futuro. Para isso, é necessário estudar em detalhes todos os itens envolvidos e identificar qual etapa do método tem mais impacto nos erros inseridos. 


\section{REFERÊNCIAS}

Abend, O., Reichart, R. e Rappoport, A. (2008): A Supervised Algorithm for Verb Disambiguation into VerbNet Classes. In Proceedings of the 22nd International Conference on Computational Linguistics (COLING 2008). Manchester, UK, pp. 916.

Afonso, S., Bick, E., Haber, R. e Santos, D. (2002): "Floresta sintá(c)tica": a treebank for Portuguese, In Proceedings of the Third International Conference on Language Resources and Evaluation (LREC 2002). Las Palmas de Gran Canaria, Espanha, pp. 1698-1703.

Allbeck, J., Kipper, K., Adams, C., Schuler, W., Zoubanova, E., Badler, N., Palmer, M. e Joshi, A. (2002): ACUMEN: Amplifying Control and Understanding of Multiple ENtities. In Proceedings of First International Joint Conference on Autonomous Agents and Multi-Agent Systems (AAMAS 2002). Bologna, Itália, pp. 191-198.

Altamirano, I. R. e Alonso i Alemany, L. (2010): IRASubcat, a highly customizable, language independent tool for the acquisition of verbal subcategorization information from corpus. In Proceedings of the NAACL HLT 2010 Young Investigators Workshop on Computational Approaches to Languages of the Americas, in conjunction with NAACL HLT 2010. Los Angeles, CA, USA, pp. 84-91.

Aluísio, S., Pinheiro, G. M., Manfrim, A. M. P, Oliveira, L. H. M. de, Genoves Jr., L. C. e Tagnin, S. E. O. (2004): The Lácio-Web: Corpora and Tools to advance Brazilian Portuguese Language Investigations and Computational Linguistic Tools. In Proceedings of the 4th International Conference on Language Resources and Evaluation (LREC 2004). Lisboa, Portugal, pp. 1779-1782.

Alva-Manchego, F. e Rosa, J. L. G. (2012a): Towards Semi-supervised Brazilian Portuguese Semantic Role Labeling: Building a Benchmark. In Proceedings of the 10th International Conference on Computational Processing of Portuguese (PROPOR 2012). Coimbra, Portugal, pp. 210-217.

Alva-Manchego, F. e Rosa, J. L. G. (2012b): Semantic Role Labeling for Brazilian Portuguese: A Benchmark. In Proceedings of the $13^{\text {th }}$ Ibero-American Conference on Artificial Intelligence (IBERAMIA 2012). Cartagena de Indias, Colombia, pp. 481490.

Amancio, M. A., Duran, M. S. e Aluisio, S. M. (2010): Automatic Question Categorization: a New Approach for Text Elaboration. In Proceedings of the Workshop in Natural Language Processing and web-based Technologies 2010, in conjunction with Iberamia 2010. Bahía Blanca, Argentina, v. 1, pp. 21-30.

Amaral, L. L. (2010): O Verbos de Modo de Movimento no Português Brasileiro. 53f. Trabalho de Conclusão de Curso (Bacharel em Letras) - Faculdade de Letras, Universidade Federal de Minas Gerais, Belo Horizonte.

Atkins, S., Rundell, M. e Sato, H. (2003): The contribution of Framenet to practical lexicography. International Journal of Lexicography, v. 16, n. 3, pp. 333-357. Oxford University Press. 
Ávila, M. C. (2006): Propriedades semânticas e alternâncias sintáticas do verbo: um exercício exploratório de delimitação do significado. 114f. Dissertação (Mestrado em Letras) - Faculdade de Ciências e Letras, Universidade Estadual Paulista, Araraquara.

Aziz, W. e Specia, L. (2011): Fully Automatic Compilation of Portuguese-English and Portuguese-Spanish Parallel Corpora. In Proceedings of the The 8th Brazilian Symposium in Information and Human Language Technology (STIL 2009). Cuiabá, MT, Brazil.

Baker, C. F., Fillmore, C. J. e Lowe, J. F. (1998): The Berkeley FrameNet Project. In Proceedings of the 36th Annual Meeting of the Association for Computational Linguistics and 17th International Conference on Computational Linguistics, University of Montréal, Canadá, pp. 86-90.

Bertoldi A. e Chishman, R. L. de O. (2009): Desafios para a Criação de um Léxico baseado em Frames para o Português: um estudo dos frames Judgment e Assessing. In Proceedings of the The 7th Brazilian Symposium in Information and Human Language Technology (STIL 2009). São Carlos, SP, Brazil, 1 CD-ROM ISSN 21756201 .

Bick, E. (2000): The Parsing System "Palavras": Automatic Grammatical Analysis of Portuguese in a Constraint Grammar Framework. 505f. Ph.D. Thesis (Philosophy) - University of Aarhus, Dinamarca.

Boguraev, B. e Briscoe, E. (1987): Large lexicons for natural language processing: utilising the grammar coding system of the Longman Dictionary of Contemporary English. Computational Linguistics, v. 13, n. 4, pp. 219-240.

Brent, M. R. (1993): From grammar to lexicon: unsupervised learning of lexical syntax. Computational Linguistics, v. 19, n. 2, pp. 243-262.

Briscoe, T. e Carroll, J. (1997): Automatic extraction of subcategorization from corpora. In Proceedings of the 5th conference on Applied natural language processing. Washington, D.C., USA, pp. 356-363.

Brown, S. W., Dligach, D. e Palmer, M. (2011): VerbNet Class Assignment as a WSD Task. In Proceedings of the Ninth International Conference on Computational Semantics (IWCS 2011). Oxford, UK, pp. 85-94.

Bruckschen, M., Muniz, F., Souza, J. G. C., Fuchs, J. T., Infante, K., Muniz, M., Gonçalves, P. N., Vieira, R. e Aluísio, S. M. (2008): Anotação Lingüística em XML do Corpus PLN-BR. Série de Relatórios do NILC. NILC-TR-09-08, 39 p.

Cançado, M. (1996): Verbos Psicológicos: Análise Descritiva dos Dados do Português Brasileiro. Revista de Estudos da Linguagem, v. 4, n. 1, pp. 89-114.

Cançado, M. (2005): Propriedades semânticas e posições argumentais. Revista DELTA, v. 21, n. 1, pp. 23-56.

Cançado, M., Godoy, L. e Amaral, L. (2012): The construction of a catalog of Brazilian Portuguese verbs. In Proceedings of the Workshop on Recent Developments and Applications of Lexical-Semantic Resources (LexSem 2012), in conjunction with KONVENS 2012. Viena, Itália, pp. 438-445. 
Castellón, I., Fernández-Montraveta, A., Vázquez, G., Alonso, L. e Capilla, J. (2006): The SENSEM corpus: a corpus annotated at the syntactic and semantic level. In Proceedings of the 5th International Conference on Language Resources and Evaluation (LREC 2006). Genova, Itália, pp. 355-358.

Chagas de Souza, P. (2000): A Alternância Causativa no Português do Brasil: Defaults num Léxico Gerativo. 199f. Tese (Doutorado em Linguística) - Faculdade de Filosofia, Letras e Ciências Humanas, Universidade de São Paulo, São Paulo.

Chagas de Souza, P. (2001): Notas Sobre a Construção Adversativa. Anais do $4^{\circ}$ Encontro do Círculo de Estudos Linguísticos do Sul (CELSUL), Curitiba, PR, Brasil. Disponível em: http://www.celsul.org.br/Encontros/04/artigos/100.htm. Acessado em: 27 fev. 2011.

Chen, L. e Di Eugenio, B. (2010): A Maximum Entropy Approach To Disambiguating VerbNet Classes. In Proceedings of the 2nd Interdisciplinary Workshop on Verbs, "The Identification and Representation of Verb Features". Pisa, Itália.

Chishman, R. L. de O., Bertoldi, A.; Padilha, J. G. e Lermen, L. (2008): Corpus e Anotação Semântica: um Experimento para a Língua Portuguesa a partir da Semântica de Frames. In Proceedings of the 6th Workshop in Information and Human Language Technology (TIL 2008), in conjunction with WebMedia2008. Vila Velha, ES, Brasil, pp. 321-325.

Ciríaco, L. S. (2007): A alternância causativo/ergativa no PB: restrições e propriedades semânticas. 114f. Dissertação (Mestrado em Linguística) - Faculdade de Letras, Universidade Federal de Minas Gerais, Belo Horizonte.

Collins (2010): Collins Portuguese Dictionary. London: Collins, 2010. 777 p.

Croch, D. e King, T. H. (2005). Unifying lexical resources. In Proceedings of Interdisciplinary Workshop on the Identication and Representation of Verb Features and Verb. Saarbruecken, Germany, pp. 32-37.

Cruse, D. A. (1986): Lexical Semantics. Cambridge Textbooks in Linguistics. Cambridge University Press, Cambridge, UK.

Dias-da Silva, B. C., Oliveira, M. F. d., e Moraes, H. R. d. (2002): Groundwork for the development of the brazilian portuguese wordnet. In Proceedings of the Third International Conference on Advances in Natural Language Processing. London, UK, pp. 189-196.

Dias-da Silva, B. C. (2005): A construção da base da wordnet.br: conquistas e desafios. In Proceedings of the Third Workshop in Information and Human Language Technology (TIL 2005), in conjunction with XXV Congresso da Sociedade Brasileira de Computação. São Leopoldo, RS, Brasil, pp. 2238-2247.

Dias-da-Silva, B. C., Di Felippo, A. e Nunes, M. G. V. (2008): The automatic mapping of Princeton WordNet lexicalconceptual relations onto the Brazilian Portuguese WordNet database. In Proceedings of the 6th International Conference on Language Resources and Evaluation (LREC 2008), Marrakech, Morocco, pp. 1535-1541. 
Dias-da-Silva, B. C. (2010): Brazilian Portuguese WordNet: A Computational Linguistic Exercise of Encoding Bilingual Relational Lexicons. International Journal of Computational Linguistics and Applications, New Delhi, v.1, n. 1-2, p.137 - 150.

Di Felipo, A. e Dias-da Silva, B. C. (2007): Towards na automatic strategy for acquiring the wordnert.br hierarchical relations. In Proceedings of the 5th Workshop in Information and Human Language Technology (TIL 2007), in conjunction with XXVII Congresso da Sociedade Brasileira de Computação. Rio de Janeiro, RJ, Brasil, pp. 1717-1720.

Duran, M. S., Amancio, M. A e Aluísio, S.M. (2010a): Assigning Wh-Questions to Verbal Arguments in a Corpus of Simplified Texts. In Proceedings of 9th International Conference on Computational Processing of the Portuguese Language, Extended Activities Proceedings (PROPOR 2010). Porto Alegre, RS, Brasil, 1 CD-ROM, pp. 16. ISSN: 21773580.

Duran, M. S., Amancio, M. A e Aluísio, S.M. (2010b): Assigning Wh-Questions to Verbal Arguments: Annotation Tools Evaluation and Corpus Building. In Proceedings of the 7th conference on International Language Resources and Evaluation (LREC 2010). Valeta, Malta, pp. 1445-1451. ISBN 2-9517408-6-7

Duran, M. S. e Aluísio, S. M. (2011): Propbank-Br: a Brazilian Portuguese corpus annotated with semantic role labels. In Proceedings of the 8th Brazilian Symposium in Information and Human Language Technology (STIL 2011). Cuiabá-MT, Brazil.

Duran, M. S. e Aluísio, S. M. (2012): Propbank-Br: a Brazilian Treebank annotated with semantic role labels. In Proceedings of the Eight International Conference on Language Resources and Evaluation (LREC 2012). Istanbul, Turkey, pp.1862-1867.

Fellbaum, C. (1998): WordNet: An electronic lexical database. MIT Press. Cambridge, Massachusetts.

Ferrer, E. E. (2004): Towards a semantic classification of Spanish verbs based on subcategorisation information. In Proceedings of the Workshop on Student research (ACLstudent 2004), in conjunction with ACL 2004. Barcelona, Espanha.

Fonseca, E. R. e Rosa, J. L. G. (2012): An Architecture for Semantic Role Labeling on Portuguese. In Proceedings of the 10th International Conference on Computational Processing of Portuguese (PROPOR 2012). Coimbra, Portugal, pp. 204-209.

Girju, R., Roth, D. e Sammons, M. (2005): Token-level disambiguation of VerbNet classes. In Proceedings of Interdisciplinary Workshop on the Identification and Representation of Verb Features and Verb Classes. Saarbruecken, Germany.

Godoy, L. (2009): Verbos Psicológicos: Análise Descritiva dos Dados do Português Brasileiro. ALFA - Revista de Linguística, v. 53, n. 1, pp. 283-299.

Gonçalo Oliveira, H., Santos, D., Gomes, P. e Seco, N. (2008): PAPEL: a dictionary-based lexical ontology for Portuguese. In Proceedings of the 7th International Conference on Computational Processing of Portuguese Language (PROPOR 2008). Aveiro, Portugual, pp. 31-40.

Graff, D. (1995): North American News Text Corpus. Linguistic Data Consortium. LDC95T21. 
Graham, R. L., Knuth, D. E. e Patashnik O. (1994): Concrete Mathematics : A Foundation for Computer Science. Addison-Wesley.

Grishman, R., Macleod, C. e Meyers, A. (1994): Comlex syntax: building a computational lexicon. In Proceedings of the 20th International Conference on Computational Linguistics (COLING 1994). Genebra, Suiça, pp. 268-272.

Jackendoff, R. (1990): Semantic Structures. MIT Press. Cambridge, Massachusetts.

Joanis, E. e Stevenson, S. (2003): A general feature space for automatic verb classification. In Proceedings of the 10th conference on European chapter of the Association for Computational Linguistics (EACL 2003). Budapest, Hungria, pp. 163-170.

Jurafsky, D. e Martin, J.H. (2009): Speech and Language Processing. An Introduction to Natural Language Processing, Computational Linguistics, and Speech Recognition. Person/Prentice Hall. 2nd edition.

Kilgarriff, A. e Rundell, M. (2002): Lexical Profiling Software and its Lexicographic Applications: A Case Study. In Proceedings of the 10th EURALEX Congress. Copenhagen, Dinamarca, pp. 807-819.

Kingsbury, P. e Kipper, K. (2003): Deriving Verb-Meaning Clusters from Syntactic Strucutres. In Proceedings of the Workshop on Text Meaning, in conjunction with HLT NAACL 2003. Edmonton, Canadá.

Kipper, K., Dang, H. T., Schuler, W. e Palmer, M. (2000a): Building a class-based verb lexicon using TAGs. In Proceedings of the 5th International Workshop on Tree Adjoining Grammars and Related Formalisms (TAG+5). Paris, France, pp. 147-154.

Kipper, K., Dang, H. T. e Palmer, M. (2000b): Class-Based Construction of a Verb Lexicon. In Proceedings of the 14th National Conference on Artificial Intelligence (AAAI-2000). Austin, TX, USA, pp. 691-696.

Kipper, K. (2005): Verbnet: A broad coverage, comprehensive verb lexicon. $146 f$. Ph.D. Thesis (Philosophy) - University of Pennsylvania, USA.

Kipper K., Korhonen A., Ryant N. e Palmer, M. (2006): Extending VerbNet with Novel Verb Classes. In Proceedings of the 5th International Conference on Language Resources and Evaluation (LREC 2006). Genova, Itália, pp. 1027-1032.

Klavans, J. L. e Resnik, P. (1996): The Balancing Act: Combining Symbolic and Statistical Approaches to Language. MIT Press. Cambridge, Massachusetts.

Korhonen, A. (2002): Semantically Motivated Subcategorization Acquisition. In Proceedings of the ACL Workshop on Unsupervised Lexical Acquisition, in conjunction with ACL 2012. Philadelphia, PA, USA, pp. 51-58.

Korhonen, A. e Preiss, J. (2003): Improving Subcategorization Acquisition using Word Sense Disambiguation. In Proceedings of the 41st Annual Meeting of the Association for Computational Linguistics (ACL 2003). Sapporo, Japan, pp. 48-55.

Korhonen, A., Krymolowski, Y. e Marx, Z. (2003): Clustering Polysemic Subcategorization Frame Distributions Semantically. In Proceedings of the 41st Annual Meeting of the Association for Computational Linguistics. Sapporo, Japan, pp. 64-71. 
Korhonen, A., Krymolowski, I. e Briscoe, T. (2006): A Large Subcategorization Lexicon for Natural Language Processing Applications. In Proceedings of the 5th International Conference on Language Resources and Evaluation (LREC 2006). Genova, Itália, pp. 1015-1020.

Leech. G. (1992): 100 million words of English: the British National Corpus. Language Research, v. 28, n. 1, pp. 1-13.

Levin, B. (1993): English Verb Classes and Alternation, A Preliminary Investigation. The University of Chicago Press.

Levin, B. e Rappaport Hovav, M. (2005): Argument Realization. Cambridge University Press, Cambridge.

Lima, B. A. F. (2007): Valência dos Verbos de Vitória e Derrota em Português. 128f. Dissertação (Mestrado em Letras) - Pontifícia Universidade Católica de Minas Gerais, Belo Horizonte.

Lima, V. L., Nunes, M., e Vieira, R. (2007): Desafios do processamento de línguas naturais. In Anais do XXVII Congresso da SBC. Rio de Janeiro, RJ, pp 2202-2216.

Lippincott, T., Ó Séaghdha, D. e Korhonen, A. (2012): Learning syntactic verb frames using graphical models. In Proceedings of the 50th Annual Meeting of the Association for Computational Linguistics (ACL 2012). Jeju, Coreia.

Loper, E., Yi, S-T e Palmer, M. (2007): Combining Lexical Resources: Mapping between PropBank and VerbNet. In Proceedings of the 7th International Workshop on Computational Linguistics. Tilburg, Países Baixos.

Manning, C. D. (1993): Automatic acquisition of a large subcategorization dictionary from corpora. In Proceedings of the 31st annual meeting on Association for Computational Linguistics (ACL 1993). Columbus, OH, USA, pp. 235-242.

Marcus, M. P., Santorini, B. e Marcinkiewicz, M. A. (1993): Building a Large Annotated Corpus of English: The Penn Treebank. Computational Linguistics, v. 19, n. 2, pp. 313-330.

Marrafa, P. (2002): Portuguese WordNet: general architecture and internal semantic relations. Revista DELTA, v. 18, n. Especial, pp. 131-146.

McCarthy, D. (2001): Lexical Acquisition at the Syntax-Semantics Interface: Diathesis Alternations, Subcategorization Frames and Selectional Preferences. 189f. Ph.D. Thesis (Philosophy) - University of Sussex, UK.

McCarthy, D. e A. Korhonen (1998): Detecting verbal participation in diathesis alternations In Proceedings of the 36th Annual Meeting of the Association for Computational Linguists (ACL 1998). Montreal, Canadá, pp 1493-1495.

McFate, C. (2010): Expanding Verb Coverage in Cyc With VerbNet. In Proceedings of the ACL 2010 Student Research Workshop, in conjunction with ACL 2010. Uppsala, Suécia, pp. 61-66.

Meila, M. and Shi, J. (2001): A random walks view ofspectral segmentation. In Proceedings of 8th International Workshop on Artificial Intelligence and Statistics (AISTATS 2001). Key West, FL, USA. 
Menezes, R. C. (2005): Verbos de Trajetória: uma Análise Sintático-Semântica. 106f. Dissertação (Mestrado em Linguística) - Faculdade de Letras, Universidade Federal de Minas Gerais, Belo Horizonte.

Merlo, P. e Stevenson, S. (2001): Automatic verb classification based on statistical distributions of argument structure. Computational Linguistics, v. 27, n. 3, pp. 373408.

Merlo, P., Stevenson, S., Tsang, V. e Allaria, G. (2002): A multilingual paradigm for automatic verb classification. In Proceedings of the 40th Annual Meeting of the Association for Computational Linguistics (ACL 2002). Philadelphia, PA, USA, pp. 207-214.

Messiant, C. (2008): A Subcategorization Frames Acquisition System for French Verbs. In Proceedings of the ACL Student Research Workshop, in conjunction with ACL HLT 2008, Colombus, OH, USA.

Messiant, C., Korhonen, A. e Poibeau, T. (2008): LexSchem: A Large Subcategorization Lexicon for French Verbs. In Proceedings of the 6th International Conference on Language Resources and Evaluation (LREC 2008). Marrakech, Marrocos, pp. 533538.

Miller, G. A., Beckwith, R., Fellbaum, C., Gross, D., and Miller, K. J. (1990): Introduction to wordnet: an on-line lexical database. International Journal of Lexicography, v. 3, n. 4, pp. 235-244.

Moraes, H. R. (2008): Aspectos sintaticamente relevantes do significado lexical: estudo dos verbos de movimento. 171f. Tese (Doutorado em Linguística e Língua Portuguesa) - Faculdade de Ciências e Letras, Universidade Estadual Paulista, Araraquara.

Nadeau D. e Sekine S. (2007): A survey of named entity recognition and classification. National Research Council Canada/New York University.

Muniz, M. C. M. (2004): A construção de recursos lingüístico-computacionais para o português do Brasil: o projeto de Unitex-PB. 72f. Dissertação (Mestrado em Ciências de Computação e Matemática Computacional) - Instituto de Ciências Matemáticas e de Computação, Universidade de São Paulo, São Carlos.

Palmer, M., Gildea D. e Kingsbury, P. (2005): The Proposition Bank: A Corpus Annotated with Semantic Roles, Computational Linguistics Journal, v. 31, n. 1, pp. 71-106.

Palmer, M.; Gildea, D.; Xue, N. (2010): Semantic Role Labeling. Synthesis Lectures on Human Language Technology Series, Ed. Graeme Hirst, Mogan \& Claypoole Publishers.

Perini, M. A. (2008): Estudos de Gramática Descritiva - As Valências Verbais. Parábola Editorial, São Paulo, Brasil.

Pianta, E. Bentivogli, L. e Girardi, C. (2002): Multiwordnet: developing an aligned multilingual database. In Proceedings of the First International Conference on Global WordNet Conference, Mysore, India, pp. 293-302.

Preiss, J., Briscoe, T. e Korhonen, A. (2007): A System for Large-Scale Acquisition of Verbal, Nominal and Adjectival Subcategorization Frames from Corpora. In 
Proceedings of the 45th Annual Meeting of the Association of Computational Linguistics (ACL 2007). Pragua, República Tcheca, pp. 912-919.

Pustejovsky, James (1995): The Generative Lexicon. MIT Press, Cambridge, Massachusetts.

Ribeiro, P. N. (2010): A alternância causativa no português do Brasil : a distribuição do cíclico SE. 128f. Dissertação (Mestrado em Teoria e Análise Linguística) Universidade Federal do Rio Grande do Sul, Porto Alegre.

Saint-Dizier, P. (1996): Constructing verb semantic classes for French: methods and evaluation. In Proceedings of the 16th conference on Computational linguistics (COLING 1996). Copenhagen, Dinamarca, pp. 1127-1130.

Salomão, Maria M. M. (2009): FrameNet Brasil: Um trabalho em progresso. Revista Calidoscópio, v. 7, n. 3, pp. 171-182.

Sampson, G. (1995): English for the computer. Oxford University Press, Oxford, UK.

Santos, D., Barreiro, A., Costa, L., Freitas, C., Gomes, P., Gonçalo Oliveira, H., Medeiros, J. C. e Silva, R. (2009): O papel das relações semânticas em português: Comparando o TeP, o MWN.PT e o PAPEL. In XXV Encontro Nacional da Associação Portuguesa de Linguística. Lisboa, Portugal.

Scarton, C. E. e Aluísio, S. M. (2009): Herança Automática das Relações de Hiperonímia para a Wordnet.Br. Série de Relatórios do NILC. NILC-TR-09-10, 48p.

Scarton, C. E., Almeida, D. M. e Aluisio, S. M. (2009): Análise da Inteligibilidade de textos via ferramentas de Processamento de Língua Natural: adaptando as métricas do Coh-Metrix para o Português. In Proceedings of the The 7th Brazilian Symposium in Information and Human Language Technology (STIL 2009). São Carlos, SP, Brazil, 1 CD-ROM ISSN 2175-6201.

Scarton, C. E. e Aluísio, S. M. (2010): Análise da Inteligibilidade de textos via ferramentas de Processamento de Língua Natural: adaptando as métricas do Coh-Metrix para o Português. Revista Linguamática (Revista para o Processamento Automático das Línguas Ibéricas - ISSN: 1647-0818), v. 2, n. 1, pp. 45-61.

Scarton, C. E., Gasperin, C. e Aluisio, S. M. (2010): Revisiting the Readability Assessment of Texts in Portuguese. In Proceedings of the 12th Ibero-American Conference on Artificial Intelligence (Iberamia 2010). Bahia Blanca, Argentina, pp. 306-315.

Scarton, C. E. (2011): VerbNet.Br: construção semiautomática de um léxico computacional de verbos para o português do Brasil. In Proceedings of the The 8th Brazilian Symposium in Information and Human Language Technology (STIL 2009). Cuiabá, MT, Brazil.

Scarton, C. e Aluisio, S. (2012): Towards a cross-linguistic VerbNet-style lexicon to Brazilian Portuguese. In Proceedings of the LREC 2012 Workshop on Creating Cross-language Resources for Disconnected Languages and Styles (CREDISLAS 2012). Istambul, Turquia, pp 11-18.

Schulte im Walde, S. e Brew, C. (2002): Inducing German semantic verb classes from purely syntactic subcategorisation information. In Proceedings of the 40th Annual Meeting of the Association for Computational Linguistics (ACL 2002). Philadelphia, PA, USA, pp. 223-230. 
Schulte im Walde, S. (2006): Experiments on the Automatic Induction of German Semantic Verb Classes. Computational Linguistics, v. 32, n. 2, pp. 159-194.

Shi, L. e Mihalcea, R. (2005): Putting pieces together: Combining FrameNet, VerbNet and WordNet for robust semantic parsing. In Proceedings of 6th International Conference on Computational Linguistics and Intelligent Text Processing (CICLing 2005). Cidade do México, México, pp. 99-110.

Sun, L. (2007): Automatic Lexical Classification. 50f. M. Phil. Thesis (Computer Speech, Text, and Internet Technology) - University of Cambridge, UK.

Sun, L., Korhonen, A. e Krymolowski, Y. (2008): Verb class discovery from rich syntactic data. In Proceedings of the 9th international conference on Computational linguistics and intelligent text processing (CICLing 2008). Haifa, Israel, pp. 16-27.

Sun, L. e Korhonen, A. (2009): Improving verb clustering with automatically acquired selectional preferences. In Proceedings of the 2009 Conference on Empirical Methods in Natural Language Processing (EMNLP 2009). Singapura, pp. 638-647.

Sun, L., Korhonen, A., Poibeau, T. e Messiant, C. (2010): Investigating the cross-linguistic potential of VerbNet: style classification. In Proceedings of the 23rd International Conference on Computational Linguistics (COLING 2010). Beijing, China, pp. 10561064.

Sun, L. e Korhonen, K. (2011): Hierarchical Verb Clustering Using Graph Factorization. In Proceedings of the 2011 Conference on Empirical Methods in Natural Language Processing (EMNLP 2011). Edinburgh, UK, pp. 1023-1033.

Swier, R. e Stevenson, S. (2004): Unsupervised semantic role labelling. In Proceedings of the 2004 Conference on Empirical Methods in Natural Language Processing (EMNLP 2004). Barcelona, Spain, pp. 95-102.

Takeuchi, K. Inui, K., Takeuchi, N. e Fujita, A. (2010): A Thesaurus of PredicateArgument Structure for Japanese Verbs to Deal with Granularity of Verb Meanings. In Proceedings of the 8th Workshop on Asian Language Resources (ALR 2010), Beijing, China, pp. 1-8.

Ushioda, A., Evans, D. A., Gibson, T. e Waibel, A. (1993): The automatic acquisition of frequencies of verb subcategorization frames from tagged corpora. In Proceedings of the SIGLEX ACL Workshop on the Acquisition of Lexical Knowledge from Text, in conjunction with ACL (1993). Columbus, OH, USA, pp. 95-106.

Vázquez, G., Fernández, A., Castellón, I. e Martí, M. A. (2000): Clasificasión verbal: Alternancias de diátesis. Quaderns de Sintagma. Universitat de Lleida.

Vossen, P. (2002): Eurowordnet general document. Technical report, EuroWordNetProject.

Vossen, P. (2004): Eurowordnet: a multilingual database of autonomous and language specific wordnets connected via an interlingual-index. International Journal of Linguistics, v. 17.

Whitaker-Franchi, R. C. M. (1989): As Construções Ergativas: Um estudo sintático e semântico. 199f. Dissertação (Mestrado em Linguística) - Departamento de Linguística, Universidade Estadual de Campinas, Campinas. 
Witten, I. H. and Frank, E. (2005): Data Mining: Practical machine learning tools and techniques, 2nd Edition. Morgan Kaufmann, San Francisco.

Yang, Z. and Oja, E. (2012): Clustering by Low-Rank Doubly Stochastic Matrix Decomposition. In Proceedings of the $29^{\text {th }}$ International Conference on Machine Learning (ICML 2012), Edinburgh, UK.

Yi, S. e Palmer, M. (2004): Pushing the boundaries of Semantic Role Labeling with SVM. In Proceedings of the 3rd International Conference on Natural Language Processing (ICON 2004). Hyderabad, India.

Yi, S., Lopper, E. e Palmer, M. (2007): Can Semantic Roles Generalize Across Genres?. In Proceedings of NAACL HLT 2007, Rochester, NY, USA, pp. 548-555.

Zavaglia, C. (2006): O papel do léxico na elaboração de ontologias computacionais: do seu resgate à sua disponibilização. Lingüística IN FOCUS - Léxico e morfofonologia: perspectivas e análises, EDUFU, Uberlândia, v. 4, n. 1, pp. 233-274.

Zanette, A. (2010): Aquisição de Subcategorization Frames para Verbos da Língua Portuguesa. 53f. Trabalho de Conclusão de Curso (Bacharel em Ciência da Computação) - Instituto de Informática, Universidade Federal do Rio Grande do Sul, Porto Alegre.

Zanette, A., Scarton, C. and Zilio, L. (2012): Automatic extraction of subcategorization frames from corpora: an approach to Portuguese. In Demonstration Session of the International Conference on Computational Processing of Portuguese Language (PROPOR 2012). Coimbra, Portugual.

Zilio, L., Zanette, A. e Scarton, C. (2012): Extração Automática de Subcategorization Frames a partir de corpora em português. Em Anais do XI Encontro de Linguística de Corpus (ELC 2012). São Carlos-SP, Brasil.

Ziviani, N. (2005): Projeto de Algoritmos: com implementações em Pascal e C, $2^{\mathrm{a}}$ Edição. Pioneira Thomson Learning, São Paulo. 


\section{APÊNDICE A - Classes da VerbNet.Br e resultados}

Neste Apêndice são apresentadas as 202 classes da VerbNet.Br, os verbos selecionados e a taxa de aceitação para cada classe. A seleção dos verbos apresentada foi obtida pelo experimento 1 (EXP1), que foi o experimento que apresentou melhores resultados.

\section{accompany-51.7}

Taxa de aceitação: 1.0

Número selecionados: 14

Número candidatos: 14

Selecionados: seguir, pegar, orientar, acompanhar, levar, dirigir, conduzir, ladear, buscar, apanhar, guiar, encaminhar, escoltar, aconselhar.

Alternâncias definidas para a classe - Etapa1: V_SN, V_SN_SP[até], V_SN_SP[a], V_SN_SP[para].

\section{adjust-26.9}

Taxa de aceitação: 0.8

Número Selecionados: 8

Número candidatos: 10

Selecionados: ajustar, adaptar, gostar, aplicar, acondicionar, aderir, acomodar, adequar. Alternâncias definidas para a classe - Etapa1: V_SN, V_SN_SP[a], V_SN_SP[para], V_SP[a], V_SP[para].

\section{admire-31.2}

Taxa de aceitação: 0.913978494624

Número Selecionados: 85

Número candidatos: 93

Selecionados: ilustrar, elevar, amaldiçoar, defender, imaginar, sustentar, pensar, enobrecer, resistir, detestar, consagrar, socorrer, comportar, pisar, desdenhar, temer, viver, desprezar, subir, consentir, abençoar, querer, estimar, ornar, abominar, agüentar, deplorar, gostar, permitir, preconizar, duvidar, estremecer, odiar, lastimar, chorar, gabar, encarecer, prestigiar, conceber, prezar, amparar, enaltecer, idolatrar, considerar, menosprezar, lamentar, suportar, desconfiar, invejar, admitir, postergar, suspeitar, exaltar, renegar, tragar, padecer, julgar, elogiar, cantar, respeitar, gemer, aborrecer, tolerar, levar, supor, cultuar, venerar, adorar, glorificar, proteger, curtir, aturar, digerir, louvar, recear, desfazer, engrandecer, humilhar, amar, apreciar, sofrer, engolir, extremar, levantar, cobiçar.

Alternâncias definidas para a classe - Etapa1: V_SN, V_SN_SP[de], V_SN_SP[em], V_SN_SP[por].

advise-37.9

Taxa de aceitação: 0.909090909091

Número Selecionados: 10 


\section{Número candidatos: 11}

Selecionados: avisar, exortar, incentivar, alertar, encorajar, prevenir, animar, estimular, advertir, excitar.

Alternâncias definidas para a classe - Etapa1: V_SN, V_SN_SP[contra], V_SN_SP[sobre], V_SN_SP[de].

\section{amalgamate-22.2}

Taxa de aceitação: 0

Número Selecionados: 82

Número candidatos: 82

Selecionados: interligar, ocorrer, balancear, conviver, coincidir, juntar, casar, meter, revolver, opor, entrar, integrar, suceder, introduzir, mestiçar, totalizar, atrelar, inserir, cruzar, combinar, conferir, alternar, privar, harmonizar, aproximar, tratar, misturar, inovar, mesclar, pôr, reunir, ligar, balançar, empatar, somar, comparar, embeber, engatar, renovar, federar, tecer, ajustar, relacionar, calhar, coordenar, assemelhar, recortar, perfazer, contrapor, conciliar, concorrer, incluir, aferir, acontecer, dar, coexistir, condizer, aderir, atar, tramar, unir, solidificar, bater, completar, vir, enquadrar, encaixar, cair, colar, pegar, aliar, coadunar, aglutinar, grudar, confrontar, consolidar, prender, convir, trocar, intercalar, cingir, ornar.

Alternâncias definidas para a classe - Etapa1: all.

\section{amuse-31.1}

Taxa de aceitação: 0.93536121673

Número Selecionados: 246

Número candidatos: 263

Selecionados: diluir, aquecer, revoltar, magoar, insinuar, atrapalhar, agradar, alegrar, toldar, acalmar, perturbar, estremecer, arruinar, calcar, incomodar, penetrar, esmagar, debilitar, abaixar, pregar, desapontar, aguçar, esfriar, exultar, cansar, arrombar, minorar, invocar, pisar, fascinar, consolar, desonrar, desgraçar, assediar, meter, dar, dilacerar, escravizar, folgar, repousar, flechar, afrontar, tumultuar, esmorecer, tranqüilizar, descer, intoxicar, pairar, apertar, diminuir, ministrar, incutir, induzir, estimular, promover, embaraçar, sangrar, derreter, sacudir, ditar, alertar, apaixonar, desagradar, sobrecarregar, influir, confortar, incentivar, envolver, acomodar, decepcionar, seduzir, danar, comover, agonizar, lenir, conquistar, agitar, exortar, arrebatar, descontentar, entristecer, enfurecer, matar, desanimar, suscitar, alarmar, doer, moderar, sugerir, confundir, engrossar, ofender, torturar, deprimir, emocionar, moer, abalar, consumir, sossegar, alucinar, descansar, contrariar, ralar, tocar, atrair, impor, soprar, distrair, abrasar, humilhar, empolgar, desencorajar, gelar, aliviar, falar, alterar, apagar, entreter, atormentar, deixar, acirrar, chatear, rolar, penalizar, irritar, transportar, desconfiar, acender, render, constranger, ameaçar, divertir, evocar, intrigar, pesar, embalar, acordar, excitar, escandalizar, aniquilar, esquentar, plantar, provocar, ninar, frustrar, devorar, machucar, enfraquecer, entusiasmar, assustar, encorajar, desesperar, maltratar, jogar, exaltar, avivar, envergonhar, brincar, incendiar, inflamar, despertar, abater, acalentar, prejudicar, comprimir, ceder, satisfazer, chocar, deslumbrar, afrouxar, obscurecer, afligir, reduzir, cativar, aborrecer, fatigar, dourar, preocupar, amaciar, materializar, abrandar, inquietar, espantar, atenuar, indignar, iludir, temperar, amortecer, embelezar, incitar, solicitar, perder, triunfar, aprazer, serenar, infundir, mover, tentar, horrorizar, desafiar, desconfortar, pastar, levantar, animar, quebrar, 
desgostar, maravilhar, arrasar, exaurir, suavizar, impregnar, tolher, enjoar, sensibilizar, arrepiar, azedar, amargar, refrescar, afetar, amenizar, iluminar, entupir, cegar, ativar, encantar, morder, arder, abanar, sufocar, intimidar, recuar, recorrer, inspirar, oprimir, aplacar, arrefecer, rebaixar, desestimular, atentar, ferir, bulir, contentar, degradar, enfadar, picar, impressionar.

Alternâncias definidas para a classe - Etapa1: V, V_SN, V_SN_SP[com].

animal_sounds-38

Taxa de aceitação: 0.947368421053

Número Selecionados: 18

Número candidatos: 19

Selecionados: zumbir, gemer, piar, balar, chiar, ranger, berrar, sussurrar, malhar, balir, chacoalhar, ressonar, rugir, estourar, zinir, ladrar, ressoar, latir.

Alternâncias definidas para a classe - Etapa1: V, V_SN, V_SN_SP[em], V_SP[para].

appeal-31.4

Taxa de aceitação: 0

Número Selecionados: 4

Número candidatos: 4

Selecionados: pesar, recair, atrair, chamar.

Alternâncias definidas para a classe - Etapa1: all.

appear-48.1.1

Taxa de aceitação: 0.837209302326

Número Selecionados: 36

Número candidatos: 43

Selecionados: raiar, objetivar, ir, correr, andar, invadir, emergir, nascer, convergir, acordar, surdir, despontar, arrebentar, resultar, caminhar, passar, sair, surgir, despertar, inçar, concorrer, aparecer, pulular, dar, evoluir, rebentar, vir, grassar, brotar, amanhecer, escorrer, espirrar, concretizar, desabar, deslizar, irromper.

Alternâncias definidas para a classe - Etapa1: V, V_SP[em], V_SP[entre], V_SP[por], V_SP[sobre], V_SP[sob].

appoint-29.1

Taxa de aceitação: 0.913043478261

Número Selecionados: 21

Número candidatos: 23

Selecionados: declarar, professar, confessar, coroar, ter, pôr, empossar, abraçar, apontar, escolher, instituir, nomear, indicar, aceitar, eleger, constituir, proclamar, seguir, deixar, adotar, designar.

Alternâncias definidas para a classe - Etapa1: V_SN, V_SN_SP[como], V_SN_SP[para].

assessment-34.1

Taxa de aceitação: 0.928571428571

Número Selecionados: 39

Número candidatos: 42 
Selecionados: vasculhar, tirar, perscrutar, examinar, observar, demandar, correr, espreitar, dissecar, analisar, escavar, esquadrinhar, comentar, estudar, devassar, apalpar, criticar, apurar, buscar, descortinar, investigar, explorar, averiguar, inquirir, sondar, reconhecer, aprofundar, encarar, profundar, perguntar, recorrer, considerar, esmiuçar, mirar, pesquisar, olhar, indagar, procurar, percorrer.

Alternâncias definidas para a classe - Etapa1: V_SN, V_SN_SP[por].

assuming_position-50

Taxa de aceitação: 0.875

Número Selecionados: 14

Número candidatos: 16

Selecionados: levantar, voar, surgir, subir, assentar, inclinar, erguer, ascender, abaixar, aparecer, emergir, ajoelhar, sentar, vergar.

Alternâncias definidas para a classe - Etapa1: V, V_SP[em], V_SP[entre], V_SP[por], V_SP[sobre], V_SP[sob].

avoid-52

Taxa de aceitação: 0.857142857143

Número Selecionados: 6

Número candidatos: 7

Selecionados: afastar, desviar, retirar, evitar, furtar, poupar.

Alternâncias definidas para a classe - Etapa1: V_SN.

banish-10.2

Taxa de aceitação: 1.0

Número Selecionados: 15

Número candidatos: 15

Selecionados: tomar, recolher, tirar, mandar, rechaçar, rebater, exterminar, expulsar, descalçar, repelir, retirar, sacar, excluir, dispor, banir.

Alternâncias definidas para a classe - Etapa1: V_SN, V_SN_SP[de], V_SN_SP[para].

battle-36.4

Taxa de aceitação: 0.0454545454545

Número Selecionados: 1

Número candidatos: 22

Selecionados: responder.

Alternâncias definidas para a classe - Etapa1: V_SP[com]_SP[por],

V_SP[com]_SP[sobre].

\section{begin-55.1}

Taxa de aceitação: 0

Número Selecionados: 24

Número candidatos: 24

Selecionados: avançar, reiniciar, iniciar, ir, introduzir, voltar, puxar, partir, estabelecer, começar, chegar, principiar, reivindicar, debutar, travar, renovar, assumir, entrar, abrir, recomeçar, largar, estrear, tornar, romper.

Alternâncias definidas para a classe - Etapa1: all. 
being_dressed-41.3.3

Taxa de aceitação: 0

Número Selecionados: 3

Número candidatos: 3

Selecionados: enfiar, vestir, pôr.

Alternâncias definidas para a classe - Etapa1: all.

bend-45.2

Taxa de aceitação: 0.9

Número Selecionados: 9

Número candidatos: 10

Selecionados: manusear, amarrotar, enrolar, franzir, vergar, embrulhar, dobrar, machucar, amassar.

Alternâncias definidas para a classe - Etapa1: V_SN, V_SN_SP[com], V, V_SN_SP[em], V_SN_SP[em]_SP[com], V_SN.

berry-13.7

Taxa de aceitação: 0.75

Número Selecionados: 3

Número candidatos: 4

Selecionados: ferrar, pescar, pegar.

Alternâncias definidas para a classe - Etapa1: V.

bill-54.5

Taxa de aceitação: 0.8

Número Selecionados: 4

Número candidatos: 5

Selecionados: jogar, arriscar, pôr, multar.

Alternâncias definidas para a classe - Etapa1: V_SN.

body internal motion-49

Taxa de aceitação: 0

Número Selecionados: 15

Número candidatos: 15

Selecionados: jogar, agitar, balançar, oscilar, sacudir, menear, arfar, girar, rodar, espernear, brandir, mover, rolar, respingar, abanar.

Alternâncias definidas para a classe - Etapa1: all.

body_internal_states-40.6

Taxa de aceitação: 0.8

Número Selecionados: 4

Número candidatos: 5

Selecionados: palpitar, agitar, bater, espernear.

Alternâncias definidas para a classe - Etapa1: V, V_SP[com], V_SP[de]. 
braid-41.2.2

Taxa de aceitação: 1.0

Número Selecionados: 13

Número candidatos: 13

Selecionados: cortar, pentear, ajeitar, trançar, arrancar, aparar, cercear, diminuir, encurtar, riçar, puxar, frisar, vazar.

Alternâncias definidas para a classe - Etapa1: V_SN.

break-45.1

Taxa de aceitação: 1.0

Número Selecionados: 19

Número candidatos: 19

Selecionados: trincar, desmoronar, romper, quebrar, engasgar, esmagar, encrencar, fraturar, partir, falhar, desfazer, comprimir, dividir, rachar, dilacerar, fragmentar, despedaçar, fender, amassar.

Alternâncias definidas para a classe - Etapa1: V_SN, V_SN_SP[com], V, V_SN, V_SN_SP[em], V_SN_SP[em]_SP[com], V_SP[em].

\section{breathe-40.1.2}

Taxa de aceitação: 1.0

Número Selecionados: 13

Número candidatos: 13

Selecionados: relaxar, vomitar, cuspir, rejeitar, sangrar, escorrer, repousar, transpirar, descansar, soluçar, suar, babar, chorar.

Alternâncias definidas para a classe - Etapa1: V, V_SP[por], V_SN, V_SN_SP[em], V_SN_SP[sobre].

\section{bring-11.3}

Taxa de aceitação: 1.0

Número Selecionados: 6

Número candidatos: 6

Selecionados: trazer, portar, pegar, levar, buscar, apanhar.

Alternâncias definidas para a classe - Etapa1: V_SN, V_SN_SP[em], V_SN_SP[para], V_SN_SP[de], V_SN_SP[de]_SP[para].

\section{build-26.1}

Taxa de aceitação: 1.0

Número Selecionados: 36

Número candidatos: 36

Selecionados: bordar, armar, construir, enrolar, arrumar, dobrar, dispor, fabricar, ajeitar, plantar, erguer, compor, cozinhar, costurar, fazer, manipular, edificar, montar, forjar, arar, recortar, alçar, trabalhar, coordenar, moldar, produzir, cultivar, cortar, coser, fundir, elevar, lavrar, embrulhar, arquitetar, talhar, consertar.

Alternâncias definidas para a classe - Etapa1: V_SN, V, V_SN_SP[em], V_SN_SP[de], V_SN_SP[com], V_SN_SP[em], V_SN_SP[para], V_SN_SP[com]_SP[para], V_SN_SP[de]_SP[para], V_SN_SP[em]_SP[para], V_SN_SP[para], V_SN_SP[em], V_SN_SP[em]_SP[por], V_SN_SP[com]_SP[por], V_SN_SP[de]_SP[por]. 
bulge-47.5.3

Taxa de aceitação: 0

Número Selecionados: 2

Número candidatos: 2

Selecionados: arregalar, escancarar.

Alternâncias definidas para a classe - Etapa1: all.

bump-18.4

Taxa de aceitação: 0.333333333333

Número Selecionados: 4

Número candidatos: 12

Selecionados: esbarrar, bater, atingir, topar.

Alternâncias definidas para a classe - Etapa1: V_SP[contra], V_SP[em].

butter-9.9

Taxa de aceitação: 0.884615384615

Número Selecionados: 23

Número candidatos: 26

Selecionados: tapar, salpicar, enrolar, coroar, decorar, adornar, cobrir, riscar, apanhar, perfumar, tomar, vestir, enfeitar, revestir, engraxar, embelezar, colorir, enquadrar, emoldurar, pegar, velar, engessar, ornar.

Alternâncias definidas para a classe - Etapa1: V_SN, V_SN_SP[com].

calibratable_cos-45.6

Taxa de aceitação: 0.916666666667

Número Selecionados: 22

Número candidatos: 24

Selecionados: ampliar, fraquear, encolher, saltar, declinar, avultar, abaixar, enfraquecer, engordar, engrandecer, vingar, pular, acrescentar, galgar, decair, cair, subir, descer, diminuir, aumentar, escalar, estreitar.

Alternâncias definidas para a classe - Etapa1: V, V_SN.

captain-29.8

Taxa de aceitação: 0

Número Selecionados: 31

Número candidatos: 31

Selecionados: presenciar, vigiar, verificar, assistir, conduzir, ensaiar, defender, escoltar, industriar, testemunhar, velar, ver, talhar, apadrinhar, costurar, ladear, guiar, cuidar, treinar, recortar, lactar, navegar, amamentar, zelar, cortar, coser, acompanhar, levar, exercitar, seguir, olhar.

Alternâncias definidas para a classe - Etapa1: all.

carry-11.4

Taxa de aceitação: 1.0

Número Selecionados: 12

Número candidatos: 12 
Selecionados: empolgar, tirar, arrebatar, arrancar, meter, partir, afundar, transportar, sacar, extrair, arrastar, puxar.

Alternâncias definidas para a classe - Etapa1: V_SN, V_SN_SP[até], V_SN_SP[a], V_SN_SP[para], V_SN_SP[de], V_SN_SP[de]_SP[até], V_SN_SP[de]_SP[a],

V_SN_SP[de]_SP[para].

carve-21.2

Taxa de aceitação: 0

Número Selecionados: 27

Número candidatos: 27

Selecionados: amarrotar, rasgar, moer, fender, esmagar, manipular, esfarelar, recortar, podar, trabalhar, ceifar, ferir, comprimir, ralar, fragmentar, picar, machucar, manusear, cortar, derramar, clarear, lavrar, esmiuçar, diminuir, britar, talhar, amassar.

Alternâncias definidas para a classe - Etapa1: all.

change_bodily_state-40.8.4

Taxa de aceitação: 1.0

Número Selecionados: 7

Número candidatos: 7

Selecionados: esmorecer, empalidecer, apagar, desmaiar, enfermar, adoecer, descair.

Alternâncias definidas para a classe - Etapa1: V, V_SP[de].

characterize-29.2

Taxa de aceitação: 0.301369863014

Número Selecionados: 22

Número candidatos: 73

Selecionados: caracterizar, ter, ver, identificar, apontar, receber, tomar, haver, descrever, aceitar, classificar, eleger, conceber, dar, retratar, procurar, reconhecer, conhecer, considerar, seguir, entender, adotar.

Alternâncias definidas para a classe - Etapa1: V_SN_SP[como].

chase-51.6

Taxa de aceitação: 1.0

Número Selecionados: 2

Número candidatos: 2

Selecionados: rastrear, seguir.

Alternâncias definidas para a classe - Etapa1: V_SN, V_SN_SP[entre], V_SN_SP[até], V_SN_SP[em], V_SN_SP[por].

cheat-10.6

Taxa de aceitação: 0.93023255814

Número Selecionados: 80

Número candidatos: 86

Selecionados: diluir, lesar, acalmar, isentar, privar, despir, desculpar, libertar, retirar, abaixar, aplicar, inocentar, dissipar, tomar, soltar, depredar, fraudar, resolver, destituir, desfavorecer, diminuir, sanar, roubar, drenar, empregar, reabilitar, esgotar, lenir, esclarecer, descobrir, pagar, consumir, solucionar, enganar, vazar, sugar, aliviar, apagar, 
exaurir, tolher, sumir, saquear, gastar, curar, puxar, suavizar, perdoar, serenar, pilhar, acalentar, prejudicar, limpar, descarregar, ceder, desnudar, afrouxar, reduzir, levar, amaciar, moderar, abrandar, atenuar, tirar, temperar, amortecer, cassar, desapropriar, liberar, minorar, quebrar, livrar, despender, absolver, desfalcar, absorver, remir, aplacar, arrefecer, amenizar, extrair.

Alternâncias definidas para a classe - Etapa1: V_SN_SP[de], V_SN.

chew-39.2

Taxa de aceitação: 0

Número Selecionados: 9

Número candidatos: 9

Selecionados: mastigar, provar, sorver, sugar, chupar, manducar, mascar, beliscar, comer.

Alternâncias definidas para a classe - Etapa1: all.

chit_chat-37.6

Taxa de aceitação: 1.0

Número Selecionados: 15

Número candidatos: 15

Selecionados: comentar, debater, disputar, dialogar, tratar, falar, conversar, brigar, praticar, argumentar, batalhar, discutir, intrigar, contestar, pleitear.

Alternâncias definidas para a classe - Etapa1: V, V_SP[com], V_SP[com]_SP[sobre], V, V_SP[sobre]_SP[com], V_SP[sobre], V_SP[sobre].

classify-29.10

Taxa de aceitação: 1.0

Número Selecionados: 11

Número candidatos: 11

Selecionados: seriar, enumerar, graduar, seqüestrar, classificar, arrumar, ordenar, contar, dividir, isolar, apurar.

Alternâncias definidas para a classe - Etapa1: V_SN, V_SN_SP[como], V_SN_SP[em].

clear-10.3

Taxa de aceitação: 1.0

Número Selecionados: 5

Número candidatos: 5

Selecionados: abrir, refluir, limpar, descarregar, vazar.

Alternâncias definidas para a classe - Etapa1: V_SN, V, V_SN_SP[de].

cling-22.5

Taxa de aceitação: 1.0

Número Selecionados: 1

Número candidatos: 1

Selecionados: aderir.

Alternâncias definidas para a classe - Etapa1: V_SP[a], V_SP[com], V_SP[em].

coil-9.6

Taxa de aceitação: 0.666666666667 
Número Selecionados: 2

Número candidatos: 3

Selecionados: enroscar, girar.

Alternâncias definidas para a classe - Etapa1: V_SN_SP[em], V_SN_SP[entre], V_SP[em], V_SP[entre].

coloring-24

Taxa de aceitação: 1.0

Número Selecionados: 6

Número candidatos: 6

Selecionados: pintar, vestir, tingir, corar, matizar, colorir.

Alternâncias definidas para a classe - Etapa1: V_SN, V_SN_SP[em].

complain-37.8

Taxa de aceitação: 1.0

Número Selecionados: 4

Número candidatos: 4

Selecionados: objetar, roncar, presumir, opor.

Alternâncias definidas para a classe - Etapa1: V, V_SP[para], V_SP[de], V_SP[sobre], V_SP[de]_SP[para], V_SP[sobre]_SP[para], V_SP[para]_SP[de], V_SP[para]_SP[sobre].

complete-55.2

Taxa de aceitação: 0.928571428571

Número Selecionados: 26

Número candidatos: 28

Selecionados: professar, resgatar, desempenhar, acabar, executar, despachar, terminar, concluir, sair, praticar, exercer, realizar, empreender, tentar, findar, fazer, resolver, preencher, completar, ocupar, consumar, atentar, encerrar, operar, cumprir, promover.

Alternâncias definidas para a classe - Etapa1: V_SN.

concealment-16

Taxa de aceitação: 0.8

Número Selecionados: 4

Número candidatos: 5

Selecionados: esconder, isolar, guardar, embotar.

Alternâncias definidas para a classe - Etapa1: V_SN_SP[de], V_SN_SP[entre]_SP[em], V_SN_SP[entre]_SP[entre], V_SN.

confess-37.10

Taxa de aceitação: 1.0

Número Selecionados: 16

Número candidatos: 16

Selecionados: declarar, tomar, reconhecer, conhecer, propagar, receber, confessar, aceitar, matar, rolar, divulgar, admitir, desvendar, decifrar, adotar, adivinhar.

Alternâncias definidas para a classe - Etapa1: V_SN, V_SN_SP[para], V_SP[para].

conjecture-29.5 
Taxa de aceitação: 0

Número Selecionados: 75

Número candidatos: 75

Selecionados: declarar, pressupor, desconfiar, imaginar, confiar, confessar, farejar, calcular, pressentir, atender, admitir, tencionar, projetar, permitir, contar, localizar, deferir, liberar, surpreender, discriminar, ver, identificar, entregar, mostrar, prever, possibilitar, presumir, suspeitar, anunciar, pretender, desejar, confirmar, querer, facultar, cuidar, prenunciar, provar, indicar, tomar, conceder, palpitar, saber, sentir, intuir, aceitar, distinguir, conceber, dar, julgar, ceder, pensar, cogitar, adivinhar, vislumbrar, predizer, detectar, outorgar, reconhecer, conhecer, receber, demonstrar, antever, considerar, meditar, antecipar, cheirar, supor, diferenciar, profetizar, deixar, fornecer, adotar, esperar, facilitar, intentar.

Alternâncias definidas para a classe - Etapa1: all.

consider-29.9

Taxa de aceitação: 0

Número Selecionados: 10

Número candidatos: 10

Selecionados: haver, opinar, saber, considerar, entender, interpretar, dar, julgar, ter, olhar. Alternâncias definidas para a classe - Etapa1: all.

contiguous_location- 47.8

Taxa de aceitação: 1.0

Número Selecionados: 30

Número candidatos: 30

Selecionados: suportar, agüentar, encabeçar, enrolar, coroar, envolver, apoiar, cobrir, segurar, abraçar, sustentar, ladear, suster, revestir, circular, abarcar, encher, assediar, escorar, liderar, rodear, anteceder, enquadrar, emoldurar, circundar, enlaçar, cercar, preceder, cingir, percorrer.

Alternâncias definidas para a classe - Etapa1: V_SN.

continue-55.3

Taxa de aceitação: 0.777777777778

Número Selecionados: 7

Número candidatos: 9

Selecionados: continuar, prosseguir, ir, levar, andar, seguir, proceder.

Alternâncias definidas para a classe - Etapa1: V, V, V_SP[até].

contribute-13.2

Taxa de aceitação: 0.844444444444

Número Selecionados: 38

Número candidatos: 45

Selecionados: reembolsar, render, trazer, reparar, repor, ofertar, obtemperar, apresentar, embolsar, entregar, indenizar, estender, voltar, aplicar, restituir, administrar, deixar, pagar, distribuir, oferecer, renegar, devolver, doar, renunciar, dar, produzir, ceder, brindar, ressarcir, ministrar, cair, levar, abandonar, tornar, dispensar, cumprir, presentear, compensar. 
Alternâncias definidas para a classe - Etapa1: V_SN_SP[para], V_SN.

convert-26.6.2

Taxa de aceitação: 0.681818181818

Número Selecionados: 15

Número candidatos: 22

Selecionados: iniciar, introduzir, voltar, reconstituir, começar, retornar, chegar, buscar, recuperar, ficar, volver, cair, recorrer, apelar, tornar.

Alternâncias definidas para a classe - Etapa1: V_SN_SP[em], V_SN_SP[para].

cooking-45.3

Taxa de aceitação: 1.0

Número Selecionados: 7

Número candidatos: 7

Selecionados: refogar, esquentar, dourar, fritar, corar, abrasar, aquecer.

Alternâncias definidas para a classe - Etapa1: V_SN, V_SN_SP[com], V_SN_SP[em], V, V_SN.

correspond-36.1

Taxa de aceitação: 0.789473684211

Número Selecionados: 45

Número candidatos: 57

Selecionados: paquerar, negociar, conviver, juntar, admitir, batalhar, concordar, cruzar, acordar, combinar, estabelecer, aproximar, tratar, consentir, reunir, firmar, estar, discutir, ligar, chorar, relaxar, ajustar, assentar, contratar, pechinchar, aceitar, comunicar, brigar, contestar, disputar, convir, ceder, comerciar, cantar, unir, querer, debater, discordar, falar, aliar, estipular, argumentar, aceder, convencionar, pleitear.

Alternâncias definidas para a classe - Etapa1: V, V_SP[sobre], V_SP[com]_SP[sobre].

cost-54.2

Taxa de aceitação: 0.8

Número Selecionados: 4

Número candidatos: 5

Selecionados: permanecer, durar, existir, avançar.

Alternâncias definidas para a classe - Etapa1: V_SN.

crane-40.3.2

Taxa de aceitação: 0.92

Número Selecionados: 23

Número candidatos: 25

Selecionados: suspender, enrolar, elevar, mover, dobrar, agitar, cerrar, içar, erguer, entreabrir, fechar, alçar, franzir, empinar, alar, abrir, abanar, embrulhar, bater, subir, esticar, levantar, encostar.

Alternâncias definidas para a classe - Etapa1: V_SN, V_SN_SP[para].

create-26.4 
Taxa de aceitação: 1.0

Número Selecionados: 58

Número candidatos: 58

Selecionados: bordar, desenhar, engendrar, articular, imaginar, reconstruir, compor, construir, idear, elaborar, calcular, evocar, elevar, organizar, escavar, fabricar, plasmar, reconstituir, erguer, criar, cunhar, encenar, manipular, avaliar, cavar, edificar, medir, bolar, reformar, montar, forjar, reorganizar, tomar, formar, reestruturar, buscar, modelar, alçar, moldar, inventar, conceber, fazer, imprimir, abrir, editar, chapar, invocar, produzir, recorrer, lavrar, publicar, aparecer, esculpir, engenhar, refazer, recompor, sair, arquitetar. Alternâncias definidas para a classe - Etapa1: V_SN, V_SN_SP[com], V_SN_SP[de], V_SN_SP[para].

curtsey-40.3.3

Taxa de aceitação: 0

Número Selecionados: 2

Número candidatos: 2

Selecionados: ajoelhar, curvar.

Alternâncias definidas para a classe - Etapa1: all.

cut-21.1

Taxa de aceitação: 0.857142857143

Número Selecionados: 12

Número candidatos: 14

Selecionados: cortar, derramar, recortar, clarear, aparar, cercear, diminuir, encurtar, ferir, picar, talhar, rasgar.

Alternâncias definidas para a classe - Etapa1: V_SN, V_SN_SP[com], V_SN, V_SN_SP[em], V_SN_SP[em]_SP[com], V_SN_SP[em], V_SN_SP[de],

V_SN_SP[de]_SP[com].

debone-10.8

Taxa de aceitação: 1.0

Número Selecionados: 1

Número candidatos: 1

Selecionados: catar.

Alternâncias definidas para a classe - Etapa1: V_SN.

declare-29.4

Taxa de aceitação: 0

Número Selecionados: 13

Número candidatos: 13

Selecionados: aclamar, eleger, conclamar, proclamar, nomear, denominar, classificar, coroar, tachar, chamar, qualificar, capitular, designar.

Alternâncias definidas para a classe - Etapa1: all.

destroy-44

Taxa de aceitação: 0.955555555556

Número Selecionados: 43 


\section{Número candidatos: 45}

Selecionados: extinguir, solapar, devorar, desmantelar, gastar, danificar, sorver, danar, estragar, extirpar, arruinar, varrer, desmanchar, talar, minar, violar, arrasar, derrubar, nivelar, devastar, maltratar, assolar, desfazer, depredar, dizimar, prejudicar, deteriorar, dilacerar, fragmentar, desrespeitar, destruir, afligir, erradicar, raspar, demolir, sufocar, exterminar, apagar, vitimar, escalar, inutilizar, desmontar, despedaçar.

Alternâncias definidas para a classe - Etapa1: V_SN, V_SN_SP[com], V_SN.

devour-39.4

Taxa de aceitação: 0

Número Selecionados: 7

Número candidatos: 7

Selecionados: tomar, engolir, devorar, abocanhar, tragar, ingerir, beber.

Alternâncias definidas para a classe - Etapa1: all.

differ-23.4

Taxa de aceitação: 0.818181818182

Número Selecionados: 9

Número candidatos: 11

Selecionados: implicar, diferir, brigar, dispersar, destoar, divergir, distar, discordar, variar. Alternâncias definidas para a classe - Etapa1: V_SP[de], V.

dine-39.5

Taxa de aceitação: 1.0

Número Selecionados: 1

Número candidatos: 1

Selecionados: pastar.

Alternâncias definidas para a classe - Etapa1: V.

disappearance-48.2

Taxa de aceitação: 0.95

Número Selecionados: 19

Número candidatos: 20

Selecionados: sair, perecer, cair, expirar, sumir, desaparecer, ir, secar, sucumbir, afundar, falecer, faltar, descansar, caducar, morrer, evaporar, ruir, fugir, prescrever.

Alternâncias definidas para a classe - Etapa1: V.

disassemble-23.3

Taxa de aceitação: 0.933333333333

Número Selecionados: 14

Número candidatos: 15

Selecionados: desatar, desarmar, descascar, desligar, lavrar, aparar, trabalhar, peneirar, desmembrar, desabotoar, abrir, desmontar, passar, manipular.

Alternâncias definidas para a classe - Etapa1: V_SN, V_SN_SP[de].

dress-41.1.1

Taxa de aceitação: 1.0 
Número Selecionados: 11

Número candidatos: 11

Selecionados: desapropriar, tirar, despir, banhar, enfiar, descobrir, raspar, privar, desnudar, pôr, vestir.

Alternâncias definidas para a classe - Etapa1: V_SN.

dressing_well-41.3.2

Taxa de aceitação: 0

Número Selecionados: 3

Número candidatos: 3

Selecionados: enfiar, vestir, pôr.

Alternâncias definidas para a classe - Etapa1: all.

drive-11.5

Taxa de aceitação: 0.0

Número Selecionados: 0

Número candidatos: 2

Selecionados:

Alternâncias definidas para a classe - Etapa1: V_SN, V_SN_SP[para], V_SN_SP[de], V_SN_SP[de]_SP[para].

dub-29.3

Taxa de aceitação: 0.863636363636

Número Selecionados: 19

Número candidatos: 22

Selecionados: sagrar, articular, pronunciar, tratar, coroar, dizer, autorizar, nomear, designar, consagrar, denominar, classificar, batizar, ferir, proferir, qualificar, sacramentar, falar, chamar.

Alternâncias definidas para a classe - Etapa1: V_SN.

eat-39.1

Taxa de aceitação: 0

Número Selecionados: 6

Número candidatos: 6

Selecionados: tomar, engolir, ingerir, beber, trincar, comer.

Alternâncias definidas para a classe - Etapa1: all.

engender-27

Taxa de aceitação: 0.96875

Número Selecionados: 31

Número candidatos: 32

Selecionados: causar, trazer, atiçar, avivar, ensejar, desencadear, engendrar, ter, puxar, parir, provocar, criar, suscitar, fazer, sugerir, captar, ocasionar, gerar, motivar, programar, promover, condicionar, instigar, dar, produzir, jogar, acarretar, originar, determinar, levantar, fornecer.

Alternâncias definidas para a classe - Etapa1: V_SN. 
entity_specific_cos-45.5

Taxa de aceitação: 0.6875

Número Selecionados: 22

Número candidatos: 32

Selecionados: alegrar, nascer, degenerar, despontar, desabrochar, apontar, desandar, definhar, pulular, corromper, germinar, secar, descair, chocar, decair, brotar, descer, alterar, florescer, apodrecer, transfigurar, murchar.

Alternâncias definidas para a classe - Etapa1: V.

entity_specific_modes_being-47.2

Taxa de aceitação: $0 . \overline{9} 75609756098$

Número Selecionados: 40

Número candidatos: 41

Selecionados: ir, correr, alegrar, convergir, nascer, desabrochar, macular, apontar, manchar, vicejar, talhar, deturpar, soprar, engrossar, enferrujar, poluir, definhar, concorrer, pular, apodrecer, corromper, germinar, conspurcar, pulular, secar, chocar, chafurdar, subir, brotar, florescer, passar, oxidar, escorrer, deslizar, azedar, sujar, crescer, percorrer, ventar, murchar.

Alternâncias definidas para a classe - Etapa1: V, V_SP[em], V_SP[entre], V_SN.

equip-13.4.2

Taxa de aceitação: 0.413793103448

Número Selecionados: 12

Número candidatos: 29

Selecionados: declarar, favorecer, beneficiar, apontar, escolher, pagar, abastecer, fornecer, ocupar, responder, indicar, gravar.

Alternâncias definidas para a classe - Etapa1: V_SN_SP[com].

escape-51.1

Taxa de aceitação: 0.870967741935

Número Selecionados: 54

Número candidatos: 62

Selecionados: adentrar, avançar, desaparecer, escapar, ir, correr, vir, galgar, emergir, voltar, traçar, regressar, declinar, cruzar, rasgar, levantar, aproximar, penetrar, erguer, chegar, despencar, fazer, sair, fugir, descrever, surgir, abalar, vazar, ascender, abater, vencer, aparecer, acostar, produzir, entrar, voar, bater, recuar, cair, subir, largar, desertar, tornar, vingar, abandonar, partir, atravessar, deixar, escalar, retornar, volver, desabar, rolar, percorrer.

Alternâncias definidas para a classe - Etapa1: V.

establish-55.5

Taxa de aceitação: 0.972222222222

Número Selecionados: 35

Número candidatos: 36

Selecionados: ditar, iniciar, instalar, organizar, infundir, pôr, arranjar, estabelecer, instituir, plantar, colocar, criar, inovar, soprar, sugerir, impregnar, edificar, insinuar, montar, 
renovar, formar, situar, meter, dar, impor, ministrar, constituir, inspirar, falar, fundar, incutir, induzir, instaurar, erguer, preparar.

Alternâncias definidas para a classe - Etapa1: V_SN.

estimate-34.2

Taxa de aceitação: 1.0

Número Selecionados: 1

Número candidatos: 1

Selecionados: calcular.

Alternâncias definidas para a classe - Etapa1: V_SN, V_SN_SP[em].

exchange-13.6

Taxa de aceitação: 1.0

Número Selecionados: 2

Número candidatos: 2

Selecionados: inverter, trocar.

Alternâncias definidas para a classe - Etapa1: V_SN_SP[por], V_SN, V_SP[entre], V_SN_SP[com].

exhale-40.1.3

Taxa de aceitação: 0

Número Selecionados: 11

Número candidatos: 11

Selecionados: tomar, aspirar, expirar, inspirar, cheirar, escorrer, sorver, transpirar, tragar, suar, puxar.

Alternâncias definidas para a classe - Etapa1: all.

exist-47.1

Taxa de aceitação: 0.457142857143

Número Selecionados: 16

Número candidatos: 35

Selecionados: habitar, viver, andar, assistir, demorar, parar, estar, existir, passar, continuar, ficar, permanecer, ocupar, dominar, prolongar, esperar.

Alternâncias definidas para a classe - Etapa1: V_SN_SP[em], V_SN_SP[entre], V_SN_SP[por], V_SN_SP[sobre], V_SN_SP[sob].

feeding-39.7

Taxa de aceitação: 0.5

Número Selecionados: 1

Número candidatos: 2

Selecionados: amamentar.

Alternâncias definidas para a classe - Etapa1: V_SN.

fill-9.8

Taxa de aceitação: 0.931506849315

Número Selecionados: 68

Número candidatos: 73 
Selecionados: envolver, saturar, contaminar, banhar, engravidar, favorecer, tapar, reter, prover, decorar, introduzir, vestir, abafar, adornar, cobrir, beneficiar, carregar, infectar, molhar, macular, manchar, acumular, preencher, folhear, amarrar, impregnar, carimbar, enobrecer, recobrir, rodear, repassar, tecer, inundar, encher, calçar, poluir, forrar, embutir, alagar, lotar, contagiar, tomar, conspurcar, embelezar, embaraçar, injetar, atar, temperar, colorir, obstruir, pavimentar, enquadrar, ocupar, acobertar, emoldurar, revestir, dourar, velar, represar, cercar, enriquecer, matizar, sujar, enfeitar, assediar, bombardear, tramar, ornar.

Alternâncias definidas para a classe - Etapa1: V_SN_SP[com], V_SN_SP[de], V_SN_SP[em], V_SN.

fire-10.10

Taxa de aceitação: 0.9

Número Selecionados: 9

Número candidatos: 10

Selecionados: cortar, despedir, exonerar, derrubar, dispensar, despachar, demitir, destituir, depor.

Alternâncias definidas para a classe - Etapa1: V_SN, V_SN_SP[de].

fit-54.3

Taxa de aceitação: 0.888888888889

Número Selecionados: 16

Número candidatos: 18

Selecionados: tomar, empregar, recolher, ocupar, comportar, assentar, recorrer, gastar, armazenar, utilizar, receber, encaixar, aproveitar, hospedar, usar, conter.

Alternâncias definidas para a classe - Etapa1: V_SN, V_SN_SP[em].

\section{fulfilling-13.4.1}

Taxa de aceitação: 0.933333333333

Número Selecionados: 42

Número candidatos: 45

Selecionados: substituir, correr, fiar, prover, caber, alimentar, transferir, carregar, depositar, apresentar, entregar, expor, submeter, crer, oferecer, pôr, legar, deixar, confiar, abastecer, refazer, explicar, transmitir, guarnecer, atender, tocar, pertencer, suprir, servir, exibir, testar, incumbir, mostrar, representar, cumprir, transpor, fornecer, propor, acreditar, compensar, colocar, confrontar.

Alternâncias definidas para a classe - Etapa1: V_SN_SP[para], V_SN.

\section{funnel-9.3}

Taxa de aceitação: 0.363636363636

Número Selecionados: 4

Número candidatos: 11

Selecionados: fincar, assentar, fixar, bater.

Alternâncias definidas para a classe - Etapa1: V_SN_SP[em], V_SN_SP[para].

future_having-13.3

Taxa de aceitação: 0.837209302326 
Número Selecionados: 36

Número candidatos: 43

Selecionados: repartir, compartilhar, coroar, retribuir, dividir, apresentar, conferir, testar, transferir, estender, legar, partilhar, ofertar, talhar, poupar, pagar, trazer, remunerar, oferecer, distribuir, renunciar, transmitir, dar, ceder, reconhecer, derramar, largar, prometer, transpor, abandonar, partir, deixar, compensar, agradecer, propor, premiar. Alternâncias definidas para a classe - Etapa1: V_SN_SP[para], V_SN, V_SN_SP[para], V_SN_SP[para].

\section{get-13.5.1}

Taxa de aceitação: 0.955223880597

Número Selecionados: 64

Número candidatos: 67

Selecionados: auferir, encomendar, adquirir, alcançar, arrancar, lograr, conseguir, reservar, procurar, conduzir, arrematar, ter, puxar, capturar, apurar, arranjar, conquistar, ganhar, embolsar, apreender, segurar, marcar, obter, perceber, receber, ligar, reunir, pilhar, angariar, apanhar, vazar, juntar, tomar, haver, filtrar, lucrar, vingar, colher, classificar, eleger, ficar, atingir, telefonar, catar, guardar, atrair, selecionar, preferir, decidir, caçar, tirar, escolher, pegar, levar, comprar, alugar, entreter, deter, chamar, sacar, extrair, adotar, arrastar, pinçar.

Alternâncias definidas para a classe - Etapa1: V_SN, V_SN_SP[de], V_SN_SP[para], V_SN_SP[a], V_SN_SP[por].

give-13.1

Taxa de aceitação: 1.0

Número Selecionados: 22

Número candidatos: 22

Selecionados: render, restituir, repor, despender, alimentar, carregar, obrigar, comprometer, substituir, abastecer, empenhar, devolver, dar, produzir, brindar, arrendar, suprir, ministrar, derramar, alugar, presentear, compensar.

Alternâncias definidas para a classe - Etapa1: V_SN_SP[para], V_SN.

gobble-39.3

Taxa de aceitação: 0

Número Selecionados: 2

Número candidatos: 2

Selecionados: ingerir, engolir.

Alternâncias definidas para a classe - Etapa1: all.

gorge-39.6

Taxa de aceitação: 0

Número Selecionados: 9

Número candidatos: 9

Selecionados: saturar, subsistir, fartar, impar, encher, viver, sobreviver, resistir, passar. Alternâncias definidas para a classe - Etapa1: all.

groom-41.1.2 
Taxa de aceitação: 1.0

Número Selecionados: 3

Número candidatos: 3

Selecionados: aprontar, vestir, arrumar.

Alternâncias definidas para a classe - Etapa1: V_SN.

grow-26.2

Taxa de aceitação: 0.35

Número Selecionados: 7

Número candidatos: 20

Selecionados: avançar, evoluir, subir, caminhar, crescer, pular, ir.

Alternâncias definidas para a classe - Etapa1: V_SP[de].

herd-47.5.2

Taxa de aceitação: 0.92

Número Selecionados: 23

Número candidatos: 25

Selecionados: juntar, colecionar, economizar, codificar, amealhar, acumular, reunir, angariar, coletar, poupar, tomar, convocar, forrar, colher, aliciar, recrutar, condensar, atrair, compilar, recolher, montear, armazenar, concentrar.

Alternâncias definidas para a classe - Etapa1: V_SN.

hiccup-40.1.1

Taxa de aceitação: 0.9

Número Selecionados: 9

Número candidatos: 10

Selecionados: engolir, respirar, bocejar, arfar, impar, ressonar, corar, ingerir, roncar.

Alternâncias definidas para a classe - Etapa1: V.

hire-13.5.3

Taxa de aceitação: 1.0

Número Selecionados: 1

Número candidatos: 1

Selecionados: alugar.

Alternâncias definidas para a classe - Etapa1: V_SN, V_SN_SP[como].

hit-18.1

Taxa de aceitação: 0.818181818182

Número Selecionados: 18

Número candidatos: 22

Selecionados: suplantar, golpear, alvejar, coçar, rachar, calcar, martelar, cutucar, esmagar, maltratar, atingir, dar, comprimir, espancar, bater, topar, encostar, amassar.

Alternâncias definidas para a classe - Etapa1: V_SN, V_SN_SP[com], V_SN_SP[em], V_SN_SP[em]_SP[com], V_SN_SP[contra], V_SN_SP[em], V_SN, V_SN_SP[em].

hold-15.1

Taxa de aceitação: 0.947368421053 
Número Selecionados: 18

Número candidatos: 19

Selecionados: ferrar, manusear, travar, agarrar, segurar, mexer, manejar, tratar, deter, entreter, empunhar, bulir, prender, apanhar, tocar, roubar, tomar, remexer.

Alternâncias definidas para a classe - Etapa1: V_SN.

hunt-35.1

Taxa de aceitação: 1.0

Número Selecionados: 12

Número candidatos: 12

Selecionados: remexer, pescar, mexer, pegar, remover, voltar, revolver, ferrar, fisgar, cavar, escavar, esvaziar.

Alternâncias definidas para a classe - Etapa1: V_SN_SP[para], V_SP[em]_SP[para], V_SN, V.

hurt-40.8.3

Taxa de aceitação: 0

Número Selecionados: 24

Número candidatos: 24

Selecionados: lesar, magoar, trilhar, abocanhar, flechar, traumatizar, contundir, roer, marcar, tascar, ofender, torcer, maltratar, afetar, prejudicar, morder, arder, ferrar, picar, machucar, ferir, torturar, pungir, trincar.

Alternâncias definidas para a classe - Etapa1: all.

illustrate-25.3

Taxa de aceitação: 1.0

Número Selecionados: 13

Número candidatos: 13

Selecionados: autografar, vestir, emoldurar, marcar, revestir, enfeitar, ferrar, decorar, assinar, embelezar, adornar, ornar, colorir.

Alternâncias definidas para a classe - Etapa1: V_SN, V_SN_SP[com].

image impression-25.1

Taxa de aceitação: 1.0

Número Selecionados: 13

Número candidatos: 13

Selecionados: bordar, ajustar, assentar, lavrar, selar, cravar, escrever, concluir, esculpir, firmar, gravar, talhar, inscrever.

Alternâncias definidas para a classe - Etapa1: V_SN_SP[em], V_SN_SP[entre], V_SN_SP[sobre], V_SN_SP[sob], V_SN, V_SN, V.

inquire-37.1.2

Taxa de aceitação: 1.0

Número Selecionados: 3

Número candidatos: 3

Selecionados: consultar, freqüentar, ler.

Alternâncias definidas para a classe - Etapa1: V_SN, V_SP[sobre]. 
instr_communication-37.4

Taxa de aceitação: 1.0

Número Selecionados: 2

Número candidatos: 2

Selecionados: ligar, telefonar.

Alternâncias definidas para a classe - Etapa1: V_SN, V_SN_SP[a], V_SN_SP[para].

interrogate-37.1.3

Taxa de aceitação: 1.0

Número Selecionados: 7

Número candidatos: 7

Selecionados: saber, perguntar, interrogar, inquirir, indagar, interpelar, questionar.

Alternâncias definidas para a classe - Etapa1: V_SN, V_SN_SP[como],

V_SN_SP[sobre].

investigate-35.4

Taxa de aceitação: 0.946428571429

Número Selecionados: 53

Número candidatos: 56

Selecionados: saquear, vasculhar, tirar, perscrutar, examinar, observar, demandar, correr, revolver, espreitar, dissecar, inspecionar, analisar, escavar, explorar, esquadrinhar, vistoriar, comentar, estudar, devassar, apalpar, criticar, monitorar, apurar, folhear, buscar, descortinar, investigar, pilhar, remexer, depredar, interrogar, averiguar, ler, inquirir, sondar, reconhecer, manusear, aprofundar, encarar, profundar, perguntar, recorrer, considerar, esmiuçar, mirar, pesquisar, grampear, olhar, indagar, procurar, visitar, percorrer.

Alternâncias definidas para a classe - Etapa1: V_SN.

\section{judgement-33}

Taxa de aceitação: 0.905882352941

Número Selecionados: 77

Número candidatos: 85

Selecionados: responder, postergar, sancionar, celebrizar, denegrir, parabenizar, festejar, pregar, ilustrar, cumprimentar, engrandecer, apoiar, extremar, encarecer, preconizar, autorizar, gostar, advertir, macular, manchar, louvar, proibir, reprimir, criticar, cantar, legitimar, desprezar, obscurecer, perseguir, desfazer, desacreditar, enobrecer, glorificar, punir, maltratar, pagar, deprimir, exaltar, consagrar, envergonhar, gabar, subscrever, ratificar, aplaudir, rebaixar, pisar, enaltecer, corresponder, desdenhar, desonrar, ignorar, desvirtuar, retribuir, acusar, elogiar, censurar, humilhar, desmoralizar, desclassificar, outorgar, subir, elevar, justificar, oprimir, aprovar, notar, demolir, desconhecer, castigar, levantar, felicitar, abençoar, degradar, adotar, ornar, agradecer, menosprezar.

Alternâncias definidas para a classe - Etapa1: V_SN, V_SN_SP[por], V_SN_SP[como].

\section{keep-15.2}

Taxa de aceitação: 0.857142857143 
Número Selecionados: 6

Número candidatos: 7

Selecionados: estocar, entulhar, armazenar, meter, guardar, depositar.

Alternâncias definidas para a classe - Etapa1: V_SN_SP[em], V_SN_SP[entre], V_SN_SP[sobre], V_SN_SP[sob], V_SN.

\section{knead-26.5}

Taxa de aceitação: 0.916666666667

Número Selecionados: 22

Número candidatos: 24

Selecionados: enrolar, encolher, derreter, dobrar, agitar, esmagar, premer, premir, espremer, retrair, comprimir, contrair, abanar, congelar, bater, estrangular, gelar, oprimir, apertar, vergar, embrulhar, amassar.

Alternâncias definidas para a classe - Etapa1: V_SN_SP[em], V_SN.

\section{learn-14}

Taxa de aceitação: 0.925925925926

Número Selecionados: 25

Número candidatos: 27

Selecionados: arquivar, tirar, examinar, observar, espreitar, dissecar, analisar, comentar, ver, estudar, criticar, receber, saber, explorar, ler, aprender, beber, decorar, encarar, reconhecer, absorver, considerar, mirar, olhar, fixar.

Alternâncias definidas para a classe - Etapa1: V_SN_SP[em], V_SP[em], V_SN.

leave-51.2

Taxa de aceitação: 0.727272727273

Número Selecionados: 8

Número candidatos: 11

Selecionados: largar, abalar, abandonar, partir, deixar, vazar, fugir, sair.

Alternâncias definidas para a classe - Etapa1: V_SN.

lecture-37.11

Taxa de aceitação: 0

Número Selecionados: 14

Número candidatos: 14

Selecionados: comunicar, preconizar, professar, proclamar, recomendar, tratar, falar, conversar, pregar, sugerir, indicar, apregoar, aconselhar, receitar.

Alternâncias definidas para a classe - Etapa1: all.

light_emission-43.1

Taxa de aceitação: 1.0

Número Selecionados: 20

Número candidatos: 20

Selecionados: cintilar, estrelar, brilhar, bater, raiar, pestanejar, faiscar, lucilar, incidir, alumiar, fulminar, esvoaçar, fuzilar, arder, tremer, piscar, refletir, resplandecer, tombar, cair. 
Alternâncias definidas para a classe - Etapa1: V, V_SP[em], V_SP[entre], V_SP[sobre], V_SP[sob], V_SP[com], V_SN.

linger-53.1

Taxa de aceitação: 0.833333333333

Número Selecionados: 5

Número candidatos: 6

Selecionados: enforcar, matar, demorar, custar, tardar.

Alternâncias definidas para a classe - Etapa1: V_SP[em], V_SP[em].

lodge-46

Taxa de aceitação: 1.0

Número Selecionados: 10

Número candidatos: 10

Selecionados: habitar, ocupar, andar, aposentar, morar, residir, demorar, assistir, viver, existir.

Alternâncias definidas para a classe - Etapa1: V_SP[em], V_SP[entre], V_SP[sobre], V_SP[sob].

long-32.2

Taxa de aceitação: 0

Número Selecionados: 8

Número candidatos: 8

Selecionados: orar, mirar, rezar, rogar, querer, desejar, pretender, pedir.

Alternâncias definidas para a classe - Etapa1: all.

manner_speaking-37.3

Taxa de aceitação: 1.0

Número Selecionados: 16

Número candidatos: 16

Selecionados: gemer, mastigar, murmurar, resmungar, segredar, ladrar, chiar, mascar, rosnar, ranger, soprar, cochichar, ciciar, roncar, delirar, suspirar.

Alternâncias definidas para a classe - Etapa1: V, V_SP[para], V_SP[sobre], V_SN, V_SN_SP[para].

marry-36.2

Taxa de aceitação: 0.5

Número Selecionados: 4

Número candidatos: 8

Selecionados: desligar, beijar, separar, namorar.

Alternâncias definidas para a classe - Etapa1: V.

marvel-31.3

Taxa de aceitação: 0.84375

Número Selecionados: 27

Número candidatos: 32 
Selecionados: sancionar, gostar, desmaiar, declinar, autorizar, criticar, vetar, chorar, recusar, consagrar, rejeitar, ratificar, condenar, rebater, renunciar, exultar, soluçar, refutar, folgar, descair, esmorecer, notar, aprovar, reprovar, apagar, adotar, estimar.

Alternâncias definidas para a classe - Etapa1: V.

meander-47.7

Taxa de aceitação: 0.0

Número Selecionados: 0

Número candidatos: 3

Selecionados:

Alternâncias definidas para a classe - Etapa1: V_SP[em], V_SP[entre], V_SP[sobre], V_SP[sob].

meet-36.3

Taxa de aceitação: 0

Número Selecionados: 31

Número candidatos: 31

Selecionados: encrencar, consultar, defrontar, lutar, tratar, batalhar, inspecionar, vistoriar, enfrentar, discutir, contestar, freqüentar, arcar, disputar, brigar, punir, ler, combater, dar, militar, encarar, debater, reinar, hostilizar, deparar, encontrar, argumentar, topar, pleitear, visitar, confrontar.

Alternâncias definidas para a classe - Etapa1: all.

mix-22.1

Taxa de aceitação: 0

Número Selecionados: 42

Número candidatos: 42

Selecionados: articular, misturar, vincular, juntar, unir, integrar, intermediar, mestiçar, agrupar, agregar, cruzar, combinar, permear, aproximar, revolver, mesclar, reunir, ligar, amarrar, conectar, relacionar, interpor, prender, conciliar, acostar, colar, fundir, atar, solidificar, bater, emendar, anexar, acrescentar, incorporar, pegar, enlaçar, aliar, aglutinar, grudar, consolidar, associar, cingir.

Alternâncias definidas para a classe - Etapa1: all.

modes_of_being_with_motion-47.3

Taxa de aceitação: 1.0

Número Selecionados: 29

Número candidatos: 29

Selecionados: oscilar, dançar, girar, revolver, vibrar, esvoaçar, sacudir, pulsar, mover, menear, agitar, manejar, arfar, saltar, soprar, aflorar, brandir, abanar, flutuar, balançar, palpitar, assoprar, latir, jogar, bater, pairar, estalar, espernear, tremer.

Alternâncias definidas para a classe - Etapa1: V, V_SP[em], V_SP[entre], V_SP[sobre], V_SP[sob], V_SN.

murder-42.1

Taxa de aceitação: 1.0

Número Selecionados: 14 


\section{Número candidatos: 14}

Selecionados: aniquilar, oferecer, abater, fulminar, exterminar, assassinar, imolar, massacrar, liquidar, executar, sacrificar, eliminar, destruir, matar.

Alternâncias definidas para a classe - Etapa1: V_SN, V_SN_SP[com].

nonvehicle-51.4.2

Taxa de aceitação: 1.0

Número Selecionados: 5

Número candidatos: 5

Selecionados: remar, navegar, vogar, caminhar, singrar.

Alternâncias definidas para a classe - Etapa1: V, V_SP[em], V_SP[entre], V_SP[por], V_SP[sobre], V_SP[sob].

nonverbal_expression-40.2

Taxa de aceitação: 0.96

Número Selecionados: 24

Número candidatos: 25

Selecionados: respirar, rir, malhar, roncar, ridicularizar, arfar, ressonar, sorrir, chorar, zombar, gozar, brincar, mexer, satirizar, impar, gracejar, soluçar, troçar, gemer, ironizar, bocejar, escarnecer, caçoar, desfrutar.

Alternâncias definidas para a classe - Etapa1: V, V_SN, V_SN, V_SP[para], V_SP[de], V_SP[de].

\section{obtain-13.5.2}

Taxa de aceitação: 0.963855421687

Número Selecionados: 80

Número candidatos: 83

Selecionados: reclamar, auferir, adquirir, alcançar, juntar, colecionar, economizar, levar, invadir, condensar, pretender, ter, codificar, arrematar, reconquistar, retomar, apurar, arranjar, cobrar, ganhar, apreender, amealhar, forrar, resgatar, tributar, obter, acumular, receber, reivindicar, exigir, reunir, pilhar, angariar, recobrar, coletar, requisitar, pedir, tomar, haver, reassumir, filtrar, recuperar, conquistar, clamar, reaver, aceitar, classificar, eleger, escolher, aliciar, atingir, recrutar, gritar, catar, selecionar, atrair, impor, segurar, preferir, procurar, compilar, recolher, ocupar, requerer, tirar, protestar, taxar, declamar, ficar, armazenar, comprar, conseguir, entreter, deter, concentrar, sacar, adotar, poupar, readquirir, pinçar.

Alternâncias definidas para a classe - Etapa1: V_SN, V_SN_SP[de].

occurrence-48.3

Taxa de aceitação: 0.857142857143

Número Selecionados: 12

Número candidatos: 14

Selecionados: ser, ocorrer, objetivar, ir, correr, resultar, concretizar, acontecer, dar, advir, suceder, sair.

Alternâncias definidas para a classe - Etapa1: V, V_SP[em], V_SP[entre], V_SP[por], V_SP[sobre], V_SP[sob]. 
orphan-29.7

Taxa de aceitação: 0.8

Número Selecionados: 4

Número candidatos: 5

Selecionados: trair, arrolar, enganar, recrutar.

Alternâncias definidas para a classe - Etapa1: V_SN.

other_cos- 45.4

Taxa de aceitação: 0.958333333333

Número Selecionados: 368

Número candidatos: 384

Selecionados: separar, alegrar, acalmar, colecionar, desenvolver, endurecer, adiantar, abaixar, acumular, balançar, brandir, esfriar, relaxar, desligar, assentar, regredir, semelhar, definhar, pular, precipitar, conspurcar, desenrolar, folgar, funcionar, tranqüilizar, pairar, ornar, revigorar, silenciar, equiparar, economizar, afiar, madurar, nascer, estabilizar, emperrar, amaciar, amplificar, envelhecer, desdobrar, reavivar, vigorar, vibrar, moer, abalar, variar, mudar, descansar, atrair, naufragar, congelar, exaurir, acender, curar, desocupar, unir, premer, caiar, talhar, ninar, manipular, sarar, vazar, encher, refluir, continuar, mexer, ressecar, rebaixar, melhorar, vacilar, recolher, desequilibrar, desmaiar, anoitecer, prolongar, facilitar, incrementar, fulminar, reacender, derreter, expandir, soltar, dispersar, desmoronar, reanimar, harmonizar, animar, estender, retroceder, voltar, nivelar, respaldar, forrar, lotar, germinar, destravar, torrar, estrangular, igualar, lavrar, repugnar, romper, diluir, aquecer, elevar, cerrar, esmagar, padronizar, entreabrir, aguçar, passar, curtir, renascer, inclinar, pisar, consolar, aliciar, desvirtuar, exultar, rebentar, contrair, profundar, subir, estalar, matizar, convir, escurecer, confortar, engrandecer, acomodar, inteiriçar, engordar, multiplicar, agitar, amealhar, matar, carregar, estacar, afagar, recrudescer, adoecer, descair, enquadrar, cair, acrescentar, alterar, apagar, redobrar, emagrecer, misturar, arder, encolher, acordar, maturar, preencher, serenar, angariar, encarnar, repassar, poupar, sobrecarregar, despertar, descentralizar, picar, chocar, compilar, cicatrizar, dourar, refrescar, mergulhar, repousar, aumentar, crescer, banhar, declinar, estacionar, detonar, forçar, quebrar, furar, pulular, cegar, trabalhar, morder, recrutar, uniformizar, dissolver, fundir, arrefecer, azedar, contentar, estreitar, nutrir, balancear, agradar, aprofundar, abrir, desatar, sustentar, empalidecer, aprimorar, encurtar, emudecer, alargar, cansar, arrombar, minorar, procriar, explodir, enjoar, dilatar, proliferar, apertar, sanar, satisfazer, esticar, molhar, acelerar, umedecer, agravar, palpitar, alagar, contrabalançar, abrasar, amadurecer, gelar, concentrar, atear, rolar, enxugar, saturar, juntar, andar, codificar, degenerar, cruzar, esquentar, equilibrar, reunir, plantar, pregar, caducar, queimar, enferrujar, espremer, acalentar, comprimir, afrouxar, reduzir, encontrar, curvar, chamar, tomar, progredir, alvejar, embalar, temperar, soçobrar, fraquear, cobrir, desfiar, dobrar, operar, empacar, desandar, retrair, iluminar, estourar, cultivar, abanar, obstruir, restaurar, clarear, oprimir, aplacar, amenizar, emular, sacudir, apressar, combinar, deprimir, desabrochar, macular, debilitar, parar, enfermar, fechar, arar, duplicar, fortalecer, tostar, desacelerar, alisar, afrontar, voar, piorar, brotar, ampliar, diminuir, compensar, murchar, alongar, ajuntar, lenir, rasgar, violentar, arrebentar, apontar, manchar, afinar, alumiar, apurar, prosperar, engrossar, comparar, comandar, desestabilizar, sossegar, depreciar, cristalizar, secar, suavizar, ocupar, fatigar, aliviar, corar, sujar, encostar, lavar, afundar, aperfeiçoar, reforçar, transformar, enfraquecer, potencializar, premir, inundar, 
modificar, espalhar, descarregar, ceder, disseminar, decair, capotar, reformar, oxidar, vergar, moderar, abrandar, atenuar, empanar, melar, amortecer, inflamar, triunfar, escavar, avultar, impregnar, carimbar, adormecer, intensificar, condensar, exacerbar, esmiuçar, armazenar, embotar, limpar.

Alternâncias definidas para a classe - Etapa1: V_SN, V_SN_SP[com], V, V_SN, V_SN_SP[em], V_SN_SP[em]_SP[com].

overstate-37.12

Taxa de aceitação: 0.952380952381

Número Selecionados: 20

Número candidatos: 21

Selecionados: enaltecer, consagrar, subir, gabar, levantar, encarecer, glorificar, exaltar, engrandecer, presumir, ilustrar, elevar, abençoar, extremar, louvar, enobrecer, preconizar, elogiar, cantar, ornar.

Alternâncias definidas para a classe - Etapa1: V_SN.

pain-40.8.1

Taxa de aceitação: 0.714285714286

Número Selecionados: 5

Número candidatos: 7

Selecionados: magoar, coçar, ferir, engrossar, machucar.

Alternâncias definidas para a classe - Etapa1: V.

peer-30.3

Taxa de aceitação: 0

Número Selecionados: 13

Número candidatos: 13

Selecionados: vigiar, entortar, observar, sondar, ouvir, fitar, espreitar, escutar, olhar, atender, espionar, esquadrinhar, espiar.

Alternâncias definidas para a classe - Etapa1: all.

performance-26.7

Taxa de aceitação: 0

Número Selecionados: 21

Número candidatos: 21

Selecionados: calcar, desenhar, musicar, pintar, pronunciar, declamar, entoar, produzir, desempenhar, cantarolar, representar, recitar, interpretar, dar, filmar, encarnar, executar, riscar, cantar, rodar, soar.

Alternâncias definidas para a classe - Etapa1: all.

pit-10.7

Taxa de aceitação: 0.666666666667

Número Selecionados: 2

Número candidatos: 3

Selecionados: descascar, limpar.

Alternâncias definidas para a classe - Etapa1: V_SN. 
pocket-9.10

Taxa de aceitação: 0.818181818182

Número Selecionados: 9

Número candidatos: 11

Selecionados: receber, aposentar, enfiar, instalar, hospedar, acomodar, prender, aprisionar, trancar.

Alternâncias definidas para a classe - Etapa1: V_SN, V_SN_SP[em].

poison-42.2

Taxa de aceitação: 0.8

Número Selecionados: 4

Número candidatos: 5

Selecionados: estrangular, afogar, sufocar, asfixiar.

Alternâncias definidas para a classe - Etapa1: V_SN, V_SN_SP[até], V_SN_SP[com].

poke-19

Taxa de aceitação: 0.882352941176

Número Selecionados: 15

Número candidatos: 17

Selecionados: bater, penetrar, cutucar, furar, cravar, meter, pregar, fincar, morder, cavar, perfurar, escavar, fixar, picar, vazar.

Alternâncias definidas para a classe - Etapa1: V_SN, V_SN_SP[com], V_SN.

pour-9.5

Taxa de aceitação: 0.535714285714

Número Selecionados: 15

Número candidatos: 28

Selecionados: rebentar, despejar, escorrer, rejeitar, derrubar, sair, cuspir, suar, fluir, respingar, vazar, vir, brotar, entornar, virar.

Alternâncias definidas para a classe - Etapa1: V SN SP[por], V SN SP[em], V_SN_SP[entre], V_SN_SP[sob], V_SN_SP[sobre], V_SP[sobre], V_SP[por], V_SP[entre], V_SP[em], V_SP[sob], V_SN_SP[de]_SP[sob], V_SN_SP[de]_SP[sobre], V_SN_SP[de]_SP[por], V_SN_SP[de]_SP[entre], V_SN_SP[de]_SP[em].

preparing-26.3

Taxa de aceitação: 0

Número Selecionados: 31

Número candidatos: 31

Selecionados: bordar, desenhar, engendrar, acender, armar, misturar, idear, fritar, mestiçar, compor, unir, dispor, fabricar, imaginar, criar, revolver, mesclar, manipular, buscar, bolar, passar, forjar, inventar, preparar, produzir, confeccionar, alisar, aprontar, bater, atear, engenhar.

Alternâncias definidas para a classe - Etapa1: all.

price-54.4

Taxa de aceitação: 1.0

Número Selecionados: 2 


\section{Número candidatos: 2}

Selecionados: ficar, calcular.

Alternâncias definidas para a classe - Etapa1: V_SN, V_SN_SP[em].

\section{push-12}

Taxa de aceitação: 1.0

Número Selecionados: 10

Número candidatos: 10

Selecionados: constranger, empolgar, tirar, arrebatar, arrancar, apertar, pressionar, premer, comprimir, extrair.

Alternâncias definidas para a classe - Etapa1: V_SN.

put-9.1

Taxa de aceitação: 0.604651162791

Número Selecionados: 26

Número candidatos: 43

Selecionados: localizar, fincar, cravar, instalar, arrumar, introduzir, botar, inserir, enterrar, depositar, plantar, colocar, compor, parar, ligar, implantar, depor, coordenar, incluir, meter, cultivar, absorver, engolir, pôr, fixar, encostar.

Alternâncias definidas para a classe - Etapa1: V_SN_SP[em], V_SN_SP[entre], V_SN_SP[sobre], V_SN_SP[sob].

put_direction-9.4

Taxa de aceitação: 1.0

Número Selecionados: 16

Número candidatos: 16

Selecionados: suspender, calar, recolher, subir, empinar, descer, içar, alçar, abaixar, elevar, alar, pender, levantar, apanhar, baixar, erguer.

Alternâncias definidas para a classe - Etapa1: V_SN, V_SN_SP[em], V_SN_SP[sobre], V_SN_SP[sob].

put_spatial-9.2

Taxa de aceitação: 0.5

Número Selecionados: 11

Número candidatos: 22

Selecionados: suspender, localizar, meter, botar, depositar, colocar, pôr, depor, assentar, pendurar, encostar.

Alternâncias definidas para a classe - Etapa1: V_SN_SP[em], V_SN_SP[sobre], V_SN_SP[sob].

reach-51.8

Taxa de aceitação: 0.8

Número Selecionados: 8

Número candidatos: 10

Selecionados: subir, alcançar, colher, chegar, atingir, galgar, tocar, montar.

Alternâncias definidas para a classe - Etapa1: V_SN. 
reflexive_appearance-48.1.2

Taxa de aceitação: 0.942307692308

Número Selecionados: 49

Número candidatos: 52

Selecionados: declarar, cometer, trazer, demonstrar, denotar, projetar, dizer, preconizar, pôr, testemunhar, apresentar, aventar, agitar, provar, expor, lembrar, submeter, colocar, oferecer, pregar, suscitar, expressar, significar, informar, confirmar, ofertar, formular, retratar, assegurar, rever, manifestar, enunciar, afirmar, revelar, explicar, dar, pretender, atestar, garantir, comprovar, exibir, protestar, mostrar, exprimir, levantar, sugerir, indicar, estender, propor.

Alternâncias definidas para a classe - Etapa1: V_SN, V_SN_SP[a], V_SN_SP[para].

rehearse-26.8

Taxa de aceitação: 1.0

Número Selecionados: 5

Número candidatos: 5

Selecionados: ensaiar, praticar, exercitar, repetir, refazer.

Alternâncias definidas para a classe - Etapa1: V, V_SN, V_SN_SP[para], V_SP[para].

remove-10.1

Taxa de aceitação: 0.95652173913

Número Selecionados: 66

Número candidatos: 69

Selecionados: extinguir, tirar, arrancar, suprimir, separar, extrair, dividir, mutilar, repelir, destacar, despejar, isolar, exterminar, apurar, expulsar, puxar, arrebatar, destituir, talhar, rechaçar, retirar, extirpar, desmembrar, derrubar, descalçar, demitir, apanhar, ressalvar, desdobrar, depor, tomar, afastar, subtrair, soltar, abolir, despedir, desfalcar, colher, rebater, secretar, dizimar, empolgar, renunciar, catar, excluir, arredar, tossir, cortar, recolher, derramar, erradicar, clarear, exonerar, mandar, pegar, diminuir, sufocar, eliminar, apagar, despachar, dispensar, sacar, expelir, afogar, renegar, banir.

Alternâncias definidas para a classe - Etapa1: V_SN, V_SN_SP[de].

resign-10.11

Taxa de aceitação: 1.0

Número Selecionados: 5

Número candidatos: 5

Selecionados: aposentar, sair, largar, deixar, abandonar.

Alternâncias definidas para a classe - Etapa1: V, V_SN.

roll-51.3.1

Taxa de aceitação: 0.962962962963

Número Selecionados: 26

Número candidatos: 27

Selecionados: balancear, substituir, girar, movimentar, mover, saltar, agitar, revolver, embalar, enroscar, balançar, circular, afastar, mexer, deslocar, remover, pular, mudar, rodar, ceder, converter, mobilizar, cair, espernear, trocar, rolar. 
Alternâncias definidas para a classe - Etapa1: V, V_SP[sobre], V_SP[por], V_SP[entre], V_SP[em], V_SP[sob], V_SN, V_SN_SP[sobre], V_SN_SP[por], V_SN_SP[entre], V_SN_SP[em], V_SN_SP[sob].

\section{rummage-35.5}

Taxa de aceitação: 0.157894736842

Número Selecionados: 3

Número candidatos: 19

Selecionados: ler, ouvir, atender.

Alternâncias definidas para a classe - Etapa1: V_SN_SP[por].

run-51.3.2

Taxa de aceitação: 0.984375

Número Selecionados: 63

Número candidatos: 64

Selecionados: desfilar, disparar, balancear, avançar, acometer, arrancar, ir, correr, gatinhar, andar, atacar, boiar, esvoaçar, perpassar, apressar, carregar, titubear, partir, remeter, adiantar, picar, engatinhar, vagar, embalar, agredir, caminhar, balançar, vingar, mancar, vacilar, fugir, esbarrar, resvalar, flutuar, aflorar, abalar, pisar, saltar, perambular, roçar, assaltar, marchar, girar, investir, galgar, tocar, pular, nadar, errar, tropeçar, alisar, voar, acelerar, subir, precipitar, transpor, desertar, lamber, mergulhar, escalar, crescer, acariciar, cambalear.

Alternâncias definidas para a classe - Etapa1: V, V_SN, V_SP[em], V_SP[entre], V_SP[por], V_SP[sobre], V_SP[sob].

rush-53.2

Taxa de aceitação: 1.0

Número Selecionados: 1

Número candidatos: 1

Selecionados: apressar.

Alternâncias definidas para a classe - Etapa1: V_SN.

say-37.7

Taxa de aceitação: 0.949152542373

Número Selecionados: 56

Número candidatos: 59

Selecionados: citar, declarar, mastigar, mencionar, ser, cometer, tornar, desvendar, intimar, recontar, narrar, voltar, contar, dizer, desfiar, participar, moer, aventar, agitar, apontar, expor, lembrar, propagar, matar, pertencer, historiar, anunciar, reiterar, informar, sugerir, renovar, referir, oferecer, reportar, pisar, comunicar, ordenar, dar, decifrar, tocar, repetir, adivinhar, alegar, segredar, martelar, notificar, noticiar, mandar, divulgar, levantar, aludir, suscitar, relatar, rolar, propor, repisar.

Alternâncias definidas para a classe - Etapa1: V_SN, V_SN_SP[a], V_SN_SP[para].

scribble-25.2

Taxa de aceitação: 1.0

Número Selecionados: 15 
Número candidatos: 15

Selecionados: calcar, desenhar, pintar, bater, lavrar, escrever, copiar, reproduzir, rabiscar, grafar, riscar, redigir, repetir, transcrever, tirar.

Alternâncias definidas para a classe - Etapa1: V_SN, V_SN_SP[em], V_SN_SP[entre], V_SN_SP[sobre], V_SN_SP[sob], V.

search-35.2

Taxa de aceitação: 0.181818181818

Número Selecionados: 2

Número candidatos: 11

Selecionados: procurar, guardar.

Alternâncias definidas para a classe - Etapa1: V_SN_SP[por], V_SP[por]_SP[em], V_SP[por]_SP[entre], V_SP[por]_SP[por], V_SP[por]_SP[sobre], V_SP[por]_SP[sob], V_SP[por].

see-30.1

Taxa de aceitação: 1.0

Número Selecionados: 29

Número candidatos: 29

Selecionados: localizar, imaginar, avistar, farejar, detectar, ouvir, discriminar, ver, identificar, descobrir, escutar, estar, descortinar, sonhar, passar, idealizar, distinguir, perceber, atender, fantasiar, reconhecer, conhecer, notar, enxergar, cheirar, diferenciar, deparar, visualizar, estranhar.

Alternâncias definidas para a classe - Etapa1: V_SN, V_SN_SP[em], V_SN_SP[entre].

send-11.1

Taxa de aceitação: 1.0

Número Selecionados: 14

Número candidatos: 14

Selecionados: transferir, render, mandar, despachar, despedir, produzir, remeter, expedir, trazer, transmitir, dar, deslocar, encaminhar, enviar.

Alternâncias definidas para a classe - Etapa1: V_SN, V_SN_SP[de], V_SN_SP[para], V_SN_SP[de]_SP[para].

separate-23.1

Taxa de aceitação: 0.888888888889

Número Selecionados: 24

Número candidatos: 27

Selecionados: desligar, separar, descolar, destacar, dividir, isolar, apurar, discriminar, esclarecer, desmembrar, demarcar, afastar, repudiar, distinguir, descobrir, desconcertar, resolver, solucionar, abrir, arredar, cortar, diferenciar, mutilar, deixar.

Alternâncias definidas para a classe - Etapa1: V_SN_SP[de], V_SN, V.

shake-22.3

Taxa de aceitação: 0

Número Selecionados: 41

Número candidatos: 41 
Selecionados: misturar, juntar, colecionar, economizar, ajuntar, mestiçar, codificar, unir, pregar, segurar, cruzar, agitar, aproximar, amealhar, revolver, mesclar, costurar, acumular, reunir, ligar, angariar, abanar, poupar, tomar, relacionar, forrar, conciliar, aliciar, recrutar, condensar, atrair, coser, compilar, recolher, bater, armazenar, aliar, concentrar, prender, fixar, consertar.

Alternâncias definidas para a classe - Etapa1: all.

sight-30.2

Taxa de aceitação: 0.959459459459

Número Selecionados: 71

Número candidatos: 74

Selecionados: presenciar, vasculhar, visitar, desvelar, tirar, perscrutar, examinar, observar, demandar, correr, assistir, dissecar, inspecionar, analisar, escavar, localizar, apurar, espionar, testemunhar, discriminar, comentar, ver, estudar, apontar, lembrar, devassar, apalpar, perguntar, criticar, esquadrinhar, vistoriar, buscar, descortinar, investigar, reparar, detectar, reconhecer, explorar, distinguir, interrogar, averiguar, inquirir, vigiar, sondar, atender, guardar, anotar, identificar, aprofundar, verificar, encarar, profundar, conhecer, espreitar, notar, recorrer, considerar, esmiuçar, mirar, diferenciar, atentar, pesquisar, velar, estranhar, olhar, indagar, procurar, saborear, resguardar, espiar, percorrer.

Alternâncias definidas para a classe - Etapa1: V_SN.

simple dressing-41.3.1

Taxa de aceitação: 1.0

Número Selecionados: 7

Número candidatos: 7

Selecionados: vestir, trazer, envergar, trajar, usar, estar, ter.

Alternâncias definidas para a classe - Etapa1: V_SN.

slide-11.2

Taxa de aceitação: 0.95

Número Selecionados: 19

Número candidatos: 20

Selecionados: afastar, trocar, agitar, converter, remover, mexer, deslocar, mudar, mobilizar, pular, movimentar, boiar, ceder, flutuar, mover, saltar, nadar, substituir, circular.

Alternâncias definidas para a classe - Etapa1: V, V_SP[por], V_SP[de], V_SP[para], V_SP[de]_SP[para], V_SP[por]_SP[para], V_SN, V_SN_SP[por], V_SN_SP[de], V_SN_SP[para].

smell_emission-43.3

Taxa de aceitação: 1.0

Número Selecionados: 1

Número candidatos: 1

Selecionados: feder.

Alternâncias definidas para a classe - Etapa1: V, V, V_SP[a].

snooze -40.4

Taxa de aceitação: 1.0 
Número Selecionados: 5

Número candidatos: 5

Selecionados: repousar, dormir, ressonar, cochilar, descansar.

Alternâncias definidas para a classe - Etapa1: V, V_SN.

sound_emission-43.2

Taxa de aceitação: 0.964285714286

Número Selecionados: 27

Número candidatos: 28

Selecionados: murmurar, tanger, rebentar, chacoalhar, ciciar, detonar, balar, balir, ressonar, vaiar, sussurrar, rugir, pipocar, assobiar, explodir, berrar, ranger, estourar, tocar, ressoar, gemer, voar, faiscar, suspirar, chiar, estalar, ladrar.

Alternâncias definidas para a classe - Etapa1: V, V_SP[em], V_SP[entre], V_SP[por], V_SP[sobre], V_SP[sob], V_SN, V_SN.

sound_existence-47.4

Taxa de aceitação: 1.0

Número Selecionados: 11

Número candidatos: 11

Selecionados: refletir, vibrar, reboar, estremecer, rugir, ecoar, repercutir, repetir, rolar, ressoar, soar.

Alternâncias definidas para a classe - Etapa1: V, V_SP[em], V_SP[entre], V_SP[por], V_SP[sobre], V_SP[sob], V_SN.

spank-18.3

Taxa de aceitação: 0.909090909091

Número Selecionados: 10

Número candidatos: 11

Selecionados: moer, cortar, golpear, esmagar, ferir, britar, rasgar, fragmentar, talhar, machucar.

Alternâncias definidas para a classe - Etapa1: V_SN, V_SN_SP[com], V_SN_SP[até], V_SN_SP[até]_SP[com], V_SN_SP[em], V_SN_SP[entre], V_SN_SP[em]_SP[com], V_SN_SP[entre]_SP[com].

spatial_configuration-47.6

Taxa de aceitação: 0.740740740741

Número Selecionados: 20

Número candidatos: 27

Selecionados: suspender, afundar, esvoaçar, balançar, dobrar, vergar, abaixar, aflorar, flutuar, inclinar, ceder, abrir, pendurar, cair, descer, pairar, encontrar, pender, ajoelhar, compensar.

Alternâncias definidas para a classe - Etapa1: V, V_SP[em], V_SP[entre], V_SP[sobre], V_SP[sob], V_SN_SP[em], V_SN_SP[entre], V_SN_SP[sobre], V_SN_SP[sob].

split-23.2

Taxa de aceitação: 0.714285714286

Número Selecionados: 5 


\section{Número candidatos: 7}

Selecionados: tirar, arrancar, sacar, extrair, puxar.

Alternâncias definidas para a classe - Etapa1: V_SN_SP[de], V_SP[de].

\section{spray-9.7}

Taxa de aceitação: 0.924242424242

Número Selecionados: 61

Número candidatos: 66

Selecionados: suspender, embargar, entulhar, difundir, cravar, umedecer, esvaziar, envolver, despejar, carregar, preencher, esfregar, jorrar, travar, atravancar, congestionar, equipar, embalar, enfiar, costurar, acumular, derrubar, semear, revestir, fechar, vazar, passar, virar, tomar, encher, verter, lotar, entupir, coçar, roçar, pender, espalhar, obstar, tolher, plantar, atestar, pendurar, cultivar, bloquear, obstruir, cortar, coser, derramar, tapar, dificultar, impedir, acondicionar, penetrar, pôr, embaraçar, engessar, embrulhar, barrar, estender, consertar, orvalhar.

Alternâncias definidas para a classe - Etapa1: V_SN_SP[para], V_SN_SP[com], V_SN, V_SN.

stalk-35.3

Taxa de aceitação: 1.0

Número Selecionados: 4

Número candidatos: 4

Selecionados: rastrear, seguir, farejar, cheirar.

Alternâncias definidas para a classe - Etapa1: V_SN.

steal-10.5

Taxa de aceitação: 0.916666666667

Número Selecionados: 22

Número candidatos: 24

Selecionados: tirar, resgatar, arrancar, extorquir, invadir, salvar, liberar, conquistar, apreender, libertar, sugar, livrar, apanhar, tomar, mamar, subtrair, soltar, sangrar, segurar, ocupar, largar, roubar.

Alternâncias definidas para a classe - Etapa1: V_SN, V_SN_SP[de], V_SN_SP[para], V_SN_SP[de]_SP[para].

stimulus_subject-30.4

Taxa de aceitação: 0

Número Selecionados: 6

Número candidatos: 6

Selecionados: feder, demonstrar, representar, afigurar, figurar, aparentar.

Alternâncias definidas para a classe - Etapa1: all.

stop-55.4

Taxa de aceitação: 0.916666666667

Número Selecionados: 33

Número candidatos: 36

Selecionados: selar, acabar, morrer, arrematar, executar, estacionar, finalizar, emperrar, cerrar, terminar, parar, paralisar, fazer, empacar, sair, estacar, ultimar, trancar, passar, 
imobilizar, perfazer, findar, rematar, dar, complementar, aviar, completar, consumar, encerrar, concluir, cumprir, cristalizar, cessar.

Alternâncias definidas para a classe - Etapa1: V, V_SN, V_SP[com], V_SN_SP[com].

substance_emission-43.4

Taxa de aceitação: 0

Número Selecionados: 46

Número candidatos: 46

Selecionados: cachimbar, dar, respirar, rebentar, minar, vomitar, transpirar, despejar, nascer, escorrer, esvaziar, surdir, jorrar, desabrochar, rejeitar, apontar, fumar, derrubar, gotejar, verter, babar, sair, cuspir, sangrar, pulular, germinar, derivar, exalar, suar, fluir, respingar, vazar, vir, brotar, derramar, entornar, manar, cheirar, coar, espirrar, desprender, lançar, transmitir, destilar, virar, pingar.

Alternâncias definidas para a classe - Etapa1: all.

suffocate -40.7

Taxa de aceitação: 1.0

Número Selecionados: 3

Número candidatos: 3

Selecionados: afogar, sufocar, asfixiar.

Alternâncias definidas para a classe - Etapa1: V_SN, V, V_SP[até], V_SN_SP[até].

sustain-55.6

Taxa de aceitação: 0.846153846154

Número Selecionados: 11

Número candidatos: 13

Selecionados: prolongar, continuar, prosseguir, ir, levar, demorar, prorrogar, seguir, renovar, conduzir, andar.

Alternâncias definidas para a classe - Etapa1: V_SN, V_SN_SP[com], V_SN_SP[por].

swarm-47.5.1

Taxa de aceitação: 0

Número Selecionados: 5

Número candidatos: 5

Selecionados: pulular, infestar, engatinhar, abundar, gatinhar.

Alternâncias definidas para a classe - Etapa1: all.

swat-18.2

Taxa de aceitação: 0.833333333333

Número Selecionados: 10

Número candidatos: 12

Selecionados: cortar, recortar, roer, abocanhar, trincar, morder, ferrar, beliscar, picar, cutucar.

Alternâncias definidas para a classe - Etapa1: V_SN, V_SN_SP[com], V_SN_SP[em], V_SN_SP[em]_SP[com], V_SN_SP[em].

talk-37.5 
Taxa de aceitação: 1.0

Número Selecionados: 4

Número candidatos: 4

Selecionados: tratar, conversar, comunicar, falar.

Alternâncias definidas para a classe - Etapa1: V, V_SP[para], V_SP[com], V_SP[para]_SP[sobre], V_SP[com]_SP[sobre], V, V_SP[sobre]_SP[para], V_SP[sobre]_SP[com], V_SP[sobre]_SP[de].

tape-22.4

Taxa de aceitação: 1.0

Número Selecionados: 14

Número candidatos: 14

Selecionados: abotoar, emendar, coser, colar, apertar, enlaçar, costurar, ligar, amarrar, prender, unir, atar, consertar, grampear.

Alternâncias definidas para a classe - Etapa1: V_SN, V_SN_SP[em].

tell-37.2

Taxa de aceitação: 0.947368421053

Número Selecionados: 18

Número candidatos: 19

Selecionados: declarar, referir, assegurar, mencionar, afirmar, mandar, intimar, expor, relatar, recontar, afiançar, historiar, ordenar, narrar, contar, dizer, garantir, desfiar.

Alternâncias definidas para a classe - Etapa1: V_SN, V_SN_SP[sobre].

throw-17.1

Taxa de aceitação: 0.95652173913

Número Selecionados: 22

Número candidatos: 23

Selecionados: disparar, tirar, meter, arrumar, afundar, projetar, sacudir, tacar, mandar, revolver, alienar, desferir, afastar, vibrar, soltar, cuspir, lançar, descarregar, jogar, arremessar, expelir, atirar.

Alternâncias definidas para a classe - Etapa1: V_SN, V_SN_SP[para], V_SN_SP[de], V_SN_SP[de]_SP[para].

tingle-40.8.2

Taxa de aceitação: 0.714285714286

Número Selecionados: 5

Número candidatos: 7

Selecionados: girar, ferir, rodar, rolar, machucar.

Alternâncias definidas para a classe - Etapa1: V, V_SP[de].

touch-20

Taxa de aceitação: 0.96

Número Selecionados: 24

Número candidatos: 25 
Selecionados: manejar, esfregar, beijar, coçar, agradar, unir, segurar, cutucar, esmagar, embalar, empunhar, travar, tomar, afagar, agarrar, acalentar, comprimir, ferrar, colar, prender, roçar, acariciar, encostar, amassar.

Alternâncias definidas para a classe - Etapa1: V_SN, V_SN_SP[com].

transcribe-25.4

Taxa de aceitação: 0.923076923077

Número Selecionados: 12

Número candidatos: 13

Selecionados: documentar, bater, retratar, transcrever, fotografar, copiar, reproduzir, rodar, registrar, filmar, repetir, tirar.

Alternâncias definidas para a classe - Etapa1: V_SN, V_SN_SP[em], V_SN_SP[para].

transfer_mesg-37.1.1

Taxa de aceitação: 1.0

Número Selecionados: 51

Número candidatos: 51

Selecionados: citar, declarar, mencionar, desvelar, iniciar, tratar, ilustrar, demonstrar, recontar, narrar, interpretar, contar, dizer, desfiar, desatar, apontar, esclarecer, instituir, instruir, ditar, alumiar, descobrir, habilitar, historiar, legitimar, informar, edificar, ensinar, educar, descrever, expor, iluminar, explicar, resolver, liquidar, abrir, desenrolar, cantar, traduzir, referir, exibir, clarear, justificar, relatar, escolher, falar, disciplinar, indicar, representar, elucidar, lecionar.

Alternâncias definidas para a classe - Etapa1: V_SN, V_SN_SP[a], V_SN_SP[para], V.

turn-26.6.1

Taxa de aceitação: 0.733333333333

Número Selecionados: 11

Número candidatos: 15

Selecionados: reduzir, converter, modificar, mudar, alterar, tornar, ficar, fazer, voltar, trocar, transformar.

Alternâncias definidas para a classe - Etapa1: V_SN_SP[de]_SP[em], V_SN_SP[em].

waltz-51.5

Taxa de aceitação: 1.0

Número Selecionados: 1

Número candidatos: 1

Selecionados: sambar.

Alternâncias definidas para a classe - Etapa1: V, V_SP[em], V_SP[entre], V_SP[por], V_SP[sobre], V_SP[sob].

want-32.1

Taxa de aceitação: 0.75

Número Selecionados: 18

Número candidatos: 24

Selecionados: reclamar, devorar, demandar, requerer, ter, aspirar, namorar, ambicionar, precisar, desejar, pedir, padecer, dever, suspirar, necessitar, querer, cobiçar, almejar. 
Alternâncias definidas para a classe - Etapa1: V_SN, V_SN_SP[por].

weather-57

Taxa de aceitação: 0

Número Selecionados: 12

Número candidatos: 12

Selecionados: serenar, murmurar, sussurrar, chover, peneirar, soprar, limpar, ciciar, abrir, suspirar, ventar, pingar.

Alternâncias definidas para a classe - Etapa1: all.

weekend-56

Taxa de aceitação: 0

Número Selecionados: 1

Número candidatos: 1

Selecionados: hibernar.

Alternâncias definidas para a classe - Etapa1: all.

wink-40.3.1

Taxa de aceitação: 0.5

Número Selecionados: 2

Número candidatos: 4

Selecionados: entortar, aplaudir.

Alternâncias definidas para a classe - Etapa1: V SN.

wipe_instr-10.4.2

Taxa de aceitação: 1.0

Número Selecionados: 5

Número candidatos: 5

Selecionados: alisar, aparar, passar, filtrar, coar.

Alternâncias definidas para a classe - Etapa1: V_SN_SP[de], V_SN, V.

wipe_manner-10.4.1

Taxa de aceitação: 0.916666666667

Número Selecionados: 44

Número candidatos: 48

Selecionados: esfregar, lavar, arrancar, coçar, sorver, puxar, despir, sugar, talhar, esmagar, reduzir, descobrir, abaixar, apanhar, polir, passar, gastar, filtrar, colher, abater, roçar, raspar, desarmar, engraxar, limpar, brunir, comprimir, catar, desnudar, vazar, alisar, cortar, derramar, clarear, aparar, pegar, diminuir, apagar, chupar, peneirar, extrair, baixar, desgastar, amassar.

Alternâncias definidas para a classe - Etapa1: V_SN_SP[de], V_SN, V_SN. 


\section{APÊNDICE B - Classes do gold standard}

Neste apêndice são apresentadas, de forma detalhada, as classes do gold standard.

\section{Amalgamate-22.2 - página 160 de Levin (1993)}

Definição: Subclasse de "Verbos relacionados com combinar e anexar" (classe 22 de Levin), a classe amalgamate-22.2 contém verbos que participam da alternância simple reciprocal (simples reciprocidade - exemplo 75), mas não participam da alternância together reciprocal (junto reciprocidade - exemplo 76). Descrevem o estado final em que o objeto direto se encontra. Paciente.

Papéis temáticos assumidos pelos argumentos: Agente (animado ou máquina) ou

Restrições definidas para o gold standard: participação nas alternâncias simples reciprocidade e cansativa/incoativa, mas não participam da alternância junto reciprocidade.

Verbos do gold standard (primeira versão) (11 verbos): alternar, casar, coincidir, combinar, comparar, contrastar, correlacionar, juntar, reunir, unificar, unir.

Verbos do gold standard (segunda versão) (8 verbos): unificar, alternar, contrastar, combinar, juntar, comparar, casar, reunir.

Verbos do gold standard (terceira versão) (26 verbos): unificar, alternar, contrastar, combinar, juntar, comparar, casar, reunir, unir, coincidir, bater, integrar, ligar, prender, aderir, aliar, atar, atrelar, combinar, coordenar, grudar, harmonizar, interligar, mesclar, misturar, relacionar, somar, ornar.

Exemplos verbo "alternar" (retirados de Levin(1993, p. 160):

(80) (a) Harriet alternated folk songs with pop songs. (Harriet alternou canções folclóricas com canções populares.)

(b) Harriet alternated folk songs and pop songs. (Harriet alternou canções folclóricas e canções poulares.)

(alternância simples reciprocidade)

(81) (a) Harriet alternated folk songs with pop songs. (Harriet alternou canções folclóricas com canções populares.)

(b) *Harriet alternated folk songs and pop songs together. (*Harriet alternou canções folclóricas e canções poulares juntas.)

(alternância junto reciprocidade)

(82) (a) Harriet alternated folk songs with pop songs. (Harriet alternou canções folclóricas com canções populares.)

(b) Folk songs alternated with pop songs. (Canções folclóricas alternaram com canções populares.)

(alternância causativa/incoativa) 


\section{Amuse-31.1 - página 189 de Levin (1993)}

Definição: Subclasse de "Verbos Psicológicos" (classe 31 de Levin), a classe amuse-31.1 contém verbos que descrevem o acarretamento de uma mudança de estado psicológico ou emocional. O sujeito é a Causa da mudança do estado psicológico do objeto (Experienciador).

Papéis temáticos assumidos pelos argumentos: Experienciador ou Causa.

Restrições definidas para o gold standard: participação na alternância transitiva com o sujeito recebendo o papel temático de Causa e o objeto recebendo o papel de Experienciador.

Verbos do gold standard (primeira versão) (24 verbos): abalar, aborrecer, agradar, alarmar, alegrar, ameaçar, amedrontar, apavorar, assustar, atemorizar, aterrorizar, chatear, chocar, confundir, contrariar, decepcionar, deliciar, desapontar, encantar, escandalizar, espantar, estimular, ferir, frustar.

Verbos do gold standard (segunda versão) (23 verbos): frustar, chatear, alarmar, escandalizar, aterrorizar, amedrontar, deliciar, apavorar, alegrar, decepcionar, aborrecer, encantar, ofender, espantar, chocar, contrariar, abalar, agradar, assustar, confundir, estimular, ferir, ameaçar.

Verbos do gold standard (terceira versão) (85 verbos): frustar, chatear, alarmar, escandalizar, aterrorizar, amedrontar, deliciar, apavorar, alegrar, decepcionar, aborrecer, encantar, ofender, espantar, chocar, contrariar, abalar, agradar, assustar, confundir, estimular, ferir, ameaçar, abater, acalmar, afetar, animar, atrair, atrapalhar, cegar, comover, consolar, desanimar, desgraçar, deslumbrar, divertir, emocionar, empolgar, excitar, fascinar, iludir, impressionar, incomodar, indignar, induzir, inquietar, inspirar, intimidar, intrigar, irritar, prejudicar, preocupar, revoltar, afligir, aliviar, atormentar, cativar, confortar, constranger, contentar, deprimir, desagradar, desapontar, descontentar, desencorajar, desestimular, desonrar, distrair, embaraçar, encorajar, enfurecer, entreter, entusiasmar, envergonhar, horrorizar, humilhar, incendiar, inflamar, penalizar, perturbar, sensibilizar, tranquilizar, satisfazer, agitar, arrasar, cansar, enfraquecer, estremecer, maravilhar, serenar, sossegar, torturar, acabrunhar, acalentar, alucinar, aprazer, arrepiar, comprazer, debilitar, deleitar, desconfortar, desesperar, desgostar, enfadar, entristecer, esmorecer, exaltar, exaurir, exultar, fatigar, impacientar, importunar, magoar, oprimir, tolher, vexar, zangar.

\section{Exemplos verbo “divertir" (retirados de Levin(1993, p. 190):}

The clown amused the children. (O palhaço divertiu as crianças.)

(alternância transitiva)

\section{Characterize-29.2 - página 181 de Levin (1993)}

Definição: Subclasse de "Verbos com complementos predicativos" (classe 29 de Levin), a classe characterize-29.2 contém verbos usados para descrever ou caracterizar propriedades de uma entidade. Não possuem a alternância as alternation (alternância como), somente a construção com as (como).

Papéis temáticos assumidos pelos argumentos: Agente (animado ou organização), Tema (concreto ou organização) ou Predicado. 
Restrições definidas para o gold standard: construções com "como", mas não participação na alternância como.

Verbos do gold standard (primeira versão) (15 verbos): classificar, definir, descrever, diagnosticar, encarar, enfrentar, enlistar, identificar, pintar, reintegrar, representar, respeitar, restabelecer, retratar, tratar.

Verbos do gold standard (segunda versão) (13 verbos): reintegrar, diagnosticar, restabelecer, pintar, retratar, encarar, respeitar, classificar, identificar, enfrentar, definir, representar, tratar.

Verbos do gold standard (terceira versão) (37 verbos): reintegrar, diagnosticar, restabelecer, pintar, retratar, encarar, respeitar, classificar, identificar, enfrentar, definir, representar, tratar, aceitar, adotar, caracterizar, reconhecer, conceber, conhecer, considerar, dar, entender, ter, tomar, ver, imaginar, interpretar, julgar, olhar, recordar, rememorar, reproduzir, supor, visualizar, perceber, tomar, conhecer, enxergar, lembrar, taxar, achar.

Exemplos verbo “caracterizar” (retirados de Levin(1993, p. 181): como uma salva-vidas.)

(b) *Angela characterized Shelly a lifesaver. (*Angela caracterizou Shelly uma salva-vidas.)

(alternância como)

\section{Correspond-36.1 - página 200 de Levin (1993)}

Definição: Subclasse de "Verbos de Interação Social" (classe 36 de Levin), a classe correspond-36.1 contém verbos relacionados com atividades que envolvem mais de um participante. Quando não possuem um sujeito no plural ou coletivo (alternância collective $S N$ subject - alternância do sujeito no coletivo) necessitam de um sintagma nominal com a preposição with (com). ou Tema.

Papéis temáticos assumidos pelos argumentos: Ator (animado ou organização)

Restrições definidas para o gold standard: apresentar sintagmas preposicionais com a preposição "com" como núcleo ou sujeitos no plural (ou coletivos).

Verbos do gold standard (primeira versão) (13 verbos): casar, coincidir, colaborar, colidir, concordar, cooperar, flertar, interagir, namorar, pechinchar, regatear, simpatizar, unir.

Verbos do gold standard (segunda versão) (11 verbos): pechinchar, flertar, simpatizar, colidir, cooperar, interagir, namorar, coincidir, colaborar, unir, concordar.

Verbos do gold standard (terceira versão) (28 verbos): pechinchar, flertar, simpatizar, colidir, cooperar, interagir, namorar, coincidir, colaborar, unir, concordar, debater, discutir, brigar, conviver, discordar, acordar, ajustar, combinar, compactuar, comunicar, conciliar, conspirar, disputar, negociar, pactuar, paquerar, relacionar, reunir.

Exemplos verbo “discutir" (retirados de Levin(1993, p. 181): 
(85) Brenda bantered with Molly. (Brenda discutiu com Molly.)

(SP com "com” como núcleo)

(86) (a) Brenda bantered with Molly. (Brenda discutiu com Molly.)

(b) Brenda and Molly bantered. (Brenda e Molly discutiram.)

(alternância do sujeito no coletivo)

\section{Get-13.5.1 - página 141 de Levin (1993)}

Definição: Subclasse de "Verbos de Mudança de Posse" (classe 13 de Levin), a classe get-1.5.1 contém verbos relacionados com atividades que envolvem troca de posse de um objeto. Participam da alternância benefativa (benefactive alternation).

Papéis temáticos assumidos pelos argumentos: Agente (animado ou organização), Tema, Fonte, Beneficiário (animado ou organização) e Local (local ou região).

Restrições definidas para o gold standard: apresenta a alternância básica transitiva (podendo aparecer informações sobre o local), apresentar a alternância benefativa e a alternância de soma de dinheiro no sujeito (sum of Money subject alternation).

Verbos do gold standard (primeira versão) (11 verbos): adquirir, arranjar, buscar, colher, comparar, conseguir, fretar, ganhar, obter, pegar, reservar.

Verbos do gold standard (segunda versão) (10 verbos): arranjar, colher, reservar, adquirir, pegar, obter, buscar, comprar, ganhar, conseguir.

Verbos do gold standard (terceira versão) (18 verbos): arranjar, colher, reservar, adquirir, pegar, obter, buscar, comprar, ganhar, conseguir, alugar, contratar, arrendar, conquistar, angariar, apanhar, arrematar, capturar.

Exemplos verbo "comprar" (retirados de Levin(1993, p. 141-142):

(87) Carmen bought a dress [at Bloomingdale's] [from Diana]. (Carmen comprou um vestido [no Bloomingdale's] [de Diana])

(básica transitiva)

(88) (a) Carmen bought a dress to Mary. (Carmen comprou um vestido para Maria.)

(b) Carmen bought Mary a dress. (Carmen comprou para Maria um vestido.)

(alternância benefativa)

(89) (a) Carmen bought a dress at Bloomingdale's for \$50. (Carmen comprou um vestido no Bloomingdale's por \$50.)

(b) $\$ 50$ won't even buy a dress at Bloomingdale's. (\$50 não poderiam comprar um vestido no Bloomingdale's.)

(alternância de soma de dinheiro no sujeito) 


\section{Hit-18.1 - página 148 de Levin (1993)}

Definição: Subclasse de "Verbos de Contato por Impacto" (classe 18 de Levin), a classe get-1.5.1 contém verbos que descrevem o movimento de uma entidade para entrar em contato com outra entidade. $\mathrm{O}$ contato não precisa ter algum efeito sobre a segunda entidade. Participam da alternância com/contra (with/against alternation).

Papéis temáticos assumidos pelos argumentos: Agente, Paciente (concreto) ou Instrumento (concreto).

Restrições definidas para o gold standard: apresenta as alternâncias com/contra, conativa, parte do corpo (body-part), junto reciprocidade (together reciprocal) e instrumento como sujeito (instrument subject).

Verbos do gold standard (primeira versão) (12 verbos): açoitar, bater, chicotear, esbofetear, esmagar, esmurrar, espancar, golpear, martelar, socar, surrar, tapear.

Verbos do gold standard (segunda versão) (4 verbos): martelar, esmagar, espancar, bater.

Verbos do gold standard (terceira versão) (16 verbos): martelar, esmagar, espancar, bater, golpear, alvejar, amassar, coçar, comprimir, cutucar, esbarrar, chutar, chicotear, esbofetear, pisotear, socar.

Exemplos verbo "bater" (retirados de Levin(1993, p. 148-149):

(90) (a) Paula hit the stick against the fence. (Paula bateu a vara contra a cerca.)

(b) Paula hit the fence with the stick. (Paula bateu na cerca com a vara.)

(alternância com/contra)

(91) (a) Paula hit the fence. (Paula bateu na cerca.)

(b) Paula hit at the fence. (Paula bateu na cerca.)

(alternância conativa)

(92) (a) Paula hit Deirdre on the back. (Paula bateu Deirdre nas costas.)

(b) Paula hit Deirdre's back. (Paula bateu nas costas de Deirdre.)

(alternância de parte do corpo)

(93) (a) Paula hit the fence with the stick. (Paula bateu na cerca com a vara.)

(b) The stick hit the fence. (A vara bateu na cerca.)

(alternância instrumento como sujeito)

\section{Light-emission-43.1 - página 148 de Levin (1993)}

Definição: Subclasse de "Verbos de Emissão" (classe 43 de Levin), a classe lightemission-43.1 contém verbos relacionados à emissão de luz. Apresentam a alternância locativa (locative alternation).

Papéis temáticos assumidos pelos argumentos: Tema (animado), Local ou Agente. 
locativa.

Restrições definidas para o gold standard: apresenta as alternâncias intransitiva e

Verbos do gold standard (primeira versão) (12 verbos): brilhar, chamejar, cintilar, flamejar, luzir, piscar, raiar, refletir, refulgir, reluzir, resplandescer, tremeluzir.

Verbos do gold standard (segunda versão) (6 verbos): resplandecer, raiar, cintilar, piscar, brilhar, refletir.

Verbos do gold standard (terceira versão) (9 verbos): resplandecer, raiar, cintilar, piscar, brilhar, refletir.

Exemplos verbo "brilhar" (retirados de Levin(1993, p. 233-234):

(94) The jewel sparkled. (A jóia brilhou.)

(alternância intransitiva)

(95) (a) Jewels sparkled on the crown. (Jóias brilhavam na coroa.)

(b) The crown sparkled with jewels. (A coroa brilhava com jóias.)

(alternância locativa)

\section{Manner_of_speaking-37.3 - página 204 de Levin (1993)}

Definição: Subclasse de "Verbos de Comunicação" (classe 37 de Levin), a classe light-emission-43.1 contém verbos relacionados à forma de falar, em outras palavras, ao modo como os sons são expressos.

Papéis temáticos assumidos pelos argumentos: Agente (animado ou organização), Tópico (comunicação) ou Recipiente (animado ou organização).

Restrições definidas para o gold standard: apresenta as alternâncias intransitiva e transitiva e construções com sintagma preposicional com núcleo "sobre".

Verbos do gold standard (primeira versão) (13 verbos): balbuciar, berrar, bradar, choramingar, cochichar, gritar, grunhir, murmurar, queixar, resmungar, rosnar, segredar, sussurrar.

Verbos do gold standard (segunda versão) (10 verbos): cochichar, rosnar, sussurrar, berrar, resmungar, balbuciar, bradar, murmurar, queixar, gritar.

Verbos do gold standard (terceira versão) (20 verbos): assobiar, cantar, ciciar, gaguejar, grunhir, vociferar, cochichar, confidenciar, gemer, murmurar, rosnar, segredar, soprar, resmungar, sussurrar, berrar, balbuciar, bradar, queixar, gritar.

Exemplos verbo “cochichar” (retirados de Levin(1993, p. 205):

(96) Susan whispered. (Susan cochichou.)

(alternância intransitiva)

(97) Susan whispered the news. (Susan cochichou as notícias.)

(alternância transitiva)

(98) Susan whispered about the party. (Susan cochichou sobre a festa.) 
(construção com sintagma preposicional com núcleo "sobre")

Modes_of_being_with_motion-47.3 - página 251 de Levin (1993)

Definição: Subclasse de "Verbos de Existência" (classe 47 de Levin), a classe modes_of_being_with_motion-47.3 contém verbos que definem a existência de entidades inanimadas que envolvem tipos de movimento típicos destas entidades. O sujeito deve ser inanimado.

Papéis temáticos assumidos pelos argumentos: Agente, Tema (concreto) ou Localização (local ou região).

Restrições definidas para o gold standard: apresentar sujeitos inanimados e sintagmas preposicionais que introduzem um local.

Verbos do gold standard (primeira versão) (7 verbos): boiar, flutuar, oscilar, rodopiar, serpear, tremular, vibrar.

Verbos do gold standard (segunda versão) (4 verbos): boiar, flutuar, vibrar, oscilar.

Verbos do gold standard (terceira versão) (18 verbos): boiar, flutuar, vibrar, oscilar, agitar, balançar, brandir, dançar, girar, pairar, palpitar, pulsar, sacudir, tremer, inclinar, ondular, pender, rebolar.

Exemplos verbo "tremular" (retirados de Levin(1993, p. 233-234):

(99) A large flag fluttered. (Uma grande bandeira tremulou.) (alternância intransitiva com sujeito inanimado)

(100) A large flag fluttered over the fort. (Uma grande bandeira tremulou sobre o forte.)

(sintagma preposicional introduzindo um local)

\section{Nonverbal_expression-40.2 - página 219 de Levin (1993)}

Definição: Subclasse de "Verbos que Envolvem o Corpo" (classe 40 de Levin), a classe light-emission-43.1 contém verbos relacionados expressões não verbais. Geralmente descrevem expressões faciais associadas com uma emoção em particular. Apresentam as alternâncias de objeto cognato (cognate object) e objeto de reação (reaction object).

Papéis temáticos assumidos pelos argumentos: Agente (animado), Tema (comunicação), Causa ou Recipiente (animado).

Restrições definidas para o gold standard: apresenta as alternâncias intransitiva, d objeto cognato e de objeto de reação.

Verbos do gold standard (primeira versão) (9 verbos): arfar, bocejar, chorar, gargalhar, rir, roncar, soluçar, sorrir, suspirar.

Verbos do gold standard (segunda versão) (8 verbos): bocejar, arfar, roncar, soluçar, suspirar, sorrir, chorar, rir. 
Verbos do gold standard (terceira versão) (18 verbos): bocejar, arfar, roncar, soluçar, suspirar, sorrir, chorar, rir, assobiar, choramingar, delirar, fungar, gargalhar, gemer, ofegar, ressonar, tossir, piscar.

Exemplos verbo "rir" (retirados de Levin(1993, p. 219):

(101) Paula laughed. (Paula riu.)

(alternância intransitiva)

(102) Paula laughed a cheerful laugh. (Paula riu uma risada animada.)

(alternância de objeto cognato)

(103) Paula laughed her excitement. (Paula riu sua excitação.)

(alternância de objeto de reação)

\section{Other_cos-45.4 - página 244 de Levin (1993)}

Definição: Subclasse de "Verbos de Mudança de Estado" (classe 45 de Levin), a classe other_cos-45.4 contém verbos relacionados mudança de estado ocasionada por causas externas. Muitas destas mudanças envolvem mudanças físicas. Participam da alternância de instrumento como sujeito.

Papéis temáticos assumidos pelos argumentos: Agente, Paciente ou Instrumento.

Restrições definidas para o gold standard: apresenta a alternância de instrumento como objeto e a alternância causativa/incoativa.

Verbos do gold standard (primeira versão) (20 verbos): afrouxar, afundar, alargar, amolecer, ampliar, aprofundar, congelar, contrair, derreter, diminuir, dissipar, dissolver, encurtar, enfraquecer, estreitar, fundir, intensificar, multiplicar, reduzir, suavizar.

Verbos do gold standard (segunda versão) (19 verbos): suavizar, encurtar, afrouxar, alargar, estreitar, derreter, dissipar, congelar, dissolver, afundar, enfraquecer, aprofundar, contrair, fundir, intensificar, multiplicar, ampliar, diminuir, reduzir.

Verbos do gold standard (terceira versão) (19 verbos): suavizar, encurtar, afrouxar, alargar, estreitar, derreter, dissipar, congelar, dissolver, afundar, enfraquecer, aprofundar, contrair, fundir, intensificar, ampliar, abaixar, abrandar, acalmar, acordar, afiar, afinar, agigantar, alagar, alegrar, alisar, alongar, alvejar, amaciar, amortecer, amplificar, apagar, aperfeiçoar, aplacar, apressar, aprimorar, arrebentar, arrefecer, arrombar, atenuar, avolumar, avultar, azedar, caiar, cegar, cicatrizar, clarear, comprimir, condensar, corar, cristalizar, curar, debilitar, degenerar, deprimir, desacelerar, desandar, desatar, descentralizar, desdobrar, desenrolar, desequilibrar, desestabilizar, desfiar, destravar, dilatar, diluir, dourar, encurtar, endurecer, entreabrir, envelhecer, enxugar, equilibrar, escurecer, esfriar, estabilizar, estalar, esticar, estourar, estrangular, expandir, explodir, fortalecer, furar, gelar, inundar, manchar, matizar, melar, molhar, nivelar, reacender, reanimar, reavivar, recrudescer, refrescar, ressecar, secar, solidificar, sujar, umedecer, vergar, abalar, abrir, acelerar, acender, agravar, apontar, aquecer, despertar, detonar, encher, encolher, engrossar, esquentar, fechar, lotar.

Exemplos verbo "secar" (retirados de Levin(1993, p. 245): 
(104) (a) Bill dried the clothes. (Bill secou as roupas.)

(b) The clothes dried. (As roupas secaram.)

(alternância causativa-incoativa)

(105) (a) Bill dried the clothes with a hairdryer. (Bill secou as roupas com um secador.)

(b) The hairdryer dried the clothes. (O secador secou as roupas.)

(alternância de instrumento como sujeito)

\section{Put-9.1 - página 111 de Levin (1993)}

Definição: Subclasse de "Verbos de Colocar" (classe 9 de Levin), a classe put-9.1 contém verbos relacionados com a colocação de uma entidade em um lugar. Não aparecem na forma intransitiva.

Papéis temáticos assumidos pelos argumentos: Agente (animado), Tema (concreto) ou Destino (local).

Restrições definidas para o gold standard: apresenta a construção com sintagma preposicional, tendo como núclo preposições que indiquem lugar (em, sobre, etc.) e não apresenta a forma intransitiva.

Verbos do gold standard (primeira versão) (13 verbos): colocar, cravar, depositar, guardar, inserir, instalar, introduzir, mergulhar, meter, montar, pôr, posicionar, situar.

Verbos do gold standard (segunda versão) (13 verbos): cravar, posicionar, mergulhar, situar, inserir, depositar, introduzir, meter, guardar, instalar, montar, pôr, colocar.

Verbos do gold standard (terceira versão) (25 verbos): cravar, posicionar, mergulhar, situar, inserir, depositar, introduzir, meter, guardar, instalar, montar, pôr, colocar, botar, implantar, incluir, enterrar, fincar, fixar, plantar, dispor, encaixar, estacionar, intercalar, semear.

Exemplos verbo "colocar" (retirados de Levin(1993, p. 112):

(106) Cheryl stood the books on the shelf. (Cheryl colocou os livros na prateleira.) (sintagma preposicional com núcleo uma preposição indicando um lugar)

\section{Remove-10.1 - página 122 de Levin (1993)}

Definição: Subclasse de "Verbos de Remoção" (classe 10 de Levin), a classe remove-10.1 contém verbos relacionados com a remoção de uma entidade de um local. Um dos seus argumentos é introduzido por um sintagma preposicional com a preposição from (de) como núcleo.

Papéis temáticos assumidos pelos argumentos: Agente, Tema e Fonte (local).

Restrições definidas para o gold standard: apresenta um dos argumentos sendo inserido via preposição "de". 
Verbos do gold standard (primeira versão) (14 verbos): arrancar, cortar, deletar, descarregar, eliminar, erradicar, extirpar, extrair, liberar, recolher, remover, retirar, subtrair, tirar.

Verbos do gold standard (segunda versão) (13 verbos): extirpar, erradicar, subtrair, descarregar, remover, extrair, arrancar, recolher, eliminar, cortar, liberar, retirar, tirar.

Verbos do gold standard (terceira versão) (29 verbos): extirpar, erradicar, subtrair, descarregar, remover, extrair, arrancar, recolher, eliminar, cortar, liberar, retirar, tirar, isolar, destituir, excluir, expulsar, separar, abolir, afastar, apagar, demitir, derrubar, despedir, destacar, exonerar, exterminar, extinguir, sacar, suprimir.

Exemplos verbo "remover" (retirados de Levin(1993, p. 122):

(107) Doug removed the smudges from the tabletop. (Doug removeu as manchas da mesa.)

(sintagma preposição introduzido pela preposição "de")

\section{Run-51.3.2 - página 265 de Levin (1993)}

Definição: Subclasse de "Verbos de Movimento" (classe 51 de Levin), a classe run-51.3.2 contém verbos que descrevem maneiras como entidades animadas se movem. Descrevem o deslocamento de um objeto em um modo ou em meio particular, mas não especifica a direção do movimento (a menos que apareça com uma frase direcional explícita).

Papéis temáticos assumidos pelos argumentos: Agente (animado), Tema (animado ou máquina) ou Localização (concreto).

Restrições definidas para o gold standard: apresenta um dos argumentos introduzidos por um sintagma preposicional com preposições de lugar (em, entre, etc.). Descrevem o modo do movimento e não a direção.

Verbos do gold standard (primeira versão) (13 verbos): andar, caminhar, correr, deslizar, escorregar, galopar, marchar, nadar, passear, perambular, planar, trotar, voar.

Verbos do gold standard (segunda versão) (11 verbos): galopar, perambular, escorregar, deslizar, marchar, nadar, passear, voar, caminhar, andar, correr.

Verbos do gold standard (terceira versão) (35 verbos): galopar, perambular, escorregar, deslizar, marchar, nadar, passear, voar, caminhar, andar, correr, avançar, desfilar, flutuar, pular, saltar, subir, vagar, engatinhar, escalar, galgar, mergulhar, boiar, esvoaçar, mancar, cambalear, cavalgar, escalar, esgueirar-se, rastejar, saltitar, sonambular, trotar, ziguezaguear, gatinhar.

Exemplos verbo "pular" (retirados de Levin(1993, p. 266):

(108) The horse jumped over the stream. (O cavalo pulou sobre o córrego.)

(um dos argumentos introduzidos por um sintagma preposicional com preposições de lugar)

Say-37.7 - página 209 de Levin (1993) 
Definição: Subclasse de "Verbos de Comunicação" (classe 37 de Levin), a classe say-37.7 contém verbos relacionados à comunicação de proposições e atitutes proposicionais. Admitem o sintagma preposicional regido por to (para) indicando o destinatário da comunicação, mas não admitem a alternância dativa.

Papéis temáticos assumidos pelos argumentos: Agente (animado ou organização), Tópico (comunicação) ou Recipiente (animado ou organização).

Restrições definidas para o gold standard: apresenta construções com o sintagma nominal regido por "para" ou "a" introduzindo o destinário e não apresenta a alternância dativa.

Verbos do gold standard (primeira versão) (23 verbos): afirmar, alegar, anunciar, apresentar, confiar, declarar, descrever, dizer, expor, exprimir, falar, formular, mencionar, narrar, noticiar, proclamar, recontar, relatar, replicar, reportar, responder, retrucar, segredar.

Verbos do gold standard (segunda versão) (23 verbos): recontar, segredar, reportar, retrucar, proclamar, exprimir, replicar, formular, noticiar, narrar, mencionar, confiar, expor, relatar, alegar, descrever, declarar, anunciar, responder, falar, apresentar, afirmar, dizer.

Verbos do gold standard (terceira versão) (40 verbos): recontar, segredar, reportar, retrucar, proclamar, exprimir, replicar, formular, noticiar, narrar, mencionar, confiar, expor, relatar, alegar, descrever, declarar, anunciar, responder, falar, apresentar, afirmar, dizer, comunicar, contar, ordenar, propor, citar, divulgar, informar, lembrar, repetir, sugerir, confidenciar, notificar, reiterar, exclamar, insinuar, verbalizar, revelar.

Exemplos verbo “dizer” (retirados de Levin(1993, p. 209-210):

(109) Ellen said something to Helen. (Ellen disse alguma coisa para Helen.) (sintagma nominal regido por "para" ou "a" introduzindo o destinário)

(110) (a) Ellen said something to Helen. (Ellen disse alguma coisa para Helen.)

(b) *Ellen said Helen something. (*Ellen disse Helen alguma coisa.)

(alternância dativa)

\section{Send-11.1 - página 132 de Levin (1993)}

Definição: Subclasse de "Verbos de Mandar e Carregar" (classe 11 de Levin), a classe send-11.1 contém verbos relacionados à causar a mudança de lugar de uma entidade. A entidade move-se sem o agente e o movimento é acompanhado de mudança de tempo e espaço. Admitem a preposição de destino to (para).

Papéis temáticos assumidos pelos argumentos: Agente (animado ou organização), Tema (concreto), Fonte (local), Destino (animado ou local).

Restrições definidas para o gold standard: apresenta construções com a preposição "para" inserindo um destino e a alternância dativa.

Verbos do gold standard (primeira versão) (11 verbos): despachar, desviar, emitir, enviar, mandar, realocar, reenviar, remeter, transferir, transmitir, transportar. 
Verbos do gold standard (segunda versão) (9 verbos): despachar, transportar, remeter, desviar, emitir, transmitir, transferir, enviar, mandar.

Verbos do gold standard (terceira versão) (14 verbos): despachar, transportar, remeter, desviar, emitir, transmitir, transferir, enviar, mandar, deslocar, trazer, encaminhar, expedir, remeter.

\section{Exemplos verbo “enviar" (retirados de Levin(1993, p. 132):}

(111) Nora sent the book [from Paris] [to London]. (Nora mandou o livro de Paris para Londres.)

(construções com a preposição "para" inserindo um destino)

(112) (a) Nora sent the book to Peter. (Nora enviou o livro para Peter.)

(b) Nora sent Peter the book. (Nora enviou para Peter o livro.)

(alternância dativa) 


\section{APÊNDICE C - Resultados da avaliação da VerbNet.Br para o gold standard}

Neste apêndice são apresentados os resultados detalhados da avaliação da VerbNet.Br em relação ao gold standard. São apresentados os verbos marcados como verdadeiros positivos, verdadeiros negativos, falsos positivos e falsos negativos para cada experimento.

\section{Experimento 1 (EXP1)}

\section{amalgamate-22.2}

Verdadeiros Positivos (24): alternar, coincidir, combinar, juntar, unir, comparar, reunir, bater, integrar, ligar, prender, aderir, aliar, atar, atrelar, coordenar, grudar, harmonizar, interligar, mesclar, misturar, relacionar, somar, ornar.

Falsos Positivos (58): ocorrer, balancear, conviver, casar, meter, revolver, opor, entrar, suceder, introduzir, mestiçar, totalizar, inserir, cruzar, conferir, privar, aproximar, tratar, inovar, pôr, balançar, empatar, embeber, engatar, renovar, federar, tecer, ajustar, calhar, assemelhar, recortar, perfazer, contrapor, conciliar, concorrer, incluir, aferir, acontecer, dar, coexistir, condizer, tramar, solidificar, completar, vir, enquadrar, encaixar, cair, colar, pegar, coadunar, aglutinar, confrontar, consolidar, convir, trocar, intercalar, cingir.

Falsos Negativos (0):

Verdadeiros Negativos (0):

Precisão: 0.292682926829

Abrangência: 1.0

F-measure: 0.452830188679

\section{amuse-31.1}

Verdadeiros Positivos (104): chatear, alarmar, escandalizar, alegrar, decepcionar, aborrecer, encantar, ofender, espantar, chocar, contrariar, abalar, agradar, assustar, confundir, estimular, ferir, ameaçar, abater, acalmar, afetar, animar, atrair, atrapalhar, cegar, comover, consolar, desanimar, desgraçar, deslumbrar, divertir, emocionar, empolgar, excitar, fascinar, iludir, impressionar, incomodar, indignar, induzir, inquietar, inspirar, intimidar, intrigar, irritar, prejudicar, preocupar, revoltar, afligir, aliviar, atormentar, cativar, confortar, constranger, contentar, deprimir, desagradar, desapontar, descontentar, desencorajar, desestimular, desonrar, distrair, embaraçar, encorajar, enfurecer, entreter, entusiasmar, envergonhar, horrorizar, humilhar, incendiar, inflamar, penalizar, perturbar, sensibilizar, satisfazer, agitar, arrasar, cansar, enfraquecer, estremecer, maravilhar, serenar, sossegar, torturar, acalentar, alucinar, aprazer, arrepiar, debilitar, 
desconfortar, desesperar, desgostar, enfadar, entristecer, esmorecer, exaltar, exaurir, exultar, fatigar, magoar, oprimir, tolher.

Falsos Positivos (142): diluir, aquecer, insinuar, toldar, arruinar, calcar, penetrar, esmagar, abaixar, pregar, aguçar, esfriar, arrombar, minorar, invocar, pisar, assediar, meter, dar, dilacerar, escravizar, folgar, repousar, flechar, afrontar, tumultuar, tranqüilizar, descer, intoxicar, pairar, apertar, diminuir, ministrar, incutir, promover, sangrar, derreter, sacudir, ditar, alertar, apaixonar, sobrecarregar, influir, incentivar, envolver, acomodar, seduzir, danar, agonizar, lenir, conquistar, exortar, arrebatar, matar, suscitar, doer, moderar, sugerir, engrossar, moer, consumir, descansar, ralar, tocar, impor, soprar, abrasar, gelar, falar, alterar, apagar, deixar, acirrar, rolar, transportar, desconfiar, acender, render, evocar, pesar, embalar, acordar, aniquilar, esquentar, plantar, provocar, ninar, frustrar, devorar, machucar, maltratar, jogar, avivar, brincar, despertar, comprimir, ceder, afrouxar, obscurecer, reduzir, dourar, amaciar, materializar, abrandar, atenuar, temperar, amortecer, embelezar, incitar, solicitar, perder, triunfar, infundir, mover, tentar, desafiar, pastar, levantar, quebrar, suavizar, impregnar, enjoar, azedar, amargar, refrescar, amenizar, iluminar, entupir, ativar, morder, arder, abanar, sufocar, recuar, recorrer, aplacar, arrefecer, rebaixar, atentar, bulir, degradar, picar.

Falsos Positivos (142): deliciar, acabrunhar, comprazer, deleitar, impacientar, importunar, vexar, zangar.

Verdadeiros Negativos (9): acanhar, ansiar, infiltrar, prostrar, esforçar, apetecer, fartar, sobressaltar, pungir.

Precisão: 0.422764227642

Abrangência: 0.928571428571

F-measure: 0.581005586592

characterize-29.2

Verdadeiros Positivos (16): retratar, classificar, descrever, identificar, aceitar, adotar, caracterizar, reconhecer, conceber, conhecer, considerar, dar, entender, ter, ver, tomar.

Falsos Positivos (6): apontar, receber, haver, eleger, procurar, seguir.

Falsos Negativos (10): pintar, imaginar, interpretar, julgar, olhar, recordar, rememorar, reproduzir, supor, visualizar.

Verdadeiros Negativos (41): traduzir, opinar, desconfiar, confessar, selecionar, detectar, arrumar, graduar, dividir, professar, apurar, empossar, distinguir, abraçar, escolher, descobrir, recapitular, desvendar, sonhar, cuidar, filtrar, saber, idealizar, ler, seriar, figurar, decifrar, pensar, catar, adivinhar, preferir, fantasiar, propagar, admitir, assinalar, ordenar, rolar, divulgar, pinçar, decodificar, matar.

Precisão: 0.727272727273

Abrangência: 0.615384615385

F-measure: 0.666666666667 
correspond-36.1

Verdadeiros Positivos (16): pechinchar, concordar, debater, discutir, brigar, conviver, unir, discordar, acordar, ajustar, combinar, comunicar, disputar, negociar, paquerar, reunir.

Falsos Positivos (29): juntar, admitir, batalhar, cruzar, estabelecer, aproximar, tratar, consentir, firmar, estar, ligar, chorar, relaxar, assentar, contratar, aceitar, contestar, convir, ceder, comerciar, cantar, querer, falar, aliar, estipular, argumentar, aceder, convencionar, pleitear.

Falsos Negativos (5): compactuar, conciliar, conspirar, pactuar, relacionar.

Verdadeiros Negativos (7): concertar, subscrever, harmonizar, privar, relevar, assentir, comprazer.

Precisão: 0.355555555556

Abrangência: 0.761904761905

F-measure: 0.484848484848

get-13.5.1

Verdadeiros Positivos (14): arranjar, colher, reservar, adquirir, pegar, obter, comprar, ganhar, conseguir, alugar, conquistar, angariar, apanhar, arrematar.

Falsos Positivos (50): auferir, encomendar, alcançar, arrancar, lograr, procurar, conduzir, ter, puxar, capturar, apurar, embolsar, apreender, segurar, marcar, perceber, receber, ligar, reunir, pilhar, vazar, juntar, tomar, haver, filtrar, lucrar, vingar, classificar, eleger, ficar, atingir, telefonar, catar, guardar, atrair, selecionar, preferir, decidir, caçar, tirar, escolher, levar, entreter, deter, chamar, sacar, extrair, adotar, arrastar, pinçar.

Falsos Negativos (0):

Verdadeiros Negativos (3): optar, impelir, rematar.

Precisão: 0.21875

Abrangência: 1.0

F-measure: 0.358974358974

hit-18.1

Verdadeiros Positivos (10): martelar, golpear, esmagar, espancar, bater, alvejar, amassar, coçar, comprimir, cutucar.

Falsos Positivos (8): suplantar, rachar, calcar, maltratar, atingir, dar, topar, encostar.

Falsos Negativos (1): esbarrar.

Verdadeiros Negativos (3): colidir, malhar, trombar.

Precisão: 0.555555555556

Abrangência: 0.909090909091

F-measure: 0.689655172414 


\section{light_emission-43.1}

Verdadeiros Positivos (9): resplandecer, raiar, cintilar, piscar, brilhar, refletir, alumiar, faiscar, lucilar.

Falsos Positivos (11): estrelar, bater, pestanejar, incidir, fulminar, esvoaçar, fuzilar, arder, tremer, tombar, cair.

Falsos Negativos (0):

Verdadeiros Negativos (0):

Precisão: 0.45

Abrangência: 1.0

F-measure: 0.620689655172

manner_speaking-37.3

Verdadeiros Positivos (8): ciciar, cochichar, gemer, murmurar, rosnar, segredar, soprar, resmungar.

Falsos Positivos (8): mastigar, ladrar, chiar, mascar, ranger, roncar, delirar, suspirar.

Falsos Negativos (0):

Verdadeiros Negativos (0):

Precisão: 0.5

Abrangência: 1.0

F-measure: 0.666666666667

modes_of_being_with_motion-47.3

Verdadeiros Positivos (15): flutuar, vibrar, oscilar, abanar, esvoaçar, agitar, balançar, brandir, dançar, girar, pairar, palpitar, pulsar, sacudir, tremer.

Falsos Positivos (14): revolver, mover, menear, manejar, arfar, saltar, soprar, aflorar, assoprar, latir, jogar, bater, estalar, espernear.

Falsos Negativos (0):

Verdadeiros Negativos (0):

Precisão: 0.51724137931

Abrangência: 1.0

F-measure: 0.681818181818

nonverbal_expression-40.2 
Verdadeiros Positivos (9): bocejar, arfar, roncar, soluçar, sorrir, chorar, rir, gemer, ressonar.

Falsos Positivos (15): respirar, malhar, ridicularizar, zombar, gozar, brincar, mexer, satirizar, impar, gracejar, troçar, ironizar, escarnecer, caçoar, desfrutar.

Falsos Negativos (0):

Verdadeiros Negativos (1): ansiar.

Precisão: 0.375

Abrangência: 1.0

F-measure: 0.545454545455

\section{other_cos-45.4}

Verdadeiros Positivos (113): suavizar, afrouxar, alargar, estreitar, derreter, congelar, dissolver, afundar, enfraquecer, aprofundar, contrair, fundir, intensificar, ampliar, abaixar, abrandar, acalmar, acordar, afiar, afinar, alagar, alegrar, alisar, alongar, alvejar, amaciar, amortecer, amplificar, apagar, aperfeiçoar, aplacar, apressar, aprimorar, arrebentar, arrefecer, arrombar, atenuar, avultar, azedar, caiar, cegar, cicatrizar, clarear, comprimir, condensar, corar, cristalizar, curar, debilitar, degenerar, deprimir, desacelerar, desandar, desatar, descentralizar, desdobrar, desenrolar, desequilibrar, desestabilizar, desfiar, destravar, dilatar, diluir, dourar, encurtar, endurecer, entreabrir, envelhecer, enxugar, equilibrar, escurecer, esfriar, estabilizar, estalar, esticar, estourar, estrangular, expandir, explodir, fortalecer, furar, gelar, inundar, manchar, matizar, melar, molhar, nivelar, reacender, reanimar, reavivar, recrudescer, refrescar, ressecar, secar, sujar, umedecer, vergar, abalar, abrir, acelerar, acender, agravar, apontar, aquecer, despertar, detonar, encher, encolher, engrossar, esquentar, fechar, lotar.

Falsos Positivos (255): separar, colecionar, desenvolver, adiantar, acumular, balançar, brandir, relaxar, desligar, assentar, regredir, semelhar, definhar, pular, precipitar, conspurcar, folgar, funcionar, tranqüilizar, pairar, ornar, revigorar, silenciar, equiparar, economizar, madurar, nascer, emperrar, vigorar, vibrar, moer, variar, mudar, descansar, atrair, naufragar, exaurir, desocupar, unir, premer, talhar, ninar, manipular, sarar, vazar, refluir, continuar, mexer, rebaixar, melhorar, vacilar, recolher, desmaiar, anoitecer, prolongar, facilitar, incrementar, fulminar, soltar, dispersar, desmoronar, harmonizar, animar, estender, retroceder, voltar, respaldar, forrar, germinar, torrar, igualar, lavrar, repugnar, romper, elevar, cerrar, esmagar, padronizar, aguçar, passar, curtir, renascer, inclinar, pisar, consolar, aliciar, desvirtuar, exultar, rebentar, profundar, subir, convir, confortar, engrandecer, acomodar, inteiriçar, engordar, multiplicar, agitar, amealhar, matar, carregar, estacar, afagar, adoecer, descair, enquadrar, cair, acrescentar, alterar, redobrar, emagrecer, misturar, arder, maturar, preencher, serenar, angariar, encarnar, repassar, poupar, sobrecarregar, picar, chocar, compilar, mergulhar, repousar, aumentar, crescer, banhar, declinar, estacionar, forçar, quebrar, pulular, trabalhar, morder, recrutar, uniformizar, contentar, nutrir, balancear, agradar, sustentar, empalidecer, emudecer, cansar, minorar, procriar, enjoar, proliferar, apertar, sanar, satisfazer, palpitar, contrabalançar, abrasar, amadurecer, concentrar, atear, rolar, saturar, juntar, andar, codificar, cruzar, reunir, plantar, pregar, caducar, queimar, enferrujar, espremer, acalentar, 
reduzir, encontrar, curvar, chamar, tomar, progredir, embalar, temperar, soçobrar, fraquear, cobrir, dobrar, operar, empacar, retrair, iluminar, cultivar, abanar, obstruir, restaurar, oprimir, amenizar, emular, sacudir, combinar, desabrochar, macular, parar, enfermar, arar, duplicar, tostar, afrontar, voar, piorar, brotar, diminuir, compensar, murchar, ajuntar, lenir, rasgar, violentar, alumiar, apurar, prosperar, comparar, comandar, sossegar, depreciar, ocupar, fatigar, aliviar, encostar, lavar, reforçar, transformar, potencializar, premir, modificar, espalhar, descarregar, ceder, disseminar, decair, capotar, reformar, oxidar, moderar, empanar, inflamar, triunfar, escavar, impregnar, carimbar, adormecer, exacerbar, esmiuçar, armazenar, embotar, limpar.

Falsos Negativos (3): agigantar, avolumar, solidificar.

Verdadeiros Negativos (13): condizer, coadunar, esforçar, esmerar, esfarelar, manobrar, descambar, desprender, embeber, aglomerar, prostrar, infiltrar, esbarrar.

Precisão: 0.307065217391

Abrangência: 0.974137931034

F-measure: 0.46694214876

\section{put-9.1}

Verdadeiros Positivos (15): cravar, inserir, depositar, introduzir, meter, instalar, pôr, colocar, botar, implantar, incluir, enterrar, fincar, fixar, plantar.

Falsos Positivos (11): localizar, arrumar, compor, parar, ligar, depor, coordenar, cultivar, absorver, engolir, encostar.

Falsos Negativos (6): situar, dispor, encaixar, estacionar, intercalar, semear.

Verdadeiros Negativos (11): afundar, embeber, ajeitar, empatar, calçar, soterrar, tragar, entrar, sorver, entranhar, sepultar.

Precisão: 0.576923076923

Abrangência: 0.714285714286

F-measure: 0.63829787234

\section{remove-10.1}

Verdadeiros Positivos (27): extirpar, erradicar, subtrair, extrair, arrancar, recolher, eliminar, cortar, retirar, tirar, isolar, destituir, excluir, expulsar, separar, abolir, afastar, apagar, demitir, derrubar, despedir, destacar, exonerar, exterminar, extinguir, sacar, suprimir.

Falsos Positivos (39): dividir, mutilar, repelir, despejar, apurar, puxar, arrebatar, talhar, rechaçar, desmembrar, descalçar, apanhar, ressalvar, desdobrar, depor, tomar, soltar, desfalcar, colher, rebater, secretar, dizimar, empolgar, renunciar, catar, arredar, tossir, derramar, clarear, mandar, pegar, diminuir, sufocar, despachar, dispensar, expelir, afogar, renegar, banir.

\section{Falsos Negativos (0):}


Verdadeiros Negativos (3): podar, apear, despegar.

Precisão: 0.409090909091

Abrangência: 1.0

F-measure: 0.58064516129

run-51.3.2

Verdadeiros Positivos (23): perambular, marchar, nadar, voar, caminhar, andar, correr, avançar, desfilar, flutuar, pular, saltar, subir, vagar, engatinhar, escalar, galgar, mergulhar, boiar, esvoaçar, mancar, cambalear, gatinhar.

Falsos Positivos (40): disparar, balancear, acometer, arrancar, ir, atacar, perpassar, apressar, carregar, titubear, partir, remeter, adiantar, picar, embalar, agredir, balançar, vingar, vacilar, fugir, esbarrar, resvalar, aflorar, abalar, pisar, roçar, assaltar, girar, investir, tocar, errar, tropeçar, alisar, acelerar, precipitar, transpor, desertar, lamber, crescer, acariciar.

Falsos Negativos (0):

Verdadeiros Negativos (1): trepar.

Precisão: 0.365079365079

Abrangência: 1.0

F-measure: 0.53488372093

say-37.7

Verdadeiros Positivos (23): recontar, reportar, noticiar, narrar, mencionar, expor, relatar, alegar, declarar, anunciar, dizer, comunicar, contar, ordenar, propor, citar, divulgar, informar, lembrar, repetir, sugerir, notificar, reiterar.

Falsos Positivos (33): mastigar, ser, cometer, tornar, desvendar, intimar, voltar, desfiar, participar, moer, aventar, agitar, apontar, propagar, matar, pertencer, historiar, renovar, referir, oferecer, pisar, dar, decifrar, tocar, adivinhar, segredar, martelar, mandar, levantar, aludir, suscitar, rolar, repisar.

Falsos Negativos (1): confidenciar.

Verdadeiros Negativos (2): concernir, insistir.

Precisão: 0.410714285714

Abrangência: 0.958333333333

F-measure: 0.575

send-11.1

Verdadeiros Positivos (10): despachar, transmitir, transferir, enviar, mandar, deslocar, trazer, encaminhar, expedir, remeter. 
Falsos Positivos (4): render, despedir, produzir, dar.

Falsos Negativos (0):

Verdadeiros Negativos (0):

Precisão: 0.714285714286

Abrangência: 1.0

F-measure: 0.833333333333 


\section{Experimento 2 (EXP2)}

\section{amalgamate-22.2}

Verdadeiros Positivos (24): alternar, coincidir, combinar, juntar, unir, comparar, reunir, bater, integrar, ligar, prender, aderir, aliar, atar, atrelar, coordenar, grudar, harmonizar, interligar, mesclar, misturar, relacionar, somar, ornar.

Falsos Positivos (58): ocorrer, balancear, conviver, casar, meter, revolver, opor, entrar, suceder, introduzir, mestiçar, totalizar, inserir, cruzar, conferir, privar, aproximar, tratar, inovar, pôr, balançar, empatar, embeber, engatar, renovar, federar, tecer, ajustar, calhar, assemelhar, recortar, perfazer, contrapor, conciliar, concorrer, incluir, aferir, acontecer, dar, coexistir, condizer, tramar, solidificar, completar, vir, enquadrar, encaixar, cair, colar, pegar, coadunar, aglutinar, confrontar, consolidar, convir, trocar, intercalar, cingir.

\section{Falsos Negativos (0):}

Verdadeiros Negativos (0):

Precisão: 0.292682926829

Abrangência: 1.0

F-measure: 0.452830188679

\section{amuse-31.1}

Verdadeiros Positivos (106): chatear, alarmar, escandalizar, alegrar, decepcionar, aborrecer, encantar, ofender, espantar, chocar, contrariar, abalar, agradar, assustar, confundir, estimular, ferir, ameaçar, abater, acalmar, afetar, animar, atrair, atrapalhar, cegar, comover, consolar, desanimar, desgraçar, deslumbrar, divertir, emocionar, empolgar, excitar, fascinar, iludir, impressionar, incomodar, indignar, induzir, inquietar, inspirar, intimidar, intrigar, irritar, prejudicar, preocupar, revoltar, afligir, aliviar, atormentar, cativar, confortar, constranger, contentar, deprimir, desagradar, desapontar, descontentar, desencorajar, desestimular, desonrar, distrair, embaraçar, encorajar, enfurecer, entreter, entusiasmar, envergonhar, horrorizar, humilhar, incendiar, inflamar, penalizar, perturbar, sensibilizar, satisfazer, agitar, arrasar, cansar, enfraquecer, estremecer, maravilhar, serenar, sossegar, torturar, acalentar, alucinar, aprazer, arrepiar, comprazer, debilitar, desconfortar, desesperar, desgostar, enfadar, entristecer, esmorecer, exaltar, exaurir, exultar, fatigar, magoar, oprimir, tolher, zangar.

Falsos Positivos (142): diluir, aquecer, insinuar, toldar, arruinar, calcar, penetrar, esmagar, abaixar, pregar, aguçar, esfriar, arrombar, minorar, invocar, pisar, assediar, meter, dar, dilacerar, escravizar, folgar, repousar, flechar, afrontar, tumultuar, tranqüilizar, descer, intoxicar, pairar, apertar, diminuir, ministrar, incutir, promover, sangrar, derreter, sacudir, ditar, alertar, apaixonar, sobrecarregar, influir, incentivar, envolver, acomodar, seduzir, danar, agonizar, lenir, conquistar, exortar, arrebatar, matar, suscitar, doer, moderar, sugerir, engrossar, moer, consumir, descansar, ralar, tocar, impor, soprar, abrasar, gelar, falar, alterar, apagar, deixar, acirrar, rolar, transportar, desconfiar, acender, render, evocar, pesar, embalar, acordar, aniquilar, esquentar, plantar, provocar, ninar, frustrar, devorar, machucar, maltratar, jogar, avivar, brincar, despertar, comprimir, ceder, afrouxar, obscurecer, reduzir, dourar, amaciar, materializar, abrandar, atenuar, temperar, amortecer, 
embelezar, incitar, solicitar, perder, triunfar, infundir, mover, tentar, desafiar, pastar, levantar, quebrar, suavizar, impregnar, enjoar, azedar, amargar, refrescar, amenizar, iluminar, entupir, ativar, morder, arder, abanar, sufocar, recuar, recorrer, aplacar, arrefecer, rebaixar, atentar, bulir, degradar, picar.

Falsos Negativos (6): deliciar, acabrunhar, deleitar, impacientar, importunar, vexar.

Verdadeiros Negativos (9): acanhar, ansiar, infiltrar, prostrar, esforçar, apetecer, fartar, sobressaltar, pungir.

Precisão: 0.427419354839

Abrangência: 0.946428571429

F-measure: 0.588888888889

\section{characterize-29.2}

Verdadeiros Positivos (23): pintar, retratar, classificar, descrever, identificar, aceitar, adotar, caracterizar, reconhecer, conceber, conhecer, considerar, dar, entender, ter, ver, imaginar, interpretar, julgar, olhar, reproduzir, supor, tomar.

Falsos Positivos (27): traduzir, confessar, selecionar, detectar, arrumar, graduar, dividir, apurar, distinguir, apontar, escolher, descobrir, receber, haver, saber, eleger, ler, figurar, pensar, catar, preferir, procurar, admitir, ordenar, divulgar, seguir, matar.

Falsos Negativos (3): recordar, rememorar, visualizar.

Verdadeiros Negativos (20): opinar, desconfiar, professar, empossar, abraçar, recapitular, desvendar, sonhar, cuidar, filtrar, idealizar, seriar, decifrar, adivinhar, fantasiar, propagar, assinalar, rolar, pinçar, decodificar.

Precisão: 0.46

Abrangência: 0.884615384615

F-measure: 0.605263157895

correspond-36.1

Verdadeiros Negativos (20): pechinchar, concordar, debater, discutir, brigar, conviver, unir, discordar, acordar, ajustar, combinar, compactuar, comunicar, conspirar, disputar, negociar, pactuar, paquerar, relacionar, reunir.

Falsos Positivos (32): juntar, admitir, batalhar, cruzar, estabelecer, harmonizar, aproximar, tratar, consentir, firmar, estar, ligar, chorar, relaxar, assentar, contratar, aceitar, contestar, convir, ceder, privar, comerciar, cantar, querer, falar, aliar, estipular, argumentar, comprazer, aceder, convencionar, pleitear.

Falsos Negativos (1): conciliar.

Verdadeiros Negativos (4): concertar, subscrever, relevar, assentir.

Precisão: 0.384615384615

Abrangência: 0.952380952381 
get-13.5.1

Verdadeiros Positivos (14): arranjar, colher, reservar, adquirir, pegar, obter, comprar, ganhar, conseguir, alugar, conquistar, angariar, apanhar, arrematar.

Falsos Positivos (50): auferir, encomendar, alcançar, arrancar, lograr, procurar, conduzir, ter, puxar, capturar, apurar, embolsar, apreender, segurar, marcar, perceber, receber, ligar, reunir, pilhar, vazar, juntar, tomar, haver, filtrar, lucrar, vingar, classificar, eleger, ficar, atingir, telefonar, catar, guardar, atrair, selecionar, preferir, decidir, caçar, tirar, escolher, levar, entreter, deter, chamar, sacar, extrair, adotar, arrastar, pinçar.

Falsos Negativos (0):

Verdadeiros Negativos (3): optar, impelir, rematar.

Precisão: 0.21875

Abrangência: 1.0

F-measure: 0.358974358974

\section{hit-18.1}

Verdadeiros Positivos (10): martelar, golpear, esmagar, espancar, bater, alvejar, amassar, coçar, comprimir, cutucar.

Falsos Positivos (8): suplantar, rachar, calcar, maltratar, atingir, dar, topar, encostar.

Falsos Negativos (1): esbarrar.

Verdadeiros Negativos (3): colidir, malhar, trombar.

Precisão: 0.555555555556

Abrangência: 0.909090909091

F-measure: 0.689655172414

light_emission-43.1

Verdadeiros Positivos (9): resplandecer, raiar, cintilar, piscar, brilhar, refletir, alumiar, faiscar, lucilar.

Falsos Positivos (11): estrelar, bater, pestanejar, incidir, fulminar, esvoaçar, fuzilar, arder, tremer, tombar, cair.

Falsos Negativos (0):

Verdadeiros Negativos (0):

Precisão: 0.45

Abrangência: 1.0

F-measure: 0.620689655172 
manner_speaking-37.3

Verdadeiros Positivos (8): ciciar, cochichar, gemer, murmurar, rosnar, segredar, soprar, resmungar.

Falsos Positivos (8): mastigar, ladrar, chiar, mascar, ranger, roncar, delirar, suspirar.

Falsos Negativos (0):

Verdadeiros Negativos (0):

Precisão: 0.5

Abrangência: 1.0

F-measure: 0.666666666667

modes_of_being_with_motion-47.3

Verdadeiros Positivos (15): flutuar, vibrar, oscilar, abanar, esvoaçar, agitar, balançar, brandir, dançar, girar, pairar, palpitar, pulsar, sacudir, tremer.

Falsos Positivos (14): revolver, mover, menear, manejar, arfar, saltar, soprar, aflorar, assoprar, latir, jogar, bater, estalar, espernear.

Falsos Negativos (0):

Verdadeiros Negativos (0):

Precisão: 0.51724137931

Abrangência: 1.0

F-measure: 0.681818181818

nonverbal_expression-40.2

Verdadeiros Positivos (9): bocejar, arfar, roncar, soluçar, sorrir, chorar, rir, gemer, ressonar.

Falsos Positivos (16): respirar, malhar, ridicularizar, zombar, gozar, brincar, mexer, satirizar, impar, gracejar, troçar, ironizar, ansiar, escarnecer, caçoar, desfrutar.

Falsos Negativos (0):

Verdadeiros Negativos (0):

Precisão: 0.36

Abrangência: 1.0

F-measure: 0.529411764706

other_cos-45.4 
Verdadeiros Positivos (113): suavizar, afrouxar, alargar, estreitar, derreter, congelar, dissolver, afundar, enfraquecer, aprofundar, contrair, fundir, intensificar, ampliar, abaixar, abrandar, acalmar, acordar, afiar, afinar, alagar, alegrar, alisar, alongar, alvejar, amaciar, amortecer, amplificar, apagar, aperfeiçoar, aplacar, apressar, aprimorar, arrebentar, arrefecer, arrombar, atenuar, avultar, azedar, caiar, cegar, cicatrizar, clarear, comprimir, condensar, corar, cristalizar, curar, debilitar, degenerar, deprimir, desacelerar, desandar, desatar, descentralizar, desdobrar, desenrolar, desequilibrar, desestabilizar, desfiar, destravar, dilatar, diluir, dourar, encurtar, endurecer, entreabrir, envelhecer, enxugar, equilibrar, escurecer, esfriar, estabilizar, estalar, esticar, estourar, estrangular, expandir, explodir, fortalecer, furar, gelar, inundar, manchar, matizar, melar, molhar, nivelar, reacender, reanimar, reavivar, recrudescer, refrescar, ressecar, secar, sujar, umedecer, vergar, abalar, abrir, acelerar, acender, agravar, apontar, aquecer, despertar, detonar, encher, encolher, engrossar, esquentar, fechar, lotar.

Falsos Positivos (255): separar, colecionar, desenvolver, adiantar, acumular, balançar, brandir, relaxar, desligar, assentar, regredir, semelhar, definhar, pular, precipitar, conspurcar, folgar, funcionar, tranqüilizar, pairar, ornar, revigorar, silenciar, equiparar, economizar, madurar, nascer, emperrar, vigorar, vibrar, moer, variar, mudar, descansar, atrair, naufragar, exaurir, desocupar, unir, premer, talhar, ninar, manipular, sarar, vazar, refluir, continuar, mexer, rebaixar, melhorar, vacilar, recolher, desmaiar, anoitecer, prolongar, facilitar, incrementar, fulminar, soltar, dispersar, desmoronar, harmonizar, animar, estender, retroceder, voltar, respaldar, forrar, germinar, torrar, igualar, lavrar, repugnar, romper, elevar, cerrar, esmagar, padronizar, aguçar, passar, curtir, renascer, inclinar, pisar, consolar, aliciar, desvirtuar, exultar, rebentar, profundar, subir, convir, confortar, engrandecer, acomodar, inteiriçar, engordar, multiplicar, agitar, amealhar, matar, carregar, estacar, afagar, adoecer, descair, enquadrar, cair, acrescentar, alterar, redobrar, emagrecer, misturar, arder, maturar, preencher, serenar, angariar, encarnar, repassar, poupar, sobrecarregar, picar, chocar, compilar, mergulhar, repousar, aumentar, crescer, banhar, declinar, estacionar, forçar, quebrar, pulular, trabalhar, morder, recrutar, uniformizar, contentar, nutrir, balancear, agradar, sustentar, empalidecer, emudecer, cansar, minorar, procriar, enjoar, proliferar, apertar, sanar, satisfazer, palpitar, contrabalançar, abrasar, amadurecer, concentrar, atear, rolar, saturar, juntar, andar, codificar, cruzar, reunir, plantar, pregar, caducar, queimar, enferrujar, espremer, acalentar, reduzir, encontrar, curvar, chamar, tomar, progredir, embalar, temperar, soçobrar, fraquear, cobrir, dobrar, operar, empacar, retrair, iluminar, cultivar, abanar, obstruir, restaurar, oprimir, amenizar, emular, sacudir, combinar, desabrochar, macular, parar, enfermar, arar, duplicar, tostar, afrontar, voar, piorar, brotar, diminuir, compensar, murchar, ajuntar, lenir, rasgar, violentar, alumiar, apurar, prosperar, comparar, comandar, sossegar, depreciar, ocupar, fatigar, aliviar, encostar, lavar, reforçar, transformar, potencializar, premir, modificar, espalhar, descarregar, ceder, disseminar, decair, capotar, reformar, oxidar, moderar, empanar, inflamar, triunfar, escavar, impregnar, carimbar, adormecer, exacerbar, esmiuçar, armazenar, embotar, limpar.

Falsos Negativos (3): agigantar, avolumar, solidificar.

Verdadeiros Negativos (13): condizer, coadunar, esforçar, esmerar, esfarelar, manobrar, descambar, desprender, embeber, aglomerar, prostrar, infiltrar, esbarrar.

Precisão: 0.307065217391 
Abrangência: 0.974137931034

F-measure: 0.46694214876

put-9.1

Verdadeiros Positivos (16): cravar, inserir, depositar, introduzir, meter, instalar, pôr, colocar, botar, implantar, incluir, enterrar, fincar, fixar, plantar, dispor.

Falsos Positivos (12): localizar, arrumar, compor, parar, ligar, depor, tragar, coordenar, cultivar, absorver, engolir, encostar.

Falsos Negativos (5): situar, encaixar, estacionar, intercalar, semear.

Verdadeiros Negativos (10): afundar, embeber, ajeitar, empatar, calçar, soterrar, entrar, sorver, entranhar, sepultar.

Precisão: 0.571428571429

Abrangência: 0.761904761905

F-measure: 0.65306122449

\section{remove-10.1}

Verdadeiros Positivos (27): extirpar, erradicar, subtrair, extrair, arrancar, recolher, eliminar, cortar, retirar, tirar, isolar, destituir, excluir, expulsar, separar, abolir, afastar, apagar, demitir, derrubar, despedir, destacar, exonerar, exterminar, extinguir, sacar, suprimir.

Falsos Positivos (39): dividir, mutilar, repelir, despejar, apurar, puxar, arrebatar, talhar, rechaçar, desmembrar, descalçar, apanhar, ressalvar, desdobrar, depor, tomar, soltar, desfalcar, colher, rebater, secretar, dizimar, empolgar, renunciar, catar, arredar, tossir, derramar, clarear, mandar, pegar, diminuir, sufocar, despachar, dispensar, expelir, afogar, renegar, banir.

Falsos Negativos (0):

Verdadeiros Negativos (3): podar, apear, despegar.

Precisão: 0.409090909091

Abrangência: 1.0

F-measure: 0.58064516129

\section{run-51.3.2}

Verdadeiros Positivos (23): perambular, marchar, nadar, voar, caminhar, andar, correr, avançar, desfilar, flutuar, pular, saltar, subir, vagar, engatinhar, escalar, galgar, mergulhar, boiar, esvoaçar, mancar, cambalear, gatinhar.

Falsos Positivos (41): disparar, balancear, acometer, arrancar, ir, atacar, perpassar, apressar, carregar, titubear, partir, remeter, adiantar, picar, embalar, agredir, balançar, 
vingar, vacilar, fugir, esbarrar, resvalar, aflorar, abalar, pisar, roçar, assaltar, girar, investir, trepar, tocar, errar, tropeçar, alisar, acelerar, precipitar, transpor, desertar, lamber, crescer, acariciar.

Falsos Negativos (0):

Verdadeiros Negativos (0):

Precisão: 0.359375

Abrangência: 1.0

F-measure: 0.528735632184

say-37.7

Verdadeiros Positivos (23): recontar, reportar, noticiar, narrar, mencionar, expor, relatar, alegar, declarar, anunciar, dizer, comunicar, contar, ordenar, propor, citar, divulgar, informar, lembrar, repetir, sugerir, notificar, reiterar.

Falsos Positivos (33): mastigar, ser, cometer, tornar, desvendar, intimar, voltar, desfiar, participar, moer, aventar, agitar, apontar, propagar, matar, pertencer, historiar, renovar, referir, oferecer, pisar, dar, decifrar, tocar, adivinhar, segredar, martelar, mandar, levantar, aludir, suscitar, rolar, repisar.

Falsos Negativos (1): confidenciar.

Verdadeiros Negativos (2): concernir, insistir.

Precisão: 0.410714285714

Abrangência: 0.958333333333

F-measure: 0.575

send-11.1

Verdadeiros Positivos (10): despachar, transmitir, transferir, enviar, mandar, deslocar, trazer, encaminhar, expedir, remeter.

Falsos Positivos (4): render, despedir, produzir, dar.

Falsos Negativos (0):

Verdadeiros Negativos (0):

Precisão: 0.714285714286

Abrangência: 1.0

F-measure: 0.833333333333 


\section{Experimento 3 (EXP3)}

\section{amalgamate-22.2}

Verdadeiros Negativos (20): alternar, combinar, juntar, unir, comparar, reunir, bater, integrar, ligar, prender, aliar, atar, coordenar, harmonizar, interligar, mesclar, misturar, relacionar, somar, ornar.

Falsos Positivos (47): acontecer, aferir, aglutinar, ajustar, aproximar, balancear, balançar, cair, casar, cingir, colar, completar, conciliar, conferir, confrontar, consolidar, contrapor, cruzar, dar, empatar, encaixar, engatar, enquadrar, entrar, incluir, inovar, inserir, intercalar, introduzir, mestiçar, meter, ocorrer, opor, pegar, perfazer, privar, pôr, recortar, renovar, revolver, suceder, tecer, totalizar, tramar, tratar, trocar, vir.

Falsos Negativos (4): coincidir, aderir, atrelar, grudar.

Verdadeiros Negativos (11): conviver, embeber, federar, calhar, assemelhar, concorrer, coexistir, condizer, solidificar, coadunar, convir.

Precisão: 0.298507462687

Abrangência: 0.833333333333

F-measure: 0.43956043956

\section{amuse-31.1}

Verdadeiros Positivos (95): chatear, alarmar, escandalizar, alegrar, decepcionar, aborrecer, encantar, ofender, espantar, chocar, contrariar, abalar, agradar, assustar, confundir, estimular, ferir, ameaçar, abater, acalmar, afetar, animar, atrair, atrapalhar, cegar, comover, consolar, desanimar, desgraçar, deslumbrar, divertir, emocionar, empolgar, excitar, fascinar, iludir, impressionar, incomodar, indignar, induzir, inquietar, inspirar, intimidar, intrigar, irritar, prejudicar, preocupar, revoltar, afligir, aliviar, atormentar, cativar, confortar, constranger, contentar, deprimir, desagradar, desapontar, descontentar, desencorajar, desestimular, desonrar, distrair, embaraçar, encorajar, enfurecer, entreter, entusiasmar, envergonhar, horrorizar, humilhar, incendiar, inflamar, penalizar, perturbar, sensibilizar, satisfazer, agitar, arrasar, cansar, enfraquecer, estremecer, maravilhar, serenar, sossegar, torturar, acalentar, alucinar, arrepiar, debilitar, exaltar, exaurir, fatigar, oprimir, tolher.

Falsos Positivos (130): abaixar, abanar, abrandar, abrasar, acender, acirrar, acomodar, acordar, afrontar, afrouxar, aguçar, alertar, alterar, amaciar, amargar, amenizar, amortecer, aniquilar, apagar, apertar, aplacar, aquecer, arrebatar, arrefecer, arrombar, arruinar, assediar, atentar, atenuar, ativar, avivar, azedar, bulir, calcar, ceder, comprimir, conquistar, consumir, danar, dar, degradar, deixar, derreter, desafiar, descansar, descer, desconfiar, despertar, devorar, dilacerar, diluir, diminuir, ditar, doer, dourar, embalar, embelezar, engrossar, entupir, envolver, escravizar, esfriar, esmagar, esquentar, evocar, exortar, falar, frustrar, gelar, iluminar, impor, impregnar, incentivar, incitar, incutir, influir, infundir, insinuar, intoxicar, invocar, jogar, lenir, levantar, machucar, maltratar, matar, materializar, meter, ministrar, minorar, moderar, moer, morder, mover, obscurecer, penetrar, perder, pesar, picar, pisar, plantar, pregar, promover, provocar, quebrar, ralar, rebaixar, recorrer, recuar, reduzir, refrescar, render, rolar, sacudir, sangrar, seduzir, sobrecarregar, solicitar, 
soprar, suavizar, sufocar, sugerir, suscitar, temperar, tentar, tocar, toldar, tranqüilizar, transportar, tumultuar.

Falsos Negativos (17): deliciar, acabrunhar, aprazer, comprazer, deleitar, desconfortar, desesperar, desgostar, enfadar, entristecer, esmorecer, exultar, impacientar, importunar, magoar, vexar, zangar.

Verdadeiros Negativos (21): acanhar, folgar, repousar, flechar, pairar, ansiar, apaixonar, agonizar, infiltrar, prostrar, esforçar, ninar, brincar, triunfar, apetecer, pastar, enjoar, fartar, arder, sobressaltar, pungir.

Precisão: 0.422222222222

Abrangência: 0.848214285714

F-measure: 0.563798219585

\section{characterize-29.2}

Verdadeiros Positivos (26): pintar, retratar, classificar, descrever, identificar, aceitar, adotar, caracterizar, reconhecer, conceber, conhecer, considerar, dar, entender, ter, ver, imaginar, interpretar, julgar, olhar, recordar, rememorar, reproduzir, supor, visualizar, tomar.

Falsos Positivos (45): abraçar, adivinhar, admitir, apontar, apurar, arrumar, assinalar, catar, confessar, decifrar, decodificar, descobrir, desconfiar, desvendar, detectar, distinguir, dividir, divulgar, eleger, empossar, escolher, fantasiar, figurar, filtrar, graduar, haver, idealizar, ler, matar, ordenar, pensar, pinçar, preferir, procurar, professar, propagar, recapitular, receber, rolar, saber, seguir, selecionar, seriar, sonhar, traduzir.

Falsos Negativos (0):

Verdadeiros Negativos (2): opinar, cuidar.

Precisão: 0.366197183099

Abrangência: 1.0

F-measure: 0.536082474227

correspond-36.1

Verdadeiros Positivos (16): pechinchar, concordar, debater, discutir, brigar, conviver, unir, discordar, acordar, ajustar, combinar, comunicar, disputar, negociar, paquerar, reunir.

Falsos Positivos (29): aceder, aceitar, admitir, aliar, aproximar, argumentar, assentar, batalhar, cantar, ceder, chorar, comerciar, consentir, contestar, contratar, convencionar, convir, cruzar, estabelecer, estar, estipular, falar, firmar, juntar, ligar, pleitear, querer, relaxar, tratar.

Falsos Negativos (5): compactuar, conciliar, conspirar, pactuar, relacionar.

Verdadeiros Negativos (7): concertar, subscrever, harmonizar, privar, relevar, assentir, comprazer. 
Precisão: 0.355555555556

Abrangência: 0.761904761905

F-measure: 0.484848484848

get-13.5.1

Verdadeiros Positivos (14): arranjar, colher, reservar, adquirir, pegar, obter, comprar, ganhar, conseguir, alugar, conquistar, angariar, apanhar, arrematar.

Falsos Positivos (50): adotar, alcançar, apreender, apurar, arrancar, arrastar, atingir, atrair, auferir, capturar, catar, caçar, chamar, classificar, conduzir, decidir, deter, eleger, embolsar, encomendar, entreter, escolher, extrair, ficar, filtrar, guardar, haver, juntar, levar, ligar, lograr, lucrar, marcar, perceber, pilhar, pinçar, preferir, procurar, puxar, receber, reunir, sacar, segurar, selecionar, telefonar, ter, tirar, tomar, vazar, vingar.

Falsos Negativos (0):

Verdadeiros Negativos (3): optar, impelir, rematar.

Precisão: 0.21875

Abrangência: 1.0

F-measure: 0.358974358974

hit-18.1

Verdadeiros Positivos (10): martelar, golpear, esmagar, espancar, bater, alvejar, amassar, coçar, comprimir, cutucar.

Falsos Positivos (8): atingir, calcar, dar, encostar, maltratar, rachar, suplantar, topar.

Falsos Negativos (1): esbarrar.

Verdadeiros Negativos (3): colidir, malhar, trombar.

Precisão: 0.555555555556

Abrangência: 0.909090909091

F-measure: 0.689655172414

light_emission-43.1

Verdadeiros Positivos (7): resplandecer, raiar, piscar, brilhar, refletir, faiscar, lucilar.

Falsos Positivos (9): arder, bater, cair, estrelar, esvoaçar, incidir, pestanejar, tombar, tremer.

Falsos Negativos (2): cintilar, alumiar.

Verdadeiros Negativos (2): fulminar, fuzilar.

Precisão: 0.4375 
Abrangência: 0.777777777778

F-measure: 0.56

manner_speaking-37.3

Verdadeiros Positivos (7): ciciar, cochichar, gemer, murmurar, rosnar, soprar, resmungar.

Falsos Positivos (8): chiar, delirar, ladrar, mascar, mastigar, ranger, roncar, suspirar.

Falsos Negativos (1): segredar.

Verdadeiros Negativos (0):

Precisão: 0.466666666667

Abrangência: 0.875

F-measure: 0.608695652174

modes_of_being_with_motion-47.3

Verdadeiros Positivos (14): flutuar, vibrar, oscilar, esvoaçar, agitar, balançar, brandir, dançar, girar, pairar, palpitar, pulsar, sacudir, tremer.

Falsos Positivos (11): aflorar, arfar, assoprar, bater, espernear, estalar, jogar, latir, mover, saltar, soprar.

Falsos Negativos (1): abanar.

Verdadeiros Negativos (3): revolver, menear, manejar.

Precisão: 0.56

Abrangência: 0.933333333333

F-measure: 0.7

nonverbal_expression-40.2

Verdadeiros Positivos (9): bocejar, arfar, roncar, soluçar, sorrir, chorar, rir, gemer, ressonar.

Falsos Positivos (11): brincar, caçoar, gozar, gracejar, impar, ironizar, malhar, mexer, respirar, troçar, zombar.

Falsos Negativos (0):

Verdadeiros Negativos (5): ridicularizar, satirizar, ansiar, escarnecer, desfrutar.

Precisão: 0.45

Abrangência: 1.0

F-measure: 0.620689655172 


\section{other_cos-45.4}

Verdadeiros Positivos (108): suavizar, afrouxar, alargar, estreitar, derreter, congelar, dissolver, afundar, enfraquecer, aprofundar, contrair, fundir, intensificar, ampliar, abaixar, abrandar, acalmar, acordar, afiar, afinar, alagar, alegrar, alisar, alongar, alvejar, amaciar, amortecer, amplificar, apagar, aperfeiçoar, aplacar, apressar, aprimorar, arrebentar, arrefecer, arrombar, atenuar, azedar, caiar, cegar, cicatrizar, clarear, comprimir, condensar, corar, cristalizar, curar, debilitar, deprimir, desandar, desatar, descentralizar, desdobrar, desenrolar, desequilibrar, desestabilizar, desfiar, destravar, dilatar, diluir, dourar, encurtar, endurecer, entreabrir, envelhecer, enxugar, equilibrar, escurecer, esfriar, estabilizar, estalar, esticar, estourar, estrangular, expandir, fortalecer, furar, gelar, inundar, manchar, matizar, melar, molhar, nivelar, reacender, reanimar, reavivar, refrescar, ressecar, secar, sujar, umedecer, vergar, abalar, abrir, acelerar, acender, agravar, apontar, aquecer, despertar, detonar, encher, encolher, engrossar, esquentar, fechar, lotar.

Falsos Positivos (206): abanar, abrasar, acalentar, acomodar, acrescentar, acumular, adiantar, afagar, afrontar, agitar, agradar, aguçar, aliciar, aliviar, alterar, alumiar, amadurecer, amealhar, amenizar, andar, angariar, animar, apertar, apurar, arar, armazenar, assentar, atear, atrair, aumentar, balancear, balançar, banhar, brandir, brotar, cair, cansar, carimbar, carregar, ceder, cerrar, chamar, chocar, cobrir, codificar, colecionar, comandar, combinar, comparar, compensar, compilar, concentrar, confortar, consolar, conspurcar, contentar, continuar, contrabalançar, crescer, cruzar, cultivar, curtir, curvar, declinar, depreciar, descansar, descarregar, desenvolver, desligar, desocupar, desvirtuar, diminuir, dispersar, disseminar, dobrar, duplicar, economizar, elevar, embalar, embotar, empanar, emperrar, emudecer, emular, encarnar, encontrar, encostar, engordar, engrandecer, enquadrar, equiparar, escavar, esmagar, esmiuçar, espalhar, espremer, estacar, estacionar, estender, exaurir, facilitar, fatigar, forrar, forçar, fulminar, funcionar, harmonizar, igualar, iluminar, impregnar, inclinar, incrementar, inflamar, juntar, lavar, lavrar, lenir, limpar, macular, manipular, matar, melhorar, mergulhar, mexer, minorar, misturar, moderar, modificar, moer, morder, mudar, multiplicar, nascer, nutrir, obstruir, ocupar, operar, oprimir, ornar, oxidar, padronizar, parar, passar, picar, pisar, plantar, potencializar, poupar, precipitar, preencher, pregar, premer, premir, profundar, prolongar, pular, quebrar, queimar, rasgar, rebaixar, rebentar, recolher, recrutar, redobrar, reduzir, reformar, reforçar, relaxar, repassar, repugnar, respaldar, restaurar, retrair, reunir, revigorar, rolar, romper, sacudir, sanar, satisfazer, saturar, semelhar, separar, serenar, silenciar, sobrecarregar, soltar, sossegar, subir, sustentar, talhar, temperar, tomar, torrar, trabalhar, tranqüilizar, transformar, uniformizar, unir, variar, vazar, vibrar, vigorar, violentar, voar, voltar.

Falsos Positivos (142): agigantar, avolumar, avultar, degenerar, desacelerar, explodir, recrudescer, solidificar.

Verdadeiros Negativos (62): regredir, definhar, condizer, folgar, pairar, madurar, naufragar, coadunar, esforçar, ninar, sarar, refluir, esmerar, vacilar, desmaiar, anoitecer, esfarelar, desmoronar, retroceder, germinar, renascer, exultar, convir, inteiriçar, adoecer, descair, emagrecer, arder, maturar, manobrar, repousar, pulular, empalidecer, procriar, enjoar, proliferar, descambar, palpitar, caducar, enferrujar, desprender, progredir, soçobrar, fraquear, empacar, embeber, desabrochar, enfermar, tostar, aglomerar, piorar, murchar, ajuntar, prostrar, prosperar, decair, capotar, infiltrar, triunfar, adormecer, esbarrar, exacerbar. 
Precisão: 0.343949044586

Abrangência: 0.931034482759

F-measure: 0.502325581395

put-9.1

Verdadeiros Positivos (21): cravar, situar, inserir, depositar, introduzir, meter, instalar, pôr, colocar, botar, implantar, incluir, enterrar, fincar, fixar, plantar, dispor, encaixar, estacionar, intercalar, semear.

Falsos Positivos (20): absorver, afundar, ajeitar, arrumar, calçar, compor, coordenar, cultivar, depor, empatar, encostar, engolir, entrar, ligar, localizar, parar, sepultar, sorver, soterrar, tragar.

Falsos Negativos (0):

Verdadeiros Negativos (2): embeber, entranhar.

Precisão: 0.512195121951

Abrangência: 1.0

F-measure: 0.677419354839

remove-10.1

Verdadeiros Positivos (27): extirpar, erradicar, subtrair, extrair, arrancar, recolher, eliminar, cortar, retirar, tirar, isolar, destituir, excluir, expulsar, separar, abolir, afastar, apagar, demitir, derrubar, despedir, destacar, exonerar, exterminar, extinguir, sacar, suprimir.

Falsos Positivos (39): afogar, apanhar, apurar, arrebatar, arredar, banir, catar, clarear, colher, depor, derramar, descalçar, desdobrar, desfalcar, desmembrar, despachar, despejar, diminuir, dispensar, dividir, dizimar, empolgar, expelir, mandar, mutilar, pegar, puxar, rebater, rechaçar, renegar, renunciar, repelir, ressalvar, secretar, soltar, sufocar, talhar, tomar, tossir.

Falsos Negativos (0):

Verdadeiros Negativos (3): podar, apear, despegar.

Precisão: 0.409090909091

Abrangência: 1.0

F-measure: 0.58064516129

run-51.3.2

Verdadeiros Positivos (22): marchar, nadar, voar, caminhar, andar, correr, avançar, desfilar, flutuar, pular, saltar, subir, vagar, engatinhar, escalar, galgar, mergulhar, boiar, esvoaçar, mancar, cambalear, gatinhar. 
Falsos Positivos (32): abalar, acelerar, adiantar, aflorar, agredir, apressar, arrancar, atacar, balançar, carregar, crescer, desertar, disparar, embalar, errar, fugir, girar, investir, ir, lamber, partir, perpassar, pisar, precipitar, remeter, resvalar, roçar, titubear, tocar, tropeçar, vacilar, vingar.

Falsos Negativos (1): perambular.

Verdadeiros Negativos (9): balancear, acometer, picar, esbarrar, assaltar, trepar, alisar, transpor, acariciar.

Precisão: 0.407407407407

Abrangência: 0.95652173913

F-measure: 0.571428571429

say-37.7

Verdadeiros Positivos (23): recontar, reportar, noticiar, narrar, mencionar, expor, relatar, alegar, declarar, anunciar, dizer, comunicar, contar, ordenar, propor, citar, divulgar, informar, lembrar, repetir, sugerir, notificar, reiterar.

Falsos Positivos (33): adivinhar, agitar, aludir, apontar, aventar, cometer, dar, decifrar, desfiar, desvendar, historiar, intimar, levantar, mandar, martelar, mastigar, matar, moer, oferecer, participar, pertencer, pisar, propagar, referir, renovar, repisar, rolar, segredar, ser, suscitar, tocar, tornar, voltar.

Falsos Negativos (1): confidenciar.

Verdadeiros Negativos (2): concernir, insistir.

Precisão: 0.410714285714

Abrangência: 0.958333333333

F-measure: 0.575

send-11.1

Verdadeiros Positivos (10): despachar, transmitir, transferir, enviar, mandar, deslocar, trazer, encaminhar, expedir, remeter.

Falsos Positivos (4): dar, despedir, produzir, render.

Falsos Negativos (0):

Verdadeiros Negativos (0):

Precisão: 0.714285714286

Abrangência: 1.0

F-measure: 0.833333333333 


\section{Experimento 4 (EXP4)}

\section{amalgamate-22.2}

Verdadeiros Negativos (20): alternar, combinar, juntar, unir, comparar, reunir, bater, integrar, ligar, prender, aliar, atar, coordenar, harmonizar, interligar, mesclar, misturar, relacionar, somar, ornar.

Falsos Positivos (47): acontecer, aferir, aglutinar, ajustar, aproximar, balancear, balançar, cair, casar, cingir, colar, completar, conciliar, conferir, confrontar, consolidar, contrapor, cruzar, dar, empatar, encaixar, engatar, enquadrar, entrar, incluir, inovar, inserir, intercalar, introduzir, mestiçar, meter, ocorrer, opor, pegar, perfazer, privar, pôr, recortar, renovar, revolver, suceder, tecer, totalizar, tramar, tratar, trocar, vir.

Falsos Negativos (4): coincidir, aderir, atrelar, grudar.

Verdadeiros Negativos (11): conviver, embeber, federar, calhar, assemelhar, concorrer, coexistir, condizer, solidificar, coadunar, convir.

Precisão: 0.298507462687

Abrangência: 0.833333333333

F-measure: 0.43956043956

\section{amuse-31.1}

Verdadeiros Positivos (95): chatear, alarmar, escandalizar, alegrar, decepcionar, aborrecer, encantar, ofender, espantar, chocar, contrariar, abalar, agradar, assustar, confundir, estimular, ferir, ameaçar, abater, acalmar, afetar, animar, atrair, atrapalhar, cegar, comover, consolar, desanimar, desgraçar, deslumbrar, divertir, emocionar, empolgar, excitar, fascinar, iludir, impressionar, incomodar, indignar, induzir, inquietar, inspirar, intimidar, intrigar, irritar, prejudicar, preocupar, revoltar, afligir, aliviar, atormentar, cativar, confortar, constranger, contentar, deprimir, desagradar, desapontar, descontentar, desencorajar, desestimular, desonrar, distrair, embaraçar, encorajar, enfurecer, entreter, entusiasmar, envergonhar, horrorizar, humilhar, incendiar, inflamar, penalizar, perturbar, sensibilizar, satisfazer, agitar, arrasar, cansar, enfraquecer, estremecer, maravilhar, serenar, sossegar, torturar, acalentar, alucinar, arrepiar, debilitar, exaltar, exaurir, fatigar, oprimir, tolher.

Falsos Positivos (130): abaixar, abanar, abrandar, abrasar, acender, acirrar, acomodar, acordar, afrontar, afrouxar, aguçar, alertar, alterar, amaciar, amargar, amenizar, amortecer, aniquilar, apagar, apertar, aplacar, aquecer, arrebatar, arrefecer, arrombar, arruinar, assediar, atentar, atenuar, ativar, avivar, azedar, bulir, calcar, ceder, comprimir, conquistar, consumir, danar, dar, degradar, deixar, derreter, desafiar, descansar, descer, desconfiar, despertar, devorar, dilacerar, diluir, diminuir, ditar, doer, dourar, embalar, embelezar, engrossar, entupir, envolver, escravizar, esfriar, esmagar, esquentar, evocar, exortar, falar, frustrar, gelar, iluminar, impor, impregnar, incentivar, incitar, incutir, influir, infundir, insinuar, intoxicar, invocar, jogar, lenir, levantar, machucar, maltratar, matar, materializar, meter, ministrar, minorar, moderar, moer, morder, mover, obscurecer, penetrar, perder, pesar, picar, pisar, plantar, pregar, promover, provocar, quebrar, ralar, rebaixar, recorrer, recuar, reduzir, refrescar, render, rolar, sacudir, sangrar, seduzir, sobrecarregar, solicitar, 
soprar, suavizar, sufocar, sugerir, suscitar, temperar, tentar, tocar, toldar, tranqüilizar, transportar, tumultuar.

Falsos Negativos (17): deliciar, acabrunhar, aprazer, comprazer, deleitar, desconfortar, desesperar, desgostar, enfadar, entristecer, esmorecer, exultar, impacientar, importunar, magoar, vexar, zangar.

Verdadeiros Negativos (21): acanhar, folgar, repousar, flechar, pairar, ansiar, apaixonar, agonizar, infiltrar, prostrar, esforçar, ninar, brincar, triunfar, apetecer, pastar, enjoar, fartar, arder, sobressaltar, pungir.

Precisão: 0.422222222222

Abrangência: 0.848214285714

F-measure: 0.563798219585

\section{characterize-29.2}

Verdadeiros Positivos (26): pintar, retratar, classificar, descrever, identificar, aceitar, adotar, caracterizar, reconhecer, conceber, conhecer, considerar, dar, entender, ter, ver, imaginar, interpretar, julgar, olhar, recordar, rememorar, reproduzir, supor, visualizar, tomar.

Falsos Positivos (45): abraçar, adivinhar, admitir, apontar, apurar, arrumar, assinalar, catar, confessar, decifrar, decodificar, descobrir, desconfiar, desvendar, detectar, distinguir, dividir, divulgar, eleger, empossar, escolher, fantasiar, figurar, filtrar, graduar, haver, idealizar, ler, matar, ordenar, pensar, pinçar, preferir, procurar, professar, propagar, recapitular, receber, rolar, saber, seguir, selecionar, seriar, sonhar, traduzir.

Falsos Negativos (0):

Verdadeiros Negativos (2): opinar, cuidar.

Precisão: 0.366197183099

Abrangência: 1.0

F-measure: 0.536082474227

\section{correspond-36.1}

Verdadeiros Positivos (16): pechinchar, concordar, debater, discutir, brigar, conviver, unir, discordar, acordar, ajustar, combinar, comunicar, disputar, negociar, paquerar, reunir.

Falsos Positivos (30): aceder, aceitar, admitir, aliar, aproximar, argumentar, assentar, batalhar, cantar, ceder, chorar, comerciar, comprazer, consentir, contestar, contratar, convencionar, convir, cruzar, estabelecer, estar, estipular, falar, firmar, juntar, ligar, pleitear, querer, relaxar, tratar.

Falsos Negativos (5): compactuar, conciliar, conspirar, pactuar, relacionar.

Verdadeiros Negativos (6): concertar, subscrever, harmonizar, privar, relevar, assentir.

Precisão: 0.347826086957 
Abrangência: 0.761904761905

F-measure: 0.477611940299

get-13.5.1

Verdadeiros Positivos (14): arranjar, colher, reservar, adquirir, pegar, obter, comprar, ganhar, conseguir, alugar, conquistar, angariar, apanhar, arrematar.

Falsos Positivos (50): adotar, alcançar, apreender, apurar, arrancar, arrastar, atingir, atrair, auferir, capturar, catar, caçar, chamar, classificar, conduzir, decidir, deter, eleger, embolsar, encomendar, entreter, escolher, extrair, ficar, filtrar, guardar, haver, juntar, levar, ligar, lograr, lucrar, marcar, perceber, pilhar, pinçar, preferir, procurar, puxar, receber, reunir, sacar, segurar, selecionar, telefonar, ter, tirar, tomar, vazar, vingar.

Falsos Negativos (0):

Verdadeiros Negativos (3): optar, impelir, rematar.

Precisão: 0.21875

Abrangência: 1.0

F-measure: 0.358974358974

hit-18.1

Verdadeiros Positivos (10): martelar, golpear, esmagar, espancar, bater, alvejar, amassar, coçar, comprimir, cutucar.

Falsos Positivos (8): atingir, calcar, dar, encostar, maltratar, rachar, suplantar, topar.

Falsos Negativos (1): esbarrar.

Verdadeiros Negativos (3): colidir, malhar, trombar.

Precisão: 0.555555555556

Abrangência: 0.909090909091

F-measure: 0.689655172414

light_emission-43.1

Verdadeiros Positivos (7): resplandecer, raiar, piscar, brilhar, refletir, faiscar, lucilar.

Falsos Positivos (9): arder, bater, cair, estrelar, esvoaçar, incidir, pestanejar, tombar, tremer.

Falsos Negativos (2): cintilar, alumiar.

Verdadeiros Negativos (2): fulminar, fuzilar.

Precisão: 0.4375

Abrangência: 0.777777777778 
F-measure: 0.56

manner_speaking-37.3

Verdadeiros Positivos (7): ciciar, cochichar, gemer, murmurar, rosnar, soprar, resmungar.

Falsos Positivos (8): chiar, delirar, ladrar, mascar, mastigar, ranger, roncar, suspirar.

Falsos Negativos (1): segredar.

Verdadeiros Negativos (0):

Precisão: 0.466666666667

Abrangência: 0.875

F-measure: 0.608695652174

modes_of_being_with_motion-47.3

Verdadeiros Positivos (14): flutuar, vibrar, oscilar, esvoaçar, agitar, balançar, brandir, dançar, girar, pairar, palpitar, pulsar, sacudir, tremer.

Falsos Positivos (11): aflorar, arfar, assoprar, bater, espernear, estalar, jogar, latir, mover, saltar, soprar.

Falsos Negativos (1): abanar.

Verdadeiros Negativos (3): revolver, menear, manejar.

Precisão: 0.56

Abrangência: 0.933333333333

F-measure: 0.7

nonverbal_expression-40.2

Verdadeiros Positivos (9): bocejar, arfar, roncar, soluçar, sorrir, chorar, rir, gemer, ressonar.

Falsos Positivos (11): brincar, caçoar, gozar, gracejar, impar, ironizar, malhar, mexer, respirar, troçar, zombar.

Falsos Negativos (0):

Verdadeiros Negativos (5): ridicularizar, satirizar, ansiar, escarnecer, desfrutar.

Precisão: 0.45

Abrangência: 1.0

F-measure: 0.620689655172

other_cos-45.4 
Verdadeiros Positivos (108): suavizar, afrouxar, alargar, estreitar, derreter, congelar, dissolver, afundar, enfraquecer, aprofundar, contrair, fundir, intensificar, ampliar, abaixar, abrandar, acalmar, acordar, afiar, afinar, alagar, alegrar, alisar, alongar, alvejar, amaciar, amortecer, amplificar, apagar, aperfeiçoar, aplacar, apressar, aprimorar, arrebentar, arrefecer, arrombar, atenuar, azedar, caiar, cegar, cicatrizar, clarear, comprimir, condensar, corar, cristalizar, curar, debilitar, deprimir, desandar, desatar, descentralizar, desdobrar, desenrolar, desequilibrar, desestabilizar, desfiar, destravar, dilatar, diluir, dourar, encurtar, endurecer, entreabrir, envelhecer, enxugar, equilibrar, escurecer, esfriar, estabilizar, estalar, esticar, estourar, estrangular, expandir, fortalecer, furar, gelar, inundar, manchar, matizar, melar, molhar, nivelar, reacender, reanimar, reavivar, refrescar, ressecar, secar, sujar, umedecer, vergar, abalar, abrir, acelerar, acender, agravar, apontar, aquecer, despertar, detonar, encher, encolher, engrossar, esquentar, fechar, lotar.

Falsos Positivos (206): abanar, abrasar, acalentar, acomodar, acrescentar, acumular, adiantar, afagar, afrontar, agitar, agradar, aguçar, aliciar, aliviar, alterar, alumiar, amadurecer, amealhar, amenizar, andar, angariar, animar, apertar, apurar, arar, armazenar, assentar, atear, atrair, aumentar, balancear, balançar, banhar, brandir, brotar, cair, cansar, carimbar, carregar, ceder, cerrar, chamar, chocar, cobrir, codificar, colecionar, comandar, combinar, comparar, compensar, compilar, concentrar, confortar, consolar, conspurcar, contentar, continuar, contrabalançar, crescer, cruzar, cultivar, curtir, curvar, declinar, depreciar, descansar, descarregar, desenvolver, desligar, desocupar, desvirtuar, diminuir, dispersar, disseminar, dobrar, duplicar, economizar, elevar, embalar, embotar, empanar, emperrar, emudecer, emular, encarnar, encontrar, encostar, engordar, engrandecer, enquadrar, equiparar, escavar, esmagar, esmiuçar, espalhar, espremer, estacar, estacionar, estender, exaurir, facilitar, fatigar, forrar, forçar, fulminar, funcionar, harmonizar, igualar, iluminar, impregnar, inclinar, incrementar, inflamar, juntar, lavar, lavrar, lenir, limpar, macular, manipular, matar, melhorar, mergulhar, mexer, minorar, misturar, moderar, modificar, moer, morder, mudar, multiplicar, nascer, nutrir, obstruir, ocupar, operar, oprimir, ornar, oxidar, padronizar, parar, passar, picar, pisar, plantar, potencializar, poupar, precipitar, preencher, pregar, premer, premir, profundar, prolongar, pular, quebrar, queimar, rasgar, rebaixar, rebentar, recolher, recrutar, redobrar, reduzir, reformar, reforçar, relaxar, repassar, repugnar, respaldar, restaurar, retrair, reunir, revigorar, rolar, romper, sacudir, sanar, satisfazer, saturar, semelhar, separar, serenar, silenciar, sobrecarregar, soltar, sossegar, subir, sustentar, talhar, temperar, tomar, torrar, trabalhar, tranqüilizar, transformar, uniformizar, unir, variar, vazar, vibrar, vigorar, violentar, voar, voltar.

Falsos Positivos (142): agigantar, avolumar, avultar, degenerar, desacelerar, explodir, recrudescer, solidificar.

Verdadeiros Negativos (62): regredir, definhar, condizer, folgar, pairar, madurar, naufragar, coadunar, esforçar, ninar, sarar, refluir, esmerar, vacilar, desmaiar, anoitecer, esfarelar, desmoronar, retroceder, germinar, renascer, exultar, convir, inteiriçar, adoecer, descair, emagrecer, arder, maturar, manobrar, repousar, pulular, empalidecer, procriar, enjoar, proliferar, descambar, palpitar, caducar, enferrujar, desprender, progredir, soçobrar, fraquear, empacar, embeber, desabrochar, enfermar, tostar, aglomerar, piorar, murchar, ajuntar, prostrar, prosperar, decair, capotar, infiltrar, triunfar, adormecer, esbarrar, exacerbar.

Precisão: 0.343949044586 
Abrangência: 0.931034482759

F-measure: 0.502325581395

put-9.1

Verdadeiros Positivos (21): cravar, situar, inserir, depositar, introduzir, meter, instalar, pôr, colocar, botar, implantar, incluir, enterrar, fincar, fixar, plantar, dispor, encaixar, estacionar, intercalar, semear.

Falsos Positivos (20): absorver, afundar, ajeitar, arrumar, calçar, compor, coordenar, cultivar, depor, empatar, encostar, engolir, entrar, ligar, localizar, parar, sepultar, sorver, soterrar, tragar.

Falsos Negativos (0):

Verdadeiros Negativos (2): embeber, entranhar.

Precisão: 0.512195121951

Abrangência: 1.0

F-measure: 0.677419354839

remove-10.1

Verdadeiros Positivos (27): extirpar, erradicar, subtrair, extrair, arrancar, recolher, eliminar, cortar, retirar, tirar, isolar, destituir, excluir, expulsar, separar, abolir, afastar, apagar, demitir, derrubar, despedir, destacar, exonerar, exterminar, extinguir, sacar, suprimir.

Falsos Positivos (39): afogar, apanhar, apurar, arrebatar, arredar, banir, catar, clarear, colher, depor, derramar, descalçar, desdobrar, desfalcar, desmembrar, despachar, despejar, diminuir, dispensar, dividir, dizimar, empolgar, expelir, mandar, mutilar, pegar, puxar, rebater, rechaçar, renegar, renunciar, repelir, ressalvar, secretar, soltar, sufocar, talhar, tomar, tossir.

Falsos Negativos (0):

Verdadeiros Negativos (3): podar, apear, despegar.

Precisão: 0.409090909091

Abrangência: 1.0

F-measure: 0.58064516129

run-51.3.2

Verdadeiros Positivos (22): marchar, nadar, voar, caminhar, andar, correr, avançar, desfilar, flutuar, pular, saltar, subir, vagar, engatinhar, escalar, galgar, mergulhar, boiar, esvoaçar, mancar, cambalear, gatinhar. 
Falsos Positivos (32): abalar, acelerar, adiantar, aflorar, agredir, apressar, arrancar, atacar, balançar, carregar, crescer, desertar, disparar, embalar, errar, fugir, girar, investir, ir, lamber, partir, perpassar, pisar, precipitar, remeter, resvalar, roçar, titubear, tocar, tropeçar, vacilar, vingar.

Falsos Negativos (1): perambular.

Verdadeiros Negativos (9): balancear, acometer, picar, esbarrar, assaltar, trepar, alisar, transpor, acariciar.

Precisão: 0.407407407407

Abrangência: 0.95652173913

F-measure: 0.571428571429

say-37.7

Verdadeiros Positivos (23): recontar, reportar, noticiar, narrar, mencionar, expor, relatar, alegar, declarar, anunciar, dizer, comunicar, contar, ordenar, propor, citar, divulgar, informar, lembrar, repetir, sugerir, notificar, reiterar.

Falsos Positivos (33): adivinhar, agitar, aludir, apontar, aventar, cometer, dar, decifrar, desfiar, desvendar, historiar, intimar, levantar, mandar, martelar, mastigar, matar, moer, oferecer, participar, pertencer, pisar, propagar, referir, renovar, repisar, rolar, segredar, ser, suscitar, tocar, tornar, voltar.

Falsos Negativos (1): confidenciar.

Verdadeiros Negativos (2): concernir, insistir.

Precisão: 0.410714285714

Abrangência: 0.958333333333

F-measure: 0.575

send-11.1

Verdadeiros Positivos (10): despachar, transmitir, transferir, enviar, mandar, deslocar, trazer, encaminhar, expedir, remeter.

Falsos Positivos (4): dar, despedir, produzir, render.

Falsos Negativos (0):

Verdadeiros Negativos (0):

Precisão: 0.714285714286

Abrangência: 1.0

F-measure: 0.833333333333 


\section{APÊNDICE D - Resultados da tarefa de agrupamento de verbos}

Neste apêndice são apresentados os resultados detalhes da tarefa de agrupamento de verbos. Foram utilizados os algoritmos K-means, MNCut Spectral Cluster e DCD (conforme citado no Capítulo 7, Seção 7.3.3).

Foram realizados experimentos variando-se o número de grupos entre 2 e 25 (dado que todos os algoritmos necessitavam do número de grupos como parametro de entrada). Vale comentar que foram utilizados os 7 atributos (apresentados na Seção 7.3.3) com os valores de frequência normalizados. Os resultados de $f$-measure para K-means com distâncias de cosenos são apresentados na Tabela 29. Na linha destacada da tabela, o número de grupos igual a 16 indica o número de classes do gold standard e na última linha é apresentado o desvio padrão STD. 
Tabela 29: Resultados de $f$-measure para K-means

\begin{tabular}{|c|c|c|c|c|c|c|c|}
\hline \# clusters & F1 & F2 & F3 & F7 & F13 & F16 & F17 \\
\hline 2 & 16,87 & 15,37 & 16,21 & 17,08 & 12,32 & 15,03 & 16,21 \\
\hline 3 & 20,45 & 16,84 & 21,91 & 19,73 & 18,99 & 17,75 & 20,27 \\
\hline 4 & 20,26 & 17,79 & 20,83 & 22,09 & 16,56 & 20,05 & 23,81 \\
\hline 5 & 21,69 & 18,27 & 23,64 & 24,85 & 21,82 & 23,38 & 28,33 \\
\hline 6 & 23,18 & 17,16 & 24,99 & 22,03 & 19,22 & 25,90 & 26,25 \\
\hline 7 & 24,15 & 19,14 & 25,34 & 27,81 & 22,84 & 28,81 & 26,58 \\
\hline 8 & 30,31 & 16,51 & 34,45 & 23,36 & 23,20 & 28,47 & 31,50 \\
\hline 9 & 31,43 & 22,55 & 35,31 & 29,77 & 22,59 & 30,80 & 30,81 \\
\hline 10 & 33,62 & 21,66 & 35,00 & 32,32 & 24,43 & 31,34 & 33,46 \\
\hline 11 & 30,08 & 21,52 & 33,61 & 31,94 & 26,05 & 32,13 & 36,79 \\
\hline 12 & 32,72 & 21,54 & 34,52 & 25,67 & 27,11 & 30,02 & 31,89 \\
\hline 13 & 29,67 & 24,47 & 34,17 & 32,85 & 23,78 & 31,71 & 37,26 \\
\hline 14 & 34,48 & 25,20 & 37,40 & 22,16 & 27,14 & 32,09 & 34,68 \\
\hline 15 & 35,23 & 24,47 & 34,36 & 30,32 & 27,09 & 34,98 & 38,13 \\
\hline $\mathbf{1 6}$ & $\mathbf{3 3 , 1 6}$ & $\mathbf{2 7 , 7 3}$ & $\mathbf{3 9 , 5 1}$ & $\mathbf{3 3 , 1 3}$ & $\mathbf{2 6 , 9 5}$ & $\mathbf{3 2 , 1 0}$ & $\mathbf{3 7 , 7 0}$ \\
\hline 17 & 35,87 & 24,05 & 35,43 & 30,18 & 31,16 & 28,94 & 39,82 \\
\hline 18 & 39,00 & 28,78 & 35,60 & 27,43 & 33,10 & 32,62 & 39,64 \\
\hline 19 & 35,42 & 23,77 & 36,06 & 34,95 & 30,93 & 32,59 & 41,60 \\
\hline 20 & 39,66 & 27,48 & 39,15 & 30,71 & 29,57 & 35,80 & 41,60 \\
\hline 21 & 38,69 & 31,85 & 40,14 & 27,73 & 35,70 & 35,88 & 40,05 \\
\hline 22 & 39,10 & 27,75 & 39,97 & 33,38 & 36,32 & 36,03 & 38,77 \\
\hline 23 & 39,33 & 27,34 & 40,50 & 29,02 & 32,59 & 32,55 & 41,63 \\
\hline 24 & 38,93 & 30,74 & 44,61 & 31,29 & 32,64 & 38,06 & 43,04 \\
\hline 25 & 40,40 & 31,55 & 38,85 & 34,64 & 29,60 & 38,18 & 40,69 \\
\hline STD & $\mathbf{7 , 1 6 3 5 6 8}$ & $\mathbf{5 , 0 0 8 7 9 8}$ & $\mathbf{7 , 2 9 3 2 1 9}$ & $\mathbf{4 , 9 6 6 0 5 4}$ & $\mathbf{6 , 0 5 4 2 6 8}$ & $\mathbf{6 , 0 3 4 , 6 5}$ & $\mathbf{7 , 2 2 0 1}$ \\
\hline & & & & & & & \\
\hline
\end{tabular}

$\mathrm{Na}$ Tabela 30 são apresentados os resultados de $f$-measure para o MNCut Spectral Cluster. Na linha destacada, número de grupos igual a 16 indica o número de classes do gold standard e na última linha é apresentado o desvio padrão - STD. 
Tabela 30: Resultados de $f$-measure para MNCut Spectral Cluster

\begin{tabular}{|c|c|c|c|c|c|c|c|}
\hline \# clusters & F1 & $\mathbf{F 2}$ & F3 & F7 & F13 & F16 & F17 \\
\hline 2 & 16,27 & 14,60 & 15,71 & 17,87 & 15,73 & 15,66 & 16,01 \\
\hline 3 & 18,46 & 17,57 & 20,02 & 18,53 & 15,68 & 16,47 & 19,78 \\
\hline 4 & 22,46 & 20,67 & 22,86 & 20,54 & 19,11 & 22,82 & 22,51 \\
\hline 5 & 24,99 & 21,85 & 22,30 & 19,89 & 20,04 & 25,42 & 25,18 \\
\hline 6 & 26,80 & 25,73 & 23,84 & 22,12 & 19,99 & 25,08 & 26,08 \\
\hline 7 & 26,94 & 24,03 & 27,95 & 25,50 & 21,66 & 26,44 & 29,36 \\
\hline 8 & 29,12 & 26,22 & 29,18 & 25,72 & 30,55 & 30,05 & 33,73 \\
\hline 9 & 31,47 & 27,65 & 31,90 & 27,85 & 26,99 & 32,18 & 36,01 \\
\hline 10 & 33,90 & 29,53 & 29,82 & 30,18 & 28,75 & 34,57 & 36,63 \\
\hline 11 & 35,10 & 33,01 & 35,37 & 35,86 & 31,05 & 33,63 & 38,61 \\
\hline 12 & 33,73 & 34,20 & 34,76 & 36,34 & 30,03 & 37,68 & 38,19 \\
\hline 13 & 34,81 & 33,89 & 37,43 & 37,43 & 34,40 & 39,07 & 37,68 \\
\hline 14 & 34,80 & 33,70 & 41,07 & 42,84 & 32,77 & 39,74 & 38,29 \\
\hline 15 & 38,61 & 33,55 & 40,17 & 40,19 & 34,44 & 37,60 & 40,91 \\
\hline 16 & 39,23 & 36,87 & 42,61 & 40,68 & 35,81 & 38,70 & 42,94 \\
\hline 17 & 39,40 & 33,92 & 42,36 & 39,51 & 36,45 & 38,40 & 44,11 \\
\hline 18 & 43,12 & 39,87 & 40,61 & 38,23 & 35,14 & 40,76 & 44,08 \\
\hline 19 & 41,35 & 38,25 & 44,21 & 43,06 & 36,97 & 38,68 & 44,44 \\
\hline 20 & 40,14 & 39,05 & 46,98 & 42,86 & 37,02 & 40,83 & 42,48 \\
\hline 21 & 39,95 & 36,23 & 46,53 & 44,27 & 39,86 & 39,67 & 43,18 \\
\hline 22 & 42,05 & 34,23 & 43,74 & 40,45 & 36,16 & 44,20 & 46,06 \\
\hline 23 & 41,91 & 34,28 & 46,31 & 45,46 & 37,70 & 44,28 & 44,61 \\
\hline 24 & 39,67 & 34,73 & 46,56 & 45,61 & 39,36 & 44,75 & 41,96 \\
\hline 25 & 38,86 & 33,18 & 45,58 & 45,43 & 38,47 & 43,15 & 45,86 \\
\hline STD & 7,733457 & 6,89312 & 9,692708 & 9,65505 & 7,802301 & 8,527191 & 86,522 \\
\hline
\end{tabular}

Por fim, na Tabela 31 são apresentados os resultados de $f$-measure para o DCD. Na linha destacada, número de grupos igual a 16 indica o número de classes do gold standard e na última linha é apresentado o desvio padrão - STD. 
Tabela 31: Resultados de $f$-measure para DCD

\begin{tabular}{|c|c|c|c|c|c|c|c|}
\hline \# clusters & F1 & F2 & F3 & F7 & F13 & F16 & F17 \\
\hline 2 & 17,29 & 14,04 & 16,75 & 17,09 & 15,65 & 15,73 & 14,42 \\
\hline 3 & 20,03 & 18,11 & 19,13 & 16,78 & 17,22 & 17,40 & 19,01 \\
\hline 4 & 23,46 & 20,28 & 21,32 & 17,97 & 18,86 & 20,06 & 20,83 \\
\hline 5 & 24,28 & 22,58 & 23,10 & 18,85 & 20,72 & 23,80 & 20,58 \\
\hline 6 & 24,41 & 22,51 & 25,24 & 24,67 & 22,56 & 26,46 & 23,52 \\
\hline 7 & 27,73 & 23,11 & 26,93 & 21,58 & 23,88 & 26,75 & 24,83 \\
\hline 8 & 29,33 & 25,98 & 30,62 & 27,67 & 28,00 & 29,13 & 26,63 \\
\hline 9 & 30,02 & 28,15 & 33,87 & 25,88 & 25,17 & 29,74 & 30,69 \\
\hline 10 & 29,99 & 28,64 & 35,89 & 27,83 & 26,93 & 31,50 & 31,43 \\
\hline 11 & 31,17 & 28,89 & 36,61 & 28,52 & 30,19 & 33,31 & 30,17 \\
\hline 12 & 33,55 & 30,55 & 39,50 & 34,13 & 31,58 & 33,39 & 31,29 \\
\hline 13 & 32,42 & 33,61 & 37,65 & 28,09 & 33,33 & 33,61 & 31,69 \\
\hline 14 & 32,77 & 34,43 & 39,22 & 31,02 & 32,77 & 34,75 & 34,98 \\
\hline 15 & 34,21 & 34,16 & 42,62 & 27,30 & 34,44 & 32,76 & 37,12 \\
\hline 16 & 35,22 & 36,64 & 42,46 & 35,86 & 34,34 & 35,85 & 38,61 \\
\hline 17 & 36,06 & 32,32 & 42,81 & 26,10 & 35,74 & 37,83 & 39,54 \\
\hline 18 & 36,93 & 32,78 & 44,38 & 37,24 & 35,14 & 39,16 & 35,29 \\
\hline 19 & 37,61 & 33,98 & 45,18 & 29,37 & 35,94 & 37,55 & 38,98 \\
\hline 20 & 38,29 & 35,19 & 44,87 & 32,87 & 39,42 & 37,69 & 41,16 \\
\hline 21 & 40,15 & 34,99 & 44,72 & 32,36 & 38,79 & 39,68 & 39,19 \\
\hline 22 & 38,99 & 34,20 & 44,48 & 31,94 & 38,18 & 39,69 & 40,43 \\
\hline 23 & 40,67 & 35,35 & 46,37 & 32,12 & 38,60 & 40,24 & 39,82 \\
\hline 24 & 38,90 & 37,03 & 43,97 & 40,18 & 39,37 & 43,05 & 39,30 \\
\hline 25 & 39,72 & 37,57 & 45,23 & 31,60 & 39,03 & 44,85 & 42,36 \\
\hline STD & 6,628648 & 6,590478 & 9,464604 & 6,330651 & 7,602254 & 7,801232 & 7,942831 \\
\hline
\end{tabular}

Outra avaliação realizada tratou de grupos de frequência:

- Grupo 1: verbos com frequência menor do que 110 (37 verbos)

- Grupo 2: verbos com frequência entre 110 e 300 (37 verbos)

- Grupo 3: verbos com frequência entre 300 e 760 (37 verbos)

- Grupo 4: verbos com frequência entre 760 e 1910 (37 verbos)

- Grupo 5: verbos com frequência maior do que 1910 (37 verbos)

$\mathrm{Na}$ Tabela 32 são apresentados os resultados de $f$-measure para estes grupos. 
Tabela 32: Resultados de $f$-measure por grupos de frequência

\begin{tabular}{|c|c|c|c|c|c|c|c||c|c|c|c|c|c|c|}
\hline & \multicolumn{10}{|c||}{ Spectral } & \multicolumn{1}{|c|}{ DCD } \\
\hline Grupo & F1 & F2 & F3 & F7 & F13 & F16 & F17 & F1 & F2 & F3 & F7 & F13 & F16 & F17 \\
\hline $\mathbf{1}$ & 52 & 27 & 43 & 27 & 29 & 46 & 52 & 37 & 45 & 50 & 39 & 50 & 47 & 38 \\
\hline $\mathbf{2}$ & 50 & 39 & 44 & 29 & 29 & 46 & 34 & 43 & 53 & 51 & 28 & 50 & 45 & 44 \\
\hline $\mathbf{3}$ & 42 & 34 & 46 & 29 & 32 & 43 & 27 & 33 & 40 & 43 & 32 & 42 & 42 & 41 \\
\hline $\mathbf{4}$ & 39 & 31 & 43 & 33 & 29 & 38 & 40 & 35 & 39 & 45 & 35 & 37 & 34 & 38 \\
\hline $\mathbf{5}$ & 37 & 31 & 41 & 39 & 32 & 38 & 40 & 35 & 37 & 42 & 36 & 37 & 34 & 39 \\
\hline
\end{tabular}

Interessava saber se o DCD superava o Spectral Cluster nos grupos de menor frequência. Porém, apesar de o DCD superar o Spectral para os atributos F2, F3, F7, F13 e F16 no grupo 1, não é possível concluir que ele seja melhor em todos os casos.

Outra análise interessante, porém não muito justa devido aos recursos utilizados, é comparar os resultados obtidos para o português com os resultados obtidos para o francês e inglês. É possível realizar a comparação com o algoritmo MNCut Spectral Cluster e com os atributos selecionados para o português. Mas, primeiro, é necessário fornecer uma descrição dos corpora utilizados e da ferramenta de extração dos algoritmos.

Para o inglês, os dados foram extraídos de cinco corpora que foram utilizados para construir o léxico VALEX (Korhonen et al., 2006). Os corpora são: The British National Corpus (BNC), The North American News Text Corpus (NANT), The Guardian Corpus, The Reuters Corpus, dados das duas conferências Text Retrieval Evaluation Conferences: TREC-4 ${ }^{61}$ and TREC- $5^{62}$. Somando os 5 corpora, obtiveram 904 milhões de palavras. Para extração dos atributos foi utilizado o sistema de Preiss et al. (2007).

Para o francês, os dados utilizados foram o do LexSchem (Messiant et al., 2008). Este léxico foi criado a partir do corpus Le Monde que conta com 200 milhões de palavras. As informações do LexSchem foram utilizadas para extração dos atributos.

Conhecendo os cenários das outras línguas, pode-se realizar uma comparação rasa. $\mathrm{Na}$ Tabela 33 são apresentados os resultados de $f$-measure para as três línguas.

\footnotetext{
${ }^{61} \mathrm{http}: / /$ trec.nist.gov/pubs/trec4/t4 proceedings.html

62 http://trec.nist.gov/pubs/trec5/t5 proceedings.html
} 
Tabela 33: Resultados de $f$-measure para inglês, francês e português

\begin{tabular}{|l|c|c|c|}
\hline & Inglês & Francês & Português \\
\hline F1 & 57,8 & 42,4 & 39,8 \\
\hline F2 & 46,7 & 45,9 & 37,1 \\
\hline F3 & 63,3 & 50,6 & 41,2 \\
\hline F7 & - & 55,1 & 38,8 \\
\hline F13 & 74,6 & 52,7 & 36 \\
\hline F16 & 73 & 53,4 & 38,7 \\
\hline F17 & $\mathbf{8 0 , 4}$ & 54,6 & $\mathbf{4 2 , 9}$ \\
\hline
\end{tabular}

$\mathrm{Na}$ Tabela 33 é possível observar que o melhor resultado para o inglês é $80,4 \%$ de $f$ measure no atributo F17, contra 42,9\% para o português no mesmo atributo (o melhor resultado obtido para a língua). Para o francês, o melhor resultado é $55,1 \%$ de $f$-measure no atributo F7 (atributo que foi introduzido no artigo para o francês, portanto, não há equivalente para o inglês), enquanto que o resultado do português para o mesmo atributo foi de $38,8 \%$.

Vale reforçar que a comparação não é completamente válida dado que os recursos utilizados para as outras línguas são maiores e mais precisos. Um ponto importante de ser observado é a ausência de um corpus representativo para a tarefa de agrupamento para o português. $\mathrm{O}$ único corpus com grandes proporções é o Corpus Brasileiro ${ }^{63}$, que não pode ser utilizado para a tarefa, pois não é possível ter acesso ao texto integral por conta de direitos autorais (de acordo com texto disponível na página do projeto).

Porém, com os resultados apresentados na Tabela 33 é possível observar que este trabalho não está distante dos melhores resultados para o francês. Se olharmos ainda o atributo F3, o segundo valor melhor, é possível observar que com 41,2\% de f-measure para o português não estamos muito longe dos resultados obtidos para o inglês ( $63.3 \%$ de $f$-measure) e para o francês $(50,6 \%$ de $f$-measure) .

\footnotetext{
${ }^{63}$ http://corpusbrasileiro.pucsp.br/cb/Inicial.html
} 